\title{
Noninvasive imaging of hypoxia, hypoxia response and drug delivery : a bridge towards individualized patient treatment
}

Citation for published version (APA):

Dubois, L. (2010). Noninvasive imaging of hypoxia, hypoxia response and drug delivery : a bridge towards individualized patient treatment. [Doctoral Thesis, Maastricht University]. Maastricht University. https://doi.org/10.26481/dis.20100211ld

Document status and date:

Published: 01/01/2010

DOI:

10.26481/dis.20100211ld

Document Version:

Publisher's PDF, also known as Version of record

Please check the document version of this publication:

- A submitted manuscript is the version of the article upon submission and before peer-review. There can be important differences between the submitted version and the official published version of record.

People interested in the research are advised to contact the author for the final version of the publication, or visit the DOI to the publisher's website.

- The final author version and the galley proof are versions of the publication after peer review.

- The final published version features the final layout of the paper including the volume, issue and page numbers.

Link to publication

\footnotetext{
General rights rights.

- You may freely distribute the URL identifying the publication in the public portal. please follow below link for the End User Agreement:

www.umlib.nl/taverne-license

Take down policy

If you believe that this document breaches copyright please contact us at:

repository@maastrichtuniversity.nl

providing details and we will investigate your claim.
}

Copyright and moral rights for the publications made accessible in the public portal are retained by the authors and/or other copyright owners and it is a condition of accessing publications that users recognise and abide by the legal requirements associated with these

- Users may download and print one copy of any publication from the public portal for the purpose of private study or research.

- You may not further distribute the material or use it for any profit-making activity or commercial gain

If the publication is distributed under the terms of Article $25 \mathrm{fa}$ of the Dutch Copyright Act, indicated by the "Taverne" license above, 


\section{Noninvasive imaging of hypoxia, hypoxia response and drug delivery:}

A bridge towards individualized patient treatment 
(C) Ludwig Dubois, Maastricht 2010

ISBN: 987-90-8151240-4

Cover design: Kinderopvang Riemst

Printed by Drukkerij Castro, Riemst

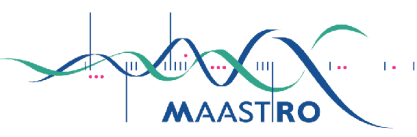

The studies presented in this thesis were performed at the Department of Radiation Oncology (MaastRO), School for Oncology and Developmental Biology (GROW) and Maastricht University, Maastricht, The Netherlands 


\section{Noninvasive imaging of hypoxia, hypoxia response and drug delivery:}

A bridge towards individualized patient treatment

\section{PROEFSCHRIFT}

ter verkrijging van de graad van doctor aan de Universiteit Maastricht, op gezag van de Rector Magnificus, Prof. mr. G.P.M.F. Mols

volgens het besluit van het College van Decanen, in het openbaar te verdedigen op donderdag 11 februari 2010 om 12.00 uur

door

Ludwig Dubois 
PROMOTORES:

Prof. dr. P. Lambin

Prof. dr. B.G. Wouters

BEOORDELINGSCOMMISSIE:

Prof. dr. F.C.S. Ramaekers (Voorzitter)

Prof. dr. C.P. Reutelingsperger

Prof. dr. A.J. van der Kogel (Radboud University Nijmegen Medical Centre)

Prof. dr. M.A.M.J van Zandvoort 


\section{Content}

$\begin{array}{lll}\text { Chapter } 1 & \text { General introduction } & 7\end{array}$

Chapter 2 Evaluation of hypoxia in an experimental 35 rat tumor model by

$\left[{ }^{18} \mathrm{~F}\right]$ Fluoromisonidazole PET and immunohistochemistry

Chapter $3 \quad\left[{ }^{18} \mathrm{~F}\right] \mathrm{EF} 3$ is not superior to $\left[{ }^{18} \mathrm{~F}\right] \mathrm{FMISO}$ for PET-based hypoxia evaluation as measured in a rat rhabdomyosarcoma tumour model

Chapter 4 Preclinical evaluation of $\left[{ }^{18} \mathrm{~F}\right] \mathrm{HX} 4$, a novel promising hypoxia marker for PET imaging

Chapter 5 Imaging the hypoxia surrogate marker CA IX requires expression and catalytic activity for binding fluorescent sulfonamide inhibitors

Chapter 6 Imaging of CA IX with fluorescent labelled sulfonamides distinguishes hypoxic and (re)-oxygenated cells in a xenograft tumour model

Chapter 7 Development and evaluation of a cetuximab-based imaging probe to target EGFR and EGFRvIII

Chapter 8 Disparity between in vivo EGFR expression 159 and Zirconium-89-labeled cetuximab uptake assessed with PET

Chapter 9 General discussion and summary Concluding remarks and future perspectives

Algemene discussie en samenvatting

Acknowledgements / Dankwoord

Curriculum Vitae

List of publications 


\section{List of abbreviations}

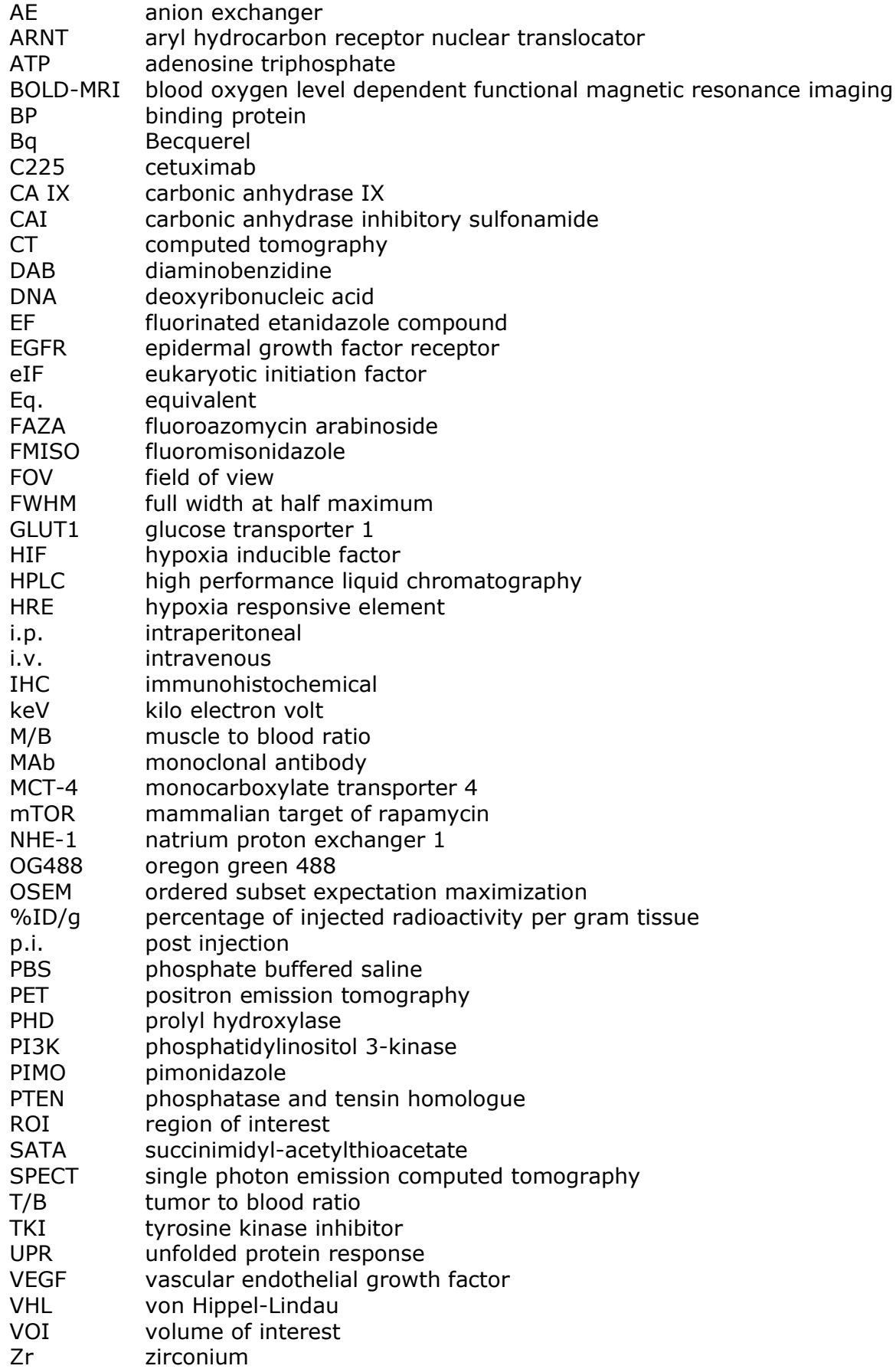




\section{CHAPTER 1}

\section{General introduction}

Adapted from:

Taking advantage of tumor cell adaptations to hypoxia for developing new tumor markers and treatment strategies.

Ebbesen P, Pettersen EO, Gorr T, Jobst G, Williams K, Kienninger J, Wenger R, Pastorekova S, Dubois L, Lambin P, Wouters BG, Van den Beucken T, Supuran CT, Poellinger L, Ratcliffe P, Kanopka A, Görlach A, Gasmann M, Harris A, Maxwell P, Scozzafava A.

J Enzym Inhib Med Chem. 2009 Apr;24 Suppl 1:1-39 


\section{Introduction}

According to the World Health Organization ${ }^{1}$, cancer is classified as the leading cause of death worldwide: it accounted for 7.9 million deaths (around $13 \%$ of all deaths) in 2007 . Lung, stomach, liver, colon and breast cancer cause the most cancer deaths on a yearly base. Deaths from cancer worldwide are projected to continue rising, with an estimated 12 million deaths in 2030. The Dutch Cancer Society (KWF Kanker Bestrijding) reported in The Netherlands 83283 new cases of cancer in 2006, an increase of $2.5 \%$ compared with 2005 . Breast (15\%, main cancer cause for women), colon and colorectal (13.5\%), lung (12.4\%), prostate (11.4\%, main cause for men) and skin (10.7\%) cancer demonstrate the highest incidence of new cancers in The Netherlands. Breast cancer (18\%) demonstrated the highest mortality rates for women, followed by lung (17.7\%) and colon $(12.5 \%)$ cancer, while for men highest mortality was observed for carcinomas of the lung (31\%), followed by colon $(11.1 \%)$ and prostate $(11 \%)^{2}$.

Cancer is a collective term for more than 100 distinct types of diseases, classified based on cell type of origin, stage and where they reside. These different types of cancer have a series of common characteristics that distinguish them from normal cells: malignant growth is dictated by 6 essential alterations in cell physiology, the so-called 6 hallmarks of cancer. Tumor cells acquire the ability (1) to have limitless proliferative capacity, (2) to be self-sufficient in growth factors, (3) to escape apoptosis, (4) to be insensitive to anti-growth factors, (5) to have the ability to invade surrounding tissue and metastasize and (6) to acquire the potential to induce angiogenesis ${ }^{3}$. There are several genes and 
pathways involved in acquiring these hallmarks, suggesting a need for multiple mutated genes for cancer to arise. Indeed, it has been shown that human cells need 4 to 5 different mutations to become malignant ${ }^{4}$. Different cancers however, acquire different combinations of mutations, leading to a diverse behavior amongst even similar cancers types ${ }^{5}$. This idea resulted in recent efforts to investigate and develop more individualized treatment taken into account specific genetic or other micro-environmental tumor characteristics.

The aim of cancer treatment is to offer affected patients cure or an improved quality of life. This can be achieved by curing the disease, increasing lifespan and/or diminishing symptomatic side effects. The available treatments have included surgery, chemotherapy and radiotherapy, mostly depending on the general condition of the patient and the clinical tumor stage and type. Other types of cancer can benefit from additional therapies such as hormone therapy (breast, prostate) ${ }^{6}$ or immunotherapy (melanoma $)^{7}$. Nevertheless, although advances in cancer research have led to better prognosis, available treatment modalities are still ineffective for a relatively large group of patients. One of the possible explanations for the variability in treatment response is the large heterogeneity of the tumor micro-environment, which is characterized by heterogeneities in nutrient supply, $\mathrm{pH}$, proliferation and oxygenation status. To allow an improved treatment efficacy as well as a reduction in therapy costs, more research needs to be performed for the evaluation of parameters which are predictive for treatment response ${ }^{8}$. This would permit a better definition of sub-groups of patients who would need a different treatment strategy right from the beginning or even during therapy. 


\section{Hypoxia, hypoxia response and clinical relevance}

One of the parameters that directly influences efficacy of conventional cancer treatment modalities is the presence of low oxygen regions, also called hypoxia, heterogeneously spread within solid tumors. This was first indicated in the 1930s and was related to a possible relevance to radiotherapy ${ }^{9}$. The first real indication that hypoxia could exist in tumors was made in 1955 by Thomlinson and Gray in human lung cancer specimens. They observed viable tumor regions surrounded by vascular stroma and as these regions expanded, areas of necrosis appeared at the centre. The thickness of the viable rim was found to be similar to the calculated oxygen diffusion distance in respiring tissues, suggesting that cells consume oxygen (figure 1). Based on these observations, they hypothesized that cells bordering the necrotic regions might be viable, but oxygen deprived or hypoxic ${ }^{10}$. Since then, it has been shown that the majority of solid tumors contain heterogeneously spread regions of low oxygenation ${ }^{11,12}{ }^{12}$ These hypoxic regions arise due to the unusual, chaotic and insufficient organization of tumor vasculature compared to normal tissues ${ }^{13}$. Hypoxia can be categorized into two main types: acute and chronic (figure 1). Acute (transient or perfusion-limited) hypoxia occurs due to aberrant blood vessels shutting down and then reopening, resulting in dramatic changes in perfusion ${ }^{14}$. Preclinical tumor models demonstrated that these temporal changes can occur several times within one hour, with intervals of 6 to 45 minutes $^{15}$. Furthermore, Dewhirst and colleagues have demonstrated that several tumors demonstrate cycling or periodic changes in blood flow and oxygenation, resulting is a dynamically changing oxygen environment for tumor cells ${ }^{16}$. Chronic (diffusion-limited) hypoxia arises when tumors outgrow their blood (and therefore their 
oxygen) supply due to uncontrolled proliferation. This occurs as a function of reduced oxygen diffusion with increasing distance from the vasculature. The calculated distance that oxygen diffuses, as it passes from the capillary to cells before it is completely metabolized, is on average $100 \mu \mathrm{m}$ (from 70 to $150 \mu \mathrm{m})^{17}$, when tumor cells are located beyond that distance from blood vessels, they become necrotic. Chronically hypoxic cells are still viable and are located in the perinecrotic regions of the tumor, reflecting the limit in oxygen diffusion ${ }^{18}$.

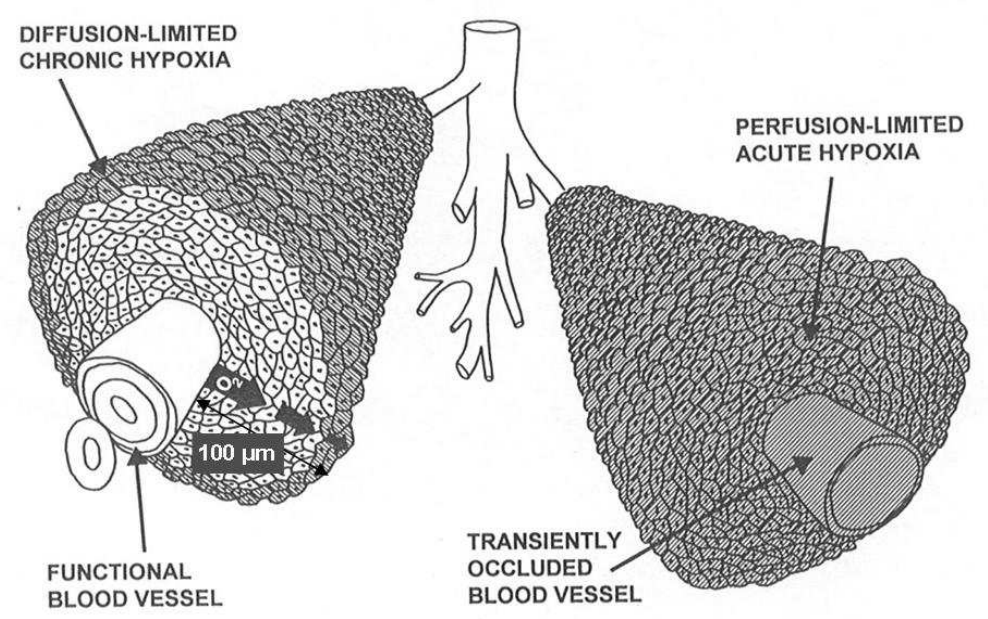

Figure 1. Schematic representation illustrating the difference between chronic and acute hypoxia (adapted from ${ }^{19}$ ).

The most investigated cellular response to hypoxia at a molecular level is the stabilization and activation of the transcription factor hypoxia inducible factor (HIF)-1 and its downstream targets. HIF-1 is a heterodimeric complex of two proteins: aryl hydrocarbon receptor nuclear translocator ARNT/HIF-1 $\beta$ which is constitutively expressed and HIFa proteins (HIF-1a, HIF-2a and HIF-3a), the stability and transactivation functions of which are regulated by 
oxygen levels ${ }^{20}$. Under normoxic conditions, HIFa is hydroxylated by one of three known prolyl hydroxylases (PHD) and therefore ubiquitinated by the E3 ubiquitin ligase von Hippel-Lindau (VHL) protein, targeting this complex for degradation ${ }^{21}$. At lower oxygen concentrations, HIFa is stabilized and activated (the PHDs are not able to hydroxylate HIFa anymore) and forms a heterodimer with HIF-1 $\beta$ on hypoxic responsive elements (HREs) within target gene promoters to drive the expression of HIF targets (figure 2).

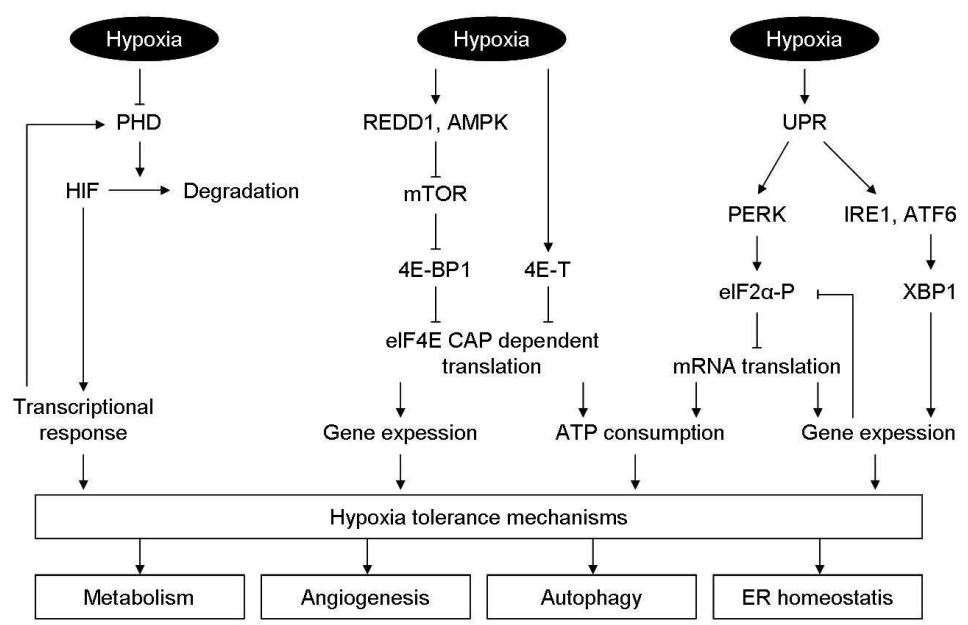

Figure 2. Cellular oxygen sensing pathways promoting hypoxia tolerance by regulating transcription and mRNA translation. Hypoxia stabilizes and activates HIF-1 mediating transcriptional response of many genes. The activity of mTOR and downstream targets is inhibited by hypoxia. The unfolded protein response (UPR) is also triggered by hypoxia by activation of PERK, IRE-1 and ATF6. Together, these pathways promote hypoxia tolerance and influence the phenotype of hypoxic cells by altering metabolism, angiogenesis, autophagy and ER homeostasis. Scheme adapted from ${ }^{23,24}$.

Hypoxia-responsive genes regulate several biological processes, including cell proliferation, angiogenesis, $\mathrm{pH}$ regulation, apoptosis, immortalization and migration. Some well-known examples of hypoxia-upregulated genes include vascular endothelial growth 
factor (VEGF; involved in angiogenesis), GLUT1 (a glucose transporter involved in glycolysis) and carbonic anhydrase IX (CA IX; a regulator of cellular $\mathrm{pH}$ ) (reviewed $\mathrm{in}^{12,20}$ ). Cancer cells have a variety of mechanism to take advantage of some of these responses (e.g. induction of angiogenesis) and to evade others (e.g. apoptosis). It has been shown that there is a crosstalk between oncogenic ( 6 hallmarks of cancer) and hypoxia response pathways. One of the best examples is transcription of VEGF which is activated by HIF-1 and blocked by inhibitors of oncogene signaling pathways, such as agents that inhibit RAS, epidermal growth factor receptor and the receptor tyrosine kinase ERBB2 ${ }^{22}$.

The cellular response to hypoxia can also arise through HIFindependent mechanisms ${ }^{24}$. One of these occurs through regulation of the kinase mammalian target of rapamycin (mTOR) and its downstream effectors which are involved in cell survival and growth through changes in the initiation of mRNA translation, ribosomal biogenesis, autophagy and apoptosis sensitivity ${ }^{25}$. It has been shown that hypoxia is able to prevent activation of the mTOR complex 1 (figure 2) and phosphorylation of its downstream targets $\mathrm{p} 70 \mathrm{~S} 6 \mathrm{~K}$ and $4 \mathrm{E}-\mathrm{BP} 1^{26}$. Inhibition of mRNA translation during hypoxia may be essential for energy preservation given the high ATP demand for protein production. In accordance, our group observed that cells lacking 4E-BP1 show increased sensitivity to hypoxia-induced cell death and develop tumors with reduced levels of ATP, supporting an important function of this protein in mediating hypoxia tolerance ${ }^{27}$. The second mechanism is through activation of the unfolded protein response (UPR) as a consequence of endoplasmic reticulum stress, resulting in an immediate, but reversible reduction in overall protein synthesis ${ }^{28}$. 
This is mediated through phosphorylation of the eukaryotic translation initiation factor eIF2a by the endoplasmic reticulum resident kinase PERK (figure 2 ). We investigated the effect of UPRdependent signaling during hypoxia on the regulation of CA IX and found that its expression is regulated by two distinct mechanisms: a HIF-dependent mechanism activated under low oxygen levels and a PERK/eIF2a/ATF4-dependent pathway regulated by the $\mathrm{UPR}^{29}$.

Hypoxia is one of the major mechanisms causing radioresistance, mainly due to lack of oxygen radicals generated by radiation to create DNA damage such that only about one third as many lethal DNA lesions are produced in hypoxic cells compared with aerobic cells ${ }^{30}$. Overexpression of HIF (driven by hypoxia) and free radical species also contribute to radiation resistance by inducing angiogenic factors which help endothelial cells to survive radiation damage $^{31}$. The activity of many chemotherapeutic drugs is also altered at low oxygen concentration due to the comparatively low rates of proliferation in hypoxic cells. This has partly been attributed to the fact that hypoxic cells are located far from the nearest blood vessel, and therefore may experience limited influx of drug $^{32}$. One of the major explanations is that an acidic extracellular $\mathrm{pH}$ blocks drug uptake into the cells, particularly for anthracyclines such as epirubicin. However, some drugs such as carboplatin and etoposide demonstrate a specifically reduced p53 independent sensitivity under hypoxic conditions, which is multifactorial ${ }^{33},{ }^{34}$. Thus, it is important to understand the underlying mechanisms that contribute to failure to adequate deliver oxygen, nutrients and drugs to tumor cells. Therefore, this 
area of research needs more intensive investigation with detailed biochemical pathways linked to drug resistance.

Hypoxia is thus an important micro-environmental parameter that influences the behavior of tumor cells and has clinically a negative impact on treatment response. It has been shown to be an independent predictor of poor progression-free survival in several types of cancer, such as cervix ${ }^{35}$, head-and-neck ${ }^{36,37}$ and soft tissue sarcomas ${ }^{38}$. An international multi-center trial in 397 patients with head-and-neck tumors demonstrated that the hypoxic fraction was the most statistical significant prognostic factor for patient survival treated with radiotherapy ${ }^{39}$. Patients with poorer tumor oxygenation exhibit a significantly lower 5-year survival probability than patients with better-oxygenated tumors. This has also been shown in patients with primary and metastatic tumors of the cervix ${ }^{40},{ }^{41}$ and breast ${ }^{42}$. Surprisingly, the lower prognosis for patients with hypoxic tumors is independent of the treatment modality (radiotherapy, chemotherapy or radical surgery). These findings are supported by studies of head-andneck and soft tissue sarcomas and indicate that hypoxia leads to a more aggressive phenotype ${ }^{43}$. In contrary, this unique tumor micro-environment characteristic makes hypoxia also an attractive target for newly developed drugs to increase the therapeutic effect of conventional cancer treatment modalities ${ }^{44}$. This has led to clinical efforts being made towards overcoming hypoxia. Possible ways to tackle hypoxia include (1) an increase in blood oxygen levels by breathing high-oxygen gas mixtures (carbogen), (2) increased perfusion (nicotinamide), (3) killing hypoxic cells using cytotoxins (tirapazamine), (4) sensitizing hypoxic cells to radiation (nimorazole), (5) reducing the tolerance of hypoxic cells using 
drugs affecting the unfolded protein response and the autophagy pathway and (6) exploiting the hypoxic microenvironment by administrating anaerobic bacteria which only grow in these regions and express something to kill or sensitize the hypoxic cells ${ }^{23,24}$ 45-47. Although treatments to counteract the negative effect of intra-tumoral hypoxia are under investigation, not all patients benefit from such selective treatments and only modest improvement in outcome was achieved ${ }^{11,48}$. Therefore, in order to guide hypoxia-directed therapies in individual patients, it is important to evaluate tumor oxygenation.

\section{Carbonic anhydrase IX}

To allow sustained expansion, tumor cells need to overcome restrictions connected with insufficient oxygen supply to areas distant from existing blood vessels. This can be done by changes in gene expression accompanied by a switch to anaerobic glycolysis ${ }^{49}$. Gatenby and Gillies suggested that increased glycolysis is an essential component of the malignant phenotype and, therefore, a hallmark of invasive cancers. Initially, the glycolytic phenotype arises as an adaptation to local hypoxia. Persistent or cycling hypoxia leads to constitutive upregulation of the glycolysis, which might occur through mutations or epigenetic changes $^{50}$. This metabolic switch influences the tumor phenotype towards invasion, by triggering neo-angiogenesis, clonal selection of more aggressive cells and acidification of the extracellular environment ${ }^{51}$. The consequential change in the microenvironment results in cellular stress and requires adaptive mechanisms to ensure tumor cell survival. For example, to prevent cell death intracellular $\mathrm{pH}$ needs to be maintained at physiological levels by the activity of ion transporters, pumps, exchangers and channels ${ }^{52}$. 
Several of these processes might require carbonic anhydrase catalytic activity. Carbonic anhydrases (CAs, EC 4.2.1.1) are ubiquitous metalloenzymes present in prokaryotes and eukaryotes and four distinct evolutionary unrelated gene families can be distinguished: $a, \beta, y$ and $\delta$. In higher vertebrates and humans, 14 a-CA isozymes have been described that catalyze the reversible hydration of carbon dioxide to bicarbonate ${ }^{53}$. Carbonic anhydrase IX (CA IX) was originally detected as a cell density-regulated antigen in human cervical carcinoma (HeLa) cells $^{54}$ and was correlated with the tumorigenic phenotype of HeLa cells ${ }^{55}$. CA IX is a trimer glycoprotein with an extracellular catalytic CA and proteoglycan-like domain ${ }^{56}$. CA IX expression is dramatically increased in a variety of human cancers, whilst its expression in normal tissues, except for the gastro-intestinal tract, is $10 w^{57}$. Wykoff and colleagues demonstrated that this tumor-associated upregulation of CA IX is the result of a strong transcriptional activation of the CA9 gene by HIF1- $a^{58-60}$. Many studies were performed to investigate if CA IX could serve as an intrinsic hypoxia marker and found a perinecrotic staining area consistent with chronic hypoxia in cervix, head-and-neck and non-small-cell lung cancers. In pancreatic and breast cancer however, CA IX staining patterns were not directly suggestive for chronic hypoxia ${ }^{61}$. Expression of CA IX is associated with poor prognosis, tumor progression and aggressiveness in head-and-neck ${ }^{62}$, cervix $^{63}$, non-small-cell lung ${ }^{64}$ and bladder $^{65}$ cancer. Furthermore, in human glioblastoma cells, CA9 displayed the highest induction amongst 32 identified hypoxia-responsive genes and was induced in the highest number of tumor cell lines ${ }^{66}$. 
CA IX functions to regulate $\mathrm{pH}$ by catalyzing the reversible conversion of carbon dioxide to bicarbonate and a proton ${ }^{53}$ (figure 3). It has been shown that the active site of CA IX resides in the extracellular space, therefore contributing to the acidification of the extracellular environment during hypoxia ${ }^{67}$ which is associated with increased invasion and metastasis ${ }^{68}$.

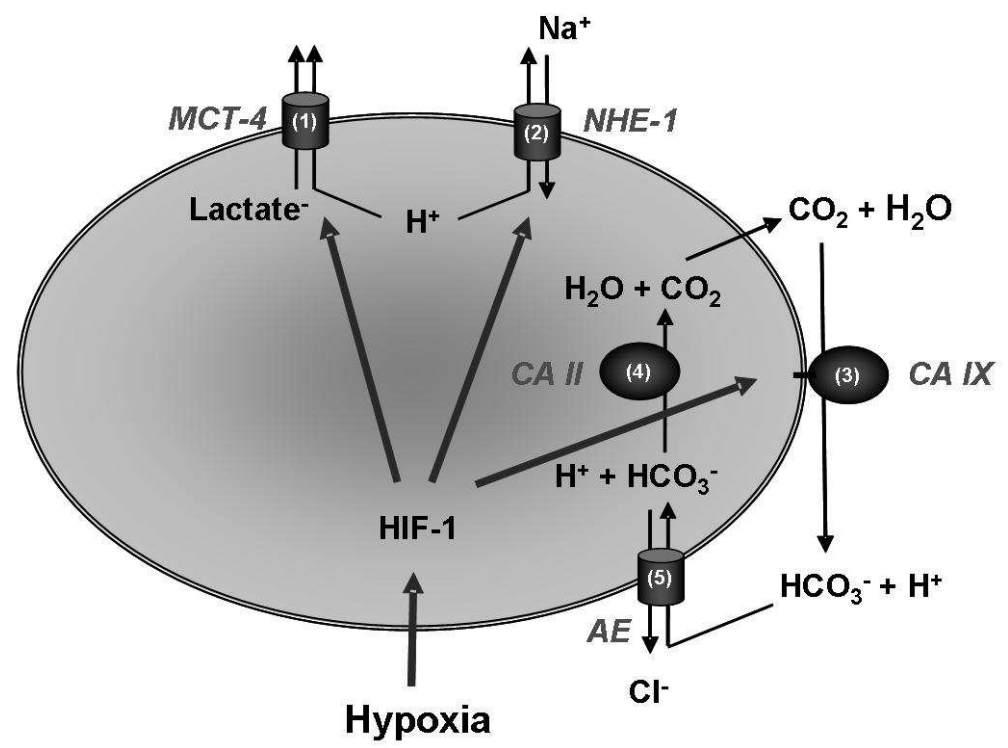

Figure 3. Mechanisms of $\mathrm{pH}$ regulation and ion transport in tumors. Glycolysis is upregulated during hypoxia in a HIF-dependent way, resulting in an increased production of lactate ion and $\mathrm{H}^{+}$. To prevent intracellular acidosis, $\mathrm{pH}$ is maintained at physiological levels by the activity of several pumps, exchangers and channels. Lactic acid is excreted by the $\mathrm{H}^{+}$/lactate co-transporter (monocarboxylate carrier MCT4, target 1). Intracellular $\mathrm{H}^{+}$ ions are extruded through the $\mathrm{Na}^{+} / \mathrm{H}^{+}$exchanger (NHE-1, target 2 ). $\mathrm{CO}_{2}$ diffuses across the membrane and is converted to bicarbonate ion by the membrane-bound carbonic anhydrase (CA) IX (target 3). $\mathrm{HCO}_{3}{ }^{-}$uptake back into the cell is regulated by the $\mathrm{Cl}^{-} / \mathrm{HCO}_{3}^{-}$anion exchanger contributing to intracellular alkalinization (target 5). In the cytoplasm, CA II catalyzes the conversion of $\mathrm{HCO}_{3}{ }^{-}$to $\mathrm{CO}_{2}$ consuming intracellular $\mathrm{H}^{+}$(target 4). Scheme adapted from ${ }^{72}$.

On the other hand, CA IX may also play an important role in maintaining a neutral intracellular $\mathrm{pH}$ within tumors through two 
distinct mechanisms. The bicarbonate ion resulting form the reaction catalyzed by CA IX can be imported into the cytoplasm by the bicarbonate chloride anion exchanger to serve as a substrate for intracellular carbonic anhydrases, such as CA II, to neutralize intracellular protons ${ }^{52}$. Secondly, CA IX is able to coordinate internal $\mathrm{pH}$ in three-dimensional multicellular growths by stimulating carbon dioxide diffusion ${ }^{69}, 70$. CA IX may thus benefit tumor progression, not only by reducing extracellular $\mathrm{pH}$, but also by raising intracellular $\mathrm{pH}$. Given its role in $\mathrm{pH}$ regulation, CA IX has been proposed as a potential therapeutic target ${ }^{53,69,71}$. Selective suppression of CA IX activity by drugs may therefore provide a means for controlling tumor development, by disrupting intracellular $\mathrm{pH}$ coordination and extracellular acidification.

The therapeutic effect of $\mathrm{CA}$ inhibition as a means of tumor $\mathrm{pH}$ manipulation could indeed be an exploitable avenue towards treating cancer. Numerous sulfonamide inhibitors of CAs have been developed in the past few years ${ }^{53}$. These sulfonamides bind in a tetrahedral geometry of the $\mathrm{Zn}$ (II) ion in a deprotonated state, with the nitrogen atom of the sulfonamide group coordinated to $\mathrm{Zn}(\mathrm{II})^{73}$. A first study using acetazolamide, a non-selective CA inhibitor, demonstrated reduced tumor growth when delivered as single treatment and an additive tumor growth delay when administrated in combination with various chemotherapeutic agents $^{74}$. More recent, acetozolamide was observed to suppress tumoral metastasis in vivo by inhibition of aquaporins which are involved in the vascular permeability and the interstitial pressure in tumors ${ }^{75}$. Another CA inhibitor, indisulam, is currently in a Phase II clinical trial for the treatment of patients with advanced nonsmall-cell lung cancer ${ }^{76}$. The possible role of the cancer-related CA 
IX in this process is currently a hot research topic, especially in the light of the knowledge that its expression levels and activity are regulated by hypoxia. To learn more about the role of CA IX and consequences of its inhibition, information on their inhibition profile with different sulfonamides is currently under investigation ${ }^{53}$.

\section{EGFR}

The epidermal growth factor receptor (EGFR also known as HER1) is a transmembrane tyrosine kinase containing an extracellular ligand-binding domain, a transmembrane lipophilic segment and a cytoplasmic protein tyrosine kinase domain. A variety of ligands are described and include epidermal growth factor (EGF), transforming growth factor, amphiregulin and heparin-binding $\mathrm{EGF}^{77}$.

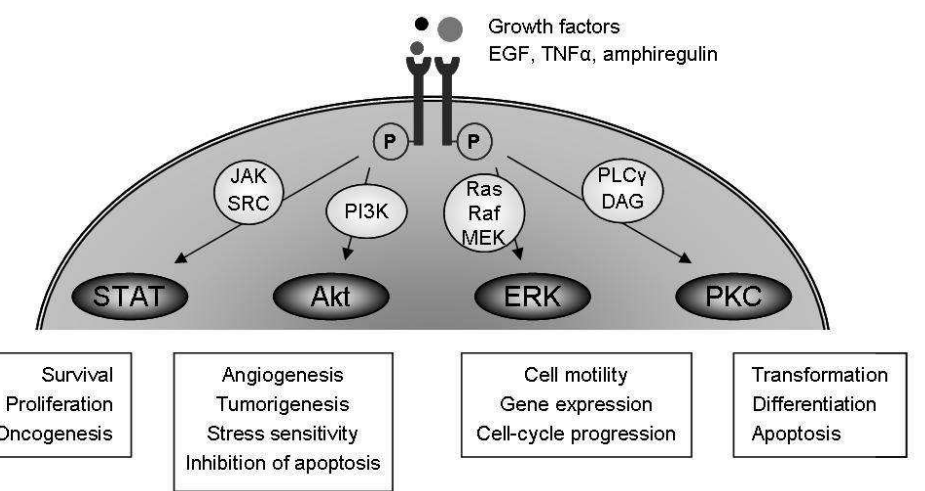

Figure 4. The main downstream signaling pathways regulated by EGFR. Transducer and activator of transcription (STAT) can be activated by EGFR leading to gene expression crucial for cell survival, proliferation and oncogenesis. EGFR activates phospatidylinositol 3-kinase (PI3K) that subsequently activates Akt. Phosporylated Akt has several effects, including inhibition of pro-apoptotic factors, activation of mTOR important in stimulation proliferation and VEGF and HIF-1 important in angiogenesis. Activated Ras by phosporylation binds to Raf, triggering activation of MEK and ERK, influencing gene expression and cell-cycle progression. PLCY binds phosporylated EGFR tyrosine kinase to become active resulting in activation of PKC, which results in transformation, differentiation and apoptosis. Adapted from ${ }^{80}$. 
Besides EGFR, the HER family contains three additional members: HER2 (ErbB-2), HER3 (c-ErbB-3) and HER4 (ErbB-4). HER3 is the only family member without a cytoplasmic tyrosine kinase domain and needs therefore dimerization with other family members to contribute to downstream signaling upon ligand binding (figure 4). This activation influences cellular growth, proliferation, differentiation and survival through various signaling pathways ${ }^{78,79}$.

Amplification of EGFR expression and signaling occurs in a significant number of human malignancies including renal, breast, glioma, non-small-cell lung, prostate and head-and-neck cancers $^{81}$. EGFR expression has been associated with tumor aggressiveness, treatment resistance and poor patient survival ${ }^{82,}$ 83. However, the causes of EGFR overexpression in human cancer vary from patient to patient. Increased EGFR expression in tumors may arise as a result of amplification of the EGFR gene, receptoractivating mutations or evasion from negative regulatory mechanisms ${ }^{84}$. The most common mutation within the EGFR gene is an in-frame deletion of exons 2-7 of the coding sequence resulting in a truncated mutant, named EGFRvIII. This mutant lacks a portion of the extracellular ligand-binding domain, leading to a constant active tyrosine kinase ${ }^{85,}{ }^{86}$. These oncogenic phenomena are most occurring in glioblastoma multiforme and non-small-cell lung cancer ${ }^{87}, 88$. Additionally, there is evidence that EGFR expression or activity may also be controlled by a common physiological event in tumors, such as hypoxia ${ }^{89}$.

Targeting EGFR with receptor-blocking monoclonal antibodies such as cetuximab and panitumumab, or with small-molecule EGFR tyrosine kinase inhibitors (TKIs) such as gefitinib and erlotinib, 
provide a promising approach for cancer therapy ${ }^{90,}{ }^{91}$. Several studies suggest sensitizing effects of these compounds for chemotherapy and irradiation. Cetuximab is a promising growthinhibitory agent that influences cellular proliferation, apoptosis and radiosensitivity ${ }^{92}$. TKIs on the other hand are particularly effective against a subset of non-small-cell lung cancer carrying several somatic mutations in the EGFR tyrosine kinase domain ${ }^{93}$. However, many patients do not show favorable responses to EGFR-targeted therapy, suggested that the response of cancer cells to this treatment is a complex process which can be affected by multiple intrinsic and extrinsic resistance mechanisms ${ }^{94}$. Early non-smallcell lung cancer clinical trials with gefitinib and erlotinib were modestly encouraging, with partial response in $\sim 10 \%$ of treated patients $^{88}$. The insensitivity to EGFR-targeted therapy could be explained by mutations in the KRAS gene being characteristic for smoking-associated cancers ${ }^{95}$. Another possible explanation is the presence of genetic alterations in PTEN, resulting in a failure to downregulate Akt, a hallmark of insensitivity to drugs ${ }^{96}$.

Interactions between hypoxia and EGFR have been demonstrated in non-small-cell lung cancer, which suggest that hypoxia induces expression of EGFR or its ligands, while EGFR might enhance the cellular response to hypoxia by increasing HIF-1a expression ${ }^{97}$. Immunohistochemical studies demonstrated a close association between expression of HIF-1a and the HIF target CA IX, but also with EGFR ${ }^{97}$. Several studies found that EGFR-targeted therapies could circumvent the hypoxia-induced drug resistance via the regulation of HIF-1a, since gefitinib or cetuximab downregulated the expression levels of HIF-1a, both under normoxic and hypoxic conditions ${ }^{94,98}$. Furthermore, tumor vasculature can be changed by 
inhibition of the oncogenic RAS-PI3K-AKT signaling pathway resulting in an improvement of vascular flow and oxygenation leading to a decrease in clinical relevant hypoxia ${ }^{22}$. Recently, Franovic and colleagues showed that EGFR protein expression levels are upregulated in response to tumor hypoxia in a HIF-2a dependent manner rather than mutational events, suggesting that HIF-2a inhibition may provide a means of circumventing EGFRmediated resistance ${ }^{89}$. This is however not a classical HIF transcriptional effect, since no HRE has been found in the EGFR promoter. Therefore, hypoxia or HIF-2a activation may result in the expression of a hypoxia-inducible activator of EGFR translation or alternatively may inhibit a negative regulator of receptor synthesis ${ }^{89}$.

Solid tumors originating from different cell types may be characterized by heterogeneity in EGFR expression, vasculature, capillary permeability perfusion and necrosis. Furthermore, tumor cells can grow and survive independently from EGFR, by altering EGFR levels through ubiquitination and degradation, resulting in EGFR-targeted therapy resistance ${ }^{99}$. All these factors might play a role in in vivo drug delivery and could explain why several patients do not benefit from EGFR-targeted therapy, since if the drug is not able to reach the complete tumor no therapeutic effect can be expected in these regions. Therefore, we believe that monitoring and visualization of drug delivery noninvasively in patients would result in an improved patient selection for EGFR-targeted treatment. 


\section{Evaluation of hypoxia}

To date, various methods have been available to measure tumor oxygenation which can be broadly classified into invasive and noninvasive. Invasive methods are based on oxygen needle electrode measurements or use immunohistological techniques and enzymatic assays to detect various intrinsic or extrinsic markers of hypoxia. The Eppendorf polarographic needle electrode is the main technique of direct oxygen measurements, while immunological analysis of biopsies is more indirect. Both have major limitations, such as availability of small tumor specimen after biopsy and therefore the lack of a global picture of oxygenation status of the whole tumor. To address these challenges, noninvasive imaging techniques have been developed and were proven to be promising. Of course, all new methods need to be validated before they can be used in clinical practice and a major drawback is the unavailability of a standard for comparison.

Despite some limitations, polarographic oxygen electrodes and immunohistological assays still remain the gold standards for the detection of hypoxia ${ }^{100}$. Oxygen electrodes, although invasive, measure oxygen values that have been shown to correlate with radiobiological hypoxia and can predict treatment response ${ }^{101}$. However, temporal changes in oxygenation cannot be measured reliably, since the electrode consumes small amounts of oxygen ${ }^{102}$. A more recent fluorescent-based optical sensor (Oxylite $®$ ) uses the principle of measuring quenching time of a fluorophore by oxygen. A major advantage is the possibility to measure oxygen concentrations continuously to assess temporal heterogeneity ${ }^{103}$. On the other hand, immunohistological assays are based on staining of bioreductive 2-nitroimidazoles, such as pimonidazole 
(Hypoxyprobe $\left.^{\mathrm{TM}}-1\right)^{104}, \quad$ 7-4'-2-nitroimidazole-1-butyl-theophyline $(\text { NITP })^{105}$ or 2-2-nitroimidazolyl-N-pentafluoropropyl-acetamide $(E F 5)^{106}$ which demonstrate a irreversible accumulation in hypoxic cells, where they are subject to reductive metabolism, which causes the formation of reactive intermediates (nitrose and hydroxylamine) that bind to macro-molecular cellular components $^{107}$. Furthermore, hypoxia can be evaluated by immunohistological staining of intrinsic markers, such as HIF- $1 a^{108}$ and CA IX ${ }^{109}$. There is however not always a consensus in staining patterns between intrinsic and extrinsic markers of hypoxia due to possible differences in specificity of CA IX when compared with $\mathrm{PIMO}^{37}$. von Hippel-Lindau mutations, which results in an upregulation of $\mathrm{CA} \mathrm{IX}^{110}$, and the relationship between CA IX expression and an acidic $\mathrm{pH}$ found in tumors ${ }^{52}$ could potentially contribute to these differences. Although these methods enable tumor oxygenation measurements, they are limited by practical challenges such as invasiveness and tumor accessibility, making their usefulness in guiding treatment modalities or for individualizing therapies based on oxygenation status limited ${ }^{100}$.

To evaluate spatial as well as temporal heterogeneity, both in distribution of hypoxia and hypoxia responses, noninvasive threedimensional imaging in a repeated fashion becomes a necessity. The real power of molecular imaging goes beyond diagnosis by identifying different biological processes within a tumor using tracers which characterize both genotypic and phenotypic signatures ${ }^{111}$. The challenge for noninvasive hypoxia imaging is to measure low levels of tissue oxygen on a spatial scale similar to the oxygen diffusion distance, a much smaller dimension than can be achieved with current imaging modalities. Currently available 
MRI and PET methods were compared and it was noted that only a few techniques have potential for in vivo assessment in humans particularly for repeated, sequential measurements. $\left[{ }^{18} \mathrm{~F}\right] \mathrm{FMISO}$ and $\left[{ }^{60 / 64} \mathrm{Cu}\right]$ ATSM-PET and BOLD-MRI were shown to be the lead contenders for human application based on their noninvasive nature, ease of use and robustness, measurement of hypoxia status, validity, ability to demonstrate heterogeneity and general availability $^{112}$. BOLD-MRI or blood oxygen level dependent functional magnetic resonance imaging uses hemoglobin as intrinsic contrast agent: oxyhemoglobin has no magnetic (diamagnetic) properties, while deoxyhemoglobin is paramagnetic $^{113}$. Lower oxygenation results in an increased deoxyhemoglobin, leading to local magnetic field inhomogeneity and in turn, to lower T2*-weighted image intensity ${ }^{114}$, which can be evaluated by MRI. PET or positron emission tomography is based on capturing annihilation photons from positron-emitting tracers and is considered the most accurate technique for in vivo noninvasive imaging of metabolic pathways and receptor-ligand interactions ${ }^{115}$. $\quad\left[{ }^{18} \mathrm{~F}\right]$ Fluoromisonidazole $\left(\left[{ }^{18} \mathrm{~F}\right] \mathrm{FMISO}\right)$ is the prototype hypoxia imaging agent and accumulates in tissues by nitroreductase dependent binding to intracellular macromolecules when oxygen levels drop below $10 \mathrm{mmHg}$, in much the same way as pimonidazole ${ }^{112}$. Limitations of $\left[{ }^{18} \mathrm{~F}\right] \mathrm{FMISO}-\mathrm{PET}$ include modest signal to noise ratios, the presence of high normal liver uptake impairing assessment of liver lesions and urinary excretion interfering with imaging near the bladder ${ }^{116}$. $\left[{ }^{18} \mathrm{~F}\right]$ Fluoroazomycin arabinoside ( $\left.\left[{ }^{18} \mathrm{~F}\right] \mathrm{FAZA}\right)$, a relatively new second generation nitroimidazole tracer, contains a sugar moiety which makes the compound less lipophilic than the standard PET hypoxia marker $\left[{ }^{18} \mathrm{~F}\right] \mathrm{FMISO}$ and possibly easier to clear from the non-hypoxic 
tissue, yielding more favorable tumor to background ratios. Furthermore, the arabinosyl-N1-a-glycosidic bond has been shown to display enhanced in vivo stability against enzymatic cleavage ${ }^{117}$. Another alternative PET agent for hypoxia is based on a metal complex of radioactive copper $(\mathrm{Cu})$ with diacetyl-bismethylthiosemicarbazone (ATSM). The simple retention mechanism is based on the reduction of $\mathrm{Cu}(\mathrm{II})$-ATSM to $\mathrm{Cu}(\mathrm{I})$ ATSM which is irreversible under low oxygen conditions ${ }^{118}$. Preclinical studies with CU-ATSM, demonstrated that it is reduced and retained in hypoxic tissues, whereas it rapidly washes out of normoxic tissues. Cu-ATSM uptake was more rapid than $\left[{ }^{18} \mathrm{~F}\right] \mathrm{FMISO}$ uptake, resulting in a larger hypoxic to normoxic ratio. This was probably related to a greater membrane permeability or a more rapid blood clearance ${ }^{119}$. The biggest disadvantage of $\mathrm{Cu}$ ATSM is that, because of its lipophilicity, early uptake and washout, it is influenced by regional blood flow, a major confounder with hypoxia ${ }^{116}$. In conclusion, MRI and PET with several hypoxia-specific tracers have the ability to quantify hypoxia, providing a basis for rational patient selection and guiding treatment ${ }^{120}$.

\section{Outline and hypothesis of this thesis}

Hypoxia and its downstream targets are important parameters influencing the behavior of tumor cells and clinically they have a negative impact on treatment response. To increase the therapeutic effect of conventional cancer treatment modalities, efforts have been made towards overcoming hypoxia. However, not all patients benefit from such selective treatments and only a modest improvement in outcome has been achieved to date. Therefore, it would be highly valuable to evaluate tumor 
oxygenation and/or hypoxia response prior to (and/or during) treatment in order to guide these hypoxia-directed therapies in individual patients. Furthermore, it is necessary to perform comparative studies to allow validation of novel methodologies for the evaluation of hypoxia by comparison with established 'socalled standard' techniques.

The first goal of this thesis was to evaluate noninvasive markers for the detection of hypoxia. The noninvasive $\left[{ }^{18} \mathrm{~F}\right]$ FMISO-PET method was further validated in chapter 2 with immunohistochemical staining techniques using pimonidazole, the 'standard' exogenous hypoxia marker. Although $\left[{ }^{18} \mathrm{~F}\right] \mathrm{FMISO}$ demonstrates a high cellular uptake and trapping in hypoxic cells and has been indicated to be a valuable tool for therapy response evaluation, its diffusion in tumor tissues might not be optimal due to the hydrophilicity of the compound. We quantitatively compared in chapter 3 the selectivity of hypoxia-dependent uptake of the more lipophilic fluorinated compound $\left[{ }^{18} \mathrm{~F}\right] \mathrm{EF} 3$ with $\left[{ }^{18} \mathrm{~F}\right] \mathrm{FMISO}$ in the same experimental rat tumor model using in vivo PET. Recently, a new noninvasive potential hypoxia marker $\left[{ }^{18} \mathrm{~F}\right] \mathrm{HX} 4$ has been developed characterized by optimized pharmacokinetics and very low metabolite formation. In chapter 4 the use of this marker to detect tumor hypoxia was validated by investigating its uptake profile upon different oxygen concentration breathing conditions.

The second aim of this thesis was to evaluate the possibility of imaging the hypoxia responsive target CA IX to learn more about its role in tumor acidification and the consequences of its inhibition. A fluorescent sulfonamide with high affinity for CA IX 
has been shown to inhibit hypoxia-mediated tumor acidification. We investigated in chapter 5 the binding properties of these CA IX-directed sulfonamides in discriminating between actual and previously hypoxic cells using several tumor cell lines. We extended these observations in chapter 6 to an in vivo animal setting where we investigated the tumor uptake of the fluorescent sulfonamide upon different oxygen concentrations.

The last goal of this thesis was to develop and test an imaging probe to visualize drug delivery of the EGFR-targeted cetuximab therapy in a noninvasive manner. We developed in chapter 7 a fluorescent Oregon Green labeled cetuximab imaging probe and validated the in vitro and in vivo binding to EGFR. To increase the clinical applicability, we developed a $\left[{ }^{89} \mathrm{Zr}\right]$ labeled cetuximab imaging probe in chapter $\mathbf{8}$, which was validated preclinically using PET in mice bearing tumors with varying EGFR expression.

Finally, in chapter 9 a summary and general discussion with future perspectives is presented. 


\section{References}

1. World Health Organization: Cancer - Key Facts 2007. http://www.who.int/cancer.

2. Signaleringsrapport 'Kanker in Nederland; Trends, prognoses en implicaties voor zorgvraag'. http://www.ikcnet.nl.

3. Hanahan D. and Weinberg R.A. The Hallmarks of Cancer. Cell, 2000. 100(1): p. 5770.

4. Hahn W.C., Counter C.M., Lundberg A.S., et al. Creation of human tumour cells with defined genetic elements. Nature, 1999. 400(6743): p. 464-8.

5. Wood L.D., Parsons D.W., Jones S., et al. The genomic landscapes of human breast and colorectal cancers. Science, 2007. 318(5853): p. 1108-13.

6. Clarke B.L. and Khosla S. New selective estrogen and androgen receptor modulators. Curr Opin Rheumatol, 2009. 21(4): p. 374-9.

7. Waldmann T.A. Immunotherapy: past, present and future. Nat Med, 2003. 9(3): p. 269-77.

8. Belkacemi Y., Tsoutsou P., Magne N., et al. Metabolic functional imaging for tumor radiosensitivity monitoring. Crit Rev Oncol Hematol, 2007. 62(3): p. 227-39.

9. Mottram J.C. Factor of importance in radiosensitivity of tumors. Br J Radiol, 1936. 9: p. 606-614.

10. Thomlinson R.H. and Gray L.H. The histological structure of some human lung cancers and the possible implications for radiotherapy. $\mathrm{Br}$ J Cancer, 1955. 9(4): $\mathrm{p}$. 539-49.

11. Brown J.M. and Wilson W.R. Exploiting tumour hypoxia in cancer treatment. Nat Rev Cancer, 2004. 4(6): p. 437-47.

12. Harris A.L. Hypoxia--a key regulatory factor in tumour growth. Nat Rev Cancer, 2002. 2(1): p. 38-47.

13. Brown J.M. and Giaccia A.J. The unique physiology of solid tumors: opportunities (and problems) for cancer therapy. Cancer Res, 1998. 58(7): p. 1408-16.

14. Coleman C.N., Mitchell J.B., and Camphausen K. Tumor Hypoxia: Chicken, Egg, or a Piece of the Farm? J Clin Oncol, 2002. 20(3): p. 610-615.

15. Chaplin D.J. and Hill S.A. Temporal heterogeneity in microregional erythrocyte flux in experimental solid tumours. Br J Cancer, 1995. 71(6): p. 1210-3.

16. Dewhirst M.W., Cao Y., and Moeller B. Cycling hypoxia and free radicals regulate angiogenesis and radiotherapy response. Nat Rev Cancer, 2008. 8(6): p. 425-37.

17. Hall E.J. and Giaccia A.G. Radiobiology for the radiologist, sixth edition. Lippencott Williams and Wilkins, a Wolters Kluwer business, Philadelphia, USA, 2006: p. 85-105.

18. Bristow R.G. and Hill R.P. Hypoxia and metabolism: Hypoxia, DNA repair and genetic instability. Nat Rev Cancer, 2008. 8(3): p. 180-192.

19. Horsman M.R. Measurement of tumor oxygenation. Int J Radiat Oncol Biol Phys, 1998. 42(4): p. 701-4.

20. Semenza G.L. Targeting HIF-1 for cancer therapy. Nat Rev Cancer, 2003. 3(10): p. 721-732.

21. Ivan M., Kondo K., Yang H., et al. HIFalpha targeted for VHL-mediated destruction by proline hydroxylation: implications for $\mathrm{O} 2$ sensing. Science, 2001. 292(5516): p. 464-8.

22. Qayum N., Muschel R.J., Im J.H., et al. Tumor Vascular Changes Mediated by Inhibition of Oncogenic Signaling. Cancer Res, 2009. 69(15): p. 6347-6354.

23. Magagnin M.G., Koritzinsky M., and Wouters B.G. Patterns of tumor oxygenation and their influence on the cellular hypoxic response and hypoxia-directed therapies. Drug Resist Updat, 2006. 9(4-5): p. 185-97.

24. Wouters B.G. and Koritzinsky M. Hypoxia signalling through mTOR and the unfolded protein response in cancer. Nat Rev Cancer, 2008. 8(11): p. 851-64.

25. Guertin D.A. and Sabatini D.M. Defining the role of mTOR in cancer. Cancer Cell, 2007. 12(1): p. 9-22.

26. Arsham A.M., Howell J.J., and Simon M.C. A novel hypoxia-inducible factorindependent hypoxic response regulating mammalian target of rapamycin and its targets. J Biol Chem, 2003. 278(32): p. 29655-60.

27. Dubois L., Magagnin M.G., Cleven A.H., et al. Inhibition of 4E-BP1 sensitizes U87 glioblastoma xenograft tumors to irradiation by decreasing hypoxia tolerance. Int ] Radiat Oncol Biol Phys, 2009. 73(4): p. 1219-27.

28. Koritzinsky M., Magagnin M.G., van den Beucken T., et al. Gene expression during acute and prolonged hypoxia is regulated by distinct mechanisms of translational control. EMBO J, 2006. 25(5): p. 1114-25. 
29. van den Beucken T., Koritzinsky M., Niessen H., et al. Hypoxia-induced expression of carbonic anhydrase 9 is dependent on the unfolded protein response. J Biol Chem, 2009. 284(36): p. 24204-12.

30. Koch C.J. Oxygen effects in radiobiology. Adv Exp Med Biol, 1982. 157: p. 123-44.

31. Moeller B.J., Dreher M.R., Rabbani Z.N., et al. Pleiotropic effects of HIF-1 blockade on tumor radiosensitivity. Cancer Cell, 2005. 8(2): p. 99-110.

32. Teicher B.A. Hypoxia and drug resistance. Cancer Metastasis Rev, 1994. 13(2): p. 139-68.

33. Sermeus A., Cosse J.P., Crespin M., et al. Hypoxia induces protection against etoposide-induced apoptosis: molecular profiling of changes in gene expression and transcription factor activity. Mol Cancer, 2008. 7: p. 27.

34. Unruh A., Ressel A., Mohamed H.G., et al. The hypoxia-inducible factor-1 alpha is a negative factor for tumor therapy. Oncogene, 2003. 22(21): p. 3213-20.

35. Fyles A., Milosevic M., Pintilie M., et al. Long-term performance of interstial fluid pressure and hypoxia as prognostic factors in cervix cancer. Radiother Oncol, 2006. 80(2): p. $132-7$

36. Brizel D.M., Sibley G.S., Prosnitz L.R., et al. Tumor hypoxia adversely affects the prognosis of carcinoma of the head and neck. Int J Radiat Oncol Biol Phys, 1997. 38(2): p. 285-9.

37. Kaanders J.H., Wijffels K.I., Marres H.A., et al. Pimonidazole binding and tumor vascularity predict for treatment outcome in head and neck cancer. Cancer Res, 2002. 62(23): p. 7066-74.

38. Nordsmark M., Alsner J., Keller J., et al. Hypoxia in human soft tissue sarcomas: adverse impact on survival and no association with p53 mutations. Br J Cancer, 2001. 84(8): p. 1070-5.

39. Nordsmark M., Bentzen S.M., Rudat V., et al. Prognostic value of tumor oxygenation in 397 head and neck tumors after primary radiation therapy. An international multicenter study. Radiother Oncol, 2005. 77(1): p. 18-24.

40. Hockel M., Schlenger K., Aral B., et al. Association between tumor hypoxia and malignant progression in advanced cancer of the uterine cervix. Cancer Res, 1996. 56(19): p. 4509-15.

41. Nordsmark M., Loncaster J., Aquino-Parsons C., et al. The prognostic value of pimonidazole and tumour pO2 in human cervix carcinomas after radiation therapy: a prospective international multi-center study. Radiother Oncol, 2006. 80(2): p. 12331.

42. Vaupel P., Schlenger K., Knoop C., et al. Oxygenation of human tumors: evaluation of tissue oxygen distribution in breast cancers by computerized $\mathrm{O} 2$ tension measurements. Cancer Res, 1991. 51(12): p. 3316-22.

43. Vaupel P. and Hoeckel M. Predictive power of the tumor oxygenation status. Adv Exp Med Biol, 1999. 471: p. 533-9.

44. Tatum J.L., Kelloff G.J., Gillies R.J., et al. Hypoxia: importance in tumor biology, noninvasive measurement by imaging, and value of its measurement in the management of cancer therapy. Int J Radiat Biol, 2006. 82(10): p. 699-757.

45. Bache M., Kappler M., Said H.M., et al. Detection and specific targeting of hypoxic regions within solid tumors: current preclinical and clinical strategies. Curr Med Chem, 2008. 15(4): p. 322-38.

46. Corry J. and Rischin D. Strategies to overcome accelerated repopulation and hypoxia-what have we learned from clinical trials? Semin Oncol, 2004. 31(6): p. 802-8.

47. Mengesha A., Dubois L., Chiu R.K., et al. Potential and limitations of bacterialmediated cancer therapy. Front Biosci, 2007. 12: p. 3880-91.

48. Wouters B.G., Weppler S.A., Koritzinsky M., et al. Hypoxia as a target for combined modality treatments. Eur J Cancer, 2002. 38(2): p. 240-57.

49. Dang C.V. and Semenza G.L. Oncogenic alterations of metabolism. Trends Biochem Sci, 1999. 24(2): p. 68-72.

50. Gatenby R.A. and Gillies R.J. Why do cancers have high aerobic glycolysis? Nat Rev Cancer, 2004. 4(11): p. 891-9.

51. Semenza G.L. Hypoxia-inducible factor 1: oxygen homeostasis and disease pathophysiology. Trends Mol Med, 2001. 7(8): p. 345-50.

52. Stubbs M., McSheehy P.M., Griffiths J.R., et al. Causes and consequences of tumour acidity and implications for treatment. Mol Med Today, 2000. 6(1): p. 15-9.

53. Supuran C.T. Carbonic anhydrases: novel therapeutic applications for inhibitors and activators. Nat Rev Drug Discov, 2008. 7(2): p. 168-81.

54. Pastorekova S., Zavadova Z., Kostal M., et al. A novel quasi-viral agent, MaTu, is a two-component system. Virology, 1992. 187(2): p. 620-6. 
55. Zavada J., Zavadova Z., Pastorekova S., et al. Expression of MaTu-MN protein in human tumor cultures and in clinical specimens. Int J Cancer, 1993. 54(2): p. 26874.

56. Opavsky R., Pastorekova S., Zelnik V., et al. Human MN/CA9 gene, a novel member of the carbonic anhydrase family: structure and exon to protein domain relationships. Genomics, 1996. 33(3): p. 480-7.

57. Pastorekova S., Parkkila S., and Zavada J. Tumor-associated carbonic anhydrases and their clinical significance. Adv Clin Chem, 2006. 42: p. 167-216.

58. Chiche J., Ilc K., Laferriere J., et al. Hypoxia-inducible carbonic anhydrase IX and XII promote tumor cell growth by counteracting acidosis through the regulation of the intracellular pH. Cancer Res, 2009. 69(1): p. 358-68.

59. Karaczyn A., Ivanov S., Reynolds M., et al. Ascorbate depletion mediates upregulation of hypoxia-associated proteins by cell density and nickel. J Cell Biochem, 2006. 97(5): p. 1025-35.

60. Wykoff C.C., Beasley N.J., Watson P.H., et al. Hypoxia-inducible expression of tumorassociated carbonic anhydrases. Cancer Res, 2000. 60(24): p. 7075-83.

61. Vordermark D. and Brown J.M. Endogenous markers of tumor hypoxia predictors of clinical radiation resistance? Strahlenther Onkol, 2003. 179(12): p. 801-11.

62. Beasley N.J., Wykoff C.C., Watson P.H., et al. Carbonic anhydrase IX, an endogenous hypoxia marker, expression in head and neck squamous cell carcinoma and its relationship to hypoxia, necrosis, and microvessel density. Cancer Res, 2001. 61(13): p. 5262-7.

63. Loncaster J.A., Harris A.L., Davidson S.E., et al. Carbonic anhydrase (CA IX) expression, a potential new intrinsic marker of hypoxia: correlations with tumor oxygen measurements and prognosis in locally advanced carcinoma of the cervix. Cancer Res, 2001. 61(17): p. 6394-9.

64. Giatromanolaki A., Koukourakis M.I., Sivridis E., et al. Expression of hypoxiainducible carbonic anhydrase- 9 relates to angiogenic pathways and independently to poor outcome in non-small cell lung cancer. Cancer Res, 2001. 61(21): p. 7992-8.

65. Turner K.J., Crew J.P., Wykoff C.C., et al. The hypoxia-inducible genes VEGF and CA9 are differentially regulated in superficial vs invasive bladder cancer. $\mathrm{Br} J$ Cancer, 2002. 86(8): p. 1276-82.

66. Lal A., Peters H., St Croix B., et al. Transcriptional response to hypoxia in human tumors. J Natl Cancer Inst, 2001. 93(17): p. 1337-43.

67. Svastova E., Hulikova A., Rafajova M., et al. Hypoxia activates the capacity of tumorassociated carbonic anhydrase IX to acidify extracellular pH. FEBS Lett, 2004. 577(3): p. 439-45.

68. Moellering R.E., Black K.C., Krishnamurty C., et al. Acid treatment of melanoma cells selects for invasive phenotypes. Clin Exp Metastasis, 2008, 25(4): p. 411-25.

69. Swietach P., Wigfield S., Cobden P., et al. Tumor-associated carbonic anhydrase 9 spatially coordinates intracellular $\mathrm{pH}$ in three-dimensional multicellular growths. J Biol Chem, 2008. 283(29): p. 20473-83.

70. Swietach P., Wigfield S., Supuran C.T., et al. Cancer-associated, hypoxia-inducible carbonic anhydrase IX facilitates CO2 diffusion. BJU Int, 2008. 101 Suppl 4: p. 22-4. Potter C.P. and Harris A.L. Diagnostic, prognostic and therapeutic implications of carbonic anhydrases in cancer. $\mathrm{Br}$ J Cancer, 2003. 89(1): p. 2-7.

72. Pouyssegur J., Dayan F., and Mazure N.M. Hypoxia signalling in cancer and approaches to enforce tumour regression. Nature, 2006. 441(7092): p. 437-43.

73. Supuran C.T. Casini A., and Scozzafava A. Protease inhibitors of the sulfonamide type: anticancer, antiinflammatory, and antiviral agents. Med Res Rev, 2003. 23(5): p. 535-58.

74. Teicher B.A., Liu S.D., Liu J.T., et al. A carbonic anhydrase inhibitor as a potential modulator of cancer therapies. Anticancer Res, 1993. 13(5A): p. 1549-56.

75. Xiang Y., Ma B., Li T., et al. Acetazolamide inhibits aquaporin-1 protein expression and angiogenesis. Acta Pharmacol Sin, 2004. 25(6): p. 812-6.

76. Talbot D.C., von Pawel J., Cattell E., et al. A randomized phase II pharmacokinetic and pharmacodynamic study of indisulam as second-line therapy in patients with advanced non-small cell lung cancer. Clin Cancer Res, 2007. 13(6): p. 1816-22.

77. Ullrich $\mathrm{A}$. and Schlessinger J. Signal transduction by receptors with tyrosine kinase activity. Cell, 1990. 61(2): p. 203-12.

78. Herbst R.S. Review of epidermal growth factor receptor biology. Int J Radiat Oncol Biol Phys, 2004. 59(2 Suppl): p. 21-6.

79. Yarden Y. and Sliwkowski M.X. Untangling the ErbB signalling network. Nat Rev Mol Cell Biol, 2001. 2(2): p. 127-37. 
80. Nyati M.K., Morgan M.A., Feng F.Y., et al. Integration of EGFR inhibitors with radiochemotherapy. Nat Rev Cancer, 2006. 6(11): p. 876-85.

81. Salomon D.S., Brandt R., Ciardiello F., et al. Epidermal growth factor-related peptides and their receptors in human malignancies. Crit Rev Oncol Hematol, 1995. 19(3): p. 183-232.

82. Arteaga C.L. Epidermal growth factor receptor dependence in human tumors: more than just expression? Oncologist, 2002. 7 Suppl 4: p. 31-9.

83. Eriksen J.G., Steiniche T., and Overgaard J. The influence of epidermal growth factor receptor and tumor differentiation on the response to accelerated radiotherapy of squamous cell carcinomas of the head and neck in the randomized DAHANCA 6 and 7 study. Radiother Oncol, 2005. 74(2): p. 93-100.

84. Bache K.G., Slagsvold T., and Stenmark H. Defective downregulation of receptor tyrosine kinases in cancer. EMBO J, 2004. 23(14): p. 2707-12.

85. Moscatello D.K., Holgado-Madruga M., Godwin A.K., et al. Frequent expression of a mutant epidermal growth factor receptor in multiple human tumors. Cancer Res, 1995. 55(23): p. 5536-9.

86. Pedersen M.W., Meltorn M., Damstrup L., et al. The type III epidermal growth factor receptor mutation. Biological significance and potential target for anti-cancer therapy. Ann Oncol, 2001. 12(6): p. 745-60.

87. Halatsch M.E., Schmidt U., Behnke-Mursch J., et al. Epidermal growth factor receptor inhibition for the treatment of glioblastoma multiforme and other malignant brain tumours. Cancer Treat Rev, 2006. 32(2): p. 74-89.

88. Sharma S.V., Bell D.W., Settleman J., et al. Epidermal growth factor receptor mutations in lung cancer. Nat Rev Cancer, 2007. 7(3): p. 169-81.

89. Franovic A., Gunaratnam L., Smith K., et al. Translational up-regulation of the EGFR by tumor hypoxia provides a nonmutational explanation for its overexpression in human cancer. Proc Natl Acad Sci U S A, 2007. 104(32): p. 13092-7.

90. Baselga J. and Arteaga C.L. Critical update and emerging trends in epidermal growth factor receptor targeting in cancer. J Clin Oncol, 2005. 23(11): p. 2445-59.

91. Imai K. and Takaoka A. Comparing antibody and small-molecule therapies for cancer. Nat Rev Cancer, 2006. 6(9): p. 714-27.

92. Huang S.M., Bock J.M., and Harari P.M. Epidermal growth factor receptor blockade with C225 modulates proliferation, apoptosis, and radiosensitivity in squamous cell carcinomas of the head and neck. Cancer Res, 1999. 59(8): p. 1935-40.

93. Lynch T.J., Bell D.W., Sordella R., et al. Activating mutations in the epidermal growth factor receptor underlying responsiveness of non-small-cell lung cancer to gefitinib. $\mathrm{N}$ Engl J Med, 2004. 350(21): p. 2129-39.

94. Lu Y., Liang K., Li X., et al. Responses of cancer cells with wild-type or tyrosine kinase domain-mutated epidermal growth factor receptor (EGFR) to EGFR-targeted therapy are linked to downregulation of hypoxia-inducible factor-1alpha. Mol Cancer, 2007. 6: p. 63.

95. Pao W., Wang T.Y., Riely G.J., et al. KRAS mutations and primary resistance of lung adenocarcinomas to gefitinib or erlotinib. PLoS Med, 2005. 2(1): p. e17.

96. Sordella R., Bell D.W., Haber D.A., et al. Gefitinib-sensitizing EGFR mutations in lung cancer activate anti-apoptotic pathways. Science, 2004. 305(5687): p. 1163-7.

97. Swinson D.E. and O'Byrne K.J. Interactions between hypoxia and epidermal growth factor receptor in non-small-cell lung cancer. Clin Lung Cancer, 2006. 7(4): p. 250-6. Rho J.K., Choi Y.J., Lee J.K., et al. Gefitinib circumvents hypoxia-induced drug

98. Rho J.K., Choi Y.J., Lee J.K., et al. Gefitinib circumvents hypoxia-induced drug
resistance by the modulation of HIF-1alpha. Oncol Rep, 2009. 21(3): p. 801-7.
99. Lu Y., Li X., Liang K., et al. Epidermal growth factor receptor (EGFR) ubiquitination as a mechanism of acquired resistance escaping treatment by the anti-EGFR monoclonal antibody cetuximab. Cancer Res, 2007. 67(17): p. 8240-7.

100. Davda S. and Bezabeh T. Advances in methods for assessing tumor hypoxia in vivo: implications for treatment planning. Cancer Metastasis Rev, 2006. 25(3): p. 469-80.

101. Gatenby R.A., Kessler H.B., Rosenblum J.S., et al. Oxygen distribution in squamous cell carcinoma metastases and its relationship to outcome of radiation therapy. Int J Radiat Oncol Biol Phys, 1988. 14(5): p. 831-8.

102. Kavanagh M.C., Sun A., Hu Q., et al. Comparing techniques of measuring tumor hypoxia in different murine tumors: Eppendorf pO2 Histograph, $[3 \mathrm{H}]$ misonidazole binding and paired survival assay. Radiat Res, 1996. 145(4): p. 491-500.

103. Bussink J., Kaanders J.H., Strik A.M., et al. Optical sensor-based oxygen tension measurements correspond with hypoxia marker binding in three human tumor xenograft lines. Radiat Res, 2000. 154(5): p. 547-55. 
104. Raleigh J.A., Chou S.C., Bono E.L., et al. Semiquantitative immunohistochemical analysis for hypoxia in human tumors. Int J Radiat Oncol Biol Phys, 2001. 49(2): p. 569-74.

105. Hodgkiss R.J. and Wardman P. The measurement of hypoxia in tumours. BJR Suppl, 1992. 24: p. 105-10.

106. Koch C.J. Measurement of absolute oxygen levels in cells and tissues using oxygen sensors and 2-nitroimidazole EF5. Methods Enzymol, 2002. 352: p. 3-31.

107. Nunn A., Linder K., and Strauss H.W. Nitroimidazoles and imaging hypoxia. Eur J Nucl Med, 1995. 22(3): p. 265-80.

108. Janssen H.L., Haustermans K.M., Sprong D., et al. HIF-1A, pimonidazole, and iododeoxyuridine to estimate hypoxia and perfusion in human head-and-neck tumors. Int J Radiat Oncol Biol Phys, 2002. 54(5): p. 1537-49.

109. Olive P.L., Aquino-Parsons C., MacPhail S.H., et al. Carbonic anhydrase 9 as an endogenous marker for hypoxic cells in cervical cancer. Cancer Res, 2001. 61(24): p. 8924-9.

110. Ashida S., Nishimori I., Tanimura M., et al. Effects of von Hippel-Lindau gene mutation and methylation status on expression of transmembrane carbonic anhydrases in renal cell carcinoma. J Cancer Res Clin Oncol, 2002. 128(10): p. 5618.

111. Chapman J.D., Bradley J.D., Eary J.F., et al. Molecular (functional) imaging for radiotherapy applications: an RTOG symposium. Int J Radiat Oncol Biol Phys, 2003. 55(2): p. 294-301.

112. Padhani A.R., Krohn K.A., Lewis J.S., et al. Imaging oxygenation of human tumours. Eur Radiol, 2007. 17(4): p. 861-72.

113. Ogawa S., Menon R.S., Tank D.W., et al. Functional brain mapping by blood oxygenation level-dependent contrast magnetic resonance imaging. A comparison of signal characteristics with a biophysical model. Biophys J, 1993. 64(3): p. 803-12.

114. Janick P.A., Hackney D.B., Grossman R.I., et al. MR imaging of various oxidation states of intracellular and extracellular hemoglobin. AJNR Am J Neuroradiol, 1991. 12(5): p. 891-7.

115. Jones T. The imaging science of positron emission tomography. Eur J Nucl Med, 1996. 23(7): p. 807-13.

116. Krohn K.A., Link J.M., and Mason R.P. Molecular imaging of hypoxia. J Nucl Med, 2008. 49 Suppl 2: p. 129S-48S.

117. Piert M., Machulla H.J., Picchio M., et al. Hypoxia-specific tumor imaging with 18Ffluoroazomycin arabinoside. J Nucl Med, 2005. 46(1): p. 106-13.

118. Vavere A.L. and Lewis J.S. CU-ATSM: a radiopharmaceutical for the PET imaging of hypoxia. Dalton Trans, 2007(43): p. 4893-902.

119. Lewis J.S., McCarthy D.W., McCarthy T.J., et al. Evaluation of 64Cu-ATSM in vitro and in vivo in a hypoxic tumor model. J Nucl Med, 1999. 40(1): p. 177-83.

120. Rajendran J.G. and Mankoff D.A. Beyond detection: novel applications for PET imaging to guide cancer therapy. J Nucl Med, 2007. 48(6): p. 855-6. 


\section{Chapter 2}

Evaluation of hypoxia in an experimental rat tumor model by $\left[{ }^{18} \mathrm{~F}\right.$ ]Fluoromisonidazole PET and immunohistochemistry

Dubois L, Landuyt W, Haustermans K, Dupont P, Bormans $G$, Vermaelen $P$, Flamen $P$, Verbeken $E$, Mortelmans $L$

Br J Cancer. 2004 Nov 29;91(11):1947-1954

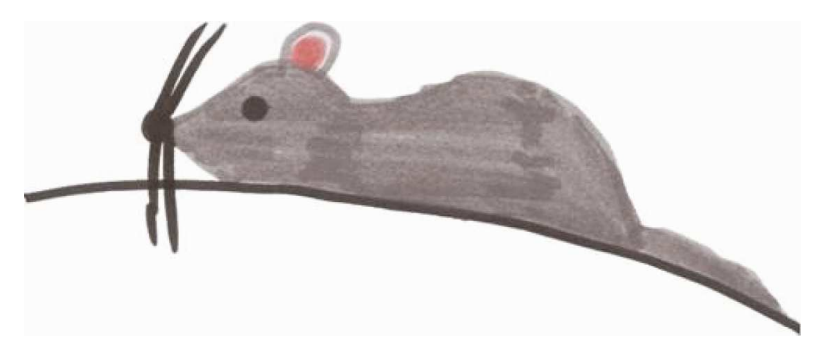




\begin{abstract}
This study aimed to evaluate tumor hypoxia by comparing $\left[{ }^{18} \mathrm{~F}\right]$ Fluoromisonidazole uptake measured using positron emission tomography ( $\left.\left[{ }^{18} \mathrm{~F}\right] \mathrm{FMISO}-\mathrm{PET}\right)$ with immunohistochemical (IHC) staining techniques. Syngeneic rhabdomyosarcoma (R1) tumor pieces were transplanted subcutaneously in the flanks of WAG/Rij rats. Tumors were analyzed at volumes between 0.9 and $7.3 \mathrm{~cm}^{3}$. Hypoxic volumes were defined using a 3D region of interest on $2 \mathrm{~h}$ post injection $\left[{ }^{18} \mathrm{~F}\right] \mathrm{FMISO}-\mathrm{PET}$ images, applying different thresholds (1.2-3.0). Monoclonal antibodies to pimonidazole (PIMO) and carbonic anhydrase IX (CA IX), an exogenous and endogenous marker of hypoxia, respectively, were used for IHC staining. Marker-positive fractions were microscopically measured for each tumor, and hypoxic volumes were calculated. A heterogeneous distribution of hypoxia was observed both with histology and $\left[{ }^{18}\right.$ F]FMISO autoradiography. A statistically significant correlation $(P<0.05)$ was obtained between the hypoxic volumes defined with $\left[{ }^{18} \mathrm{~F}\right] \mathrm{FMISO}-\mathrm{PET}$ and the volumes derived from the PIMO-stained tumor sections $(r=0.9066 ; P=$ $0.0001)$, regardless of the selected threshold between 1.4 and 2.2. A similar observation was made with the CA IX staining $(r=$ $0.8636 ; P=0.0006)$. The relationship found between $\left[{ }^{18} \mathrm{~F}\right] \mathrm{FMISO}-$ PET and PIMO- and additionally CA IX-derived hypoxic volumes in rat rhabdomyosarcomas indicates the value of the noninvasive imaging method to measure hypoxia in whole tumors.
\end{abstract}




\section{Introduction}

As a result of rapid growth and insufficient blood supply, solid tumors demonstrate hypoxia and necrosis in heterogeneous spread regions ${ }^{1,2}$. The presence of hypoxia is a major cause of resistance to cancer treatment. Hypoxia has been shown to be an independent predictor of poor progression-free survival in several types of cancer $^{3-6}$. Treatments to overcome the effect from a hypoxic environment are being evaluated ${ }^{7}{ }^{8}$. Therefore, the assessment of tumor oxygenation will be valuable to guide treatment in individual patients.

To date, various methods are available to measure tumor oxygenation, including polarographic oxygen-sensors ${ }^{9}$, luminescence-based optical sensors ${ }^{10}$ and antibody-based detection of exogenous ${ }^{11-13}$ and endogenous markers of hypoxia ${ }^{14-}$ 16. At this time, only the polarographic oxygen-sensor and the exogenous hypoxia marker pimonidazole (PIMO) can be considered as 'standard'. These methods may have limitations in clinical settings due to the invasive character of the method, the limited accessibility of the tumors and the possibility of sampling errors. Therefore, methods for noninvasive detection of hypoxia are under continued development. These methods include magnetic resonance imaging techniques ${ }^{17-19}$ and the detection of sensitizer adducts with SPECT and PET ${ }^{20-23}$.

The most widely used PET radiotracer for imaging tumor hypoxia is $\left[{ }^{18} \mathrm{~F}\right]$ Fluoromisonidazole $\left(\left[{ }^{18} \mathrm{~F}\right] \mathrm{FMISO}\right)$. The use of labeled 2-nitroimidazole compounds is based on studies with $\left[{ }^{3} \mathrm{H}\right]$ misonidazole binding in several human tumor types ${ }^{24}$. Although the $\left[{ }^{3} \mathrm{H}\right]$-misonidazole approach had limited clinical utility, it was the start of the development of noninvasive hypoxia markers based on 2-nitroimidazoles. The selective binding of $\left[{ }^{18} \mathrm{~F}\right] \mathrm{FMISO}$ to 
hypoxic cells has been demonstrated in vitro as well as preclinically in vivo 25,26 .

The present study reports on advances toward the in vivo validation of $\left[{ }^{18} \mathrm{~F}\right]$ FMISO for the evaluation of tumor hypoxia. This was carried out by comparing $\left[{ }^{18} \mathrm{~F}\right] \mathrm{FMISO}-\mathrm{PET}$ measurements with immunohistochemical analysis using PIMO, another nitroimidazole which is established as an exogenous intracellular hypoxia marker. To obtain potential complementary information, comparison was made with an endogenous transmembranous hypoxia marker CA IX. To our knowledge, it is the first time that $\left[{ }^{18} \mathrm{~F}\right] \mathrm{FMISO}$ uptake measured with PET was compared with PIMO, and additionally with CA IX staining, to evaluate hypoxic volumes in tumors.

\section{Materials and Methods}

Animals and tumor model

Male adult WAG/Rij rats with an average body weight of $300 \mathrm{~g}$ were used. Each rat was subcutaneously implanted under anaesthetics with syngeneic rhabdomyosarcomas (1-mm ${ }^{3}$ R1 tumors), in the lateral thorax or in the abdominal flank. After 12 days, when tumors reached the predetermined range of volumes, PET measurements were carried out during a 2-week follow-up. Each day, tumors were measured, using a Vernier calliper, in three orthogonal tumor diameters $A, B$ and $C$, each corrected for the thickness of the skin. Volumes were calculated using the formula $A \times B \times C \times \pi / 6$, since the tumors grew elliptically. All animal experiments were conducted in accordance with local institutional guidelines, approved by the Animal Ethics Committee of the University 'KU Leuven' and procedures were according to the guidelines defined by the UKCCCR ${ }^{27}$. 


\section{Radiolabelled tracer}

1-(2-nitro-imidazolyl)-3-[ $\left.{ }^{18} \mathrm{~F}\right]$-fluoro-2-propanol ( $\left[{ }^{18} \mathrm{~F}\right]$ Fluoromisonidazole; $\left.\left[{ }^{18} \mathrm{~F}\right] \mathrm{FMISO}\right)$ was produced by the nucleophilic fluorination of 1-(2'-nitro-1'-imidazolyl)-2-O-tetrahydropyranyl-3-O-toluenesulfonylpropandiole followed by acidic hydrolysis of the protecting group, as described by Lim and Berridge ${ }^{28}$.

\section{Experimental setup}

When PET measurements were started, each rat received $\left[{ }^{18} \mathrm{~F}\right.$ FMISO every 2 days. The rats were anaesthetized with $0.1 \mathrm{ml}$ $100 \mathrm{~g}^{-1}$ body weight sodium pentobarbital (Nembutal; Sanofi, Belgium), injected intraperitoneally. The radiolabeled tracer was administrated via an intravenous line (Venoflux $0.4 \mathrm{~mm}$ G.27; Vygon, France) inserted into a lateral tail vein, flushed with heparin saline solution. During PET examinations, anaesthesia was maintained using individual rat-adapted intraperitoneal injections (10 $-30 \%$ of the initial dose) of the anaesthetic, as needed.

\section{PET imaging}

Each PET examination was performed on an ECAT HR+ scanner (Siemens, Knoxville, TN, USA), with an axial field of view of $15 \mathrm{~cm}$ and a spatial resolution of $6 \mathrm{~mm}$ full-width at half-maximum (FWHM) at the centre of the field of view. Before positioning, four rats were placed in a custom-built, polystyrene foam that was placed in the opening of the camera. Whole-body scanning was performed with 63 axial slices each of $2.425 \mathrm{~mm}$ in a single $15-\mathrm{cm}$ field of view, yielding radioactivity concentration measurements in voxels of $1.6875 \times 1.6875 \times 2.425 \mathrm{~mm}^{3}$. The $\left[{ }^{18} \mathrm{~F}\right]$ FMISO-PET acquisition started with a 15 -min transmission scan using external rods of ${ }^{68} \mathrm{Ge}$, to correct for attenuation. An average of $17.02 \mathrm{MBq}$ 
(13.38 - $21.24 \mathrm{MBq})\left[{ }^{18} \mathrm{~F}\right] \mathrm{FMISO}$ was injected into a lateral tail vein. Simultaneously, a dynamic emission scanning was started for $60 \mathrm{~min}$, according to the following protocol: $8 \times 15 \mathrm{~s}, 4 \times 30 \mathrm{~s}, 2 \times 1 \mathrm{~min}$, $2 \times 2 \min , 10 \times 5 \mathrm{~min}$. At 2 hours post injection (p.i.), a second dynamic emission scanning was carried out for $20 \mathrm{~min}$ (4x5min). Preceding this second scanning, a 15-min transmission scan was performed after repositioning the rats. All images were reconstructed iteratively in a $128 \times 128 \times 63$ matrix using attenuation factors measured by the transmission scans. The images were corrected for scatter and randoms, frame duration and decay to the start of each emission scan. The radioactivity measured in selected tissues, determined on the images, was subsequently corrected for decay towards the time of injection.

\section{PET image analysis}

To obtain mean activity data of the blood pool, a region of interest (2D-ROI), representing a volume of $0.425 \mathrm{~cm}^{3}$, was drawn at the efflux area of the heart on the $2 \mathrm{~h}$ p.i. $\left[{ }^{18} \mathrm{~F}\right] \mathrm{FMISO}$ images. The efflux area of the heart was defined with the aid of the early $\left[{ }^{18} \mathrm{~F}\right]$ FMISO perfusion images (summation of $1-4 \mathrm{~min}$ of the first dynamic acquisition). Normal tissue evaluation was carried out using 2D-ROI analysis of the lung, muscle $\left(\mathrm{cf}^{25}\right)$ and a body area $15 \mathrm{~mm}$ above the heart $\left(\mathrm{cf}^{29}\right)$, and normal tissue to heart mean activity ratios were calculated. To assess the volume of $\left[{ }^{18} \mathrm{~F}\right] \mathrm{FMISO}$ uptake in tumors, different absolute thresholds were used, ranging from 1.2 to 3.0. A 3D-ROI was defined on the $2 \mathrm{~h}$ p.i. $\left[{ }^{18} \mathrm{~F}\right] \mathrm{FMISO}$ images to select all the voxels with activity higher than a selected absolute threshold. 


\section{Pimonidazole administration}

During the 2-week follow-up, a rat was killed daily to enable immunohistochemical analyses of tumor volumes ranging between 0.9 and $7.3 \mathrm{~cm}^{3}$. A total of 11 tumors were selected to cover the full volume range. Each rat received $0.1 \mathrm{ml} 100 \mathrm{~g}^{-1}$ body weight of pimonidazole hydrochloride (Hypoxyprobe-1; NPI, Belmont, MA, USA) intraperitoneal prior to the start of the second dynamic emission scanning. At $1 \mathrm{~h}$ p.i. of PIMO (i.e. $40 \mathrm{~min}$ after the end of scanning), the rat was killed and the tumors were rapidly excised for immunohistochemical processing.

\section{Immunohistochemistry}

Excised tumors were fixed in neutral-buffered formalin and axial $2 \mathrm{~mm}$ sections were made ( $n=3-6$, depending on tumor size), according to the PET plane separation thickness, prior to embedding in paraffin. Slices $(5 \mu \mathrm{m})$ from each axial section were deparaffinized with toluene and rehydrated by treatment with a series of alcohol and water mixtures and finally with water. To quench endogenous peroxidase, the tissue sections were exposed for $30 \mathrm{~min}$ to $0.3 \%$ hydrogen peroxide absolute methanol. Microwave heating (4min 500W, 20min defrost and 15min RT) was used in the presence of Tris EDTA buffer $(0,01 \mathrm{M} \mathrm{pH}=9.0)$ to achieve antigen retrieval prior to the application of the primary monoclonal antibody. Phosphate-buffered saline (PBS $0.1 \mathrm{M} \mathrm{pH}=$ 7.3) plus Tween 20 (polyoxyethylene sorbitan monolaurate) were used to wash slides between two steps. The sections were incubated in anti-PIMO MAb (1:100 dilution in PBS) for 30min. Secondary incubation with peroxidase-labeled anti-mouse Envision (DAKO Corporation, Carpinteria, CA, USA) was applied also for $30 \mathrm{~min}$. Bound peroxidase was developed using $0.033 \%$ hydrogen 
peroxide in $10 \%$ diaminobenzidine (DAB; DAKO Corporation, Carpinteria, CA, USA) for $7 \mathrm{~min}$. After washing in distilled water the sections were counterstained with Hematoxylin for 1min, dehydrated and mounted.

Sections contiguous to those stained for PIMO binding were immunostained for the presence of CA IX in the same manner that was used for PIMO adducts. M75 MAb (Bayer, USA; ${ }^{30}$ ) was used as primary antibody (1:25 dilution in PBS). Substitution of the primary antibody with PBS-Tween was used as a negative control for both antibodies.

Immunostained sections ( $n=50$ both for PIMO and for CA IX) of the selected tumors $(n=11)$ were viewed by means of a Zeiss Axioskop 40 FL microscope (Carl Zeiss, Inc., Thornwood, NY, USA). Each section was evaluated independently by two investigators ( $L D$ and $W L$ ) and scored by means of moving a ' $10 \mathrm{X}$ $10^{\prime}$ grid-incorporated ocular, superimposed on the image, at a total magnification of $\times 200$. Five hit-points in every grid, lying on the intersection of the grid lines, were evaluated for positive PIMO and CA IX staining in contiguous sections ${ }^{31}$. For each tumor, depending on the size, 350 - 1260 hit-points were evaluated for PIMO and CA IX separately, and the respective fraction positive staining was calculated. Care was taken that the hit-points covered the entire tumor area.

\section{Autoradiography}

In two tumor-bearing rats, an autoradiography experiment was carried out. The experimental set-up was the same as described above, but without doing the actual PET imaging. An average of $84.75 \mathrm{MBq}(91.37$ - $78.13 \mathrm{MBq}) \quad\left[{ }^{18} \mathrm{~F}\right] \mathrm{FMISO}$ was injected intravenous via the tail vein. At $150 \mathrm{~min}$ p.i., the rats were killed, 
the tumors quickly removed and immediately frozen in 2methylbutane (cooled to $-25^{\circ} \mathrm{C}$ with liquid nitrogen). The tumors were cut with a Leica CM 3050 cryotome (Germany) in $14 \mu$ m-thick slices at each sectional plane of $2 \mathrm{~mm}$ and mounted on microscope slides. The slices were immediately air dried at $50^{\circ} \mathrm{C}$ and exposed overnight to a high-performance storage phosphor screen (Packard, Meriden, USA), which was scanned in a Phosphor Imager Scanner (Packard Cyclone TM, Meriden, USA). The resolution of the images expressed in pixel size was $42 \times 42 \mu \mathrm{m}$ (600 d.p.i.).

\section{Statistics}

All statistical analyses and graphs are performed with Statistica (data analysis software system), version 6.0. (Statsoft, Inc., 2001, Tulsa, OK, USA). Correlation among the variables was analyzed using the "Spearman Rank Order Correlation" and additionally the relationships were evaluated by linear regression. A "student's $t$ test" was used to determine the statistical significance of differences between two independent groups of variables. For all tests, a $P<0.05$ was considered significant.

\section{Results}

Immunohistochemical analysis of tumors: PIMO, and CA IX, positive fraction

Independent of the tumor size (range: $0.9-7.3 \mathrm{~cm}^{3}$ ), PIMOpositive staining areas were seen in all tumor sections and they were heterogeneously distributed along the sections, as shown in Fig. 1. Localization of the MAb stain was always at a distance (several cell layers) from a blood vessel, most often near an area of necrosis, in peripheral as well as central parts of the sections. 
Similar heterogeneous staining areas were found in CA IX-stained sections.
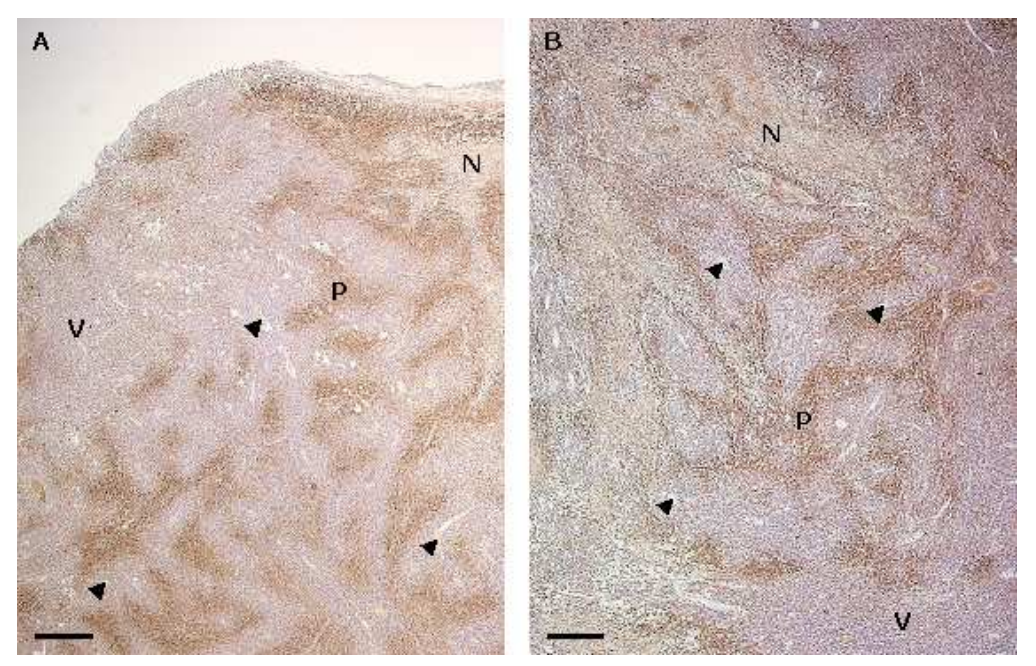

Figure 1. Pimonidazole staining photographs (made with Carl Zeiss KS100 Software). A: Peripheral view. B: Central view. Both slices are shown on a magnification $\times 25$. Scale bar is $40 \mu \mathrm{m}$. Abbreviations: $\mathrm{N}=$ necrosis, $\mathrm{V}=$ viable, well-oxygenated tumor tissue, $\mathrm{P}=\mathrm{PIMO}$-positive staining and the arrow indicates a blood vessel.

After microscopic grid-based analysis of the immunostained sections, the staining-positive fraction was calculated for each tumor (see Table 1). To check the reproducibility, the sections were evaluated twice by LD. No significant intraobserver difference (PIMO: $P=0.4469$; CA IX: $P=0.7425$ ) was seen with an interval between scoring of 1 month. Therefore, the mean of the positive fractions was used in further analyses. Random selected sections were evaluated by a second observer (WL) independently. No significant difference (PIMO: $P=0.6950$; CA IX: $P=0.1612$ ) was seen. The mean hypoxic fraction, assessed with PIMO and CA IX staining, was respectively $18.6 \pm 3.4 \%$ and $18.2 \pm 5.6 \%$. The relationship between PIMO-positive fraction and CA IX-positive 
fraction did not reach statistical significance $(r=0.5182$ and $P=$ $0.1025)$.

To allow comparison with the $\left[{ }^{18} \mathrm{~F}\right] \mathrm{FMISO}$ volume measured with PET, the PIMO-positive and CA IX-positive volume $\left(\mathrm{cm}^{3}\right)$ was calculated by multiplying the MAb staining-positive fraction with the corresponding tumor volume (see Table 1).

Table 1. Tumor volumes, PIMO-positive and CA IX-positive fractions, with their mean value and standard deviation and PIMO-positive and CA IXpositive volumes for 11 rhabdomyosarcoma (R1) tumors transplanted in WAG/Rij rats

\begin{tabular}{|c|c|c|c|c|c|}
\hline$n=11$ & $\begin{array}{c}\text { tumour } \\
\left.\text { volume (om }{ }^{3}\right)\end{array}$ & $\begin{array}{c}\text { PMO - positive } \\
\text { fraction }\end{array}$ & $\begin{array}{l}\text { CA LN - positive } \\
\text { fration }\end{array}$ & $\begin{array}{l}\text { FIMO - positive } \\
\text { volume }\left(\mathrm{cm}^{3}\right)\end{array}$ & $\begin{array}{l}\text { CA IM - po jitive } \\
\text { ualume }\left(\mathrm{cm}^{3}\right)\end{array}$ \\
\hline & 0.8 & 0.197 & 0.196 & 0175 & 0174 \\
\hline & 0,90 & 0.185 & 0,165 & 0167 & 0149 \\
\hline & 0.98 & 0,115 & 0.112 & 0106 & 0104 \\
\hline & 1,00 & 0,174 & 0,130 & $Q_{174}$ & 0133 \\
\hline & 2.5 & 0,215 & 0,260 & 0553 & 9668 \\
\hline & 2.76 & 0.204 & 0.149 & 0563 & 0410 \\
\hline & 2.88 & 0.196 & 0.15 & 0.563 & 0504 \\
\hline & 3.33 & 0. 185 & 0,236 & 0614 & 0786 \\
\hline & 4.79 & 0,250 & 0.225 & 1.198 & 1.078 \\
\hline & 4.90 & 0.157 & 0,099 & 0.775 & 0490 \\
\hline & 7.31 & 0.172 & 0.252 & 1,257 & 1.838 \\
\hline Mean & & $0,1 \Leftrightarrow 1$ & 01818 & & \\
\hline Std Dew & & 0.0343 & 00562 & & \\
\hline
\end{tabular}

$\left[{ }^{18}\right.$ F]FMISO analysis of normal tissues and tumors

The distribution of $\left[{ }^{18} \mathrm{~F}\right] \mathrm{FMISO}$ in the rat was determined on the $2 \mathrm{~h}$ p.i. images. Although a high $\left[{ }^{18} \mathrm{~F}\right]$ FMISO uptake was found in the gastrointestinal region, tumors could be clearly localized.

The $\left[{ }^{18} \mathrm{~F}\right] \mathrm{FMISO}$ uptake in normal tissue was evaluated using 2D-ROIs on lung, muscle and a body area $15 \mathrm{~mm}$ above the heart. Fig. 2 shows a composite histogram of the calculated tissue to heart ratios. A clear separation of the mean activity ratios is observed at 1.1 between normal and tumor tissue. 


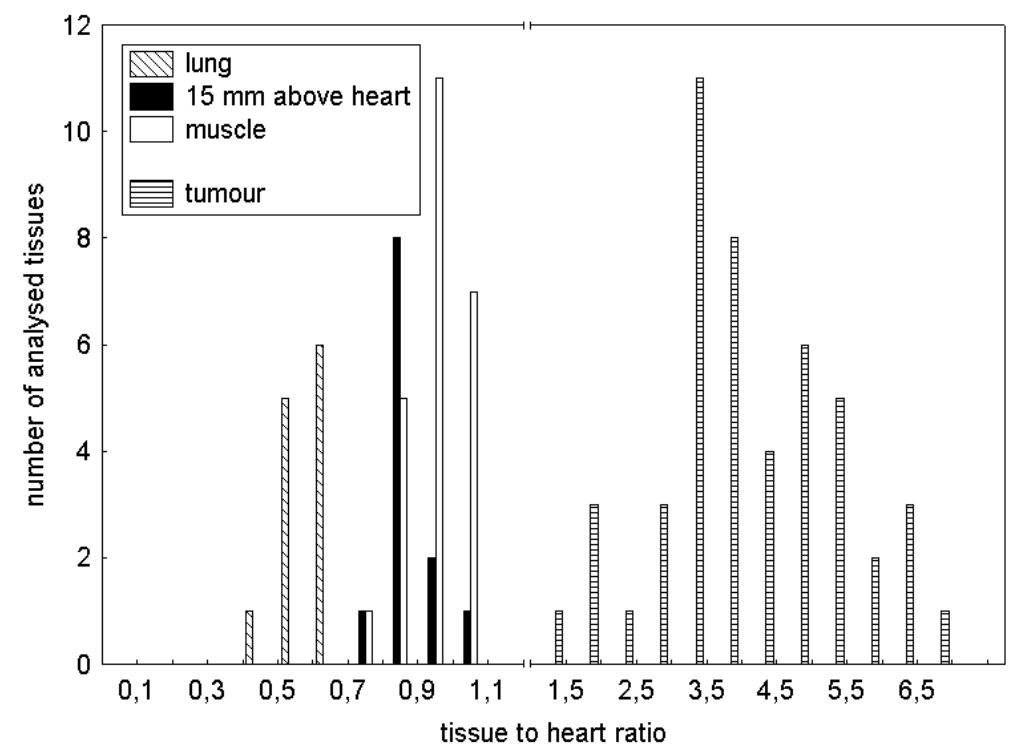

Figure 2. $\left[{ }^{18} \mathrm{~F}\right]$ FMISO-PET mean tissue to heart activity ratios of lung ( $\mathrm{n}=$ 12) $\square$, muscle ( $n=24$; that is, front leg muscle $n=12$ and hind leg muscle $\mathrm{n}=12) \square$ and a body area $15 \mathrm{~mm}$ above the heart ( $\mathrm{n}=12)$ 12 randomly chosen $2 \mathrm{~h}$ p.i. images. Similarly, tumors $(n=48)$ were analyzed on $2 \mathrm{~h}$ p.i. images. For all the tissues, cumulative histogram analysis was carried out.

To define the volume of $\left[{ }^{18} \mathrm{~F}\right] \mathrm{FMISO}$ uptake in the tumors, different thresholds ranging between 1.2 and 3.0 were used. The use of the lowest threshold $(1.2)$ resulted in $\left[{ }^{18} \mathrm{~F}\right] \mathrm{FMISO}$ volumes that were larger than the caliper-defined tumor volume. The correlation for the various thresholds above 1.4 between the $\left[{ }^{18} \mathrm{~F}\right] \mathrm{FMISO}$ volume and the PIMO-positive and CA IX-positive volumes is shown in Fig. 3. The $P$-value for each correlation is also given.

\section{Autoradiography data}

$\left[{ }^{18} \mathrm{~F}\right]$ FMISO was heterogeneously distributed within tumors. More heterogeneity was, however, seen in the central part of the tumor, showing regions with high uptake and regions with little uptake. In 
the central part of the tumor, a factor 7 difference was observed between the highest and lowest intensity of $\left[{ }^{18} \mathrm{~F}\right] \mathrm{FMISO}$ uptake.

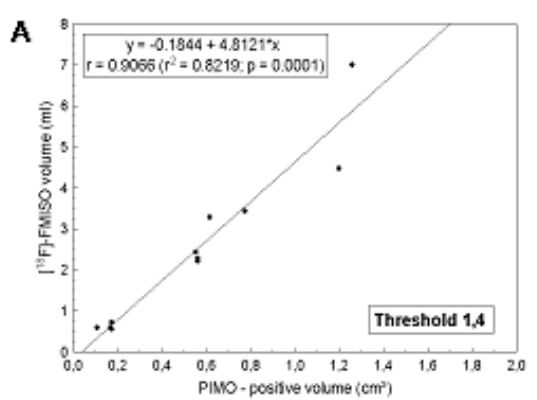

\begin{tabular}{ccc}
\hline B Threshold & $r$-value & $p$-value \\
\hline 1.4 & 0.9066 & 0.0001 \\
1.6 & 0.9431 & $<0.0001$ \\
1.8 & 0.9704 & $<0.0001$ \\
22 & 0.9795 & $<0.0001$ \\
25 & 0.8838 & 0.0003 \\
26 & 0.8813 & 0.0003 \\
3.0 & 0.8793 & 0.0004 \\
\hline & & \\
\hline Threstold & $r-v a l u e$ & $p-$ value \\
\hline 1.4 & 0.8636 & 0.0006 \\
1.6 & 0.9090 & 0.0001 \\
1.8 & 0.8727 & 0.0006 \\
2.2 & 0.8909 & 0.0002 \\
2.5 & 0.8727 & 0.0005 \\
2.6 & 0.8656 & 0.0006 \\
3.0 & 0.7636 & 0.0062 \\
\hline
\end{tabular}

Figure 3. A: $\left[{ }^{18} \mathrm{~F}\right]$ FMISO volume defined on $2 \mathrm{~h}$ p.i. images, using a threshold 1.4 plotted against PIMO-positive volume ( $n=11$ tumors). B: $r-$ and $\mathrm{P}$-values for a range of thresholds between 1.4 and 3.0 for the same comparison. C: $\left.{ }^{18} \mathrm{~F}\right]$ FMISO volume defined on $2 \mathrm{~h}$ p.i. images, using a threshold 1.4 plotted against CA IX-positive volume ( $n=11$ tumors). D: $r$ and $P$-values for a range of thresholds between 1.4 and 3.0 for the same comparison.

The lowest intensity of the central part was equal with the mean intensity of the peripheral part of the tumor. This phenomenon was seen in both large tumors (see Fig. 4A) and small tumors (see Fig. 4B). For larger tumors, larger areas without $\left[{ }^{18} \mathrm{~F}\right] \mathrm{FMISO}$ labeling were seen. 


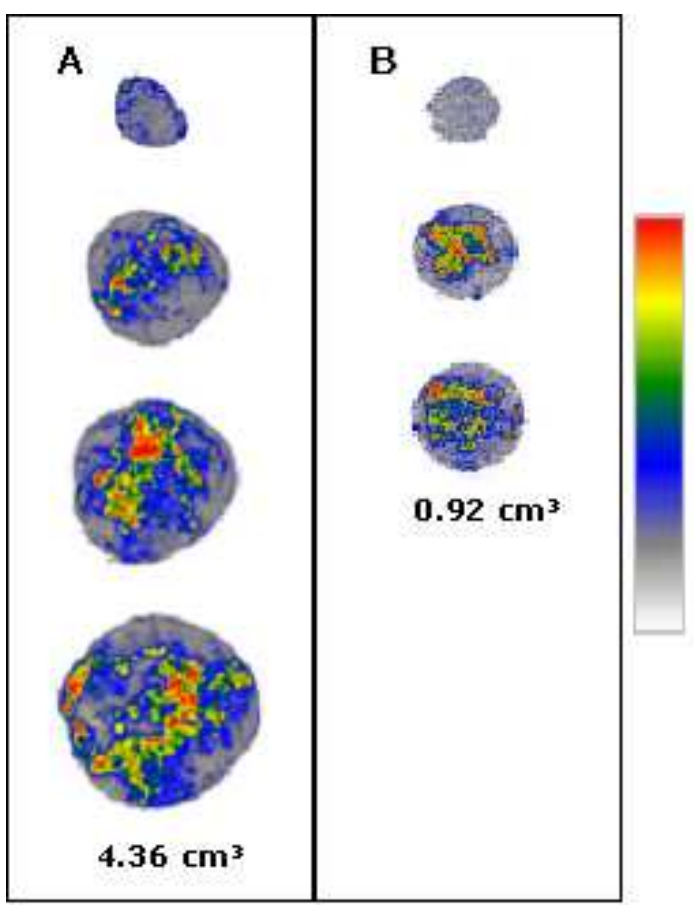

Figure 4. Autoradiography images of a large $\left(A: 4.36 \mathrm{~cm}^{3}\right)$ and a small (B: $0.92 \mathrm{~cm}^{3}$ ) tumor. From the top to bottom of the images, peripheral to central images are shown. Each image is scaled to the hottest pixel (= most $\left[{ }^{18} \mathrm{~F}\right] \mathrm{FMISO}$ uptake) in the tumor. Images are enlarged to $200 \%$.

\section{Discussion}

The knowledge that hypoxia influences the outcome of many cancer treatment modalities, emphasizes the necessity to measure these hypoxic cell populations in individual tumors. Comparative studies allow validation of novel methodologies by comparison with established 'so-called standard' techniques. Only two comparative studies between noninvasive $\left[{ }^{18} \mathrm{~F}\right] \mathrm{FMISO}-\mathrm{PET}$ and a 'standard' hypoxia measurements have been published to date. Bentzen et al. found no correlation between $\left[{ }^{18} \mathrm{~F}\right] \mathrm{FMISO}-\mathrm{PET}$ and $\mathrm{pO}_{2}$ electrode measurements in $\mathrm{C} 3 \mathrm{H}$ mammary carcinomas ${ }^{32}$. Piert et al. showed a correlation between $\left[{ }^{18} \mathrm{~F}\right] \mathrm{FMISO}-\mathrm{PET}$ data and $\mathrm{pO}_{2}$ electrode 
measurements in a study of hypoxia in pig liver tissue ${ }^{33,34}$. Until today, however, the potential of this PET technique still needs confirmation by appropriate procedures, such as comparative evaluation with nitroimidazole-related assays.

In the present study, the noninvasive $\left[{ }^{18} \mathrm{~F}\right] \mathrm{FMISO}-\mathrm{PET}$ method for the evaluation of hypoxia in experimental rat tumors was further validated with immunohistochemical staining techniques using the nitroimidazole PIMO, a 'standard' exogenous hypoxia marker, and morphometry. In addition, also CA IX, an endogenous indicator of hypoxia, was used. Microscopy-based point counting, a method used in morphometric tissue analysis ${ }^{31}$ and also in our study, is next to computerized image analysis shown to be an adequate method for quantification of hypoxia in tumors ${ }^{35}$.

$\left[{ }^{18} \mathrm{~F}\right]$ FMISO volumes are the direct result of the PET analysis. To compare these data with the immunohistochemical measurements, the staining-positive fractions of PIMO and CA IX were multiplied with the corresponding tumor volumes to obtain the respective hypoxic volumes. The decision to use hypoxic volumes rather than hypoxic fractions is also supported by Rajendran et al. ${ }^{36}$, who discussed the fact that the use of hypoxic fractions is a variable with considerable uncertainty.

In a range between 1.4 and 2.2 , the hypoxic volumes obtained with $\left[{ }^{18}\right.$ F]FMISO-PET correlated to the same high statistical significance with the PIMO-derived hypoxic volumes. A similar observation was made with the CA IX-derived hypoxic volumes. Although only a slight decrease in correlation was calculated, a dropout of data was present at a threshold above 2.2. The choice to use the $2 \mathrm{~h}$ p.i. $\left[{ }^{18} \mathrm{~F}\right]$ FMISO-PET images was made for the evaluation of the tracer uptake, because this time point has been shown to be optimal for the examination of $\left[{ }^{18} \mathrm{~F}\right] \mathrm{FMISO}$ uptake in 
tumors both in animal models ${ }^{37,38}$ and in humans ${ }^{25,39}$. Selection of normal tissue (lung, muscle and a body area $15 \mathrm{~mm}$ above the heart) for image analysis at $2 \mathrm{~h}$ p.i. using 2D ROIs, was performed in agreement with the literature ${ }^{25,29}$. Mean activity ratios were calculated and $99 \%$ of the analyzed ratios were below 1.1 . Tumor analysis indicated that using thresholds below 1.4 did not seem useful, because results indicated that the $\left[{ }^{18} \mathrm{~F}\right] \mathrm{FMISO}$ volume was larger than the caliper-defined tumor volume. This can be explained by the spatial resolution of the PET system, where the relatively large voxels, which encompass partial hypoxic regions, are considered as completely hypoxic. Based on these normal and tumor tissue observations, a threshold of 1.4 was defined as cutoff value and as indicator of significant hypoxia. This cutoff value is in agreement with the results of Koh et $\mathrm{al}^{25}$.

We are aware that within the rhabdomyosarcoma tumor type the hypoxic volumes tend to increase with tumor size. This is however tumor type dependent and we realize therefore that the same comparisons need to be done in other tumor models, at best where this relationship does not hold. A positive relationship between the hypoxic volumes assessed with $\left[{ }^{18} \mathrm{~F}\right] \mathrm{FMISO}-\mathrm{PET}$ and PIMO staining was to some extent anticipated. Indeed, both are 2nitroimidazoles, which have the same nitroreduction mechanism, and are thus expected to bind to intracellular macromolecules in cells exposed to equal microenvironmental hypoxia conditions ${ }^{40,41}$. The comparison between $\left[{ }^{18} \mathrm{~F}\right] \mathrm{FMISO}$-PET and CA IX staining was also investigated, resulting in a similar strong correlation and significance. However a factor 4 difference was found, which may be explained by the inferior resolution and the large voxel size of the PET system when compared with immunohistochemistry. The extent of a positive correlation between immunohistochemical 
staining results for these markers is the subject of a controversial discussion. Although Olive et al. found a very strong correlation ( $r$ $=0.86, n=14$ ) in human cervical cancer ${ }^{42}$, Airley et al. did not find a significant correlation $(r=0.27 ; P=0.083, n=42)^{14}$. In head and neck cancer, Kaanders et al. found a weak, but significant correlation $(r=0.36 ; P=0.02, n=42)^{5}$. Lyng et al., Raleigh et al. and Olive et al. showed for a number of animal and human tumors that PIMO labeling can give a reliable estimate of radiobiologically relevant hypoxia ${ }^{43-45}$. The variations in correlation between PIMO- and CA IX-stained hypoxic fractions may be explained by a difference in specificity of CA IX when compared with $\mathrm{PIMO}^{5}$. A difference in location and area of positive staining $(16,42$ and also the present study) supports this explanation. von Hippel-Lindau mutations, which result in a upregulation of HIF- $1 a^{46}$ and downstream components like CA IX ${ }^{47}$, and the relationship between CA IX expression and acidic $\mathrm{pH}$ found in tumors ${ }^{48}$ could potentially contribute to the published differences.

Autoradiography was performed to determine the $\left[{ }^{18} \mathrm{~F}\right] \mathrm{FMISO}$ distribution in whole tumors. Different studies have shown heterogeneity in, for example, larger $\mathrm{C} 3 \mathrm{H}$ tumors growing subcutaneously in CDF1 mice and a more uniform radioactivity distribution in smaller $\mathrm{C} 3 \mathrm{H}$ tumors ${ }^{32,49}$. Tochon-Danguy et al. observed only homogeneous distribution of $\left[{ }^{18} \mathrm{~F}\right] \mathrm{FMISO}$ throughout C6 glioma tumors in the left brain of Wistar rats ${ }^{38}$. In the present study, a heterogeneous distribution of $\left[{ }^{18} \mathrm{~F}\right] \mathrm{FMISO}$ was found both in small and large rhabdomyosarcoma tumors. More heterogeneity was observed in central parts of the tumor compared to peripheral parts. For larger tumors, larger areas with no $\left[{ }^{18} \mathrm{~F}\right] \mathrm{FMISO}$ labeling were seen, which parallels the fact that larger parts of these tumors are necrotic. Although no direct comparison was made on 
the same sections with the autoradiography data, immunohistochemical staining with PIMO confirms these results. A heterogeneous stain was seen in all tumors, both in peripheral and central parts of the tumor. A similar heterogeneous staining distribution of hypoxic areas was found in CA IX-stained sections. These autoradiography and immunohistochemical staining results support the concept that the microenvironment of solid tumors is characterized by heterogeneity in oxygenation. 


\section{Conclusion}

The strong and significant relationship between $\left[{ }^{18} \mathrm{~F}\right] \mathrm{FMISO}-\mathrm{PET}$ and PIMO immunohistochemical staining, within a range of thresholds $(1.4-2.2)$, indicates the value of $\left[{ }^{18} \mathrm{~F}\right]$ FMISO-PET to measure hypoxic volumes in whole tumors. Although a positive correlation between PIMO and CA IX is not a general finding, the equally significant and strong correlation between $\left[{ }^{18} \mathrm{~F}\right] \mathrm{FMISO}$-PET and CA IX immunohistochemical staining strengthens the application of the noninvasive PET method to evaluate hypoxia. Given the complex nature of hypoxia development and its impact on tumor progression and treatment response, it remains highly important to make additional comparative studies and to relate $\left[{ }^{18} \mathrm{~F}\right] \mathrm{FMISO}$ measurements with outcome.

\section{Acknowledgments}

We appreciate the valuable discussions with $\mathrm{Dr} W$ McBride (Department of Radiation Oncology, David Geffen School of Medicine, UCLA, Los Angeles, USA). We also thank Dr JA Raleigh (Department of Radiation Oncology, UNC School of Medicine, Arizona, USA) for the use of anti-pimonidazole MAb, $\mathrm{Dr} S$ Pastorekova and Dr J Pastorek (Institute of Virology of the Slovak Academy of Science of the Slovak Republic) and Dr J Zavada (Institute of Molecular Genetics, Academy of Science of the Czech Republic) for the use of M75 MAb for research purposes. 


\section{References}

1. Chapman J.D. The detection and measurement of hypoxic cells in solid tumors. Cancer, 1984. 54(11): p. 2441-9.

2. Vaupel P., Kallinowski F., and Okunieff P. Blood flow, oxygen and nutrient supply, and metabolic microenvironment of human tumors: a review. Cancer Res, 1989. 49(23): p. 6449-65.

3. Brizel D.M., Sibley G.S., Prosnitz L.R., et al. Tumor hypoxia adversely affects the prognosis of carcinoma of the head and neck. Int J Radiat Oncol Biol Phys, 1997. 38(2): p. 285-9.

4. Fyles A., Milosevic M., Hedley D., et al. Tumor hypoxia has independent predictor impact only in patients with node-negative cervix cancer. J Clin Oncol, 2002. 20(3): p. 680-7.

5. Kaanders J.H., Wijffels K.I., Marres H.A., et al. Pimonidazole binding and tumor vascularity predict for treatment outcome in head and neck cancer. Cancer Res, 2002. 62(23): p. 7066-74.

6. Nordsmark M. and Overgaard J. A confirmatory prognostic study on oxygenation status and loco-regional control in advanced head and neck squamous cell carcinoma treated by radiation therapy. Radiother Oncol, 2000. 57(1): p. 39-43.

7. Brown J.M. The hypoxic cell: a target for selective cancer therapy--eighteenth Bruce F. Cain Memorial Award lecture. Cancer Res, 1999. 59(23): p. 5863-70.

8. Wouters B.G., Koritzinsky M., Chiu R.K., et al. Modulation of cell death in the tumor microenvironment. Semin Radiat Oncol, 2003. 13(1): p. 31-41.

9. Vaupel P., Schlenger K., Knoop C., et al. Oxygenation of human tumors: evaluation of tissue oxygen distribution in breast cancers by computerized $\mathrm{O} 2$ tension measurements. Cancer Res, 1991. 51(12): p. 3316-22.

10. Bussink J., Kaanders J.H. Strik A.M., et al. Optical sensor-based oxygen tension measurements correspond with hypoxia marker binding in three human tumor xenograft lines. Radiat Res, 2000. 154(5): p. 547-55.

11. Haustermans K., Hofland I., Van de Pavert L., et al. Diffusion limited hypoxia estimated by vascular image analysis: comparison with pimonidazole staining in human tumors. Radiother Oncol, 2000. 55(3): p. 325-33.

12. Koch C.J. Measurement of absolute oxygen levels in cells and tissues using oxygen sensors and 2-nitroimidazole EF5. Methods Enzymol, 2002. 352: p. 3-31.

13. Raleigh J.A., Chou S.C., Bono E.L., et al. Semiquantitative immunohistochemical analysis for hypoxia in human tumors. Int J Radiat Oncol Biol Phys, 2001. 49(2): p. 569-74.

14. Airley R.E., Loncaster J., Raleigh J.A., et al. GLUT-1 and CAIX as intrinsic markers of hypoxia in carcinoma of the cervix: relationship to pimonidazole binding. Int ] Cancer, 2003. 104(1): p. 85-91.

15. Janssen H.L., Haustermans K.M., Sprong D., et al. HIF-1A, pimonidazole, and iododeoxyuridine to estimate hypoxia and perfusion in human head-and-neck tumors. Int J Radiat Oncol Biol Phys, 2002. 54(5): p. 1537-49.

16. Wykoff C.C., Beasley N.J., Watson P.H., et al. Hypoxia-inducible expression of tumorassociated carbonic anhydrases. Cancer Res, 2000. 60(24): p. 7075-83.

17. Landuyt W., Hermans R., Bosmans H., et al. BOLD contrast fMRI of whole rodent tumour during air or carbogen breathing using echo-planar imaging at $1.5 \mathrm{~T}$. Eur Radiol, 2001. 11(11): p. 2332-40.

18. Mason R.P., Constantinescu A., Hunjan S., et al. Regional tumor oxygenation and measurement of dynamic changes. Radiat Res, 1999. 152(3): p. 239-49.

19. Robinson S.P., Howe F.A., Rodrigues L.M., et al. Magnetic resonance imaging techniques for monitoring changes in tumor oxygenation and blood flow. Semin Radiat Oncol, 1998. 8(3): p. 197-207.

20. Ballinger J.R. Imaging hypoxia in tumors. Semin Nucl Med, 2001. 31(4): p. 321-9.

21. Chapman J.D., Engelhardt E.L., Stobbe C.C., et al. Measuring hypoxia and predicting tumor radioresistance with nuclear medicine assays. Radiother Oncol, 1998. 46(3): p. 229-37.

22. Hoebers F.J., Janssen H.L., Olmos A.V., et al. Phase 1 study to identify tumour hypoxia in patients with head and neck cancer using technetium-99m BRU 59-21. Eur J Nucl Med Mol Imaging, 2002. 29(9): p. 1206-11.

23. Van de Wiele $C$., Lahorte $C$. Oyen $W_{\text {., }}$ et al. Nuclear medicine imaging to predict response to radiotherapy: a review. Int J Radiat Oncol Biol Phys, 2003. 55(1): p. 515. 
24. Urtasun R.C., Koch C.J., Franko A.J., et al. A novel technique for measuring human tissue pO2 at the cellular level. Br J Cancer, 1986. 54(3): p. 453-7.

25. Koh W.J., Rasey J.S., Evans M.L., et al. Imaging of hypoxia in human tumors with [F18]fluoromisonidazole. Int J Radiat Oncol Biol Phys, 1992. 22(1): p. 199-212.

26. Rasey J.S., Koh W.J., Grierson J.R., et al. Radiolabelled fluoromisonidazole as an imaging agent for tumor hypoxia. Int J Radiat Oncol Biol Phys, 1989. 17(5): p. 98591.

27. Workman P., Twentyman P., Balkwill F., et al. United Kingdom Co-ordinating Committee on Cancer Research (UKCCCR) Guidelines for the Welfare of Animals in Experimental Neoplasia (Second Edition). Br J Cancer, 1998. 77(1): p. 1-10.

28. Lim J.L. and Berridge M.S. An efficient radiosynthesis of [18F]fluoromisonidazole. Appl Radiat Isot, 1993. 44(8): p. 1085-91.

29. Bentzen L., Keiding S., Horsman M.R., et al. Feasibility of detecting hypoxia in experimental mouse tumours with $18 \mathrm{~F}$-fluorinated tracers and positron emission tomography--a study evaluating [18F]Fluoro-2-deoxy-D-glucose. Acta Oncol, 2000. 39(5): p. 629-37.

30. Pastorekova S., Zavadova Z., Kostal M., et al. A novel quasi-viral agent, MaTu, is a two-component system. Virology, 1992. 187(2): p. 620-6.

31. Weibel E.R. Stereological methods in cell biology: where are we--where are we going? J Histochem Cytochem, 1981. 29(9): p. 1043-52.

32. Bentzen L., Keiding S., Horsman M.R., et al. Assessment of hypoxia in experimental mice tumours by [18F]fluoromisonidazole PET and pO2 electrode measurements. Influence of tumour volume and carbogen breathing. Acta Oncol, 2002. 41(3): p. 304-12.

33. Piert M., Machulla H., Becker G., et al. Introducing fluorine-18 fluoromisonidazole positron emission tomography for the localisation and quantification of pig liver hypoxia. Eur J Nucl Med, 1999. 26(2): p. 95-109.

34. Piert M., Machulla H.J., Becker G., et al. Dependency of the [18F]fluoromisonidazole uptake on oxygen delivery and tissue oxygenation in the porcine liver. Nucl Med Biol, 2000. 27(8): p. 693-700.

35. Varia M.A., Calkins-Adams D.P., Rinker L.H., et al. Pimonidazole: a novel hypoxia marker for complementary study of tumor hypoxia and cell proliferation in cervical carcinoma. Gynecol Oncol, 1998. 71(2): p. 270-7.

36. Rajendran J.G., Wilson D.C., Conrad E.U., et al. [(18)F]FMISO and [(18)F]FDG PET imaging in soft tissue sarcomas: correlation of hypoxia, metabolism and VEGF expression. Eur J Nucl Med Mol Imaging, 2003. 30(5): p. 695-704.

37. Kubota K., Tada M., Yamada S., et al. Comparison of the distribution of fluorine-18 fluoromisonidazole, deoxyglucose and methionine in tumour tissue. Eur J Nucl Med, 1999. 26(7): p. 750-7.

38. Tochon-Danguy H.J., Sachinidis J.I., Chan F., et al. Imaging and quantitation of the hypoxic cell fraction of viable tumor in an animal model of intracerebral high grade glioma using [18F]fluoromisonidazole (FMISO). Nucl Med Biol, 2002. 29(2): p. 191-7.

39. Valk P.E., Mathis C.A., Prados M.D., et al. Hypoxia in human gliomas: demonstration
by PET with fluorine-18-fluoromisonidazole. J Nucl Med, 1992. 33(12): p. 2133-7.

39. Valk P.E., Mathis C.A., Prados M.D., et al. Hypoxia in human gliomas: demonstration
by PET with fluorine-18-fluoromisonidazole. J Nucl Med, 1992. 33(12): p. 2133-7. tumor hypoxia with [F-18]fluoromisonidazole PET time-activity data. Med Phys, 1995. 22(7): p. 1127-39.

41. Raleigh J.A. and Koch C.J. Importance of thiols in the reductive binding of 2nitroimidazoles to macromolecules. Biochem Pharmacol, 1990. 40(11): p. 2457-64.

42. Olive P.L., Aquino-Parsons C., MacPhail S.H., et al. Carbonic anhydrase 9 as an endogenous marker for hypoxic cells in cervical cancer. Cancer Res, 2001. 61(24): p. 8924-9.

43. Lyng H., Sundfor K., and Rofstad E.K. Oxygen tension in human tumours measured with polarographic needle electrodes and its relationship to vascular density, necrosis and hypoxia. Radiother Oncol, 1997. 44(2): p. 163-9.

44. Olive P.L., Durand R.E., Raleigh J.A., et al. Comparison between the comet assay and pimonidazole binding for measuring tumour hypoxia. $\mathrm{Br}$ J Cancer, 2000. 83(11): $\mathrm{p}$. 1525-31.

45. Raleigh J.A., Chou S.C., Arteel G.E., et al. Comparisons among pimonidazole binding, oxygen electrode measurements, and radiation response in $\mathrm{C} 3 \mathrm{H}$ mouse tumors. Radiat Res, 1999. 151(5): p. 580-9.

46. Cockman M.E., Masson N., Mole D.R., et al. Hypoxia inducible factor-alpha binding and ubiquitylation by the von Hippel-Lindau tumor suppressor protein. J Biol Chem, 2000. 275(33): p. 25733-41. 
47. Ashida S., Nishimori I., Tanimura M., et al. Effects of von Hippel-Lindau gene mutation and methylation status on expression of transmembrane carbonic anhydrases in renal cell carcinoma. J Cancer Res Clin Oncol, 2002. 128(10): p. 5618.

48. Stubbs M., McSheehy P.M., Griffiths J.R., et al. Causes and consequences of tumour acidity and implications for treatment. Mol Med Today, 2000. 6(1): p. 15-9.

49. Gronroos T., Bentzen L., Marjamaki P., et al. Comparison of the biodistribution of two hypoxia markers [18F]FETNIM and [18F]FMISO in an experimental mammary carcinoma. Eur J Nucl Med Mol Imaging, 2004. 31(4): p. 513-20. 


\section{Chapter 3}

$\left[{ }^{18} \mathrm{~F}\right] \mathrm{EF} 3$ is not superior to $\left[{ }^{18} \mathrm{~F}\right] \mathrm{FMISO}$ for PETbased hypoxia evaluation as measured in a rat rhabdomyosarcoma tumor model

Dubois L, Landuyt W, Cloetens L, Bol A, Bormans G, Haustermans K, Labar D, Nuyts J, Grégoire V, Mortelmans L

Eur J Nucl Med Mol Imaging. 2009 Feb;36(2): 209-218

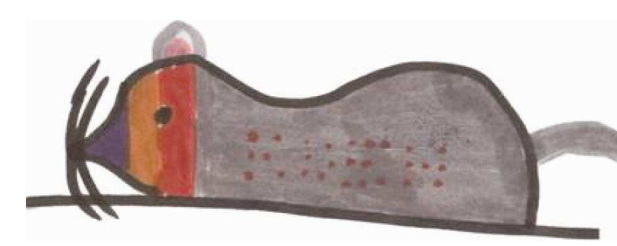




\begin{abstract}
Purpose: The aim of this investigation was to quantitatively compare the novel positron emission tomography (PET) hypoxia marker 2-(2-nitroimidazol-1-yl)-N-(3[ $\left.{ }^{18} \mathrm{~F}\right], 3,3$-trifluoropropyl)acetamide $\left(\left[{ }^{18} \mathrm{~F}\right] \mathrm{EF} 3\right)$ with the reference hypoxia tracer $\left[{ }^{18} \mathrm{~F}\right]$ fluoromisonidazole ( $\left.\left[{ }^{18} \mathrm{~F}\right] \mathrm{FMISO}\right)$.

Methods: $\left[{ }^{18} \mathrm{~F}\right] \mathrm{EF} 3$ or $\left[{ }^{18} \mathrm{~F}\right] \mathrm{FMISO}$ was injected every 2 days into two separate groups of rats bearing syngeneic rhabdomyosarcoma tumors. In vivo PET analysis was done by drawing regions of interest on the images of selected tissues. The resulting activity data were quantified by the percentage of injected radioactivity per gram tissue $(\% \mathrm{ID} / \mathrm{g})$ and tumor to blood (T/B) ratio. The spatial distribution of radioactivity was defined by autoradiography on frozen tumor sections.

Results: The blood clearance of $\left[{ }^{18} \mathrm{~F}\right] \mathrm{EF} 3$ was faster than that of $\left[{ }^{18} \mathrm{~F}\right]$ FMISO. The clearance of both tracers was slower in tumor tissue as compared with other tissues. This results in increasing T/B ratios as a function of time post tracer injection (p.i.). The maximal $\left[{ }^{18} \mathrm{~F}\right] \mathrm{EF} 3$ tumor uptake, compared to the maximum $\left[{ }^{18} \mathrm{~F}\right] \mathrm{FMISO}$ uptake, was significantly lower at $2 \mathrm{~h}$ p.i. but reached similar levels at $4 \mathrm{~h}$ p.i. The tumor uptake for both tracers was independent of the tumor volume for all investigated time points. Both tracers showed heterogeneous intra-tumoral distribution.

Conclusions: $\left[{ }^{18} \mathrm{~F}\right] \mathrm{EF} 3$ tumor uptake reached similar levels at $4 \mathrm{~h}$ p.i. compared with tumor retention observed after injection of $\left[{ }^{18} \mathrm{~F}\right]$ FMISO at $2 \mathrm{~h}$ p.i. Although $\left[{ }^{18} \mathrm{~F}\right] \mathrm{EF} 3$ is a promising noninvasive tracer, it is not superior over $\left[{ }^{18} \mathrm{~F}\right] \mathrm{FMISO}$ for the visualization of tumor hypoxia. No significant differences between $\left[{ }^{18} \mathrm{~F}\right] \mathrm{EF} 3$ and $\left[{ }^{18} \mathrm{~F}\right]$ FMISO were observed with regard to the intra-tumoral distribution and the extra-tumoral tissue retention.
\end{abstract}




\section{Introduction}

Oxygen deficiency (hypoxia) is heterogeneously spread in regions of solid tumors as a result of rapid cellular expansion and/or insufficient tumor angiogenesis ${ }^{1,2}$. Hypoxia has been related to increased malignant progression and metastatic potential of primary carcinomas as well as to resistance to cancer therapies ${ }^{3,4}$. Strategies to counteract the negative effect of intra-tumoral hypoxia are being evaluated ${ }^{5}$, but not all patients show benefits from such selective treatments. To facilitate treatment guidance in individual patients, a variety of methods have been proposed to measure oxygenation levels in tumoral tissues.

During the last 20 years, a lot of research has been devoted to noninvasive imaging techniques for the detection of hypoxia in solid tumors. One such technique involves positron emission tomography (PET) using radiolabeled nitroimidazoles. In hypoxic environments, these compounds are subject of a reductive metabolism, which causes the formation of reactive intermediates (nitrose and hydroxylamine) that become covalently bound to macromolecular cellular components ${ }^{6}$. Based on this principle, their selective binding to hypoxic cells has already been demonstrated in vitro as well as in vivo ${ }^{7-10}$.

$\left[{ }^{18} \mathrm{~F}\right]$ Fluoromisonidazole $\left(\left[{ }^{18} \mathrm{~F}\right] \mathrm{FMISO}\right)$ was the first radiolabeled 2-nitroimidazole derivative proposed for hypoxia imaging with $\mathrm{PET}^{11}$. This tracer has been evaluated extensively for the detection of tumor hypoxia both preclinically, using different animal models ${ }^{12-15}$, and clinically, for different cancer types ${ }^{16-19}$. Other ${ }^{18} \mathrm{~F}$ labeled nitroimidazoles, such as $\left[{ }^{18} \mathrm{~F}_{\text {FETNIM }}{ }^{20},{ }^{21}\right.$ and $\left[{ }^{18} \mathrm{~F}\right] \mathrm{FAZA}{ }^{22,23}$, have been synthesized and validated as hypoxia markers. However, being more hydrophilic compounds, the latter PET tracers' diffusion into tumoral tissues might be limited ${ }^{24}$. 
Therefore, a new class of more lipophilic, fluorinated etanidazole compounds (e.g. EF3 and EF5) is of potential interest. Preliminary animal experiments involving these fluorinated derivatives indicated more homogeneous distribution in normal tissues together with tracer clearance through the kidneys and tracer accumulation in hypoxic tumors ${ }^{25}, 26$. Recently, Josse et al. successfully radiolabeled 2-(2-nitroimidazol-1-yl)- $N$-(3,3,3trifluoropropyl)acetamide (EF3) using ${ }^{18} \mathrm{~F}$ for PET-based hypoxia evaluation ${ }^{27}$. Based on ex vivo pharmacokinetics and biodistribution data, Mahy et al. demonstrated that $\left[{ }^{18} \mathrm{~F}\right] \mathrm{EF} 3$ could be a good alternative for $\left[{ }^{18} \mathrm{~F}\right] \mathrm{FMISO}$ for the detection of tumor hypoxia ${ }^{28}$.

The aim of the present study was to quantitatively compare the in vivo hypoxia-dependent uptake of $\left[{ }^{18} \mathrm{~F}\right] \mathrm{EF} 3$ and $\left[{ }^{18} \mathrm{~F}\right] \mathrm{FMISO}$ in experimental rat tumors by noninvasive investigation with PET. The experiments also involved the evaluation of the in vivo pharmacokinetics of both tracers and their biodistribution in normal tissues.

\section{Materials and Methods}

\section{Animal and tumor model}

Male adult WAG/Rij rats with an average body weight of $315 \mathrm{~g}$ were used. Each rat was implanted subcutaneously under sodium pentobarbital anesthesia (Nembutal $0.1 \mathrm{ml} 100 \mathrm{~g}^{-1}$ body weight; Sanofi, Belgium) with syngeneic rhabdomyosarcomas (1-mm ${ }^{3} \mathrm{R} 1$ tumors, $\left.{ }^{29}\right)$, in the lateral thorax or in the abdominal flank. Tumors were measured every day during the experiment using a Vernier calliper in three orthogonal tumor diameters $A, B$ and $C$, each corrected for the thickness of the skin. Volumes were calculated 
using the formula $A \times B \times C \times \pi / 6$, since the tumors grew elliptically. PET measurements were performed within a 2-week follow-up. Procedures were performed according to the guidelines defined in the "Principles of laboratory animal care" (NIH publication no. 86-23, revised 1985). All animals were maintained in a facility which was approved by the Belgian Ministry of Agriculture in accordance to current regulations and standards. Animals were given food and water ad libitum for the duration of the experiments. The experimental design was approved by the Animal Ethics Committee of the Katholieke Universiteit Leuven, Leuven (FMISO experiment) and of the Université Catholique de Louvain, Louvain-la-Neuve (EF3 experiment).

\section{Synthesis of the hypoxia markers}

The ${ }^{18} \mathrm{~F}$-labeled 2-nitroimidazole derivative 2-(2-nitroimidazol-1yl)-N-(3,3,3-trifluoropropyl)acetamide ([ $\left.\left.{ }^{18} \mathrm{~F}\right] \mathrm{EF} 3\right)$ (Fig. 1a) was synthesized as previously described ${ }^{27}$. Briefly, the radiolabeled perfluorinated aminodithioester precursor group was de-protected and coupled to 2-nitroimidazole acetic acid to generate $\left[{ }^{18} \mathrm{~F}\right] \mathrm{EF} 3$, which was isolated by reverse phase semi-preparative highperformance liquid chromatography (HPLC). The HPLC-isolated $\left[{ }^{18} \mathrm{~F}\right] \mathrm{EF} 3$ fractions demonstrated a radiochemical purity higher than $95 \%$. Specific radioactivity was typically in the range of 150 $\mathrm{GBq} / \mathrm{mmol}$ reflecting the difficulty and yield of the $\left[{ }^{18} \mathrm{~F}\right] \mathrm{EF} 3$ synthesis.

$\left[{ }^{18} \mathrm{~F}\right]$ Fluoromisonidazole $\left(\left[{ }^{18} \mathrm{~F}\right] \mathrm{FMISO}\right.$ ) (Fig. 1b) was produced by the nucleophilic substitution of 1 -(2'-nitro-1'-imidazolyl)-2-Otetrahydropyranyl-3-O-toluenesulfonylpropandiole with $\left[{ }^{18} \mathrm{~F}\right]$ fluoride followed by acidic hydrolysis of the protecting group, as described by Lim and Berridge ${ }^{30}$. Radiochemical purity was always 
higher than 95\%, specific radioactivity was higher than 37000 $\mathrm{GBq} / \mathrm{mmol}$.

A<smiles>O=C(Cn1ccnc1[N+](=O)[O-])NCCC(F)(F)F</smiles>

B<smiles>O=[N+]([O-])c1nccn1CC(O)CF</smiles>

Figure 1. Chemical structure of the 2-nitroimidazole hypoxia markers (a) trifluoropropyl acetamide derivative (EF3) and (b) fluoromisonidazole (FMISO).

\section{Experimental design}

Two different sets of tumor-bearing rats with similar starting volumes were injected either with $\left[{ }^{18} \mathrm{~F}\right] \mathrm{EF} 3$ or $\left[{ }^{18} \mathrm{~F}\right] \mathrm{FMISO}$ at different imaging centres. Injection of the tracer occurred at a 2days interval to assure complete clearance between successive studies. Prior to and during PET acquisition, the animals were anesthetized with sodium pentobarbital at a dose of $0.1 \mathrm{ml} 100 \mathrm{~g}^{-1}$ body weight, injected intraperitoneally. The radiolabeled tracer was administrated via an intravenous catheter (Venoflux $0.4 \mathrm{~mm}$ G.27; Vygon, France) inserted into a lateral tail vein, flushed with diluted heparin saline solution. The bladder of the animal was emptied by gentle pressure at the lower abdominal area before each PET acquisition and the rats were placed in a custom-built, polystyrene foam placed in the opening of the camera. During PET 
image acquisition, anesthesia was maintained using individual ratadapted intraperitoneal injections (10 - 30\% of the initial dose) of the anesthetic, as needed. Following the PET acquisitions, a blood sample from each animal was collected by retro-orbital puncture and $\left[{ }^{18} \mathrm{~F}\right] \mathrm{EF} 3$ radioactivity concentration in the blood samples was measured using a gamma counter (1480 Wallac Wizard 3" Automatic Gamma Counter, PerkinElmer, USA). At defined time points, randomly selected rats were euthanized by an overdose sodium pentobarbital injected into the heart and tumors were removed immediately for histopathological examination.

\section{PET imaging}

PET images with $\left[{ }^{18} \mathrm{~F}\right] \mathrm{FMISO}$ were obtained at the Department of Nuclear Medicine KU Leuven as previously described ${ }^{13}$. PET imaging with $\left[{ }^{18} \mathrm{~F}\right] \mathrm{EF} 3$ was performed at the UCL Centre for Molecular Imaging and Experimental Radiotherapy, using an ECAT HR scanner (Siemens/CTI Knoxville) with an axial field of view (AFOV) of $15 \mathrm{~cm}$ and a reconstructed spatial resolution of $8 \mathrm{~mm}$ full-width at half-maximum at the centre of the FOV. Phantom measurements were performed on both imaging devices to compute calibration factors and thus enabling comparison between images obtained with both cameras.

The PET sequence started with a 15 -min transmission scan using external rods of ${ }^{68} \mathrm{Ge}$ to allow subsequent attenuation correction of the emission images. Simultaneously with tracer injection into a lateral tail vein $\left(12.22 \pm 1.63 \mathrm{MBq}\left[{ }^{18} \mathrm{~F}\right] \mathrm{FMISO}\right.$ or $19.69 \pm 2.22 \mathrm{MBq}\left[{ }^{18} \mathrm{~F}\right] \mathrm{EF} 3$ ), a dynamic emission scanning (26 frames) to obtain heart outflow clearance data was started for 60 min, according to the following protocol: $8 \times 15 \mathrm{~s}, 4 \times 30 \mathrm{~s}, 2 \times 1 \mathrm{~min}$, $2 \times 2 \mathrm{~min}, 10 \times 5 \mathrm{~min}$. Two hours post injection (p.i.), a second 
dynamic emission scan for $20 \mathrm{~min}(4 \times 5 \mathrm{~min})$ following repositioning and a 15 -min transmission scan were performed as previously described ${ }^{13}$. To allow extensive comparison with $\left[{ }^{18} \mathrm{~F}\right] \mathrm{FMISO}$, the same sequence (transmission followed by $20-\mathrm{min}$ dynamic emission) was repeated twice ( 3 and 4 hours p.i.) on the $\left[{ }^{18} \mathrm{~F}\right] \mathrm{EF} 3$ injected animals. All images were reconstructed iteratively (2D-OSEM) using attenuation factors obtained from the transmission scans. The images were also corrected for scatter, randoms, deadtime, frame duration and decay to the start of each emission scan. The activity concentrations, obtained in selected tissues from regions of interest (ROI) drawn on the images, were subsequently corrected for decay towards the time of injection.

\section{PET image analysis}

Blood pool activity data were obtained by drawing a volume of interest (VOI) with an average diameter of $9 \mathrm{~mm}$ on the outflow area of the heart, which was defined with the aid of the early perfusion images. To validate these data, they were compared to the results obtained from the blood samples quantified using ex vivo counting in a gamma counter which was cross-calibrated versus the PET-scanner. Blood clearance curves for both tracers were then created by plotting the activity values within each VOI in all single time frames of the dynamic acquisition (expressed as percent of injected dose per gram tissue) against time. Normal tissue evaluation was done using VOI analysis (diameter of $9 \mathrm{~mm}$ ) on the lung, muscle (as described $\mathrm{in}^{8}$ ) and head and neck (H\&N) area (as described $\mathrm{in}^{31}$ ). Tracer uptake in tumors was evaluated by VOI analysis on the summed frames at 2, 3 and $4 \mathrm{~h}$ p.i. VOIs were defined by drawing isocontours on all slices where visible tumor uptake was present. All activity data were corrected for ${ }^{18} \mathrm{~F}$ decay 
and quantified by calculation of the percentage of injected radioactivity per gram tissue $(\% \mathrm{ID} / \mathrm{g})$. The mean and maximal activities for $\left[{ }^{18} \mathrm{~F}\right] \mathrm{EF} 3$ and $\left[{ }^{18} \mathrm{~F}\right] \mathrm{FMISO}$ were obtained from the selected tissue ROI and divided by the mean activity of a heart outflow ROI to calculate tissue to blood (T/B) ratios.

\section{Histology}

Excised tumors were fixed in neutral buffered formalin (1 - 4\%), embedded in paraffin and cut into 5 - $\mu$ m-thick slices using a Leica2045 microtome (Germany). Slices were deparaffinized with toluene and rehydrated by treatment with a series of alcohol and water mixtures and finally with water. Tissue sections were stained using Mayer's Haematoxylin (Klinipath b.v. Belgium) for $5 \mathrm{~min}$. After incubation in tap water $(10 \mathrm{~min})$, the sections were counterstained with Eosin (Klinipath b.v. Belgium) for $3 \mathrm{~min}$, dehydrated and mounted. Sections were scored by means of moving a ' $10 \times 10$ ' grid-incorporated ocular, superimposed on the image, at a total magnification of $\times 200$. For each tumor, an average of $807 \pm 319$ hit-points was evaluated and the necrotic fraction (NF) was calculated.

\section{Autoradiography}

Additional tumor-bearing rats $(n=5)$ were injected with either $\left[{ }^{18} \mathrm{~F}\right]$ FMISO $(84.75 \pm 9.36 \mathrm{MBq})$ or $\left[{ }^{18} \mathrm{~F}\right] \mathrm{EF} 3(108.25 \pm 8.00 \mathrm{MBq})$. Upon euthanasia at 2 or $4 \mathrm{~h}$ p.i., tumors were excised, rapidly frozen in 2-methylbutane (cooled to $-25^{\circ} \mathrm{C}$ with liquid nitrogen) and cut with a Leica-CM-3050 cryotome (Germany) into 7- $\mu \mathrm{m}$ thick sections. Selected tumor sections were mounted onto microscope slides, air-dried and exposed overnight to a high performance storage phosphor screen (Packard, Meriden, USA). 
The spatial distribution of radioactivity was autoradiographically recorded with a Phosphor Imager Scanner (Packard Cyclone TM, Meriden, USA). The resolution of the images expressed in pixel size was $42 \times 42 \mu \mathrm{m}$ (600 dpi).

\section{Statistics}

All statistical analyses were performed with SPSS 12.0.1 for Windows (SPSS, 2003, Chicago, USA). Graphs were drawn using Origin 6.0 (Microcal Software, 1999, Northampton, USA). Correlation among the variables was analyzed using Spearman rank order correlation and additionally evaluated by linear regression. An unpaired Student's $t$ test and non-parametric MannWhitney $U$ test for small groups were used to determine the statistical significance of differences between two independent groups of variables. For all tests, a $P<0.05$ was considered significant.

\section{Results}

Heart outflow as reference tissue

Comparison (Fig. 2) of the heart outflow data, defined by VOI-PET analysis on $\left[{ }^{18} \mathrm{~F}\right] \mathrm{EF} 3$ images with the blood activity data quantified ex vivo in a gamma counter, resulted in a strong, significant correlation $\left(r^{2}=0.924 ; P<0.001 ; y=1.006 x+34.792\right)$. ROI analysis of the heart outflow area was performed independently by a second observer. No significant difference $(P=0.986)$ was seen. Based on these results, the heart outflow was selected as reference tissue for the calculation of the T/B ratios. 


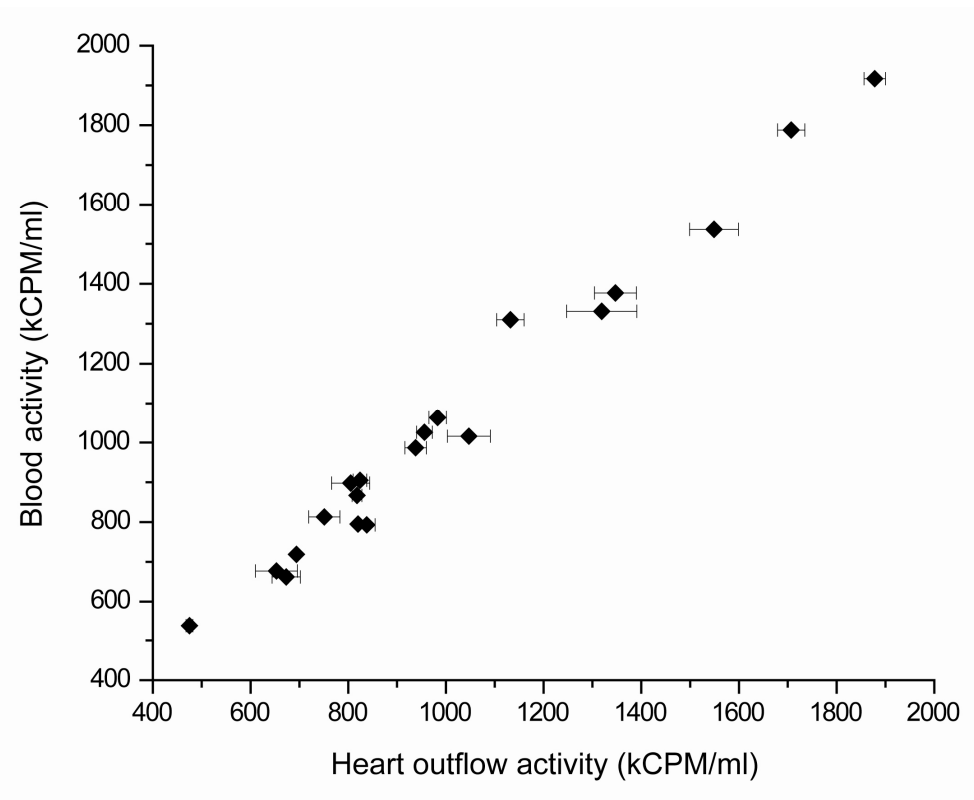

Figure 2. Validation of heart 'outflow' as reference tissue by comparison, after phantom-based cross-calibration, between $\left[{ }^{18} \mathrm{~F}\right]$ activity defined by image analysis of the heart and gamma counter analysis of blood samples. Heart analysis data represent the mean \pm SD of 3 independent analyses of 20 animals. Heart 'outflow' regions were defined on the $\left.{ }^{18} \mathrm{~F}\right] \mathrm{EF} 3$ images acquired using the ECAT HR scanner from the UCL imaging facility.

\section{Blood pharmacokinetics}

For analysis of the blood pharmacokinetics, we used the monocompartmental hypothesis. Data were better fitted applying a biexponential elimination model $\left(r^{2}=0.614\right.$ for $\left[{ }^{18} \mathrm{~F}\right] \mathrm{FMISO}$ and $r^{2}=$ 0.787 for $\left.\left[{ }^{18} \mathrm{~F}\right] \mathrm{EF} 3\right)$ compared to a mono-exponential model $\left(r^{2}=\right.$ 0.399 and 0.569 for $\left[{ }^{18} \mathrm{~F}\right]$ FMISO and $\left[{ }^{18} \mathrm{~F}\right] \mathrm{EF} 3$, respectively). The $\left[{ }^{18} \mathrm{~F}\right] \mathrm{EF} 3$ initial and late elimination half-lives (up to $2 \mathrm{~h}$ p.i.) were $0.62 \mathrm{~min}(0.56-0.70 \mathrm{~min}$ ) and $51.36 \mathrm{~min}(42.63-64.56 \mathrm{~min})$, respectively. The pharmacokinetics of $\left[{ }^{18} \mathrm{~F}\right] \mathrm{FMISO}$ were slower with elimination half-lives of $1.19 \mathrm{~min}(1.03-1.42 \mathrm{~min}$ ) and $94.59 \mathrm{~min}$ (70.44 - $143.95 \mathrm{~min}$ ). Linear regression analysis showed a significant difference in clearance for both tracers $(P<0.001)$, as 
witnessed from the interaction between time and group (Fig. 3). $\left[{ }^{18} \mathrm{~F}\right] \mathrm{EF} 3$ elimination half-lives up to $4 \mathrm{~h}$ p.i. were only slightly different: $0.65 \min (0.58-0.72 \mathrm{~min})$ and $59.72 \min (49.75$ $74.65 \mathrm{~min})$.

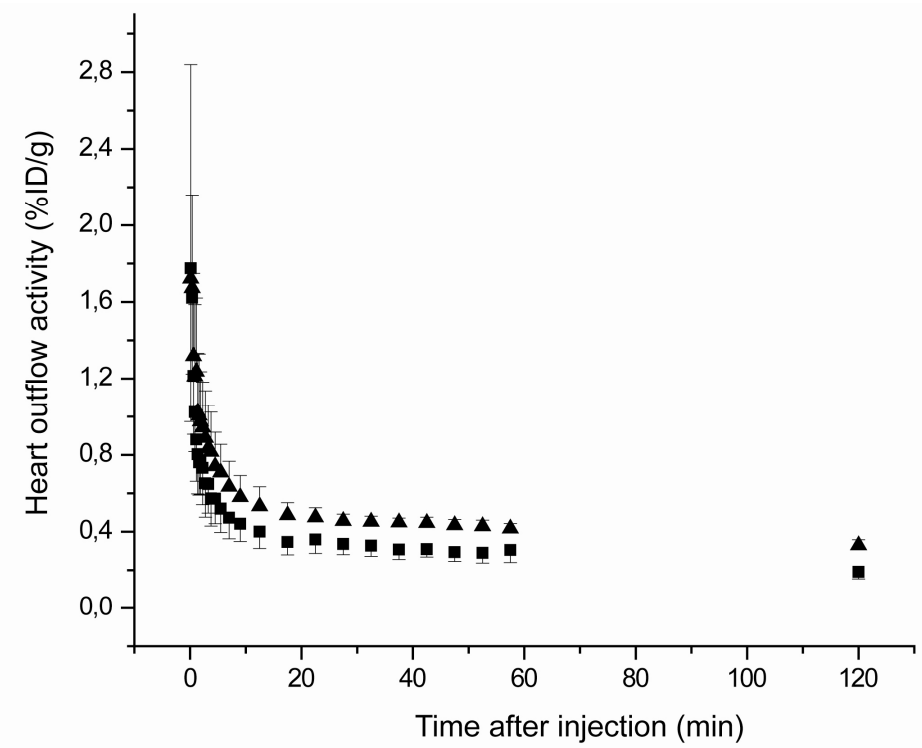

Figure 3. Time-activity blood clearance curves for $\left[{ }^{18} \mathrm{~F}\right] \mathrm{EF} 3$ (squares) and for $\left[{ }^{18} \mathrm{~F}\right]$ FMISO (triangles) up to $2 \mathrm{~h}$ p.i. Data represent the mean $\pm \mathrm{SD}$ of eight and ten animals injected with $\left[{ }^{18} \mathrm{~F}\right] \mathrm{EF} 3$ or $\left[{ }^{18} \mathrm{~F}\right] \mathrm{FMISO}$, respectively.

\section{PET analysis of normal tissues}

Comparison between $\left[{ }^{18} \mathrm{~F}\right] \mathrm{EF} 3$ and $\left[{ }^{18} \mathrm{~F}\right] \mathrm{FMISO}$ normal tissue uptake, investigated in the $\mathrm{H} \& \mathrm{~N}$ area and muscle (front and hind leg) area on the $2 \mathrm{~h}$ p.i. images, did not reveal statistical differences, except for lung tissue where the $\left[{ }^{18} \mathrm{~F}\right] \mathrm{FMISO} \mathrm{T} / \mathrm{B}$ ratio was lower than the $\left[{ }^{18} \mathrm{~F}\right] \mathrm{EF} 3 \mathrm{~T} / \mathrm{B}$ ratios $(P<0.001)$ (Table 1$)$. No significant differences were observed between mean and maximum activity data for all investigated normal tissues (data not shown), confirming the homogeneous uptake characteristics in these 
tissues. All normal tissues exhibited activity levels lower than in blood, resulting in T/B ratios below unity. Later time points ( 3 and $4 \mathrm{~h}$ p.i.) did not demonstrate differences in $\left[{ }^{18} \mathrm{~F}\right] \mathrm{EF} 3 \mathrm{~T} / \mathrm{B}$ ratios compared with 2 h p.i. (Table 1 ).

Table 1. Uptake (tissue to blood ratio) of $\left[{ }^{18} \mathrm{~F}\right] \mathrm{FMISO}$ and $\left[{ }^{18} \mathrm{~F}\right] \mathrm{EF} 3$ at $2 \mathrm{~h}$ p.i. and of $\left[{ }^{18} \mathrm{~F}\right] \mathrm{EF} 3$ at 3 and $4 \mathrm{~h}$ p.i. in selected normal tissues and tumors.

\begin{tabular}{|c|c|c|c|c|c|}
\hline \multirow{2}{*}{\multicolumn{2}{|c|}{ Tissue/blood }} & \multirow{2}{*}{$\begin{array}{c}{\left[{ }^{18} \mathrm{~F}\right] \mathrm{FMISO}} \\
2 \mathrm{~h} \mathrm{p.i.}\end{array}$} & \multicolumn{3}{|c|}{$\left[{ }^{18} \mathrm{~F}\right] \mathrm{EF} 3$} \\
\hline & & & 2h p.i. & 3h p.i. & 4h p.i. \\
\hline \multicolumn{2}{|c|}{$\mathrm{H} \& \mathrm{~N}$ area } & $0.88 \pm 0.02$ & $0.88 \pm 0.02$ & $0.90 \pm 0.02$ & $0.90 \pm 0.02$ \\
\hline \multicolumn{2}{|c|}{ Muscle front leg } & $0.97 \pm 0.02$ & $0.89 \pm 0.02$ & $0.90 \pm 0.02$ & $0.88 \pm 0.03$ \\
\hline \multicolumn{2}{|c|}{ Muscle hind leg } & $0.95 \pm 0.03$ & $0.92 \pm 0.05$ & $0.93 \pm 0.03$ & $0.94 \pm 0.03$ \\
\hline \multicolumn{2}{|l|}{ Lung } & $0.60 \pm 0.02$ & $0.80 \pm 0.02$ & $0.83 \pm 0.03$ & $0.82 \pm 0.03$ \\
\hline \multicolumn{6}{|c|}{ Tumor/blood } \\
\hline All & Mean & $3.99 \pm 0.18$ & $1.83 \pm 0.06$ & $2.25 \pm 0.09$ & $2.63 \pm 0.11$ \\
\hline \multicolumn{2}{|l|}{$<1 \mathrm{~cm}^{3}$} & $3.87 \pm 0.28$ & $1.65 \pm 0.09$ & $1.95 \pm 0.13$ & $2.35 \pm 0.17$ \\
\hline \multicolumn{2}{|l|}{$>1 \mathrm{~cm}^{3}$} & $4.13 \pm 0.22$ & $2.09 \pm 0.07$ & $2.67 \pm 0.11$ & $3.03 \pm 0.12$ \\
\hline \multirow{2}{*}{\multicolumn{2}{|c|}{$\begin{array}{l}\text { All } \\
<1 \mathrm{~cm}^{3}\end{array}$}} & $5.46 \pm 0.27$ & $2.89 \pm 0.11$ & $3.86 \pm 0.18$ & $4.84 \pm 0.23$ \\
\hline & & $5.11 \pm 0.42$ & $2.55 \pm 0.15$ & $3.21 \pm 0.22$ & $4.26 \pm 0.33$ \\
\hline \multicolumn{2}{|l|}{$>1 \mathrm{~cm}^{3}$} & $5.86 \pm 0.31$ & $3.38 \pm 0.14$ & $4.78 \pm 0.24$ & $5.66 \pm 0.25$ \\
\hline
\end{tabular}

Normal tissues: $n=12$ for $\left[{ }^{18} \mathrm{~F}\right]$ FMISO and $n=20$ for $\left[{ }^{18} \mathrm{~F}\right]$ EF3.

Tumors: $\mathrm{n}=48$ for $\left[{ }^{18}\right.$ F $]$ FMISO $\left(<1 \mathrm{~cm}^{3}: \mathrm{n}=26 ;>1 \mathrm{~cm}^{3}: \mathrm{n}=22\right)$ and $\mathrm{n}$ $=80$ for $\left[{ }^{18} \mathrm{~F}\right]$ EF3 $\left(<1 \mathrm{~cm}^{3}: \mathrm{n}=44 ;>1 \mathrm{~cm}^{3}: \mathrm{n}=36\right)$.

Data are presented as mean \pm SD.

\section{PET analysis of tumor tissues}

No significant differences $(P=0.285)$ were found between the median of the tumor volumes for the animals in the $\left[{ }^{18} \mathrm{~F}\right] \mathrm{EF} 3(0.87$ $\left.\mathrm{cm}^{3}\right)$ and $\left[{ }^{18} \mathrm{~F}\right]$ FMISO group $\left(0.94 \mathrm{~cm}^{3}\right)$, which allows comparison of the results obtained with both tracers. The decrease in $\left[{ }^{18} \mathrm{~F}\right] \mathrm{EF} 3$ activity concentration as a function of time was fastest in blood and the washout was lowest in tumor tissue, resulting in increasing $T / B$ ratios over time. Since tumors are known to be 
heterogeneous, we analyzed the $T / B$ ratios based both on mean and maximum tumor concentration. A statistical difference was observed between the two T/B values, both for $\left[{ }^{18} \mathrm{~F}\right] \mathrm{FMISO}$ and $\left[{ }^{18} \mathrm{~F}\right] \mathrm{EF} 3(P<0.001)$. The increase in T/B ratio over time was faster for tumoral regions which showed the highest radioactivity concentration (Table 1 ). The maximum $\left[{ }^{18} \mathrm{~F}\right] \mathrm{EF} 3$ uptake at $2 \mathrm{~h}$ p.i. was significantly lower $(P<0.001)$ compared with the $\left[{ }^{18} \mathrm{~F}\right] \mathrm{FMISO}$ activity uptake at the same time point (Fig. 5a). However, at $4 \mathrm{~h}$ p.i., maximum $\left[{ }^{18} \mathrm{~F}\right] \mathrm{EF} 3 \mathrm{~T} / \mathrm{B}$ ratios were not significantly different anymore compared with the maximum $\left[{ }^{18} \mathrm{~F}\right] \mathrm{FMISO} \mathrm{T} / \mathrm{B}$ ratios at $2 \mathrm{~h}$ p.i. $(P=0.088)$. Comparison of the mean uptake indicated statistical differences between both tracers for all investigated time points $(P<0.001)$. The maximum $\left[{ }^{18} \mathrm{~F}\right] \mathrm{FMISO}$ uptake $(\% \mathrm{ID} / \mathrm{g})$ was independent of the tumor volume for all investigated time points (Fig. 4 and Table 2). $\left[{ }^{18} \mathrm{~F}\right] \mathrm{EF} 3$ uptake, however, seemed to better correlate with tumor volume. Mean uptake data showed comparable results (data not shown).

Table 2. $r^{2}$ - and $P$-values for the correlation between maximum tracer uptake $(\% \mathrm{ID} / \mathrm{g})$ at various time points and tumor volumes.

\begin{tabular}{|c|c|c|c|c|c|c|c|}
\hline & & \multicolumn{2}{|c|}{ All } & \multicolumn{2}{|c|}{$<1 \mathrm{~cm}^{3}$} & \multicolumn{2}{|c|}{$>1 \mathrm{~cm}^{3}$} \\
\hline & & $r^{2}$-value & $P$-value & $r^{2}$-value & $P$-value & $r^{2}$-value & $P$-value \\
\hline \multirow{4}{*}{$\begin{array}{l}{\left[{ }^{18} \mathrm{~F}\right] \mathrm{FMISO}} \\
{\left[{ }^{18} \mathrm{~F}\right] \mathrm{EF} 3}\end{array}$} & $2 h$ p.i. & 0.12 & 0.016 & 0.12 & 0.084 & 0.047 & 0.331 \\
\hline & 2h p.i. & 0.268 & $<0.001$ & 0.13 & 0.013 & 0.221 & 0.006 \\
\hline & 3h p.i. & 0.403 & $<0.001$ & 0.231 & $<0.001$ & 0.298 & $<0.001$ \\
\hline & 4h p.i. & 0.315 & $<0.001$ & 0.228 & $<0.001$ & 0.219 & 0.006 \\
\hline
\end{tabular}

We found a correlation $\left(r^{2}=0.508\right.$ and $\left.P=0.009\right)$ between the NF and tumor volume with a clear significant separation in NF between tumors smaller $(\mathrm{NF}=5.8 \pm 1.8 \%)$ and larger $(\mathrm{NF}=39.1$ $\pm 7.8 \%)$ than $1 \mathrm{~cm}^{3}(P=0.004$; data not shown $)$. When 
comparison was made between tracer uptake and tumor volumes separately for tumors smaller or larger than $1 \mathrm{~cm}^{3}$, similar results were obtained (Table 2) as for the whole dataset.
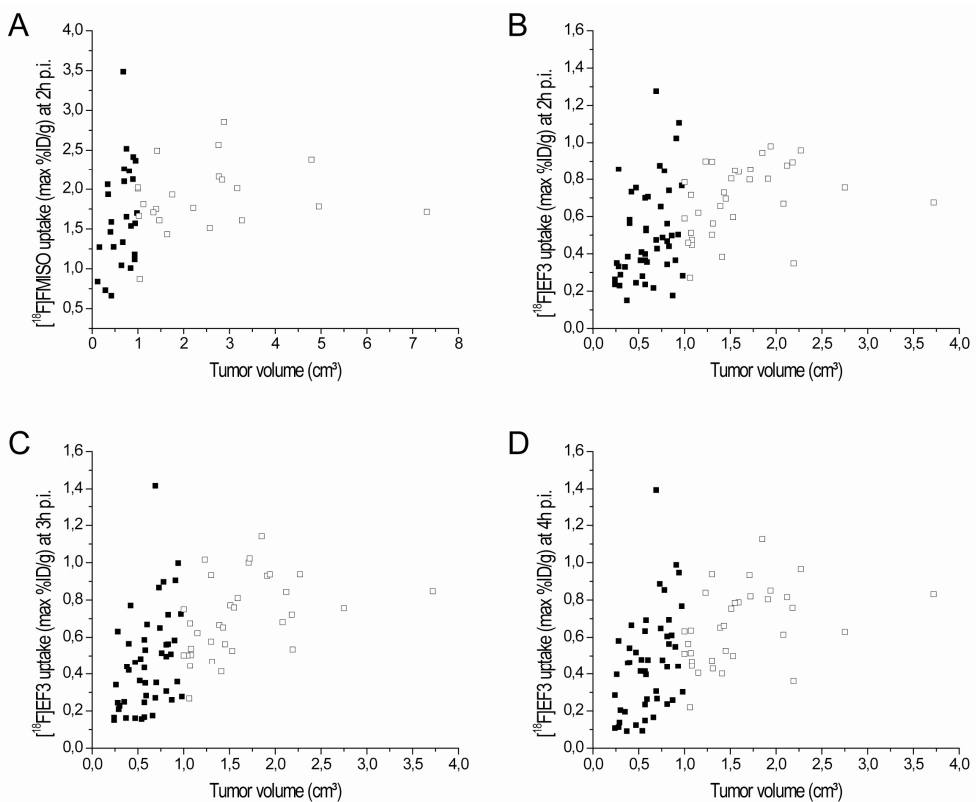

Figure 4. Maximum $\left[{ }^{18} \mathrm{~F}\right] \mathrm{FMISO}$ tracer uptake $(\% \mathrm{ID} / \mathrm{g})$ at $2 \mathrm{~h}$ p.i. (a) and maximum $\left[{ }^{18} \mathrm{~F}\right] \mathrm{EF} 3$ tracer uptake at $2 \mathrm{~h}$ p.i. (b), $3 \mathrm{~h}$ p.i. (c) and $4 \mathrm{~h}$ p.i. (d) plotted against tumor volume $\left(\mathrm{cm}^{3}\right)$. Filled squares represent tumors smaller than $1 \mathrm{~cm}^{3}$ ( $n=44$ for $\left[{ }^{18} \mathrm{~F}\right] \mathrm{EF} 3$ and $n=26$ for $\left.\left[{ }^{18} \mathrm{~F}\right] \mathrm{FMISO}\right)$ whilst open squares show tumors larger than $1 \mathrm{~cm}^{3}\left(n=36\right.$ for $\left[{ }^{18} \mathrm{~F}\right] \mathrm{EF} 3$ and $n=$ 22 for $\left.\left[{ }^{18} \mathrm{~F}\right] \mathrm{FMISO}\right)$. Note differences in scales on the $\mathrm{Y}$-axis.

\section{Autoradiography}

Autoradiographic analysis of the frozen tumor sections obtained from rats 2 or $4 \mathrm{~h}$ post intravenous injection of respectively $\left[{ }^{18} \mathrm{~F}\right] \mathrm{FMISO}$ or $\left[{ }^{18} \mathrm{~F}\right] \mathrm{EF} 3$ showed that both tracers were heterogeneously distributed within tumors (Fig. 5b). On average, the $\left[{ }^{18} \mathrm{~F}\right] \mathrm{FMISO}$ tracer uptake was higher compared with the $\left[{ }^{18} \mathrm{~F}\right] \mathrm{EF} 3$ uptake. 
A

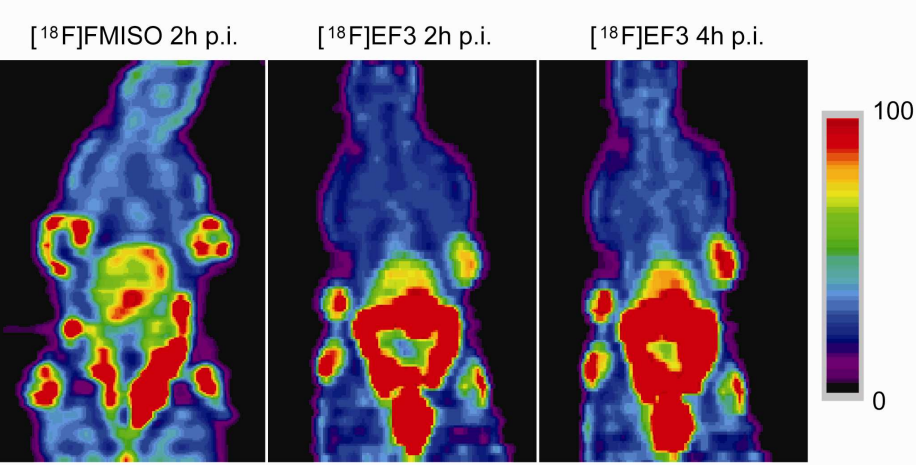

B

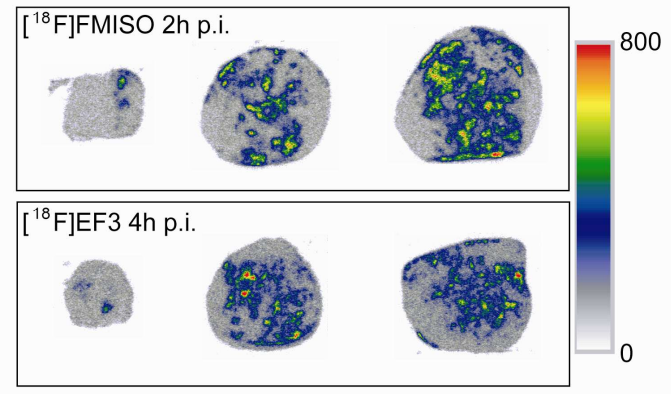

Figure 5. PET images (a) of rats injected with $\left[{ }^{18} \mathrm{~F}\right] \mathrm{FMISO}$ (2h p.i.) and $\left[{ }^{18} \mathrm{~F}\right] \mathrm{EF} 3$ (2h and $4 \mathrm{~h}$ p.i.). Autoradiography images (b) of tumors injected with $\left[{ }^{18} \mathrm{~F}\right] \mathrm{FMISO}$ at $2 \mathrm{~h}$ p.i. $\left(1.66 \mathrm{~cm}^{3}\right)$ or with $\left[{ }^{18} \mathrm{~F}\right] \mathrm{EF} 3$ at $4 \mathrm{~h}$ p.i. $(1.60$ $\mathrm{cm}^{3}$ ). From left to right, peripheral to central images of the tumors are shown. Both PET $(0-100)$ and autoradiography $(0-800)$ images is scaled to the hottest pixel (= highest tracer uptake) in the image.

\section{Discussion}

Over the last decade, interest into the development of radiolabeled markers for the noninvasive diagnosis of tumor hypoxia in solid tumors has increased dramatically. Based on its high cellular uptake and trapping in hypoxic cells, $\left[{ }^{18} \mathrm{~F}\right] \mathrm{FMISO}$ has been tested for in vivo visualization of reduced oxygen tension in tumors, both in preclinical ${ }^{12-15}$ and clinical ${ }^{17,}{ }^{19}$ settings. $\left[{ }^{18} \mathrm{~F}\right] \mathrm{FMISO}$ has also been indicated to be a valuable tool for therapy response 
evaluation ${ }^{16,18}$. However, the diffusion of $\left[{ }^{18} \mathrm{~F}\right] \mathrm{FMISO}$ into tissues and, in particular, into tumor tissues, which are known to have abnormal vascularization, might not be optimal due to the hydrophilicity of the compound (octanol-to-buffer partition coefficient of 0.4 ).

Therefore, a new class of more lipophilic fluorinated compounds, such as $\mathrm{EF} 3^{25}$ and $\mathrm{EF}^{26}$ showing an octanol-to-buffer partition coefficient of 1.12 and 5.7, respectively, have been developed. Recently, EF3 has been radiolabeled with ${ }^{18} \mathrm{~F}$ $\left(\left[{ }^{18} \mathrm{~F}\right] \mathrm{EF} 3\right)^{27}$ and based on ex vivo pharmacokinetics and biodistribution data, Mahy et al. demonstrated that $\left[{ }^{18} \mathrm{~F}\right] \mathrm{EF} 3$ could be a good candidate for the detection of tumor hypoxia ${ }^{28}$. The use of $\left[{ }^{18} \mathrm{~F}\right] \mathrm{EF} 3$ to detect tumor hypoxia has been further validated by comparison with the intracellular EF5 uptake as detected by immunofluorescence ${ }^{32}$. On the other hand, Dubois et al. validated the noninvasive $\left[{ }^{18} \mathrm{~F}\right] \mathrm{FMISO}-\mathrm{PET}$ method to measure tumor hypoxia by comparison with the exogeneous hypoxia marker pimonidazole ${ }^{13}$. Further preclinical in vivo evaluation of $\left[{ }^{18} \mathrm{~F}\right] \mathrm{EF} 3$ by comparison with other radiolabeled hypoxia tracers is a very important issue. The aim of the present study has been to quantitatively compare the selectivity of hypoxia-dependent uptake of both tracers in the same experimental rat tumor model using in vivo PET.

We evaluated the potential use of the heart 'outflow' ROI as "reference tissue" to avoid retro-orbital sampling of blood, a procedure which may cause radioactive contamination and which may interfere with the quality of life of the animals particularly when performed repeatedly. Moreover, the heart 'outflow' ROI was preferred as reference rather than muscle, since tracer uptake in muscle tissue might be sensitive to changes in oxygenation 
status $^{20}$. Lehtiö et al. also demonstrated a variable $\left[{ }^{18} \mathrm{~F}\right] \mathrm{FETNIM}$ muscle uptake which could be related to a variable muscle blood flow caused, for example, by patient stress during the imaging session $^{33}$. Our data demonstrate a strong correlation between the $\left[{ }^{18} \mathrm{~F}\right] \mathrm{EF} 3$ activity obtained by heart 'outflow' region with PET and by blood samples analysis with gamma-counting $\left(r^{2}=0.924 ; P<\right.$ $0.001)$. This validates the use of heart 'outlflow' as reference tissue to analyze whole blood ${ }^{18} \mathrm{~F}$ activity noninvasively, an approach which deserves attention in clinical PET examination.

$\left[{ }^{18} \mathrm{~F}\right] \mathrm{EF} 3$ biodistribution in all investigated normal tissues was fast and homogeneous. Our data agree with previous biodistribution studies performed in mice using $\left[{ }^{18} \mathrm{~F}\right] \mathrm{EF} 3^{28}$ and in rats using $\left[{ }^{18} \mathrm{~F}\right] \mathrm{EF} 5^{34}$. A progressive clearance of $\left[{ }^{18} \mathrm{~F}\right] \mathrm{EF} 3$ concentration with time was observed and the uptake in normal tissues was always lower than in the blood. This results in maintained $T / B$ ratios below 1 which is favorable for imaging purposes ${ }^{22}$. When comparing $\left[{ }^{18} \mathrm{~F}\right] \mathrm{EF} 3$ and $\left[{ }^{18} \mathrm{~F}\right] \mathrm{FMISO}$ normal tissue uptake, no statistical differences in $T / B$ ratios were observed, except for lung tissue.

Previous studies confirmed the use of both $\left[{ }^{18} \mathrm{~F}\right] \mathrm{FMISO}^{13,15}$ and $\left[{ }^{18} \mathrm{~F}\right] \mathrm{EF} 3^{32}$ to detect tumor hypoxia by comparison with established immunohistochemistry techniques. In the present study, we found that $\left[{ }^{18} \mathrm{~F}\right] \mathrm{EF} 3$ tumor to blood ratios were significantly lower than the corresponding $\left[{ }^{18} \mathrm{~F}\right] \mathrm{FMISO}$ tumor to blood ratios, when comparison was made at $2 \mathrm{~h}$ p.i. However, $\left[{ }^{18} \mathrm{~F}\right] \mathrm{EF} 3$ tumor to blood ratios increased with time, resulting in radioactivity levels at $4 \mathrm{~h}$ p.i. comparable with $\left[{ }^{18} \mathrm{~F}\right] \mathrm{FMISO}$ at $2 \mathrm{~h}$ p.i. This finding is comparable with the difference in rate of tracer binding in hypoxic tumor cells as well as with the faster $\left[{ }^{18} \mathrm{~F}\right] \mathrm{EF} 3$ clearance from blood. Even though the tumor to blood ratios for $\left[{ }^{18} \mathrm{~F}\right] \mathrm{EF} 3$ reached 
similar values to $\left[{ }^{18} \mathrm{~F}\right.$ FMISO but at a later time, this is probably not helpful since image quality will always be poorer at $4 \mathrm{~h}$ p.i. than at $2 \mathrm{~h}$ p.i. due to decay. Similar results were reported by other groups for $\mathrm{EF}^{28}$, but also for the 2-nitroimidazole analogues $\mathrm{EF} 1^{35}$ and $E F 5^{34}$. A possible explanation for the discrepancy between $\left[{ }^{18} \mathrm{~F}\right] \mathrm{EF} 3$ and $\left[{ }^{18} \mathrm{~F}\right] \mathrm{FMISO}$ tumor uptake could be the use of the anesthetic sodium pentobarbital, since this could cause substantial physiological changes in uptake. However, a recent study demonstrated that the structurally related phenobarbital did not affect the tumor to blood ratio $(P=0.27)$ in $\mathrm{C} 3 \mathrm{Hf} / \mathrm{kam}$ mice bearing syngeneic FSA II fibrosarcoma tumors ${ }^{36}$. Another, more plausible explanation would be the use of different PET scanners with inherent different resolution and sensitivity. However, phantom measurements were performed on both systems and correction factors were obtained and included in the reconstruction of the images. Therefore, we believe that the demonstrated discrepancy between $\left[{ }^{18} \mathrm{~F}\right] \mathrm{EF} 3$ and $\left[{ }^{18} \mathrm{~F}\right] \mathrm{FMISO}$ tumor uptake and following conclusions are still valid.

Some studies showed heterogeneity in larger tumors and a more uniform tracer distribution in smaller tumors ${ }^{12,} 20$. In a previous study, we showed, however, heterogeneity of $\left[{ }^{18} \mathrm{~F}\right] \mathrm{FMISO}$ uptake both in small and large rhabdomyosarcoma tumors ${ }^{13}$. The $\left[{ }^{18} \mathrm{~F}\right]$ FMISO-PET images demonstrated a clear heterogeneous tracer distribution in the tumors. The $\left[{ }^{18} \mathrm{~F}\right] \mathrm{EF} 3-\mathrm{PET}$ images, however, indicated a more homogeneous tracer distribution. To further investigate this phenomenon, we used autoradiography images with higher resolution to compare the $\left[{ }^{18} \mathrm{~F}\right] \mathrm{EF} 3$ and $\left[{ }^{18}\right.$ F]FMISO radioactivity uptake in tumors with similar size. The images demonstrated a heterogeneous distribution within all tumors for both tracers. For reasons of heterogeneity, we analyzed 
both the mean and the maximum activity uptake as done by Sorger et $\mathrm{al}^{23}$. We observed that the maximum $\left[{ }^{18} \mathrm{~F}\right] \mathrm{EF} 3 \mathrm{~T} / \mathrm{B}$ ratios increased faster over time than the mean T/B ratios. In addition, both mean and maximum ${ }^{18} \mathrm{~F}$-labelled hypoxia tracer uptake $\left(\left[{ }^{18} \mathrm{~F}\right] \mathrm{EF} 3\right.$ and $\left.\left[{ }^{18} \mathrm{~F}\right] \mathrm{FMISO}\right)$ were independent of the tumor volume. Experimental animal studies ${ }^{12,14,20}$ as well as clinical studies ${ }^{17-19,37}$ have demonstrated similar results using $\left[{ }^{18} \mathrm{~F}\right] \mathrm{FMISO}$. However, in our study $\left[{ }^{18} \mathrm{~F}\right] \mathrm{EF} 3$ uptake seemed to correlate better with tumor volume compared with $\left[{ }^{18} \mathrm{~F}\right] \mathrm{FMISO}$ uptake. Differences in lipophilicity compared with $\left[{ }^{18} \mathrm{~F}\right] \mathrm{FMISO}$ could not explain this better relationship, since both the uptake of the more hydrophilic hypoxia marker $\left[{ }^{18} \mathrm{~F}\right]$ FETNIM ${ }^{20}$ or the more lipophilic tracer $\mathrm{EF} 5^{38}$ has been shown to be independent of the tumor volume. Based on histological evaluation of tumor necrosis, we found a correlation between the tumor volume and NF with a clear significant separation in NF between tumors smaller and larger than $1 \mathrm{~cm}^{3}$. Although a statistical difference was observed between the NF of both groups, mean and maximum tracer uptake were also independent of the tumor volume when analyzing both groups separately. Also, in this case, $\left[{ }^{18} \mathrm{~F}\right] \mathrm{EF} 3$ uptake demonstrated a better correlation with tumor volume compared with $\left[{ }^{18} \mathrm{~F}\right] \mathrm{FMISO}$ uptake. The overall trend, however, indicates the use of maximum activity data, since Stadler et al. demonstrated that the maximum level of FMISO uptake is most closely related to the biological changes induced by the genomic instability associated with hypoxia and may reflect the severity of hypoxia ${ }^{39}$. In addition, it has been shown recently that FMISO maximum T/B ratios were highly predictive in a multivariate analysis ${ }^{17}$ and lead to an enhancement of the reproducibility of the measurements together with a reduced effect of the partial volume effects ${ }^{40}$. 


\section{Conclusion}

Using PET in an experimental rat model, we showed that $\left[{ }^{18} \mathrm{~F}\right] \mathrm{EF} 3$ is cleared slightly faster from the blood compared to the $\left[{ }^{18} \mathrm{~F}\right] \mathrm{FMISO}$ reference hypoxia marker. The maximum $\left[{ }^{18} \mathrm{~F}\right] \mathrm{EF} 3$ tumor uptake was significantly lower at $2 \mathrm{~h}$ p.i., but similar at $4 \mathrm{~h}$ p.i. compared with the $\left[{ }^{18} \mathrm{~F}\right] \mathrm{FMISO}$ uptake at $2 \mathrm{~h}$ p.i. Additionally, we showed a similarly fast and uniform distribution of both tracers in normal tissues and the intra-tumoral distribution was comparable. Finally, maximum activities should be used since it is shown that tumor uptake is heterogeneous and independent of the tumor volume. Based on the overall results, $\left[{ }^{18} \mathrm{~F}\right] \mathrm{EF} 3$ appears to be a potential in vivo tracer for the noninvasive detection and evaluation of tumor hypoxia, yet without being superior over $\left[{ }^{18} \mathrm{~F}\right]$ FMISO.

\section{Acknowledgements}

We appreciate the excellent and extensive support of all members of the PET and animal facilities of the KU Leuven and UCL Louvainla-Neuve. We also thank Ruud Houben for his statistical assistance. This work was supported by research grants from the "Fonds de la Recherche Scientifique Médicale" of Belgium (grants \#3.4571.95, 3.4610.99 and 3.4560.00), by grants from the "Fonds Joseph Maisin" of the Université catholique de Louvain and by the LSCHCT-2003-502932/Euroxy $6^{\text {th }}$ framework grant. 


\section{References}

1. Chapman J.D. The detection and measurement of hypoxic cells in solid tumors. Cancer, 1984. 54(11): p. 2441-9.

2. Vaupel P., Kallinowski F., and Okunieff P. Blood flow, oxygen and nutrient supply, and metabolic microenvironment of human tumors: a review. Cancer Res, 1989. 49(23): p. 6449-65.

3. Brizel D.M., Sibley G.S., Prosnitz L.R., et al. Tumor hypoxia adversely affects the prognosis of carcinoma of the head and neck. Int J Radiat Oncol Biol Phys, 1997. 38(2): p. 285-9.

4. Wouters B.G., Koritzinsky M., Chiu R.K., et al. Modulation of cell death in the tumor microenvironment. Semin Radiat Oncol, 2003. 13(1): p. 31-41.

5. Magagnin M.G., Koritzinsky M., and Wouters B.G. Patterns of tumor oxygenation and their influence on the cellular hypoxic response and hypoxia-directed therapies. Drug Resist Updat, 2006. 9(4-5): p. 185-97.

6. Nunn A., Linder K., and Strauss H.W. Nitroimidazoles and imaging hypoxia. Eur J Nucl Med, 1995. 22(3): p. 265-80.

7. Ballinger J.R. Imaging hypoxia in tumors. Semin Nucl Med, 2001. 31(4): p. 321-9.

8. Koh W.J., Rasey J.S., Evans M.L., et al. Imaging of hypoxia in human tumors with [F18]fluoromisonidazole. Int J Radiat Oncol Biol Phys, 1992. 22(1): p. 199-212.

9. Rasey J.S., Hofstrand P.D., Chin L.K., et al. Characterization of [18F]fluoroetanidazole, a new radiopharmaceutical for detecting tumor hypoxia. ] Nucl Med, 1999. 40(6): p. 1072-9.

10. Zanzonico P., O'Donoghue J., Chapman J.D., et al. Iodine-124-labeled iodoazomycin-galactoside imaging of tumor hypoxia in mice with serial microPET scanning. Eur J Nucl Med Mol Imaging, 2004. 31(1): p. 117-28.

11. Rasey J.S., Grunbaum Z., Magee $S_{\text {, }}$ et al. Characterization of radiolabeled fluoromisonidazole as a probe for hypoxic cells. Radiat Res, 1987. 111(2): p. 292304.

12. Bentzen L., Keiding S., Horsman M.R., et al. Assessment of hypoxia in experimental mice tumours by [18F]fluoromisonidazole PET and $\mathrm{pO} 2$ electrode measurements. Influence of tumour volume and carbogen breathing. Acta Oncol, 2002. 41(3): p. 304-12.

13. Dubois L., Landuyt W., Haustermans K., et al. Evaluation of hypoxia in an experimental rat tumour model by [(18)F]fluoromisonidazole PET and immunohistochemistry. Br J Cancer, 2004. 91(11): p. 1947-54.

14. Tochon-Danguy H.J., Sachinidis J.I., Chan F., et al. Imaging and quantitation of the hypoxic cell fraction of viable tumor in an animal model of intracerebral high grade glioma using [18F]fluoromisonidazole (FMISO). Nucl Med Biol, 2002. 29(2): p. 191-7.

15. Troost E.G., Laverman P., Kaanders J.H., et al. Imaging hypoxia after oxygenationmodification: comparing [18F]FMISO autoradiography with pimonidazole immunohistochemistry in human xenograft tumors. Radiother Oncol, 2006. 80(2): p. 157-64.

16. Gagel B., Reinartz P., Demirel C., et al. [18F] fluoromisonidazole and [18F] fluorodeoxyglucose positron emission tomography in response evaluation after chemo-/radiotherapy of non-small-cell lung cancer: a feasibility study. BMC Cancer, 2006. 6: p. 51.

17. Rajendran J.G., Schwartz D.L., O'Sullivan J., et al. Tumor hypoxia imaging with [F18] fluoromisonidazole positron emission tomography in head and neck cancer. Clin Cancer Res, 2006. 12(18): p. 5435-41.

18. Thorwarth D., Eschmann S.M., Holzner F., et al. Combined uptake of [18F]FDG and [18F]FMISO correlates with radiation therapy outcome in head-and-neck cancer patients. Radiother Oncol, 2006. 80(2): p. 151-6.

19. Zimny M., Gagel B., Dimartino E., et al. FDG-a marker of tumour hypoxia? A comparison with [(18)F]fluoromisonidazole and pO (2)-polarography in metastatic head and neck cancer. Eur J Nucl Med Mol Imaging, 2006.

20. Gronroos T., Bentzen L., Marjamaki P., et al. Comparison of the biodistribution of two hypoxia markers [18F]FETNIM and [18F]FMISO in an experimental mammary carcinoma. Eur J Nucl Med Mol Imaging, 2004. 31(4): p. 513-20.

21. Lehtio K., Eskola O., Viljanen T., et al. Imaging perfusion and hypoxia with PET to predict radiotherapy response in head-and-neck cancer. Int J Radiat Oncol Biol Phys, 2004. 59(4): p. 971-82.

22. Piert M., Machulla H.J., Picchio M., et al. Hypoxia-specific tumor imaging with $18 \mathrm{~F}-$ fluoroazomycin arabinoside. J Nucl Med, 2005. 46(1): p. 106-13. 
23. Sorger D., Patt M., Kumar P., et al. [18F]Fluoroazomycinarabinofuranoside (18FAZA) and [18F]Fluoromisonidazole (18FMISO): a comparative study of their selective uptake in hypoxic cells and PET imaging in experimental rat tumors. Nucl Med Biol, 2003. 30(3): p. 317-26.

24. Dewhirst M.W. Concepts of oxygen transport at the microcirculatory level. Semin Radiat Oncol, 1998. 8(3): p. 143-50.

25. Busch T.M., Hahn S.M., Evans S.M., et al. Depletion of tumor oxygenation during photodynamic therapy: detection by the hypoxia marker EF3 [2-(2-nitroimidazol$1[\mathrm{H}]-\mathrm{yl})-\mathrm{N}-(3,3,3$-trifluoropropyl)acetamide ]. Cancer Res, 2000. 60(10): p. 263642.

26. Koch C.J. Measurement of absolute oxygen levels in cells and tissues using oxygen sensors and 2-nitroimidazole EF5. Methods Enzymol, 2002. 352: p. 3-31.

27. Josse O., Labar D., Georges B., et al. Synthesis of [18F]-labeled EF3 [2-(2nitroimidazol-1-yl)-N-(3,3,3-trifluoropropyl)-acetamide], a marker for PET detection of hypoxia. Bioorg Med Chem, 2001. 9(3): p. 665-75.

28. Mahy P., De Bast M., Leveque P.H., et al. Preclinical validation of the hypoxia tracer 2-(2-nitroimidazol-1-yl)- N-(3,3,3-[(18)F]trifluoropropyl)acetamide, [(18)F]EF3. Eur ] Nucl Med Mol Imaging, 2004. 31(9): p. 1263-72.

29. Barendsen G.W. and Broerse J.J. Experimental radiotherapy of a rat rhabdomyosarcoma with $15 \mathrm{MeV}$ neutrons and $300 \mathrm{kV}$ x-rays. I. Effects of single exposures. Eur J Cancer, 1969. 5(4): p. 373-91.

30. Lim J.L. and Berridge M.S. An efficient radiosynthesis of [18F]fluoromisonidazole. Appl Radiat Isot, 1993. 44(8): p. 1085-91.

31. Bentzen L., Keiding S., Horsman M.R., et al. Feasibility of detecting hypoxia in experimental mouse tumours with $18 \mathrm{~F}$-fluorinated tracers and positron emission tomography--a study evaluating [18F]Fluoro-2-deoxy-D-glucose. Acta Oncol, 2000. 39(5): p. 629-37.

32. Mahy P., De Bast M., Gillart J., et al. Detection of tumour hypoxia: comparison between EF5 adducts and [(18)F]EF3 uptake on an individual mouse tumour basis. Eur J Nucl Med Mol Imaging, 2006. 33(5): p. 553-6.

33. Lehtio K., Oikonen V., Nyman S., et al. Quantifying tumour hypoxia with fluorine-18 fluoroerythronitroimidazole ([18F]FETNIM) and PET using the tumour to plasma ratio. Eur J Nucl Med Mol Imaging, 2003. 30(1): p. 101-8.

34. Ziemer L.S., Evans S.M., Kachur A.V., et al. Noninvasive imaging of tumor hypoxia in rats using the 2-nitroimidazole 18F-EF5. Eur J Nucl Med Mol Imaging, 2003. 30(2): p. 259-66.

35. Evans S.M., Kachur A.V., Shiue C.Y., et al. Noninvasive detection of tumor hypoxia using the 2-nitroimidazole [18F]EF1. J Nucl Med, 2000. 41(2): p. 327-36.

36. Christian N., Bol A., De Bast M., et al. Determination of tumour hypoxia with the PET tracer [18F]EF3: improvement of the tumour-to-background ratio in a mouse tumour model. Eur J Nucl Med Mol Imaging, 2007. 34(9): p. 1348-54.

37. Rajendran J.G., Wilson D.C., Conrad E.U., et al. [(18)F]FMISO and [(18)F]FDG PET imaging in soft tissue sarcomas: correlation of hypoxia, metabolism and VEGF expression. Eur J Nucl Med Mol Imaging, 2003. 30(5): p. 695-704.

38. Skov K., Adomat H., Bowden M., et al. Hypoxia in the androgen-dependent Shionogi model for prostate cancer at three stages. Radiat Res, 2004. 162(5): p. 547-53.

39. Stadler P., Becker A., Feldmann H.J., et al. Influence of the hypoxic subvolume on the survival of patients with head and neck cancer. Int J Radiat Oncol Biol Phys, 1999. 44(4): p. 749-54.

40. Hutchings M., Loft A., Hansen M., et al. Different histopathological subtypes of Hodgkin lymphoma show significantly different levels of FDG uptake. Hematol Oncol, 2006. 24(3): p. 146-50. 


\section{Chapter 4}

Preclinical evaluation of $\left[{ }^{18} \mathrm{~F}\right] \mathrm{HX} 4$, a novel promising hypoxia marker for PET imaging

Dubois L, Lieuwes NG, Janssen MHM, Secrest J, Windhorst $A D$, van Dongen GAMS, Kolb $H$, Oellers $M C$, Zhang J, Lambin $\mathrm{P}$

In preparation

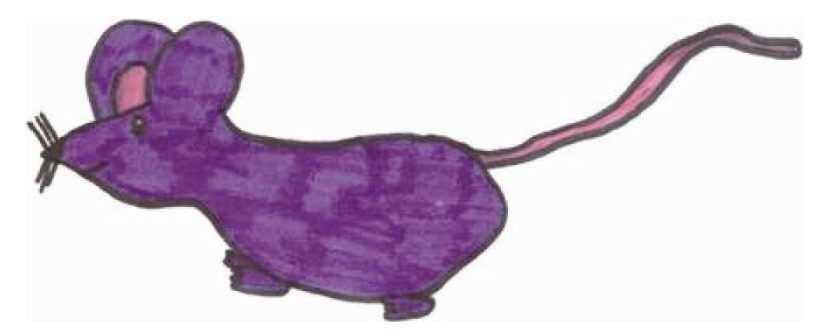




\begin{abstract}
Backgound and Purpose: Hypoxia has been shown to be an important micro-environmental parameter influencing tumor progression and treatment efficacy. Patient guidance for hypoxiatargeted therapy requires evaluation of tumor oxygenation, preferably in a noninvasive manner. The aim of this study was to evaluate the uptake of $\left[{ }^{18} \mathrm{~F}\right] \mathrm{HX} 4$, a recently developed hypoxia marker for PET imaging, over time in animal and human tumor models. $\left[{ }^{18} \mathrm{~F}\right] \mathrm{HX} 4$ tumor to blood ratios were furthermore compared with uptake of already validated noninvasive hypoxia markers: $\left[{ }^{18} \mathrm{~F}\right] \mathrm{FMISO}$ and $\left[{ }^{18} \mathrm{~F}\right] \mathrm{FAZA}$.

Material and Methods: WAG/Rij rats bearing rhabdomyosarcoma tumors and BxPC-3, A-427, U-87 MG, NCI-H2122 or A-431 tumorbearing Foxn1-nu (nu/nu) mice were injected intravenously with $\left[{ }^{18} \mathrm{~F}\right] \mathrm{HX} 4$ and PET images were acquired when animals were exposed to normal air, $7 \%$ oxygen or a combination of nicotinamide and carbogen. Accumulation of $\left[{ }^{18} \mathrm{~F}\right] \mathrm{HX} 4$ in selected tissues was quantified up to $6 \mathrm{~h}$ after injection and expressed as $\% \mathrm{ID} / \mathrm{ml}$.

Results: $\left[{ }^{18} \mathrm{~F}\right] \mathrm{HX} 4$ accumulation in the rat tumor model was found to be significantly $(P<0.0001)$ higher compared to the surrounding tissues with increased tumor to blood ratios over time, reaching a plateau $4 \mathrm{~h}$ after injection with a maximum tumor to blood ratio of $7.6 \pm 3.8$. Combination treatment of nicotinamide and carbogen significantly $(P<0.001)$ reduced $\left[{ }^{18} \mathrm{~F}\right] \mathrm{HX} 4$ accumulation in the tumor. Treating the animals with $7 \%$ oxygen breathing, to increase tumor hypoxia, resulted in a significant $(P<$ 0.05 ) increased uptake. Furthermore, $\left[{ }^{18} \mathrm{~F}\right] \mathrm{HX} 4$ accumulation in the human tumor models demonstrated a clear increase with time $(P=$ 0.019). Although all investigated tracers demonstrated a clear
\end{abstract}


increased tumor uptake with time, no significant differences in uptake were observed compared with $\left[{ }^{18} \mathrm{~F}\right] \mathrm{HX} 4$. However, when comparing normal tissue uptake between the hypoxia tracers, $\left[{ }^{18} \mathrm{~F}\right] \mathrm{HX} 4$ accumulation was found to be cleared faster from normal muscle tissues.

Conclusion: $\left[{ }^{18} \mathrm{~F}\right] \mathrm{HX} 4$ proved to be a good in vivo tracer for the noninvasive detection and evaluation of tumor hypoxia, with optimal imaging properties $4 \mathrm{~h}$ after injection. $\left[{ }^{18} \mathrm{~F}\right] \mathrm{HX} 4$ is able to better visualize tumor heterogeneity and is cleared faster from normal tissues, indicating to be a better alternative for hypoxia assessment when compared to the already known PET hypoxia markers. 


\section{Introduction}

The presence of low oxygen regions, also called hypoxia, heterogeneously spread within solid tumors has a major impact on the efficacy of conventional cancer treatment modalities. These hypoxic regions are due to the unusual, chaotic and insufficient organization of normal tumor vasculature ${ }^{1}$ and influence the clinical outcome, where it is an independent predictor of poor prognosis-free survival in several types of cancer ${ }^{2}, 3$. In contrary, this unique tumor micro-environment characteristic makes it an attractive target for newly developed drugs to increase the therapeutic effect of conventional cancer treatment modalities ${ }^{4}$. Another approach to increase the treatment outcome is the use of intensity modulated radiotherapy to give a higher dose to the hypoxic subvolume while sparing the surrounding normal structures $^{5}$. Although treatments to counteract the negative effect of intra-tumoral hypoxia are under investigation ${ }^{6}$, not all patients benefit from such selective treatments. Therefore, in order to guide hypoxia-directed therapies in individual patients, it is important to evaluate tumor oxygenation, using a reliable noninvasive method.

To date, a variety of methods are available for the assessment of tumor oxygenation in solid tumors ${ }^{7}$ and during the last decade, research has been focused on noninvasive imaging techniques, such as positron emission tomography (PET). The 2-nitroimidazole derivative fluoromisonidazole (FMISO) has been radiolabeled with $\left[{ }^{18} \mathrm{~F}\right]^{8}$ and evaluated extensively both preclinically ${ }^{9},{ }^{10}$ and clinically ${ }^{11-13}$ for different cancer types. The clinical potential of $\left[{ }^{18}\right.$ F]FMISO PET imaging might be limited since the uptake of $\left[{ }^{18} \mathrm{~F}\right] \mathrm{FMISO}$ in hypoxic lesions is not optimal due to the hydrophilicity of the compound. Other ${ }^{18} \mathrm{~F}$-labeled 2- 
nitroimidazoles, such as $\left[{ }^{18} \mathrm{~F}\right] \mathrm{FAZA}$ have been validated as hypoxia marker ${ }^{14}$, but being even more hydrophilic compared with $\left[{ }^{18} \mathrm{~F}\right.$ FMISO, its diffusion into tumoral tissue might be hampered ${ }^{15}$. On the other hand, more lipophilic fluorinated compounds, such as EF3, could be a good alternative for the detection of tumor hypoxia ${ }^{16}$. However, in a comparative PET imaging study using an experimental rat model, our group demonstrated no superiority of $\left[{ }^{18} \mathrm{~F}\right]$ EF3 to $\left[{ }^{18} \mathrm{~F}\right] \mathrm{FMISO}$ for the evaluation of hypoxia ${ }^{17}$.

Alternatively, the 2-nitroimidazole nucleoside analogue, 3$\left[{ }^{18} \mathrm{~F}\right]$ fluoro-2-(4-((2-nitro-1H-imidazol-1-yl)methyl)-1H-1,2,3-triazol-1-yl)propan-1-ol $\left(\left[{ }^{18} \mathrm{~F}\right] \mathrm{HX} 4\right)$, was developed and investigated as a potential marker for hypoxic tumor cells. Because of the better water solubility and faster clearance, we hypothesize that $\left[{ }^{18} \mathrm{~F}\right] \mathrm{HX} 4$ will have a higher tumor to background signal ratio. The aim of this study was to evaluate the in vivo hypoxia-dependent uptake of $\left[{ }^{18} \mathrm{~F}\right] \mathrm{HX} 4$ over time in experimental rat and mouse tumor models by noninvasive PET imaging. Furthermore $\left[{ }^{18} \mathrm{~F}\right] \mathrm{HX} 4$ tumor to blood ratios were quantitatively compared with uptake of the already validated noninvasive hypoxia markers $\left[{ }^{18} \mathrm{~F}\right] \mathrm{FMISO}$ and $\left[{ }^{18}\right.$ F]FAZA.

\section{Materials and Methods}

Animal and tumor model

Animal experiments were performed using adult WAG/Rij male rats and Foxn1-nu (nu/nu) athymic female mice with a respective average body weight of 275 and $30 \mathrm{~g}$. All procedures were performed according to the guidelines defined in "Principles of laboratory animal care" (NIH publication no. 86-23, revised 1985) and were approved by the Animal Ethical Committee of the 
University of Maastricht. The animal facilities were in accordance with local institutional guidelines for animal welfare. Food and water were provided ad libitum to all animals for the duration of the experiments. The rats were implanted subcutaneously with syngeneic rhabdomyosarcomas (1- $\mathrm{mm}^{3} \mathrm{R} 1$ tumors), in the lateral flank. Exponentially growing human BxPC-3 (ATCC CRL-1687) pancreatic, A-427 (ATCC HTB-53) lung, U-87 MG (ATCC HTB-14) glioblastoma, NCI-H2122 (ATCC CRL-5985) non-small-cell lung or A-431 (ATCC CRL-1555) epidermoid carcinoma cells were resuspended in Basement Membrane Matrix (Matrigel ${ }^{\mathrm{TM}} \mathrm{BD}$ Biosciences) and were injected subcutaneously in the lateral flank of the mice. Tumors were measured using a Vernier calliper, in three orthogonal tumor diameters A, B and C, each corrected for the thickness of the skin, and volumes were calculated using the formula $A \times B \times C \times \pi / 6$.

\section{Synthesis of the hypoxia markers}

3- $\left[{ }^{18} \mathrm{~F}\right]$ fluoro-2-(4-((2-nitro-1H-imidazol-1-yl)methyl)-1H-1,2,3-triazol-1-yl)propan-1-ol $\left(\left[{ }^{18} \mathrm{~F}\right] \mathrm{HX} 4\right)$ was synthesized from the $3-$ (formyloxy)-2-\{4-[(2-nitro-1H-imidazol-1-yl)methyl]-1H-1,2,3-triazol-1-yl\}propyl 2-nitrobenzenesulfonate (HX4) supplied by Siemens Molecular Imaging (Culver City, California, USA). The first step included a nucleophilic substitution 2-nitrobenzenesulfonic acid with $\left[{ }^{18} \mathrm{~F}\right]$ fluoride followed by hydrolysis to obtain the active drug product. The HPLC isolated $\left[{ }^{18} \mathrm{~F}\right] \mathrm{HX} 4$ fractions demonstrated a radiochemical purity which was always higher than 95\%. Specific activity was typically in the range of $24 \mathrm{GBq} / \mu \mathrm{mol}$. $\left[{ }^{18} \mathrm{~F}\right] \mathrm{FMISO}$, $\left[{ }^{18} \mathrm{~F}\right] \mathrm{EF} 3,\left[{ }^{18} \mathrm{~F}\right] \mathrm{FAZA}$ and $\left[{ }^{18} \mathrm{~F}\right] \mathrm{FRP}-170$ were produced as previously described $^{14,17,18}$. 


\section{Experimental design}

Nicotinamide (Sigma-Aldrich) was injected intraperitoneally at a concentration of $500 \mathrm{mg} / \mathrm{kg} 50$ minutes prior injection of $\left[{ }^{18} \mathrm{~F}\right] \mathrm{HX} 4$. For carbogen $\left(95 \% \mathrm{O}_{2}, 5 \% \mathrm{CO}_{2}\right)$ and $7 \%$ oxygen (residual $\mathrm{N}_{2}$ ) breathing, animals were placed in an induction chamber with a continuous flow of $5 \mathrm{l} / \mathrm{min}$ for respectively 30 and 50 minutes before administration of $\left[{ }^{18} \mathrm{~F}\right] \mathrm{HX} 4$. Prior to and during PET acquisition, rats were anesthetized with sodium pentobarbital at a dose of $0.1 \mathrm{ml} 100 \mathrm{~g}^{-1}$ body weight, injected intraperitoneally. The radiolabeled tracer was administrated via an intravenous line (Venoflux $0.4 \mathrm{~mm} \mathrm{G.27;} \mathrm{Vygon,} \mathrm{France)} \mathrm{inserted} \mathrm{into} \mathrm{a} \mathrm{lateral} \mathrm{tail}$ vein, flushed with diluted heparin saline solution. During PET acquisition, anesthesia was maintained using individual ratadapted subcutaneous injections (10 - 30\% of the initial dose) of the anesthetic, as needed. Mice were anesthetized using isoflurane (flow $2-2.5 \mathrm{l} / \mathrm{min}$ ) and the radioactive tracer was injected directly into a lateral tail vein.

\section{Rat imaging acquisition}

Rat imaging was performed using a dedicated PET/CT Biograph ${ }^{\mathrm{TM}}$ scanner (SOMATOM TruePoint Sensation-40 with an ECAT ACCEL PET scanner, Siemens, CTI Knoxville) with an axial field of view (FoV) of $162 \mathrm{~mm}$, a transaxial FoV of $605 \mathrm{~mm}$ and a spatial resolution of $5.3 \mathrm{~mm}$ full-width at half-maximum (FWHM) at the centre of the field of view. The acquired CT images were used for attenuation correction of the PET data. Also, the acquired PET data were corrected for scatter (3D), randoms, deadtime and decay of the injected radionuclides. Before starting the acquisition, rats were placed in a polystyrene box which was positioned in the opening of the camera. After acquiring a topogram, a whole-body 
CT-scan covering the rat from neck to tail (approximately 165 $\mathrm{mm}$ ) was acquired using a $1 \mathrm{~mm}$ reconstructed slice thickness and a pitch of 0.8 . Simultaneously with tracer injection into a lateral tail vein (20.43 $\pm 2.42 \mathrm{MBq}$ ), a dynamic emission scan (26 frames) in list-mode (LM) was started for 60 min in 1 bed position encompassing the heart, tumor and hind leg muscle of the rat. Afterwards, LM data were rebinned using Fourier rebinning and PET images were reconstructed using 2D Ordered Subset Expectation Maximization (OSEM 2D) with 4 iterations, 8 subsets, a 5 $\mathrm{mm}$ Gaussian filter and according to the following time frames: $8 \times 15 \mathrm{~s}, 4 \times 30 \mathrm{~s}, 2 \times 1 \mathrm{~min}, 2 \times 2 \mathrm{~min}, 10 \times 5 \mathrm{~min}^{10}$. Two hours post injection (p.i.), the rats were carefully repositioned using external markers on the polystyrene box and a dedicated laser positioning system (LAP GmbH, Lüneburg, Germany) in the scanner for a CTscan, immediately followed by a second dynamic emission scan performed for $20 \mathrm{~min}$ (rebinned into 4 frames of $5 \mathrm{~min}$ each). The same sequence was repeated each hour until $6 \mathrm{~h}$ p.i.

\section{Mouse imaging acquisition}

Mouse imaging was done using an Inveon dedicated PET scanner (Siemens, MIBR, CA, USA) with an AFOV of $7.5 \mathrm{~cm}$ and a spatial resolution below $1.8 \mathrm{~mm}$ at FWHM at the centre of the field of view. Whole body emission scanning was performed for $15 \mathrm{~min}$ at 1 and $2 \mathrm{~h}$ after tracer injection $\left(5.95 \pm 1.85 \mathrm{MBq}\left[{ }^{18} \mathrm{~F}\right] \mathrm{HX} 4 ; 6.70 \pm\right.$ $0.90 \mathrm{MBq}\left[{ }^{18} \mathrm{~F}\right] \mathrm{FMISO} ; 6.02 \pm 1.42 \mathrm{MBq}\left[{ }^{18} \mathrm{~F}\right] \mathrm{FAZA}$ or $6.22 \pm 1.44$ $\left.\mathrm{MBq}\left[{ }^{18} \mathrm{~F}\right] \mathrm{FRP}-170\right)$. The images were reconstructed iteratively (OSEM 3D with 2 iterations and 16 subsets) in a $128 \times 128 \times 159$ matrix followed by MAP (18 iterations). Images were also corrected for deadtime, frame duration and decay to the start of 
each emission scan. No attenuation and scatter correction was performed.

PET image analysis

The reconstructed rat PET and CT images were viewed and analyzed in dedicated software (TrueD VC50, Siemens, Erlangen, Germany). PET and CT images were automatically registered based on a Mutual Information algorithm. Reconstructed mouse images were visualized using ASIPro VM software (version 6.3.3.0.; Concorde Microsystems Inc.). Activity data ( $\mathrm{Bq} / \mathrm{ml})$ in tumor, muscle and blood pool (heart) were obtained by drawing a volume of interest (VOI) on the CT images of the fused PET-CT data for the rat acquistions and on the PET images for the mouse experiments. All activity data were corrected for fluorine-18 decay towards injection time and to minimize partial volume effects, recovery coefficients were calculated ${ }^{19}$ and applied on all the data. Quantification of the data was done by calculation of the percentage of injected radioactivity per $\mathrm{ml}(\% \mathrm{ID} / \mathrm{ml})$ and the tissue to blood (T/B) or tissue to muscle (T/M) activity ratios.

\section{Statistics}

All statistical analyses were performed with GraphPad Prism version 5.01 for Windows (GraphPad software, 2007, CA, USA). An unpaired student's $t$-test and non-parametric Mann-Whitney $U$ test for small groups were used to determine the statistical significance of differences between two independent groups of variables. For all tests, a $P<0.05$ was considered significant. 


\section{Results}

Accumulation of $\left[{ }^{18} \mathrm{~F}\right] \mathrm{HX} 4$ in an experimental rat tumor model

To evaluate the potential of $\left[{ }^{18} \mathrm{~F}\right] \mathrm{HX} 4$ as a noninvasive marker of hypoxia, an experimental rat tumor model was used to obtain more clinically relevant tumor volumes $\left(12.89 \pm 5.10 \mathrm{~cm}^{3}\right)$.
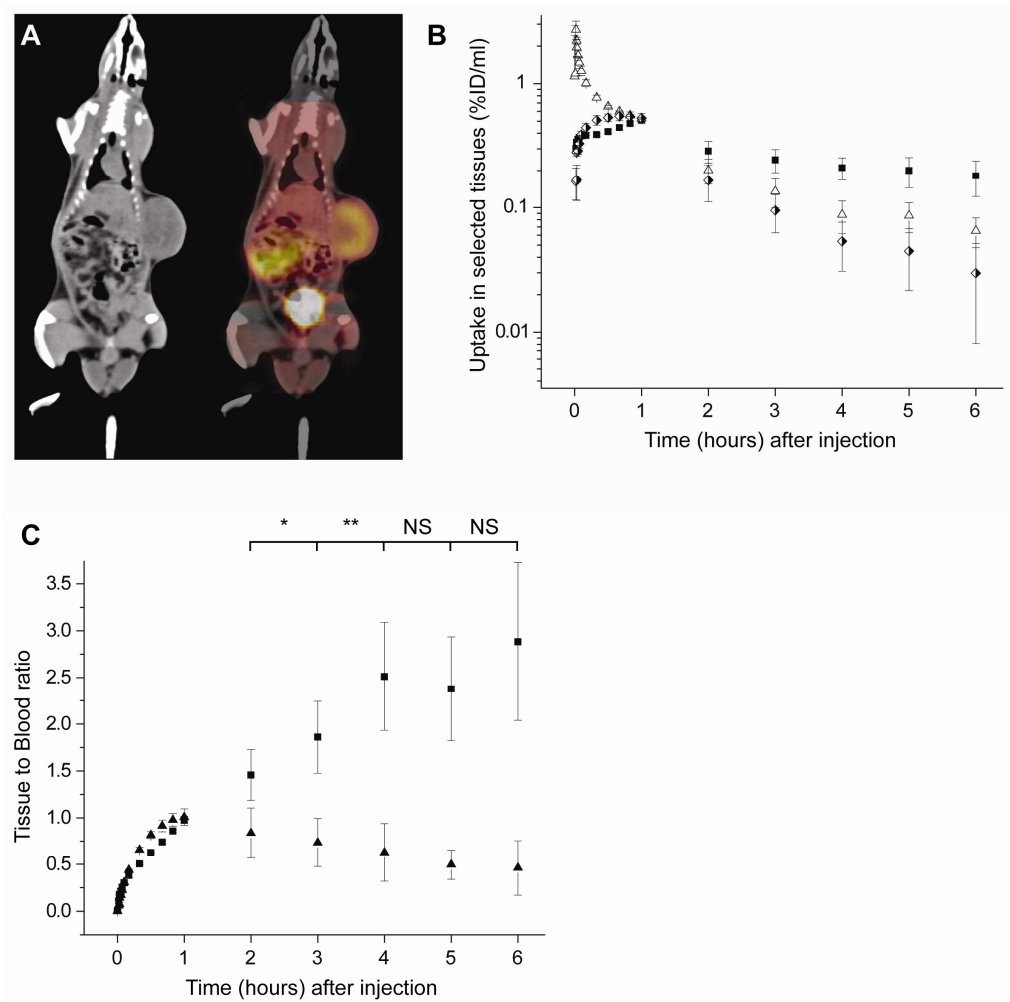

Figure 1. (A) Representative CT and PET/CT image of rhabdomyosarcoma $\mathrm{R} 1$ tumor-bearing rat $2 \mathrm{~h}$ after injection of $\left[{ }^{18} \mathrm{~F}\right] \mathrm{HX} 4$. (B) Quantification of $\left[{ }^{18} \mathrm{~F}\right] \mathrm{HX} 4$ uptake up to $6 \mathrm{~h}$ after injection. Mean uptake data $(n=17)$ for tumor (squares), heart (triangles), and muscles from the hind legs (diamonds) are shown and data are expressed as mean \pm SD $\% \mathrm{ID} / \mathrm{ml}$. (C) Tissue to blood ratios of $\left[{ }^{18} \mathrm{~F}\right] \mathrm{HX} 4$ uptake up to $6 \mathrm{~h}$ after injection. Ratios represent mean tumor (squares) and mean muscle (triangles) uptake divided by mean heart uptake. Data are expressed as mean \pm SD. Asteriks indicate significant increase in tumor to blood ratios between individual time points $(* P<0.01 ; * * P<0.001)$.NS, not significant. 
The in vivo uptake of $\left[{ }^{18} \mathrm{~F}\right] \mathrm{HX} 4$ was assessed by performing PET-CT imaging at several time points after injection of $20.43 \pm 2.42 \mathrm{MBq}$ $\left[{ }^{18} \mathrm{~F}\right] \mathrm{HX} 4$. A clear accumulation of $\left[{ }^{18} \mathrm{~F}\right] \mathrm{HX} 4$ with time was observed in the tumor (Fig. 1A), whereas equal $\left[{ }^{18} \mathrm{~F}\right] \mathrm{HX} 4$ activities were found in surrounding normal tissues. Furthermore, a high accumulation of $\left[{ }^{18} \mathrm{~F}\right] \mathrm{HX} 4$ was found in the bladder confirming the renal clearance of $\left[{ }^{18} \mathrm{~F}\right] \mathrm{HX} 4$. Quantification of $\left[{ }^{18} \mathrm{~F}\right] \mathrm{HX} 4$ accumulation was done in selected tissues, by VOI analysis of the heart, hind leg muscles and tumor. The heart was selected as reference tissue to noninvasively analyze whole-blood ${ }^{18} \mathrm{~F}$ activity, as previously shown ${ }^{17}$. Mean $\left[{ }^{18} \mathrm{~F}\right] \mathrm{HX} 4$ activities in tumor and muscle tissue were comparable $(P=0.619)$ during the first hour after $\left[{ }^{18} \mathrm{~F}\right] \mathrm{HX} 4$ injection (Fig. 1B), while the activity in the blood pool was found to be significantly higher $(P<0.001)$. From $2 \mathrm{~h}$ p.i. onwards, we observed a significant $(P<0.0001)$ faster clearance of $\left[{ }^{18} \mathrm{~F}\right] \mathrm{HX} 4$ from the blood and muscle when compared with the tumor. This resulted in a significant $(P<0.001)$ increase in mean tumor to blood (T/B) ratios until $4 \mathrm{~h}$ p.i., where a mean $T / B$ of $2.512 \pm 0.578$ was reached (Fig. 1C). No further increase was observed for later time points, making $4 \mathrm{~h}$ after injection an optimal time point for $\left[{ }^{18} \mathrm{~F}\right] \mathrm{HX} 4$ evaluation in tumors. Since tumors are known to be heterogeneous, we also analyzed the maximum T/B signal ratios and found a similar pattern of increase, with a maximum of $7.638 \pm 3.816$ at $4 \mathrm{~h}$ post injection (Table 1 ). Furthermore, a progressive clearance from normal tissues was observed since muscle to blood (M/B) ratios gradually decreased with time, resulting is significant $(P<0.05)$ lower $M / B$ ratios from $4 \mathrm{~h}$ p.i. on. Both mean and maximum $\left[{ }^{18} \mathrm{~F}\right] \mathrm{HX} 4$ uptake $(\% \mathrm{ID} / \mathrm{ml})$ was independent of the tumor volume $\left(r^{2}<0.05 ; P>0.4\right)$ for all investigated time points (data not shown). 
Comparative analysis with other radiolabeled hypoxia markers

Previously, we demonstrated in a comparative study that the more lipophilic $\left[{ }^{18} \mathrm{~F}\right] \mathrm{EF} 3$ hypoxia marker presented a similarly fast and uniform distribution in normal tissues as $\left[{ }^{18} \mathrm{~F}\right] \mathrm{FMISO}$ and that the tumor uptake reached similar levels, although at different time points ${ }^{17}$. Compared with these $\left[{ }^{18} \mathrm{~F}\right] \mathrm{EF} 3$ activities, uptake of $\left[{ }^{18} \mathrm{~F}\right] \mathrm{HX} 4$ in general was lower $(P<0.001)$, both in normal as in tumor tissue (Table 1 ). Mean T/B ratios were comparable for both hypoxia markers at all investigated time points, while maximum $\mathrm{T} / \mathrm{B}$ ratios for $\left[{ }^{18} \mathrm{~F}\right] \mathrm{HX} 4$ were significantly higher $(P<0.01)$, suggesting that heterogeneity of the tumor could be better assessed using $\left[{ }^{18} \mathrm{~F}\right] \mathrm{HX} 4$. M/B ratios were similar for both at $2 \mathrm{~h}$ p.i., but while $\left[{ }^{18} \mathrm{~F}\right] \mathrm{EF} 3 \mathrm{M} / \mathrm{B}$ ratios remained equal with time ${ }^{17}$, $\left[{ }^{18} \mathrm{~F}\right] \mathrm{HX} 4$ ratios decreased indicative for a faster clearance from normal tissues compared with $\left[{ }^{18} \mathrm{~F}\right] \mathrm{EF} 3$.

Table 1. Mean and maximum $\left[{ }^{18} \mathrm{~F}\right] \mathrm{HX} 4$ activity uptake $(\% \mathrm{ID} / \mathrm{ml})$ with corresponding tissue to blood ratios for rhabdomyosarcoma bearing rats

\begin{tabular}{|c|c|c|c|c|c|c|c|c|}
\hline & \multicolumn{5}{|c|}{$[18 \mathrm{~F}] \mathrm{HX}-4$} & \multicolumn{3}{|c|}{ [18F]EF3 } \\
\hline & 2h p.i. & 3h p.i. & 4h p.i. & 5 h p.i. & 6h p.i. & 2h p.i. & 3h p.i. & 4h p.i. \\
\hline \multicolumn{9}{|l|}{$\% \mid \mathrm{D} / \mathrm{ml}$} \\
\hline Muscle & $0.186 \pm 0.054$ & $0.095 \pm 0.032$ & $0.054 \pm 0.023$ & $0.045 \pm 0.023$ & $0.030 \pm 0.022$ & $0.405 \pm 0.087$ & $0.301 \pm 0.072$ & $0.231 \pm 0.073$ \\
\hline Blood & $0.201 \pm 0.046$ & $0.135 \pm 0.035$ & $0.088 \pm 0.026$ & $0.086 \pm 0.023$ & $0.065 \pm 0.018$ & $0.477 \pm 0.083$ & $0.354 \pm 0.099$ & $0.271 \pm 0.088$ \\
\hline Tumor mean & $0.287 \pm 0.057$ & $0.244 \pm 0.052$ & $0.210 \pm 0.042$ & $0.200 \pm 0.054$ & $0.181 \pm 0.058$ & $0.948 \pm 0.223$ & $0.877 \pm 0.184$ & $0.808 \pm 0.198$ \\
\hline Tumor max & $0.694 \pm 0.220$ & $0.628 \pm 0.211$ & $0.633 \pm 0.279$ & $0.638 \pm 0.364$ & $0.571 \pm 0.236$ & $1.577 \pm 0.345$ & $1.624 \pm 0.324$ & $1.507 \pm 0.336$ \\
\hline Muscle/blood & $0.837 \pm 0.268$ & $0.735 \pm 0.258$ & $0.629 \pm 0.308$ & $0.497 \pm 0.156$ & $0.462 \pm 0.292$ & $0.853 \pm 0.157$ & $0.862 \pm 0.109$ & $0.859 \pm 0.116$ \\
\hline \multicolumn{9}{|l|}{ Tumor/blood } \\
\hline mean & $1.456 \pm 0.270$ & $1.860 \pm 0.385$ & $2.512 \pm 0.578$ & $2.378 \pm 0.557$ & $2.883 \pm 0.844$ & $1.770 \pm 0.301$ & $2.133 \pm 0.350$ & $2.497 \pm 0.485$ \\
\hline $\max$ & $3.516 \pm 1.118$ & $4.841 \pm 1.756$ & $7.638 \pm 3.816$ & $7.588 \pm 4.204$ & $9.491 \pm 4.957$ & $2.952 \pm 0.541$ & $3.992 \pm 0.878$ & $4.723 \pm 1.212$ \\
\hline
\end{tabular}

$\left[{ }^{18} \mathrm{~F}\right] \mathrm{HX} 4$ accumulation is dependent on available oxygen

To test this hypothesis, we used two short-term treatments to modify tumor oxygenation. To increase or decrease tumor hypoxia, animals were exposed to an environment containing respectively 
$7 \%$ oxygen or a combination of nicotinamide and carbogen. No adverse effects were observed for both treatment regimens. First, a basal $\left[{ }^{18} \mathrm{~F}\right] \mathrm{HX} 4$ acquisition was performed on tumor bearing $\left(13.03 \pm 5.15 \mathrm{~cm}^{3}\right)$ animals breathing normal air.
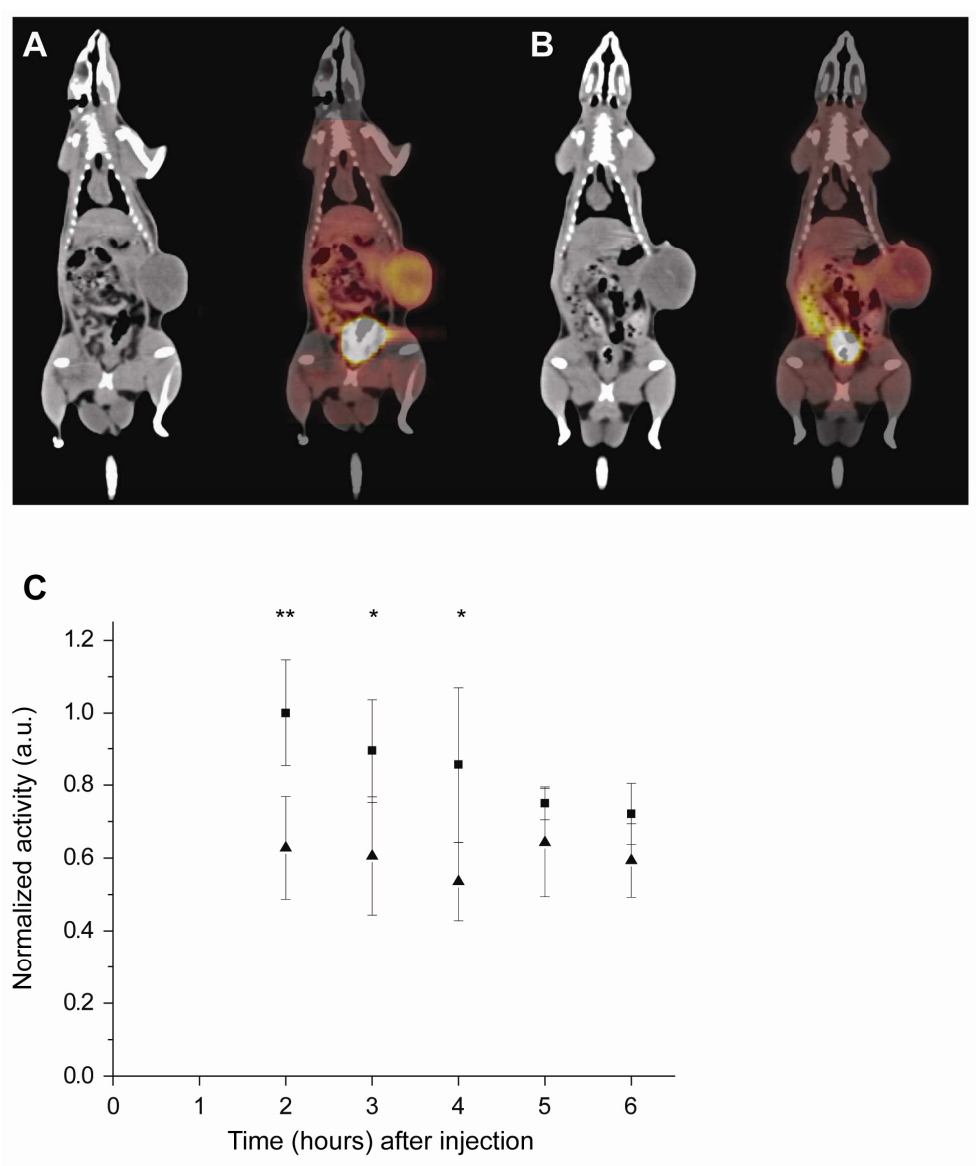

Figure 2. Representative $C T$ and $P E T / C T$ images within the same animal 2 $h$ after injection of $\left[{ }^{18} \mathrm{~F}\right] \mathrm{HX} 4$ before $(A)$ and after $(B)$ treatment (interval of 2 days) with a combination of nicotinamide and carbogen. Images are scaled to the maximum intensity values of all images. (C) Quantification of maximum $\left[{ }^{18} \mathrm{~F}\right] \mathrm{HX} 4$ uptake in animals $(n=7)$ treated with nicotinamide and carbogen (triangles) compared to no treatment (squares) at several time points. Data are expressed as mean \pm SD. Asteriks indicate significant difference $(* P<0.01 ; * * P<0.001)$ compared to no treatment. 
Two days later (tumor volume $15.88 \pm 6.22 \mathrm{~cm}^{3}$ ), animals were randomized into two treatment groups and $\left[{ }^{18} \mathrm{~F}\right] \mathrm{HX} 4$ accumulation was compared with the basal uptake. Maximum $\left[{ }^{18} \mathrm{~F}\right] \mathrm{HX} 4$ uptake in the same animal was found to be significantly lower (approximately 40\%; $P<0.001$ ) after treatment with a combination of nicotinamide and carbogen (Fig. 2A). This reduced $\left[{ }^{18} \mathrm{~F}\right] \mathrm{HX} 4$ accumulation persisted over time until $4 \mathrm{~h}$ after injection (Fig. 2B) and was lost at later time points. Also the mean $\left[{ }^{18} \mathrm{~F}\right] \mathrm{HX} 4$ uptake was significantly lower $(P<0.01)$ after treatment, but to a smaller extent $(25 \%)$. Furthermore, no significant differences in $\left[{ }^{18} \mathrm{~F}\right] \mathrm{HX} 4$ accumulation were observed after treating the animals with a combination of nicotinamide and carbogen for blood and muscle tissue (Table 2), indicating that normal tissues can indeed cope with changes in oxygenation.

Table 2. [18F]HX4 activity uptake (\%ID/ml) before and after treatment with $7 \%$ oxygen or a combination of nicotinamide and carbogen

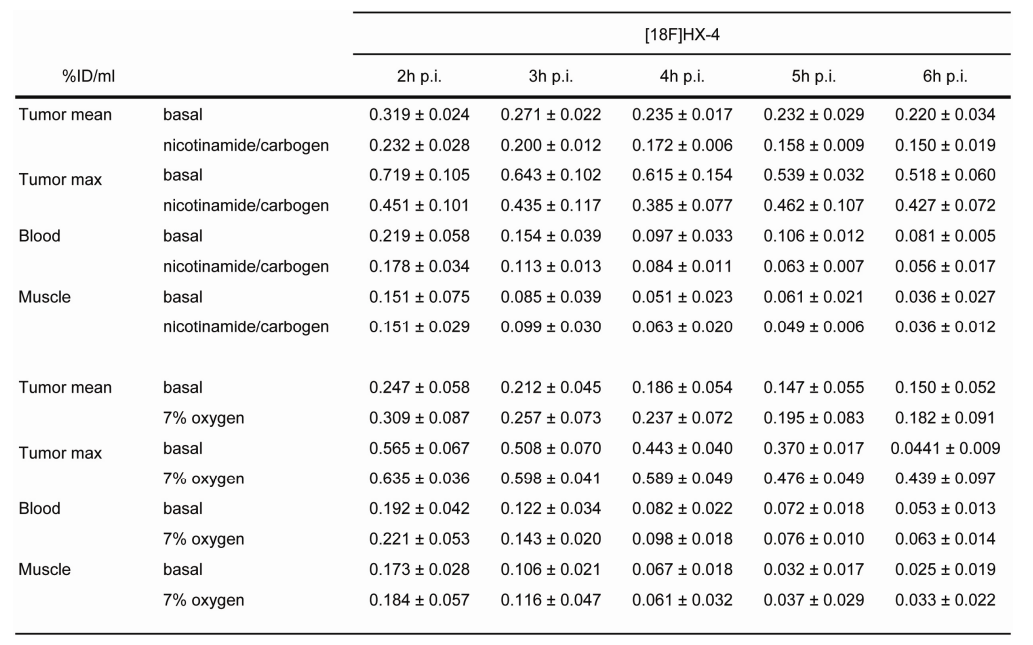

On the other hand, when animals were treated with 7\% oxygen, a significant increase (approximately $20 \% ; P<0.05$ ) in maximum 
$\left[{ }^{18} \mathrm{~F}\right] \mathrm{HX} 4$ uptake in the tumor was observed (Fig. 3A), persisting over time (Fig. 3B). Similarly with the combination treatment of nicotinamide and carbogen, the effect of $7 \%$ oxygen breathing on normal tissues was negligible (Table 2).
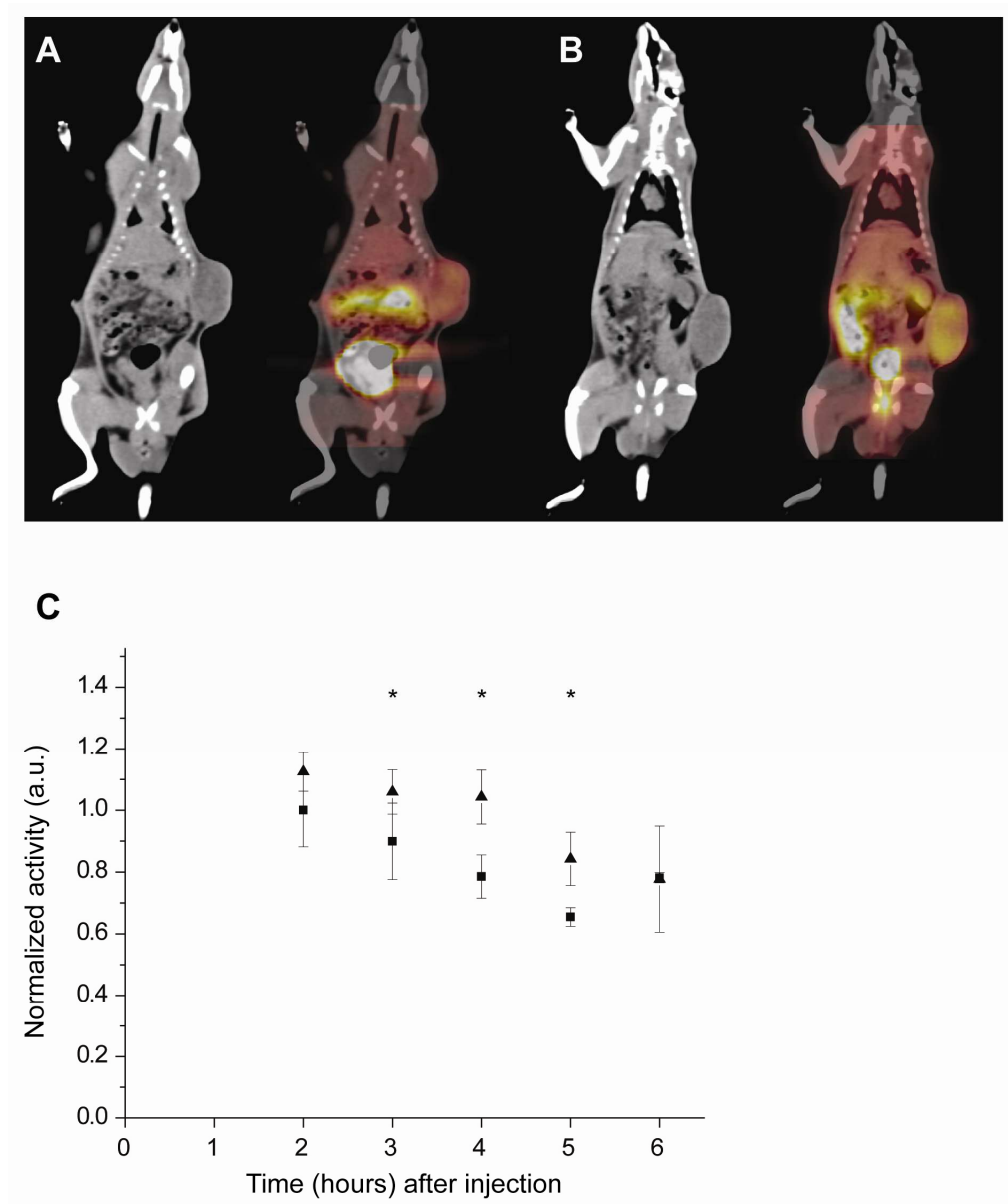

Figure 3. Representative $C T$ and PET/CT images within the same animal 2 $\mathrm{h}$ after injection of $\left[{ }^{18} \mathrm{~F}\right] \mathrm{HX} 4$ before $(A)$ and after $(B)$ treatment (interval of 2 days) with $7 \%$ oxygen breathing. Images are scaled to the maximum intensity values of all images. (C) Quantification of maximum $\left[{ }^{18} \mathrm{~F}\right] \mathrm{HX} 4$ uptake in animals $(n=6)$ treated with 7\% oxygen breathing (triangles) compared to no treatment (squares) at several time points. Data are expressed as mean $\pm \mathrm{SD}$. Asteriks indicate significant difference $\left({ }^{*} P<\right.$ 0.05 ) compared to no treatment. 
Evaluation of the mean $\left[{ }^{18} \mathrm{~F}\right] \mathrm{HX} 4$ activity in the tumor after $7 \%$ oxygen treatment resulted in an increased accumulation, but statistical significancy was lost. Furthermore, also the mean and maximum $\left[{ }^{18} \mathrm{~F}\right] \mathrm{HX} 4$ uptake after oxygen modification was independent $\left(r^{2}<0.13 ; P>0.3\right.$ and $r^{2}<0.14 ; P>0.3$ for $7 \%$ oxygen breathing or a combination of nicotinamde and carbogen respectively) of the tumor volume (data not shown).

In vivo accumulation of $\left[{ }^{18} \mathrm{~F}\right] \mathrm{HX} 4$ in human xenograft models To further evaluate $\left[{ }^{18} \mathrm{~F}\right] \mathrm{HX} 4$ as a potential hypoxia marker, we also used mice bearing xenografts originating from a variety of human cancers: pancreatic (BXPC-3), lung (A-427 and NCIH2122), glioblastoma (U-87 MG) and epidermoid (A-431) carcinoma. A clear $\left[{ }^{18} \mathrm{~F}\right] \mathrm{HX} 4$ accumulation was observed in the tumor (Fig. 4A, upper row) as compared with the surrounding tissue 1 hour after injection, without showing a significant difference between tracers $(P>0.5)$. Furthermore, a similarly high tracer accumulation was found in the organs of the gastrointestinal tract, the kidneys and the bladder. Tumor uptake increased with time, with the fastest increase for $\left[{ }^{18} \mathrm{~F}\right] \mathrm{FAZA}$ (Fig. $4 A$, bottom row). On the other hand, we observed an even more pronounced clearance from normal tissues for $\left[{ }^{18} \mathrm{~F}\right] \mathrm{HX} 4$. Quantification of the accumulation for the different hypoxia tracer was done by VOI analysis of the tumor and hind leg muscles and tumor to muscle ratios were calculated for a variety of human cancers (Fig. 4B). $\left[{ }^{18} \mathrm{~F}\right] \mathrm{HX} 4$ tumor to muscle ratios was comparable in all investigated xenograft models, except for the NCI-H2122 lung carcinoma model, where tumor to muscle ratios were higher. $\left[{ }^{18} \mathrm{~F}\right] \mathrm{FMISO}$ uptake followed a similar pattern, but was in general higher than $\left[{ }^{18} \mathrm{~F}\right] \mathrm{HX} 4$ uptake, although without being significant. 
$\left[{ }^{18} \mathrm{~F}\right] \mathrm{FAZA}$ uptake was less consistent over the different xenografts, being higher in BxPC-3, lower in A-427 and similar in U-87 MG tumors compared with $\left[{ }^{18} \mathrm{~F}\right] \mathrm{HX} 4$ and $\left[{ }^{18} \mathrm{~F}\right] \mathrm{FMISO}$.

A

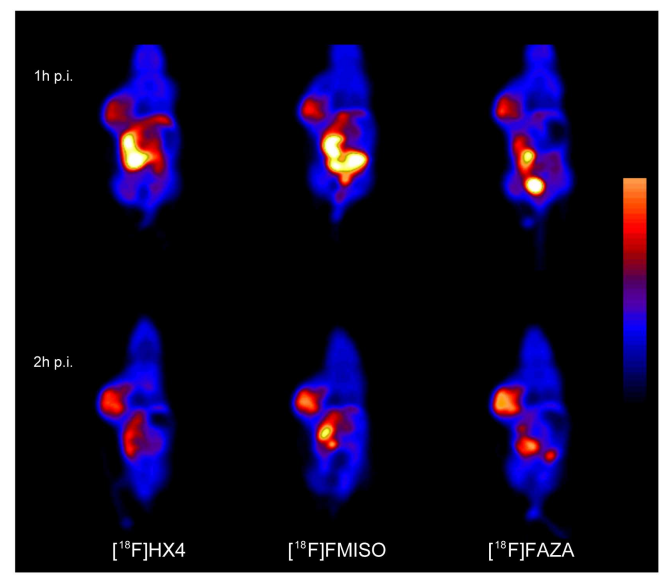

B
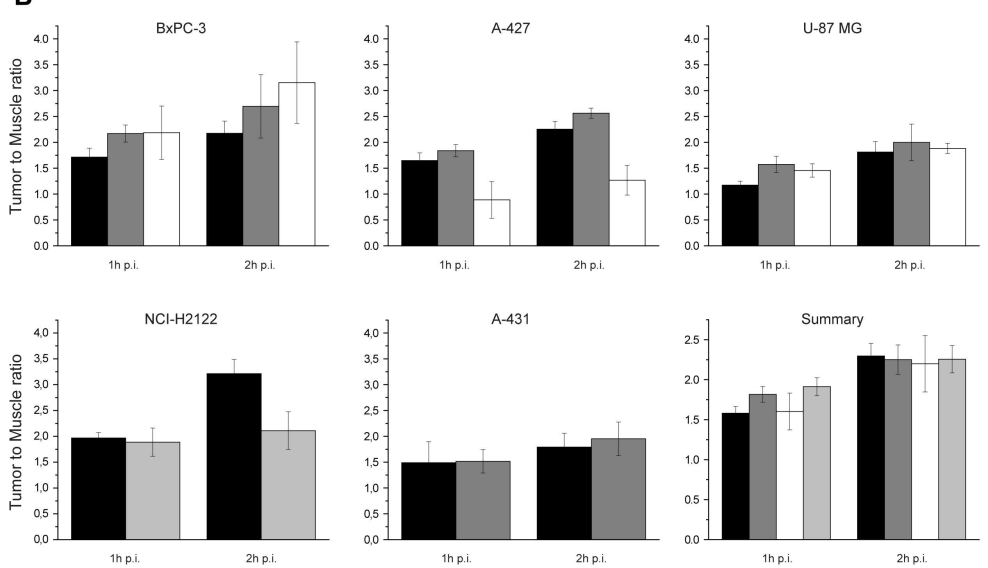

Figure 4. (A) Representative small animal PET images 1 and $2 \mathrm{~h}$ after injection of a BXPC-3 pancreatic tumor bearing mouse injected with $\left[{ }^{18} \mathrm{~F}\right] \mathrm{HX} 4, \quad\left[{ }^{18} \mathrm{~F}\right] \mathrm{FMISO}$ and $\left[{ }^{18} \mathrm{~F}\right] \mathrm{FAZA}$ on consecutive days. To allow comparison, images are corrected for injected dose and scales similarly. (B) Mean tumor to muscle ratios of $\left[{ }^{18} \mathrm{~F}\right] \mathrm{HX} 4$ (black), $\left[{ }^{18} \mathrm{~F}\right] \mathrm{FMISO}$ (dark gray), $\left[{ }^{18} \mathrm{~F}\right]$ FAZA (white) and $\left[{ }^{18} \mathrm{~F}\right] \mathrm{FRP}-170$ (light gray) uptake from several tumor types. Data are expressed as mean \pm SD. The summary graph indicates the average of all investigated xenografts. 
For the NCI-H2122 carcinoma model, only $\left[{ }^{18} \mathrm{~F}\right] \mathrm{FRP}-170$ uptake data were available and uptake was markedly lower compared with $\left[{ }^{18} \mathrm{~F}\right] \mathrm{HX} 4$ at 2 hours after injection. When tracer uptake from the different tumors was averaged, although a clear increase was observed over time, no significant differences were found between the several hypoxia markers.

\section{Discussion}

The importance of hypoxia has been demonstrated clinically, where it has been shown that patients with a hypoxic tumor have a worse outcome as they are less sensitive to radio - and chemotherapy ${ }^{20}$, indicating the necessity to evaluate oxygenation in individual tumors. Over the last decade, noninvasive methods which can identify tumors with substantial hypoxic fractions have been developed and may be used to acquire knowledge of the variations in spatial distribution of hypoxia ${ }^{21}$. Positron emission tomography (PET) using the 2-nitroimidazole $\left[{ }^{18} \mathrm{~F}\right] \mathrm{FMISO}$ holds promise for the evaluation of tumor hypoxia at both global and local levels. Several alternative nitroimidazole derivatives have been described in order to decrease the nonspecific retention of the used tracer, the number of metabolites and to improve the partition coefficient, all resulting in faster clearance properties ${ }^{22}$. Alternatively, tumor hypoxia response can also be evaluated by imaging of molecular markers of hypoxia, such as CA IX using specific sulfonamides ${ }^{23}$. In the current study, we evaluated the in vivo oxygen dependent uptake of $\left[{ }^{18} \mathrm{~F}\right] \mathrm{HX} 4$, a 2-nitroimidazole nucleoside analogue, in experimental rat and mouse tumor models. 
We found a clear $\left[{ }^{18} \mathrm{~F}\right] \mathrm{HX} 4$ accumulation in the rat tumor as compared with the surrounding normal tissue and a progressive decrease in concentration with time was observed. The corresponding blood and muscle clearance however was faster, resulting in increasing tumor to blood ( $T / B)$ ratios reaching a plateau $(2.512 \pm 0.578)$ at $4 \mathrm{~h}$ after injection. A mean T/B ratio of 1.4 was observed 2 hours after injection, in agreement with the described cut-off value indicative for significant hypoxia obtained from $\left[{ }^{18} \mathrm{~F}\right] \mathrm{FMISO}$ imaging of human tumors ${ }^{24}$. A similar T/B ratio was observed $2 \mathrm{~h}$ after injection of $\left[{ }^{18} \mathrm{~F}\right] \mathrm{FMISO}$ in patients with head and neck cancer ${ }^{12}$. In non-small-cell lung cancer patients a T/B ratio of $1.99 \pm 0.49$ was observed $3 \mathrm{~h}$ after $\left[{ }^{18} \mathrm{~F}\right] \mathrm{FMISO}$ injection ${ }^{11}$. These results indicate that the optimal time point for $\left[{ }^{18} \mathrm{~F}\right] \mathrm{FMISO}$ imaging is probably not yet reached at $3 \mathrm{~h}$ post injection. Our data demonstrated a plateau of $\left[{ }^{18} \mathrm{~F}\right] \mathrm{HX} 4$ accumulation from $4 \mathrm{~h}$ after injection onwards. For future clinical studies, $\left[{ }^{18} \mathrm{~F}\right] \mathrm{HX} 4$ accumulation should be monitored at least until $4 \mathrm{~h}$ after injection. We found that the uptake of $\left[{ }^{18} \mathrm{~F}\right] \mathrm{HX} 4$ was generally lower compared with previously reported $\left[{ }^{18} \mathrm{~F}\right] \mathrm{EF} 3$ activities ${ }^{17}$, both in normal as in tumor tissue, resulting in comparable mean $\mathrm{T} / \mathrm{B}$ ratios between hypoxia markers at all investigated time points. As tumors are known to be heterogeneous ${ }^{25}$, we also analyzed the maximum T/B uptake and observed significantly higher ratios for $\left[{ }^{18} \mathrm{~F}\right] \mathrm{HX} 4(7.638 \pm 3.816$ at $4 \mathrm{~h}$ post injection) compared with previously described $\left[{ }^{18} \mathrm{~F}\right] \mathrm{EF} 3$ ratios ${ }^{17}$. This suggests that $\left[{ }^{18} \mathrm{~F}\right] \mathrm{HX} 4$ in this rat tumor model reflects better the tumor heterogeneity and the severity of hypoxia 26 .

Also in mice bearing tumors originating from different human cancers, a clear accumulation of $\left[{ }^{18} \mathrm{~F}\right] \mathrm{HX} 4$ was observed compared 
with the surrounding tissue. $\left[{ }^{18} \mathrm{~F}\right] \mathrm{HX} 4$ tumor to muscle ratios were comparable in all xenograft models and were above 1.4, indicative for hypoxia. $\left[{ }^{18} \mathrm{~F}\right] \mathrm{FMISO}$ uptake followed a similar pattern, but was in general higher than $\left[{ }^{18} \mathrm{~F}\right] \mathrm{HX} 4$ uptake, although without being significant, while $\left[{ }^{18} \mathrm{~F}\right] \mathrm{FAZA}$ uptake was less consistent over the different tumor types, probably related to the tumor dependent $\left[{ }^{18} \mathrm{~F}\right]$ FAZA uptake. In advanced Walker 256 rat tumors, $\left[{ }^{18} \mathrm{~F}\right] \mathrm{FAZA}$ uptake was slightly but significantly lower compared with $\left[{ }^{18} \mathrm{~F}\right] \mathrm{FMISO}$ uptake ${ }^{25}$. On the other hand, in mouse bearing different murine and human tumor models, $\left[{ }^{18} \mathrm{~F}\right] \mathrm{FAZA} T / \mathrm{B}$ ratios were almost 3 -fold higher ${ }^{14}$, 27 . Summarizing tracer uptake throughout all investigated human tumor types, no significant differences were found in uptake between the several hypoxia markers.

Furthermore, the $\left[{ }^{18} \mathrm{~F}\right] \mathrm{HX} 4$ accumulation was dependent on the oxygen levels, since a significant reduction in uptake was observed within the same animal when $\left[{ }^{18} \mathrm{~F}\right] \mathrm{HX} 4$ was injected after a treatment combining nicotinamide and carbogen. This combination treatment has been shown to reduce tumor hypoxia in preclini$\mathrm{cal}^{9,28}$ and clinical practice ${ }^{29}$. Carbogen breathing is known to reduce chronic hypoxia by increasing the oxygen diffusion distance ${ }^{30}$, while nicotinamide prevents intermittent vascular shutdown resulting in a reduction in perfusion-limited hypoxia ${ }^{31}$. More evidence supporting the hypoxia dependent $\left[{ }^{18} \mathrm{~F}\right] \mathrm{HX} 4$ accumulation was demonstrated by the increased uptake after 7\% oxygen breathing. A similar increase in mean $\left[{ }^{18} \mathrm{~F}\right] \mathrm{FMISO}$ intensity was observed in a glioblastoma model after clamping the tumor ${ }^{32}$. The effect of the oxygen modification treatment persisted approximately 4 hours, in agreement with the observed decrease in $\left[{ }^{18} \mathrm{~F}\right] \mathrm{EF} 3$ accumulation in FSA II tumor bearing mice breathing carbogen ${ }^{33}$. 
$\left[{ }^{18} \mathrm{~F}\right] \mathrm{HX} 4$ biodistribution in normal tissues was found to be fast and homogeneous, as has already been published for $\left[{ }^{18} \mathrm{~F}\right] \mathrm{EF} 3$ and $\left[{ }^{18} \mathrm{~F}\right] \mathrm{FMISO}$ in the same rat model ${ }^{17}$. A progressive clearance was observed with time and the uptake in muscle was always lower than in the blood, resulting in muscle to blood (M/B) ratios below unity, which is favorable for imaging purposes ${ }^{14}$. $\left[{ }^{18} \mathrm{~F}\right] \mathrm{HX} 4 \mathrm{M} / \mathrm{B}$ ratios were comparable with the $\left[{ }^{18} \mathrm{~F}\right] \mathrm{EF} 3 \mathrm{M} / \mathrm{B}$ ratios $2 \mathrm{~h}$ after injection, but while $\left[{ }^{18} \mathrm{~F}\right] \mathrm{EF} 3$ ratios remained equal with time ${ }^{17}$, $\left[{ }^{18} \mathrm{~F}\right] \mathrm{HX} 4$ ratios decreased, indicating a faster clearance from normal tissues. It has been reported that $\left[{ }^{18} \mathrm{~F}\right]$ FETNIM uptake in muscle tissue might be sensitive to changes in oxygenation status ${ }^{34}$. However, $\left[{ }^{18} \mathrm{~F}\right] \mathrm{HX} 4$ clearance from normal tissue after $7 \%$ oxygen breathing or combination treatment of nicotinamide and carbogen was not different compared with non-treated animals.

Adequate measurements of tumor oxygenation are necessary for hypoxia-directed therapy guidance. Although a lot of research has been done in developing simple and efficient methods to image and evaluate oxygenation, it remains highly important to make additional comparative studies in the same tumor model and to relate hypoxia measurements with outcome. Therefore, ex vivo hypoxia measurements using pimonidazole are currently under investigation and will be compared with the in vivo $\left[{ }^{18} \mathrm{~F}\right] \mathrm{HX} 4$ accumulation. Future clinical trials should also explore the possibility of applying dose painting to hypoxic regions with IMRT based on $\left[{ }^{18} \mathrm{~F}\right] \mathrm{HX} 4$ hypoxia imaging. 


\section{Conclusion}

$\left[{ }^{18} \mathrm{~F}\right] \mathrm{HX} 4$ shows to be a promising in vivo tracer for the noninvasive detection and evaluation of tumor hypoxia. Both in animal and human tumors, a clear $\left[{ }^{18} \mathrm{~F}\right] \mathrm{HX} 4$ accumulation was observed with optimal imaging properties $4 \mathrm{~h}$ after injection, which has been proven to be dependent on the presence of hypoxia. Compared with commonly used hypoxia markers, $\left[{ }^{18} \mathrm{~F}\right] \mathrm{HX} 4$ is cleared faster from normal tissues and maximum $\left[{ }^{18} \mathrm{~F}\right] \mathrm{HX} 4$ ratios are higher, therefore being able to better visualize tumor heterogeneity and severity of hypoxia. Taken together, our results indicate that $\left[{ }^{18} \mathrm{~F}\right] \mathrm{HX} 4$ is a better alternative for hypoxia assessment.

\section{Acknowledgements}

This work has been funded with the support of the EU $7^{\text {th }}$ framework Program (Metoxia Project Ref. 2008-222741) and Siemens Molecular Imaging. 


\section{References}

1. Brown J.M. and Giaccia A.J. The unique physiology of solid tumors: opportunities (and problems) for cancer therapy. Cancer Res, 1998. 58(7): p. 1408-16.

2. Kaanders J.H., Wijffels K.I., Marres H.A., et al. Pimonidazole binding and tumor vascularity predict for treatment outcome in head and neck cancer. Cancer Res, 2002. 62(23): p. 7066-74.

3. Nordsmark M. and Overgaard J. A confirmatory prognostic study on oxygenation status and loco-regional control in advanced head and neck squamous cell carcinoma treated by radiation therapy. Radiother Oncol, 2000. 57(1): p. 39-43.

4. Tatum J.L., Kelloff G.J., Gillies R.J., et al. Hypoxia: importance in tumor biology, noninvasive measurement by imaging, and value of its measurement in the management of cancer therapy. Int J Radiat Biol, 2006. 82(10): p. 699-757.

5. Lin Z., Mechalakos J., Nehmeh S., et al. The influence of changes in tumor hypoxia on dose-painting treatment plans based on 18F-FMISO positron emission tomography. Int J Radiat Oncol Biol Phys, 2008. 70(4): p. 1219-28.

6. Brown J.M. and Wilson W.R. Exploiting tumour hypoxia in cancer treatment. Nat Rev Cancer, 2004. 4(6): p. 437-47.

7. Ebbesen P., Pettersen E.O., Gorr T.A., et al. Taking advantage of tumor cell adaptations to hypoxia for developing new tumor markers and treatment strategies. J Enzyme Inhib Med Chem, 2009. 24 Suppl 1: p. 1-39.

8. Rasey J.S., Grunbaum Z., Magee S., et al. Characterization of radiolabeled fluoromisonidazole as a probe for hypoxic cells. Radiat Res, 1987. 111(2): p. 292304.

9. Bentzen L., Keiding S., Horsman M.R., et al. Assessment of hypoxia in experimental mice tumours by [18F]fluoromisonidazole PET and $\mathrm{pO} 2$ electrode measurements. Influence of tumour volume and carbogen breathing. Acta Oncol, 2002. 41(3): p. 304-12.

10. Dubois L., Landuyt W., Haustermans K., et al. Evaluation of hypoxia in an experimental rat tumour model by [(18)F]fluoromisonidazole PET and immunohistochemistry. Br J Cancer, 2004. 91(11): p. 1947-54.

11. Gagel B., Reinartz P., Demirel C., et al. [18F] fluoromisonidazole and [18F] fluorodeoxyglucose positron emission tomography in response evaluation after chemo-/radiotherapy of non-small-cell lung cancer: a feasibility study. BMC Cancer, 2006. 6: p. 51.

12. Rajendran J.G., Schwartz D.L., O'Sullivan J., et al. Tumor hypoxia imaging with [F18] fluoromisonidazole positron emission tomography in head and neck cancer. Clin Cancer Res, 2006. 12(18): p. 5435-41.

13. Thorwarth D., Eschmann S.M., Scheiderbauer J., et al. Kinetic analysis of dynamic 18 F-fluoromisonidazole PET correlates with radiation treatment outcome in head-andneck cancer. BMC Cancer, 2005. 5: p. 152.

14. Piert M., Machulla H.J., Picchio M., et al. Hypoxia-specific tumor imaging with $18 \mathrm{~F}-$ fluoroazomycin arabinoside. J Nucl Med, 2005. 46(1): p. 106-13.

15. Dewhirst M.W. Concepts of oxygen transport at the microcirculatory level. Semin Radiat Oncol, 1998. 8(3): p. 143-50.

16. Busch T.M., Hahn S.M., Evans S.M., et al. Depletion of tumor oxygenation during photodynamic therapy: detection by the hypoxia marker EF3 [2-(2-nitroimidazol$1[\mathrm{H}]-\mathrm{yl})-\mathrm{N}-(3,3,3$-trifluoropropyl)acetamide ]. Cancer Res, 2000. 60(10): p. 263642.

17. Dubois L., Landuyt W., Cloetens L., et al. [18F]EF3 is not superior to [18F]FMISO for PET-based hypoxia evaluation as measured in a rat rhabdomyosarcoma tumour model. Eur J Nucl Med Mol Imaging, 2009. 36(2): p. 209-18.

18. Ishikawa Y., Iwata R., Furumoto S., et al. Automated preparation of hypoxic cell marker [18F]FRP-170 by on-column hydrolysis. Appl Radiat Isot, 2005. 62(5): p. 705-10.

19. Soret M., Bacharach S.L., and Buvat I. Partial-volume effect in PET tumor imaging. ] Nucl Med, 2007. 48(6): p. 932-45.

20. Magagnin M.G., Koritzinsky M., and Wouters B.G. Patterns of tumor oxygenation and their influence on the cellular hypoxic response and hypoxia-directed therapies. Drug Resist Updat, 2006. 9(4-5): p. 185-97.

21. O'Donoghue J.A., Zanzonico P., Pugachev A., et al. Assessment of regional tumor hypoxia using 18F-fluoromisonidazole and 64Cu(II)-diacetyl-bis(N4methylthiosemicarbazone) positron emission tomography: Comparative study featuring microPET imaging, Po2 probe measurement, autoradiography, and 
fluorescent microscopy in the R3327-AT and FaDu rat tumor models. Int J Radiat Oncol Biol Phys, 2005. 61(5): p. 1493-502.

22. Krohn K.A., Link J.M., and Mason R.P. Molecular imaging of hypoxia. J Nucl Med, 2008. 49 Suppl 2: p. 129S-48S.

23. Dubois L., Lieuwes N.G., Maresca A., et al. Imaging of CA IX with fluorescent labelled sulfonamides distinguishes hypoxic and (re)-oxygenated cells in a xenograft tumour model. Radiother Oncol, 2009. 92(3): p. 423-8.

24. Koh W.J., Rasey J.S., Evans M.L., et al. Imaging of hypoxia in human tumors with [F18]fluoromisonidazole. Int J Radiat Oncol Biol Phys, 1992. 22(1): p. 199-212.

25. Sorger D., Patt M., Kumar P., et al. [18F]Fluoroazomycinarabinofuranoside (18FAZA) and [18F]Fluoromisonidazole (18FMISO): a comparative study of their selective uptake in hypoxic cells and PET imaging in experimental rat tumors. Nucl Med Biol, 2003. 30(3): p. 317-26.

26. Stadler P., Becker A., Feldmann H.J., et al. Influence of the hypoxic subvolume on the survival of patients with head and neck cancer. Int J Radiat Oncol Biol Phys, 1999. 44(4): p. 749-54.

27. Reischl G., Dorow D.S., Cullinane C., et al. Imaging of tumor hypoxia with [124I]IAZA in comparison with [18F]FMISO and [18F]FAZA--first small animal PET results. J Pharm Pharm Sci, 2007. 10(2): p. 203-11.

28. van Laarhoven H.W., Bussink J., Lok J., et al. Effects of nicotinamide and carbogen in different murine colon carcinomas: immunohistochemical analysis of vascular architecture and microenvironmental parameters. Int J Radiat Oncol Biol Phys, 2004. 60(1): p. 310-21.

29. Kaanders J.H., Pop L.A., Marres H.A., et al. Accelerated radiotherapy with carbogen and nicotinamide (ARCON) for laryngeal cancer. Radiother Oncol, 1998. 48(2): p. 115-22.

30. Powell M.E., Hill S.A., Saunders M.I., et al. Effect of carbogen breathing on tumour microregional blood flow in humans. Radiother Oncol, 1996. 41(3): p. 225-31.

31. Chaplin D.J., Horsman M.R., and Trotter M.J. Effect of nicotinamide on the microregional heterogeneity of oxygen delivery within a murine tumor. J Natl Cancer Inst, 1990. 82(8): p. 672-6.

32. Troost E.G., Laverman P., Kaanders J.H., et al. Imaging hypoxia after oxygenationmodification: comparing [18F]FMISO autoradiography with pimonidazole immunohistochemistry in human xenograft tumors. Radiother Oncol, 2006. 80(2): p. $157-64$.

33. Mahy P., De Bast M., de Groot T., et al. Comparative pharmacokinetics, biodistribution, metabolism and hypoxia-dependent uptake of [18F]-EF3 and [18F]MISO in rodent tumor models. Radiother Oncol, 2008. 89(3): p. 353-60.

34. Gronroos T., Bentzen L., Marjamaki P., et al. Comparison of the biodistribution of two hypoxia markers [18F]FETNIM and [18F]FMISO in an experimental mammary carcinoma. Eur J Nucl Med Mol Imaging, 2004. 31(4): p. 513-20. 


\section{Chapter 5}

Imaging the hypoxia surrogate marker CA IX requires expression and catalytic activity for binding fluorescent sulfonamide inhibitors

Dubois L, Douma K, Supuran CT, Chiu RK, van Zandvoort MAMJ, Pastoreková S, Scozzafava A, Wouters BG, Lambin P

Radiother Oncol. 2007 Jun;83(3):367-373

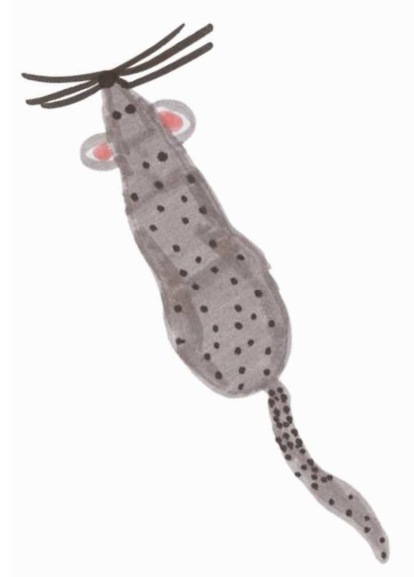




\begin{abstract}
Background and Purpose: Carbonic anhydrase (CA) IX expression is increased in response to hypoxia. Recently, sulfonamide based carbonic anhydrase inhibitors (CAI) showing specificity for CA IX have been designed. Aim was to investigate the CAI binding properties under normoxia, hypoxia and reoxygenation.

Material and Methods: Cells with varying CA IX expression were incubated with fluorescein labeled CAI (1mM) during normoxia, hypoxia $(0.2 \%)$ and reoxygenation. CA IX expression levels were assessed using Western blotting. CAI binding was determined by immunostaining and flow cytometry.

Results: CAI binding in hypoxic cells was significantly higher compared with normoxic cells and correlated with upregulated CA IX levels. Binding occurred within 15 min of hypoxia, but was gradually lost upon reoxygenation. Interestingly, although CA IX levels remained high upon reoxygenation, CAI binding was dramatically reduced and no longer correlated with CA IX expression. Similarly, RCC4 cells, constitutively expressing CA IX, do not bind CAI under normoxic conditions.

Conclusions: Our results confirm and extend previous results showing that CAI binding occurs only under hypoxia. The inability of CAI to bind CA IX in RCC4 cells and following reoxygenation in other cells demonstrates that formation of the active site not only depends on HIF-1a-dependent gene activity, but also on the absence of oxygen per se.
\end{abstract}




\section{Introduction}

Solid tumors often contain regions at very low oxygen concentration. These hypoxic regions are an important microenvironmental parameter which influences the behavior of tumor cells and has a negative impact on treatment response. Hypoxia has been shown to be an independent predictor of poor progression-free survival in several types of cancer ${ }^{1-5}$. Treatments to overcome the effects of hypoxia are being evaluated ${ }^{6,}$. Therefore, guidance of hypoxia-directed treatments on an individual basis necessitates adequate measurements of tumor oxygenation.

At a molecular level, the widely investigated response to hypoxia is the stabilization and activation of the transcription factor HIF-1a and its downstream targets ${ }^{8}$. Under normoxic conditions, HIF-1a is hydroxylated and therefore ubiquitinated by the E3 ubiquitin ligase von Hippel-Lindau ( $\mathrm{VHL}$ ) protein, targeting this complex for degradation ${ }^{9}$. Loss or mutation in VHL triggers the hypoxic phenotype also under normoxic conditions ${ }^{10}$.

Carbonic anhydrase (CA) IX expression is dramatically increased in a variety of human tumors, whilst its expression in normal tissues is low $^{11}$. This tumor-associated upregulation of CA IX is the result of a strong transcriptional activation of the CA9 gene by HIF-1 $1 a^{12}$. Expression of CA IX in tumors is associated with poor prognosis, tumor progression and aggressiveness, suggesting that CA IX may be a good therapeutic target ${ }^{13,14}$. Furthermore CA IX seems also to be implicated in tumorigenesis via its capacity to modulate cell adhesion and acidification of the tumor microenvironment ${ }^{15,16}$.

Numerous sulfonamide inhibitors of CAIX have been developed in the past few years ${ }^{17}$. A fluorescent sulfonamide with high affinity 
for CA IX (inhibition constant, $K_{\mathrm{i}}=24 \mathrm{nM},{ }^{18,19}$ ) has been shown to inhibit hypoxia-mediated tumor acidification and to bind CA IX expressed under hypoxic conditions, but not under aerobic conditions ${ }^{15}$. Based on these reports, we further investigated the binding properties of these CA IX inhibitors in distinguishing cells that have been hypoxic and thus show an increase in hypoxia regulated genes, but then reoxygenated in several tumor cell lines.

\section{Materials and Methods}

Cell culture

Exponentially growing cervical (HeLa, ATCC CCL-2), colorectal (HT29, ATCC HTB-38), pVHL-deficient renal (RCC4; kindly provided by Patrick Maxwell, Imperial College London) carcinoma cell lines were cultivated in Dulbecco's modified Eagle's medium supplemented with $10 \%$ fetal bovine serum and incubated in a humidified $5 \% \mathrm{CO}_{2}$ chamber at $37^{\circ} \mathrm{C}$. Cells were plated at a density of $0.5 \times 10^{6}$ per $6 \mathrm{~cm}$ dish a day before the start of the experiment and transfer to a hypoxic culture chamber (MACS VA500 microaerophilic workstation, Don Whitley Scientific, Shipley, UK). The atmosphere in the chamber consisted of $0.2 \% \mathrm{O}_{2}, 5 \% \mathrm{H}_{2}$, $5 \% \mathrm{CO}_{2}$ and residual $\mathrm{N}_{2}$. Normoxic dishes were incubated in parallel in air with $5 \% \mathrm{CO}_{2}$. HIF-1a stabilization under normoxia was assessed using $150 \mu \mathrm{M} \mathrm{CoCl}$. $\mathrm{pH}$ of the culture medium was immediately measured at the end of each experiment.

\section{Sulfonamide treatment of cells}

The fluorescent labeled CA IX inhibitor sulfonamide (CAI) has been prepared by reaction of fluorescein isothiocyanate (FITC) with the amino-substituted aromatic homosulfanilamide ${ }^{19}$. The CAI showed 
a $K_{\mathrm{i}}$ value, as assessed by $\mathrm{CO}_{2}$ hydration methods using purified CA domain of CA IX, of $24 \mathrm{nM}$. The sulfonamide was dissolved in PBS containing $10 \%$ DMSO at $100 \mathrm{mM}$ concentration and diluted in culture medium to a final concentration of $1 \mathrm{mM}$ just before addition to the cells. Cells were incubated with CAI the last 30 minutes of normoxic, hypoxic exposure or upon reoxygenation.

\section{Flow cytometric analysis}

Cells were rinsed with PBS, scraped and fixed in fresh prepared $2 \%$ paraformaldehyde on ice. Single cell suspensions were obtained by passing cells through $70 \mu \mathrm{m}$ nylon cell strainers (BD Biosciences). Mean fluorescent intensity was analyzed using a FACSAria ${ }^{\circledR}$ flow cytometer (BD Biosciences) using FIT-C filter settings. Data were corrected for both background signals (cells without CAI) and normalized to the signal intensity of cells incubated with CAI under normoxia.

\section{Western blot analysis}

Cells were extracted in RIPA buffer for $30 \mathrm{~min}$ on ice and protein concentrations were determined by a Bradford assay (Bio-Rad) with BSA as standard. Proteins were separated on a $10 \%$ SDSpolyacrylamide gel and transferred $\left(100 \mathrm{~V}, 1 \mathrm{~h}, 4^{\circ} \mathrm{C}\right)$ to nitrocellulose membranes (Amersham Corp.). Membranes were blocked $\left(\mathrm{ON}, 4^{\circ} \mathrm{C}\right)$ with $5 \%$ Blotting Grade Blocker non fat dry milk (Bio-Rad) and subsequently incubated (2h, RT) with a 1:20 dilution of mouse monoclonal CA IX antibody M75 (Bayer USA, ${ }^{20}$ ). Proteins were visualized by a horseradish peroxidase method using Enhanced Chemiluminescence (Amersham Corp.). Mouse monoclonal $\beta$-Actin (Sigma) was used as loading control. 


\section{Immunofluorescence}

Cells were grown on glass coverslips and incubated with fluorescein labeled sulfonamide. At the end of the experiment, cells were fixed with freshly prepared $2 \%$ paraformaldehyde. Nonspecific binding was blocked by incubation $\left(30 \mathrm{~min}, 37^{\circ} \mathrm{C}\right.$ ) with PBS containing $1 \%$ BSA. Cells were incubated $\left(1 \mathrm{~h}, 37^{\circ} \mathrm{C}\right)$ with $\mathrm{CA}$ IX-specific monoclonal antibody (MAb) M75 (Bayer USA, ${ }^{20}$ ) followed by incubation $\left(1 \mathrm{~h}, 37^{\circ} \mathrm{C}\right)$ with goat anti-mouse Alexa fluor 568-conjugated IgG antibody. Cells were post-fixed using $1 \%$ formaldehyde, mounted onto slides with Fluorescence Mounting Medium (DAKO) and analyzed with a Leica DM-5000B fluorescence microscope (Leica Mircosystems) using FIT-C and TRIT-C filter settings.

\section{Statistics}

All statistical analyses were performed with SPSS 12.0.1 for Windows (SPSS Inc., 2003, Chicago, USA). Graphs were drawn using Origin 6.0 (Microcal Software Inc., 1999, Northampton, USA). An unpaired Student's $t$-test and non-parametric MannWhitney $U$ test for small groups were used to determine the statistical significance of differences between two independent groups of variables. For all tests, a $P<0.05$ was considered significant.

\section{Results}

Characterization of CA IX expression levels in different carcinoma cell models

A panel of cell lines was investigated by Western blotting for their CA IX expression levels under normoxia, hypoxia or upon 
reoxygenation (Fig. 1A). HeLa cervical and HT-29 colorectal carcinoma cells showed elevated levels of CA IX under hypoxia, which remained high upon reoxygenation. No CA IX expression was observed in normoxic HeLa cells, while HT-29 cells showed intermediate expression levels. As expected, RCC4 cells, characterized by VHL loss and HIF-1a activation, demonstrated constitutive expression of CA IX even under normoxic conditions.
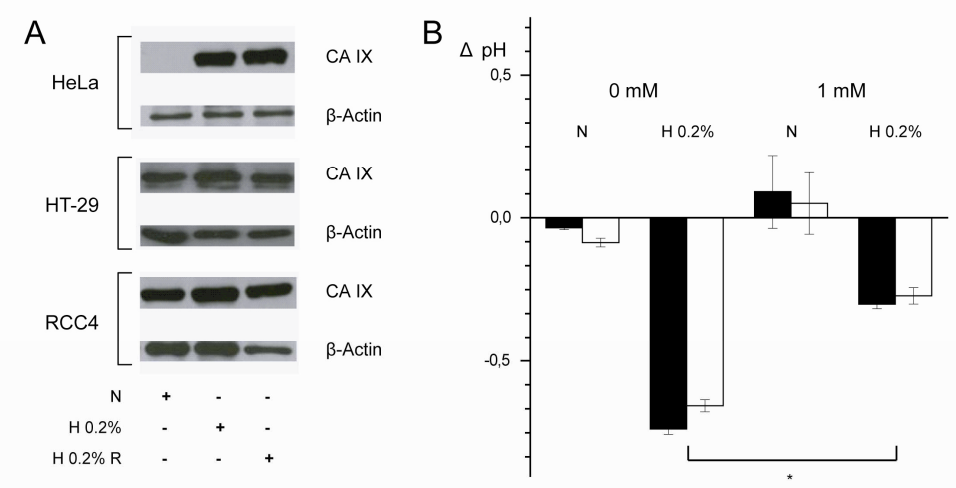

Figure 1. (A) Western blot analysis of CA IX expression in normoxic (21\% $\left.\mathrm{O}_{2}, 24 \mathrm{~h}\right)$, hypoxic $\left(0.2 \% \mathrm{O}_{2}, 24 \mathrm{~h}\right)$ or reoxygenated $\left(0.2 \% \mathrm{O}_{2}, 24 \mathrm{~h}\right.$ followed by $30 \min 21 \% \mathrm{O}_{2}$ ) HeLa, HT-29 and RCC4 carcinoma cells using the monoclonal CA IX antibody. $\beta$-Actin was used as loading control. (B) Efficacy of CAI sulfonamide treatment. CAI sulfonamide were added to HeLa (black) and HT-29 (white) cells just before incubation under normoxia (N) or hypoxia $\left(\mathrm{H} 0.2 \%\right.$ ) and $\mathrm{pH}_{\mathrm{e}}$ was measured $24 \mathrm{~h}$ later. Data show means \pm SEM of at least three independent experiments and are expressed as difference between $\mathrm{pH}_{\mathrm{e}}$ values $\left(\Delta \mathrm{pH}=\mathrm{pH}_{\text {after incubation }}-\mathrm{pH}_{\text {before incubation }}\right)$ measured in absence $(0 \mathrm{mM})$ or in presence $(1 \mathrm{mM})$ of CAI sulfonamide. Significant reduction extracellular $\mathrm{pH}$ is indicated by an asterisk ( ${ }^{*} P<$ 0.001).

\section{Assessment of CAI efficacy}

Hypoxic incubation led to an acidification (up to $\mathrm{pH} 6.7$ ) of the extracellular culture medium. A previous study has shown that acidification is dependent upon CA IX activity ${ }^{15}$. In agreement, we found that upon incubation with $1 \mathrm{mM}$ of CAI, a significant $(P<$ 0.001 ) reduction of the extracellular acidification (to $\mathrm{pH} 7.0$ ) 
occurred for both HeLa and HT-29 cells (Fig. 1B). Moreover, the effect of CAI on the normoxic extracellular $\mathrm{pH}$ was negligible, indicating the specificity for CA IX. Although HT-29 cells show intermediate CA IX expression under normoxia and little acidification was seen under these conditions, no significant effect was observed after incubation with CAI.

\section{CAI binding during hypoxia and reoxygenation}

Immunofluorescence analysis and flow cytometry demonstrated a significantly higher binding $(P<0.001)$ of CAI at HeLa cells exposed to hypoxia for $24 \mathrm{~h}$, compared with their normoxic counterparts (Fig. $2 A$ and $B$ ), corresponding with an upregulation of CA IX expression. When CAI was added to the cells upon reoxygenation, binding was dramatically reduced $(P<0.01)$ compared with hypoxic conditions and was not statistically different $(P=0.06)$ with binding under normoxia. Similar significant results $(P<0.001$ for HT-29 and $P<0.01$ for RCC4, respectively) were obtained using HT-29 and RCC4 cell lines (Fig. $3 A)$.

Immunofluorescence imaging demonstrated presence of CA IX monoclonal antibody predominantly localized at the cell surface of hypoxic and reoxygenated HeLa cells (Fig. 2C). Co-localization between CA IX inhibitor and monoclonal antibody was only observed under hypoxic conditions, as seen by the yellowish color (Fig. 2C). Comparable results were observed in HT-29 and RCC4 cell lines (data not shown).

Since HT-29 cells express CA IX under normal culture conditions, we used these cells to monitor the binding of CAI as a function of time after the cells were made hypoxic. This gives an 
indication as to the time required to activate CA IX and to allow binding of the CAI.

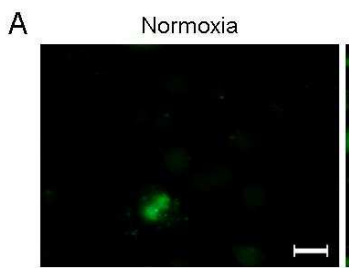

B

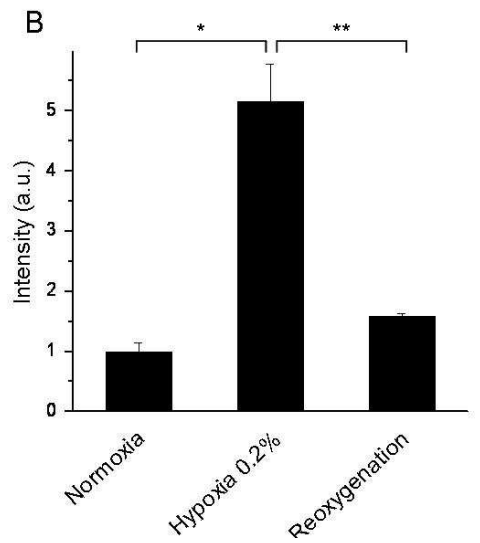

Hypoxia $0.2 \%$

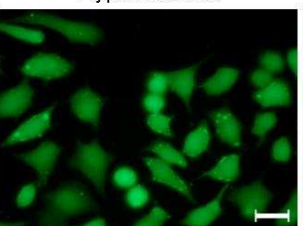

C

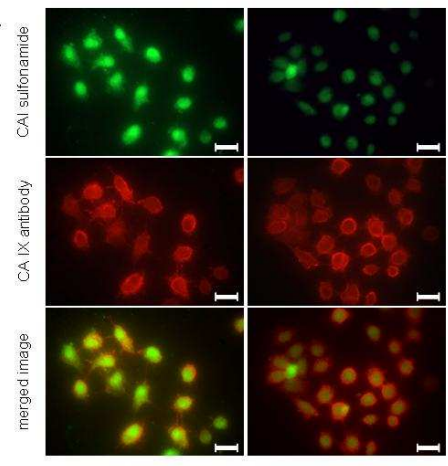

Hypoxia $0.2 \%$
Reoxygenation

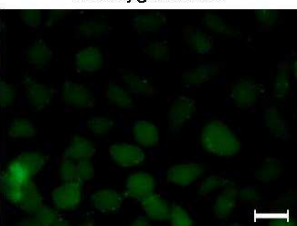

Reoxygenation

Figure 2. (A) Fluorescence analysis of HeLa cells treated with $1 \mathrm{mM}$ of CAI during normoxia, hypoxia exposure or upon reoxygenation. (B) Quantitative FACS analysis of CAI binding to HeLa cells treated with CAI under the respective conditions. Data demonstrate the fold accumulation compared with CAI treated normoxic cells and are represented by means \pm SEM of at least six independent experiments. (C) Immunofluorescence analysis of HeLa cells treated with CAI during hypoxia or upon reoxygenation (green). Presence of CA IX was assessed using the monoclonal CA IX (M75) antibody (red). Co-localization of CAI sulfonamide and CA IX monoclonal antibody was assessed by merging the images (yellow). Significant differences are indicated by an asterisk ( $P<0.001$; $* * P<0.01)$. Scale bars are $25 \mu \mathrm{m}$.

We exposed HT-29 cells to hypoxia for different durations. Rapidly after hypoxic exposure (15 min), high CAI accumulation levels were observed (Fig. 3B) which remained stable throughout the time course. These data strongly suggest that activation of CA IX does not require de novo protein expression. 

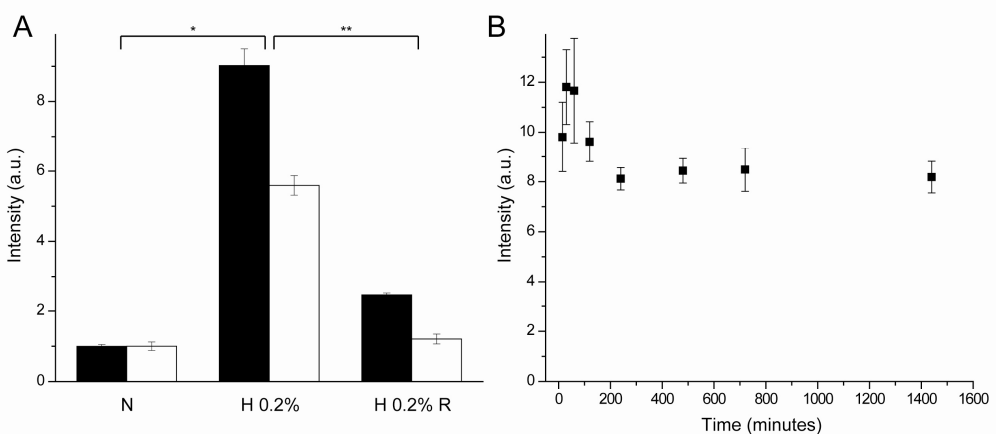

Figure 3. (A) FACS analysis of CAI binding to HT-29 (black) and RCC4 (white) during normoxia $(\mathrm{N})$, hypoxia $(\mathrm{H} 0.2 \%)$ or reoxygenation $(\mathrm{H} 0.2 \%$ R) conditions. (B) CAI binding in HT-29 incubated for increasing durations (minutes) under hypoxia. Data represent means \pm SEM of at least three independent experiments and show the fold accumulation compared with CAI treated normoxic cells. Significant differences are indicated by an asterisk $(* P<0.001 ; * * P<0.01)$.

\section{CAI binding to CA IX is not dependent on HIF1-a}

Previous studies have demonstrated that CAI cannot bind to CA IX under aerobic conditions, but does so avidly during hypoxic conditions ${ }^{15}$. HIF-1a is an important mediator of gene expression during hypoxia and we therefore tested the hypothesis that HIF-1a mediates not only CA IX expression, but also its activation and thus ability to bind the CAI. This was done by two different methods. Cells were exposed to $\mathrm{CoCl}_{2}$ incubation, which stabilized HIF-1a under normoxia by preventing its hydroxylation. As expected this led to increased CA IX levels in both HeLa and HT-29 cells (Fig. 4A). However, activation of HIF-1a under aerobic conditions did not significantly increase the binding of CAI to CA IX in these cells, indicating that HIF-1a is not sufficient to cause binding. Similarly, RCC4 cells, which constitutively express HIF-1a and CA IX, did not show increased binding to CAI under aerobic conditions (Fig. 4B and $\mathrm{C}$ ). In these cells, binding of the CAI was greatly stimulated by hypoxia (Fig. 4B and D). 

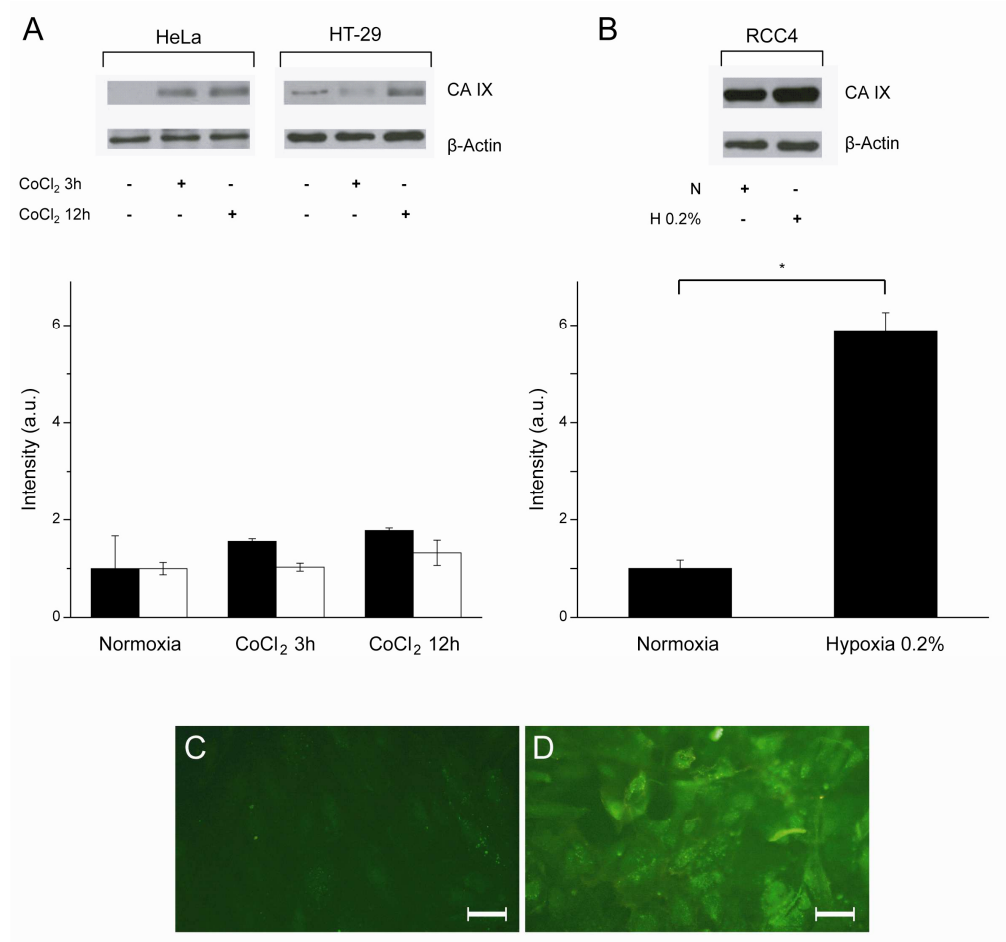

Figure 4. (A) Western blot and FACS analysis of CA IX expression in HeLa and $\mathrm{HT}-29$ cells upon incubation with $\mathrm{CoCl}_{2}$ under normoxic conditions. (B) Western blot and FACS analysis of CA IX levels in RCC4 cells upon normoxia and hypoxia. Data represent means \pm SEM of at least three independent experiments. $\beta$-Actin was used as loading control. Immunofluorescence analysis of CAI binding in RCC4 cells under normoxia (C) and hypoxia (D). Significant differences are indicated by an asterisk (* $P<0.001)$. Scale bars are $25 \mu \mathrm{m}$.

\section{Loss of CAI binding upon reoxygenation}

Next, we investigated the loss of CAI signal in HeLa and HT-29 cells exposed to the inhibitor during hypoxia followed by reoxygenation. In contrast to cells exposed to the inhibitor after reoxygenation, CAI which was bound to cells during hypoxia remained associated with cells during reoxygenation. We observed a gradual loss of CAI binding when HeLa cells were re-exposed to normoxic oxygen conditions (Fig. 5A). Within $30 \mathrm{~min}$, accumulation 
was reduced approximately 50\%, but was still significantly higher than background binding $(P=0.011)$. Background levels were reached only after more than $1 \mathrm{~h}(P=0.299)$ of reoxygenation. Similar results were seen for the HT-29 cells (Fig. 5B) although accumulation levels remained approximately $50 \%$, but statistical significance was lost after more than $1 \mathrm{~h}(1 / 2 \mathrm{~h}: P=0.022$ and 1 $\mathrm{h}: P=0.052)$.
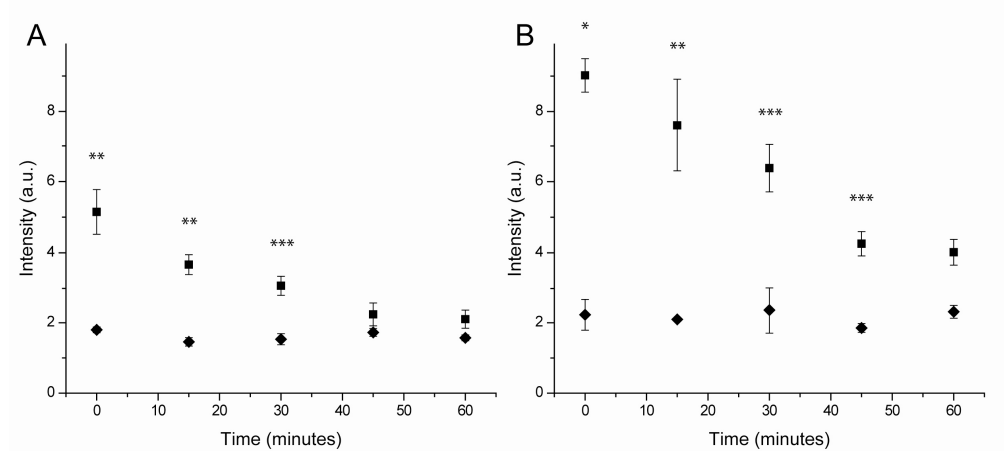

Figure 5. Gradual loss over time (minutes) of hypoxic CAI binding upon reoxygenation (squares) in HeLa (A) and HT-29 (B) cells. Diamonds show CAI accumulation during reoxygenation for the corresponding time points. Data represent means \pm SEM of at least four independent experiments. Significant differences are indicated by an asterisk $(* P<0.001$; $* * P<$ $0.01 ; * * * P<0.05)$.

\section{Discussion}

CA IX expression levels were assessed in several carcinoma cell lines. HeLa and HT-29 cells exposed to hypoxia showed a strong CA IX upregulation. However, HT-29 cells also demonstrated CA IX expression under normoxic conditions, probably since these cells grow in clusters resulting in cell density related CA IX expression ${ }^{21}$. Upon reoxygenation, CA IX expression levels stayed elevated, in agreement with the known CA IX half-life of $38 \mathrm{~h}$ in reoxygenated 
cells ${ }^{22}$. Loss of VHL in RCC4 cells resulted in constitutive high levels of CA IX, as seen previously ${ }^{9,10}$.

Hypoxia resulted in an acidification (up to $\mathrm{pH}$ 6.7) of the extracellular compartment and it has been reported that CA IX is a main contributor for this process ${ }^{15}$. Also the production of lactic acid could possibly contribute to this acidification, since it has been reported that lactic acid production is increased upon hypoxia and could predict treatment outcome ${ }^{23}$. However, using CA IX-positive and CA IX-negative MDCK immortalized canine kidney epithelial cells, lactic acid production was similar between both cell lines, both under normoxia and hypoxia ${ }^{15}$. Further proof is given by investigation of the involvement of specific CA IX extracellular domains in the $\mathrm{pH}_{\mathrm{e}}$ control. Elimination of the catalytic active domain perturbed the acidification capacity of CA IX, but still produced similar levels of lactic acid compared with the intact domain ${ }^{15}$. These results indicate that the excessive $\mathrm{pH}$ decrease observed upon hypoxia could be explained by CA IX activation and not by the production of lactic acid. We demonstrated in this study, that the used CAI showed an ability to prevent extracellular acidification during hypoxia, while the effect on normoxic cells was negligible. These results are in agreement with previously tested CA IX-selective inhibitors ${ }^{15}$. Recently, it has been shown that at lower $\mathrm{pH}_{\mathrm{e}}$ (6.3), the expression of hypoxia-induced genes was suppressed $^{24}$ which could indicate that CA IX is not involved in the extracellular acidification. Our study however, indicated clear CA IX expression under hypoxia (at $\mathrm{pH}$ 6.7), which is in agreement with the results of Vordermark et al. ${ }^{25}$ who observed no influence of changed $\mathrm{pH}$ (6.7) on CA IX expression. It remains therefore important to further investigate the $\mathrm{pH}$ dependency for the expression of hypoxia-induced genes. 
Our results indicate that CAI binding to CA IX requires both its expression and its activation and that this occurs only during hypoxia. Binding was observed exclusively during conditions of hypoxia in all cell lines tested, irrespective of the levels of CA IX or HIF-1a activity. The fact that CAI binding in HeLa cells occurs only after several hours of hypoxic exposure also demonstrates the selectivity of the CAI for CA IX. CAI did not bind to hypoxic HeLa cells until CA IX levels had been induced, indicating that no significant binding occurred to other potentially present $C A$ isoforms even during hypoxia ${ }^{15}, 17$. Furthermore, we found that despite having high levels of CA IX, and presumably other HIF-1a dependent genes, virtually no binding of the CAI occurred after reoxygenation in HeLa or HT-29 cells. These data were also supported by studies in VHL deficient RCC4 cells, and in cells treated with cobalt chloride. In both of these systems CA IX and other HIF-1a dependent genes are upregulated during normoxia ${ }^{10}$ 12. However, again no significant binding of CAI was observed during aerobic exposure. Together, these results indicate that the active site of CA IX is only available for binding during hypoxia.

Interestingly, we found that CAI which bound to CA IX under hypoxic conditions remained associated with cells during reoxygenation. This is in contrast to a near complete lack of binding when the CAI was introduced after reoxygenation. The CAI bound fraction was gradually lost with time during reoxygenation, falling to near background levels after more than $1 \mathrm{~h}$. This loss, is much faster than the normal turnover of CA IX ${ }^{22}$, and is thus due either to loss of binding, or internalization and degradation. Preliminary data suggest that the CAI may indeed promote internalization, but this needs further investigation. 
The consequences of hypoxic regions within solid tumors are well known ${ }^{1-5}, 13$ and hypoxia specific treatments are under investigation $^{6,7}$. Therefore, adequate measurements of tumor oxygenation are necessary. However, the lack of simple and efficient methods to measure and image oxygenation hampers further understanding of hypoxia ${ }^{26}$. Recent studies are focussing on molecular markers of hypoxia, such as HIF- $1 a^{27}$ or CA IX ${ }^{13,} 28$. Our data demonstrated that no discrimination can be made between hypoxic and aerobic cells that express CA IX, since antibody binding is also observed upon reoxygenation. CAI binding and co-localization with the antibody is only observed under hypoxia exposure. Our data suggest that CAI imaging probes are promising to pursue because of their ability to discriminate between such areas. 


\section{Conclusion}

Not only CA IX expression, but also the presence of active CA IX is necessary to enable CA IX sulfonamide inhibitor binding. These requirements are only obtained under hypoxia exposure. CA IX inhibitor binding is HIF-1a and cell-type independent. This allows for the distinction between actual and previously hypoxic cells. Furthermore, our data suggest an attractive possibility not only for imaging of fluctuating hypoxia in vivo, as currently under investigation, but also for increasing radiotherapy efficiency by specific targeting of CA IX. This may finally lead to individualized patient treatment.

\section{Acknowledgements}

This work was financially supported by the LSCH-CT-2003502932/Euroxy $6^{\text {th }}$ framework grant. We especially thank $\mathrm{Dr} \mathrm{J}$ Pastorek (Institute of Virology of the Slovak Academy of Science of the Slovak Republic) and $\mathrm{Dr} J$ Zavada (Institute of Molecular Genetics, Academy of Science of the Czech Republic) for the use of M75 MAb for research purposes. 


\section{References}

1. Nordsmark M. and Overgaard J. A confirmatory prognostic study on oxygenation status and loco-regional control in advanced head and neck squamous cell carcinoma treated by radiation therapy. Radiother Oncol, 2000. 57(1): p. 39-43.

2. Kaanders J.H., Wijffels K.I., Marres H.A., et al. Pimonidazole binding and tumor vascularity predict for treatment outcome in head and neck cancer. Cancer Res, 2002. 62(23): p. 7066-74.

3. Nordsmark M., Bentzen S.M., Rudat V., et al. Prognostic value of tumor oxygenation in 397 head and neck tumors after primary radiation therapy. An international multicenter study. Radiother Oncol, 2005. 77(1): p. 18-24.

4. Fyles A., Milosevic M., Pintilie M., et al. Long-term performance of interstial fluid pressure and hypoxia as prognostic factors in cervix cancer. Radiother Oncol, 2006. 80(2): p. $132-7$

5. Nordsmark M., Loncaster J., Aquino-Parsons C., et al. The prognostic value of pimonidazole and tumour pO2 in human cervix carcinomas after radiation therapy: a prospective international multi-center study. Radiother Oncol, 2006. 80(2): p. 12331.

6. Brown J.M. and Wilson W.R. Exploiting tumour hypoxia in cancer treatment. Nat Rev Cancer, 2004. 4(6): p. 437-47.

7. Magagnin M.G., Koritzinsky M., and Wouters B.G. Patterns of tumor oxygenation and their influence on the cellular hypoxic response and hypoxia-directed therapies. Drug Resist Updat, 2006. 9(4-5): p. 185-97.

8. Semenza G.L. Targeting HIF-1 for cancer therapy. Nat Rev Cancer, 2003. 3(10): p. 721-32.

9. Ivan M., Kondo K., Yang H., et al. HIFalpha targeted for VHL-mediated destruction by proline hydroxylation: implications for 02 sensing. Science, 2001. 292(5516): p. 464-8.

10. Wiesener M.S., Munchenhagen P.M., Berger I., et al. Constitutive activation of hypoxia-inducible genes related to overexpression of hypoxia-inducible factor-1alpha in clear cell renal carcinomas. Cancer Res, 2001. 61(13): p. 5215-22.

11. Pastorekova S., Parkkila S., and Zavada J. Tumor-associated carbonic anhydrases and their clinical significance. Adv Clin Chem, 2006. 42: p. 167-216.

12. Wykoff C.C., Beasley N.J., Watson P.H., et al. Hypoxia-inducible expression of tumorassociated carbonic anhydrases. Cancer Res, 2000. 60(24): p. 7075-83.

13. Jonathan R.A., Wijffels K.I., Peeters W., et al. The prognostic value of endogenous hypoxia-related markers for head and neck squamous cell carcinomas treated with ARCON. Radiother Oncol, 2006. 79(3): p. 288-97.

14. Potter C.P. and Harris A.L. Diagnostic, prognostic and therapeutic implications of carbonic anhydrases in cancer. Br J Cancer, 2003. 89(1): p. 2-7.

15. Svastova E., Hulikova A., Rafajova M., et al. Hypoxia activates the capacity of tumorassociated carbonic anhydrase IX to acidify extracellular pH. FEBS Lett, 2004. 577(3): p. 439-45.

16. Svastova E., Zilka N., Zat'ovicova M, et al. Carbonic anhydrase IX reduces Ecadherin-mediated adhesion of MDCK cells via interaction with beta-catenin. Exp Cell Res, 2003. 290(2): p. 332-45.

17. Supuran C.T., Scozzafava A., and Casini A. Carbonic anhydrase inhibitors. Med Res Rev, 2003. 23(2): p. 146-89.

18. Alterio V., Vitale R.M., Monti S.M., et al. Carbonic anhydrase inhibitors: X-ray and molecular modeling study for the interaction of a fluorescent antitumor sulfonamide with isozyme II and IX. J Am Chem Soc, 2006. 128(25): p. 8329-35.

19. Cecchi A., Hulikova A., Pastorek J., et al. Carbonic anhydrase inhibitors. Design of fluorescent sulfonamides as probes of tumor-associated carbonic anhydrase IX that inhibit isozyme IX-mediated acidification of hypoxic tumors. J Med Chem, 2005. 48(15): p. 4834-41.

20. Pastorekova S., Zavadova Z., Kostal M., et al. A novel quasi-viral agent, MaTu, is a two-component system. Virology, 1992. 187(2): p. 620-6.

21. Chrastina A., Zavada J., Parkkila S., et al. Biodistribution and pharmacokinetics of 125I-labeled monoclonal antibody M75 specific for carbonic anhydrase IX, an intrinsic marker of hypoxia, in nude mice xenografted with human colorectal carcinoma. Int J Cancer, 2003. 105(6): p. 873-81.

22. Rafajova M., Zatovicova M., Kettmann R., et al. Induction by hypoxia combined with low glucose or low bicarbonate and high posttranslational stability upon 
reoxygenation contribute to carbonic anhydrase IX expression in cancer cells. Int J Oncol, 2004. 24(4): p. 995-1004.

23. Quennet V., Yaromina A., Zips D., et al. Tumor lactate content predicts for response to fractionated irradiation of human squamous cell carcinomas in nude mice. Radiother Oncol, 2006. 81(2): p. 130-5.

24. Sorensen B.S., Hao J., Overgaard J., et al. Influence of oxygen concentration and pH on expression of hypoxia induced genes. Radiother Oncol, 2005. 76(2): p. 187-93.

25. Vordermark D., Kaffer A., Riedl S., et al. Characterization of carbonic anhydrase IX (CA IX) as an endogenous marker of chronic hypoxia in live human tumor cells. Int J Radiat Oncol Biol Phys, 2005. 61(4): p. 1197-207.

26. Tatum J.L., Kelloff G.J., Gillies R.J., et al. Hypoxia: importance in tumor biology, noninvasive measurement by imaging, and value of its measurement in the management of cancer therapy. Int J Radiat Biol, 2006. 82(10): p. 699-757.

27. Hutchison G.J., Valentine H.R., Loncaster J.A., et al. Hypoxia-inducible factor 1alpha expression as an intrinsic marker of hypoxia: correlation with tumor oxygen, pimonidazole measurements, and outcome in locally advanced carcinoma of the cervix. Clin Cancer Res, 2004. 10(24): p. 8405-12.

28. Loncaster J.A., Harris A.L., Davidson S.E., et al. Carbonic anhydrase (CA IX) expression, a potential new intrinsic marker of hypoxia: correlations with tumor oxygen measurements and prognosis in locally advanced carcinoma of the cervix. Cancer Res, 2001. 61(17): p. 6394-9. 


\section{Chapter 6}

Imaging of CA IX with fluorescent labelled sulfonamides distinguishes hypoxic and (re)oxygenated cells in a xenograft tumor model

Dubois L, Lieuwes NG, Maresca A, Thiry A, Supuran CT, Scozzafava A, Wouters BG, Lambin P

Radiother Oncol. 2009 Sep;92(3): 423-428 


\begin{abstract}
Background and Purpose: Carbonic anhydrase (CA) IX is suggested to be an endogenous marker of hypoxia. Fluorescent sulfonamides with high affinity for CA IX (CAI) have been developed and shown to bind to cells only when CA IX protein was expressed and while cells were hypoxic. The aim of this study was to investigate the in vivo CAI binding properties in a xenograft tumor model using fluorescent imaging.

Material and Methods: NMRI-nu mice subcutaneously transplanted with HT-29 colorectal tumors were treated with 7\% oxygen or with nicotinamide and carbogen and were compared with control animals. CAI accumulation was monitored by noninvasive fluorescent imaging.

Results: Specific CAI accumulation could be observed in delineated tumor areas as compared with a non-sulfonamide analogue $(P<$ 0.01 ). Administration of nicotinamide and carbogen, decreasing acute and chronic hypoxia, respectively, prevented CAI accumulation $(P<0.05)$. When treated with $7 \%$ oxygen breathing, a 3-fold higher CAI accumulation $(P<0.01)$ was observed. Furthermore, the bound CAI fraction was rapidly reduced upon tumor reoxygenation $(P<0.01)$.

Conclusions: Our in vivo imaging results confirm previous in vitro data demonstrating that CAI binding and retention require exposure to hypoxia. Fluorescent labeled sulfonamides provide a powerful tool to visualize hypoxia response. An important step is made towards clinical applicability, indicating the potential of patient selection for CA IX-directed therapies.
\end{abstract}




\section{Introduction}

The efficacy of conventional cancer treatment modalities has been hampered by the presence of low oxygen regions heterogeneously distributed within solid tumors. These regions, collectively referred to as the hypoxic fraction, arise as a result of the unusual, chaotic and insufficient organization of blood vessels in the tumors ${ }^{1}$. The importance of hypoxia has been demonstrated clinically, where it is an independent predictor of poor survival in several types of cancer $^{2}, 3$. This unique tumor micro-environment characteristic makes hypoxia an attractive target for newly developed drugs to increase the therapeutic effect of conventional cancer treatment modalities ${ }^{4}$. Treatments to counteract the negative effect of intratumoral hypoxia are being evaluated ${ }^{5,6}$, but not all patients show benefits from such selective treatments. To guide hypoxia-directed therapies in individual patients, a variety of methods to measure tumor oxygenation are available ${ }^{7}$.

In response to hypoxia, the transcription factor HIF-1a is stabilized and activated ${ }^{8}$. One of the most investigated targets of HIF-1a is carbonic anhydrase (CA) IX, containing a HRE element essential for its transcriptional activation upon hypoxia ${ }^{9}$. CA IX expression is heavily increased in a variety of human tumors and is associated with poor prognosis and tumor progression ${ }^{10,11}$. CA IX is also involved in increased invasion and metastasis via its capacity to acidify the extracellular environment during hypoxia ${ }^{12}$, 13. This suggests that CA IX may be an attractive target for diagnosis and therapy.

Recently, fluorescent sulfonamides with high affinity for CA IX (inhibition constant $K_{\mathrm{i}}=24 \mathrm{nM}^{14}$ ) have been developed. Our group and others have demonstrated in vitro that sulfonamide binding to CA IX requires both its expression and its activation and this was 
observed exclusively during conditions of hypoxia in several cell lines tested, irrespective of the levels of CA IX or HIF-1a activity. This indicates that the active site of CA IX is only available for sulfonamide binding during hypoxia ${ }^{12,}{ }^{15}$. Furthermore, CA IX sulfonamides are able to discriminate between actual and previously hypoxic cells, while the antibody against CA IX does not, suggesting a possibility to image hypoxia response ${ }^{12}$. Based on these previously published results, we further investigated the in vivo sulfonamide accumulation using noninvasive fluorescence imaging.

\section{Materials and Methods}

Cell culture, animal and tumor model

Exponentially growing colorectal (HT-29, ATCC HTB-38) carcinoma cells were cultured in Dulbecco's modified Eagle's medium supplemented with $10 \%$ fetal bovine serum. Hypoxic conditions were acquired as previously described ${ }^{12}$. In parallel, normoxic dishes were incubated in air with $5 \% \mathrm{CO}_{2}$. Animal experiments were performed using adult NMRI-nu ( $\mathrm{nu} / \mathrm{nu}$ ) female mice with an average body weight of $30 \mathrm{~g}$. The animal facilities and experiments were in accordance with local institutional guidelines for animal welfare and were approved by the Animal Ethical Committee of the University. HT-29 cells were resuspended in Basement Membrane Matrix (Matrigel ${ }^{\mathrm{TM}}$ BD Biosciences) and injected subcutaneously into the lateral flank of the animal. When tumors reached an average volume of $400 \mathrm{~mm}^{3}$, animals were injected with fluorescent labeled sulfonamide via a lateral tail vein. 
Sulfonamide, nicotinamide and carbogen breathing, 7\% oxygen breathing treatment

The fluorescent labeled sulfonamide directed against CA IX $(\mathrm{CAI}(+))$ has been synthesized as previously described ${ }^{14}$. For the animal experiments, the sulfonamide was dissolved in $\mathrm{NaCl} 0.9 \%$ containing $1 \%$ DMSO to a final concentration of $45 \mathrm{mg} / \mathrm{kg}$. In parallel, a fluorescent analogue without sulfonamide group (inhibition constant $K_{\mathrm{i}}>100 \mu \mathrm{M}$, Supuran et al., unpublished observations) was used as negative control (CAI(-)) and was prepared similarly. Nicotinamide (Sigma-Aldrich) was injected intraperitoneally at a concentration of $500 \mathrm{mg} / \mathrm{kg}$. For carbogen $\left(95 \% \mathrm{O}_{2}, 5 \% \quad \mathrm{CO}_{2} ; \mathrm{NTG} \mathrm{Sol}\right.$ ) and $7 \%$ oxygen (residual $\mathrm{N}_{2}$ ) breathing, animals were placed in an induction chamber with a continuous flow of 5 and $2.5 \mathrm{l} / \mathrm{min}$ respectively.

\section{FACS analysis}

Cells were incubated with $2 \mu \mathrm{M}$ syto 41 blue (hypoxic cells) or syto 84 orange (normoxic and reoxygenated cells) fluorescent nuclear marker (Invitrogen) 5 min before fixation in freshly prepared $2 \%$ paraformaldehyde. Normoxic, hypoxic and reoxygenated cells were mixed in equal amounts $(1: 1: 1)$ and a single cell suspension was obtained using 70- $\mu \mathrm{m}$ nylon cell strainers (BD biosciences). Signals were gated by fluorescent nuclear marker color and the mean green fluorescent intensity of each group was analyzed using a FACSAria ${ }^{\circledR}$ flow cytometer (BD biosciences). Data are corrected for background signals and normalized to the signal intensity of cells incubated with $\mathrm{CAI}(+)$ under normoxia. 


\section{Immunoblotting}

Experiments were performed as previously described ${ }^{12}$. Briefly, whole cell extracts were resolved on a $10 \%$ SDS-polyacrylamide

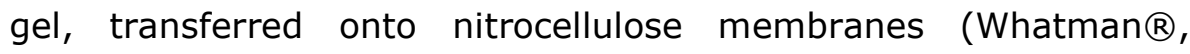
Protran) and probed overnight with antibodies to CA IX M75 (Bayer $\mathrm{USA}^{16}{ }^{16}$ ) or $\beta$-actin (Cell Signaling). Proteins were visualized by a horseradish peroxidase method using SuperSignal West Pico Chemiluminescence Substrate (Thermo Scientific).

\section{Imaging acquisition and analysis}

Animals were positioned on a heating path and anesthetized using isoflurane (flow 2-2.5 l/min). Fluorescent images were acquired with the Optix-MX2 (ART Advanced Research Technologies Inc., Montreal, Canada) using a scan resolution of $1 \mathrm{~mm}$ and a 470-nm pulsed laser diode with $40 \mathrm{MHz}$ frequency and 25-ns time window. Emitted photons were collected through a 494 Long Pass and a 525-nm Band Pass filter (band width of $25 \mathrm{~nm}$ ). Images were analyzed using Optix-MX2 Optiview Software (version 2.01.00). Raw intensity images were reconstructed based on fluorescence lifetime (FIT-C: $2.75 \mathrm{~ns}$ ) and mean intensity values were obtained within a rectangular ROI on these images.

\section{Statistics}

All statistical analyses were performed with GraphPad Prism version 5.01 for Windows (GraphPad Software, 2007, California, USA). Unpaired Student's $t$-test and non-parametric Mann-Whitney $U$ test for small groups were used to determine the statistical significance of differences between two independent groups of variables. For all tests, a $P<0.05$ was considered significant. 


\section{Results}

In vitro CAI(+) accumulation in HT-29 tumour cells

To mimic the tumor micro-environment, HT-29 cells were exposed either to normoxia (24h), hypoxia ( $24 \mathrm{~h} 0.2 \%$ ) or reoxygenation ( $24 \mathrm{~h}$ hypoxia $0.2 \%$, followed by $1 \mathrm{~h}$ normoxia) conditions, and were incubated with $\mathrm{CAI}(+)$ for the last $30 \mathrm{~min}$ of the different exposures. Cells were stained with nuclear markers to identify hypoxic or (re)-oxygenated groups, mixed and analyzed. Flow cytometry demonstrated a significant higher $\mathrm{CAI}(+)$ accumulation $(P<0.01)$ in hypoxic (Syto 41 gated) cells, compared with their normoxic or reoxygenated (Syto 84 gated) counterparts (Fig. 1A).

A

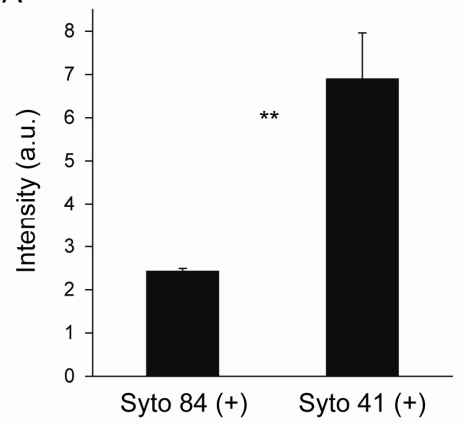

B

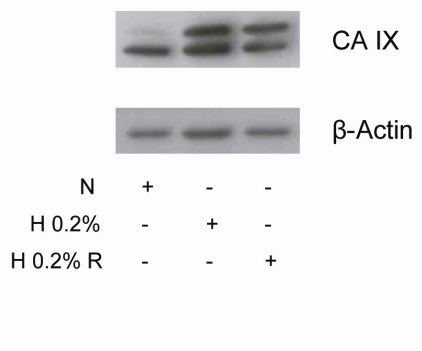

Figure 1. (A) FACS analysis of $\mathrm{CAI}(+)$ accumulation in hypoxic (Syto 41 gated) and (re)-oxygenated (Syto 84 gated) HT-29 carcinoma cells. Data demonstrate the fold accumulation compared with $\mathrm{CAI}(+)$-treated normoxic cells and are represented by the mean \pm SD of three independent experiments. Asterisk indicates significant difference $(* * P<0.01)$. (B) Western blot analysis of CA IX expression in normoxic $\left(21 \% \mathrm{O}_{2}, 24 \mathrm{~h}\right)$, hypoxic $\left(0.2 \% \mathrm{O}_{2}, 24 \mathrm{~h}\right)$ or reoxygenated $\left(0.2 \% \mathrm{O}_{2}, 24 \mathrm{~h}\right.$ followed by $1 \mathrm{~h}$ $\left.21 \% \mathrm{O}_{2}\right)$ HT-29 cells. $\beta$-Actin was used as loading control.

Presence of CA IX under hypoxia was confirmed by immunoblotting (Fig. 1B), which remained elevated upon reoxygenation. These data indicate that fluorescent sulfonamides can be used to 
distinguish hypoxic CA IX-positive cells from normoxic cells CA IXpositive or CA IX-negative cells.

\section{In vivo sulfonamide accumulation in a xenograft tumour model}

Accumulation of fluorescent sulfonamide $(\mathrm{CAI}(+))$ in $\mathrm{HT}-29$ tumors was evaluated at several time points post injection (p.i.) using noninvasive fluorescence imaging.

A

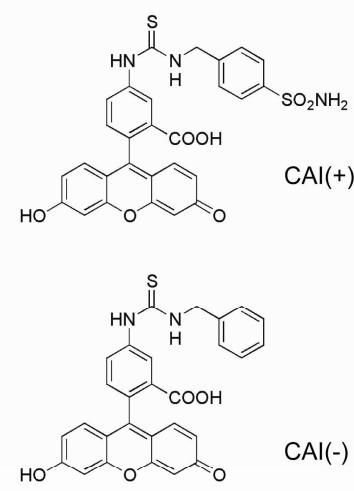

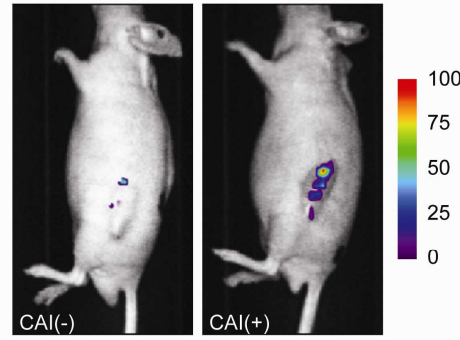

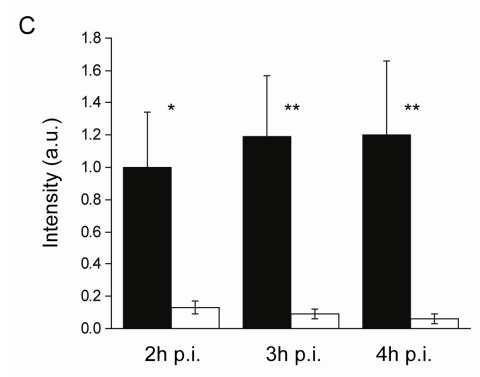

Figure 2. (A) Chemical structures of the fluorescent labeled sulfonamide $\mathrm{CAI}(+)$ and the non-sulfonamide analogue $\mathrm{CAI}(-)$. (B) Representative images of HT-29 tumor-bearing mice injected with CAI(-) or CAI $(+)$. Both images are scaled to the maximum intensity value (set to $100 \%$ ) within the image. (C) Quantification of $\mathrm{CAI}(+)$ (black) and $\mathrm{CAI}(-)$ (white) accumulation at several time points. Data represent the mean \pm SD of 10 independent animals. Asterisks indicate significant difference $(* P<0.05$; $* * P<0.01)$. 
In parallel, a fluorescent analogue, lacking the critical CA IX interaction sulfonamide group ( $\mathrm{CAI}(-))$, was used as negative control. The chemical structures of both compounds are shown in Fig. 2A. A clear accumulation was found in delineated hotspots in the tumor after injection of $\mathrm{CAI}(+)$ compared with the negative control (Fig. 2B). Each image is scaled to the maximum intensity within the image in order to visualize possible accumulation of the negative control. $\mathrm{CAI}(+)$ accumulation was significantly higher ( $P$ $<0.01$ ) at all investigated time points (Fig. 2C). Furthermore, $\mathrm{CAI}(+)$ accumulation seemed to increase over time, while CAI(-) uptake decreased, although these trends were not significant, resulting in a 20 -fold increase at $4 \mathrm{~h}$ p.i.

Sulfonamide accumulation in vivo is oxygen dependent

Previous studies have demonstrated that tumor hypoxia can be reduced by increasing the oxygen delivery through administration of carbogen (for chronic hypoxia) in combination with nicotinamide (for acute hypoxia) ${ }^{17}$. To test the hypothesis that sulfonamide accumulation is dependent not only on the presence of CA IX protein, but also on available oxygen we used two short-term treatments to transiently modify tumor oxygenation. To increase or decrease tumor hypoxia, HT-29 tumor-bearing animals were exposed to an environment containing $7 \%$ oxygen or to a combination of nicotinamide and carbogen, respectively, according to the scheme in Fig. 3A. $\mathrm{CAI}(+)$ accumulation was significantly lower (6-fold; $P<0.05$ ) after treatment with a combination of nicotinamide and carbogen (Fig. 3B) compared with non-treated animals. This reduced accumulation persisted over time (Fig. 3C), while no loss in CA IX protein expression was observed (data not shown), indicating that the CA IX open-active-site conformation is 
lost. On the other hand, when animals were treated with $7 \%$ oxygen, a significant increase (3-fold; $P<0.01$ ) in $\mathrm{CAI}(+)$ accumulation was observed (Fig. 3B) compared with non-treated animals, which persisted over time (Fig. 3C). These results confirm that CAI binding in vivo is influenced positively by hypoxic conditions and also indicate that a substantial amount of CA IX protein in the tumor does not bind $\mathrm{CAI}(+)$ under ambient conditions, presumably due to the fact that some of the cells expressing CA IX are not (no longer) hypoxic.

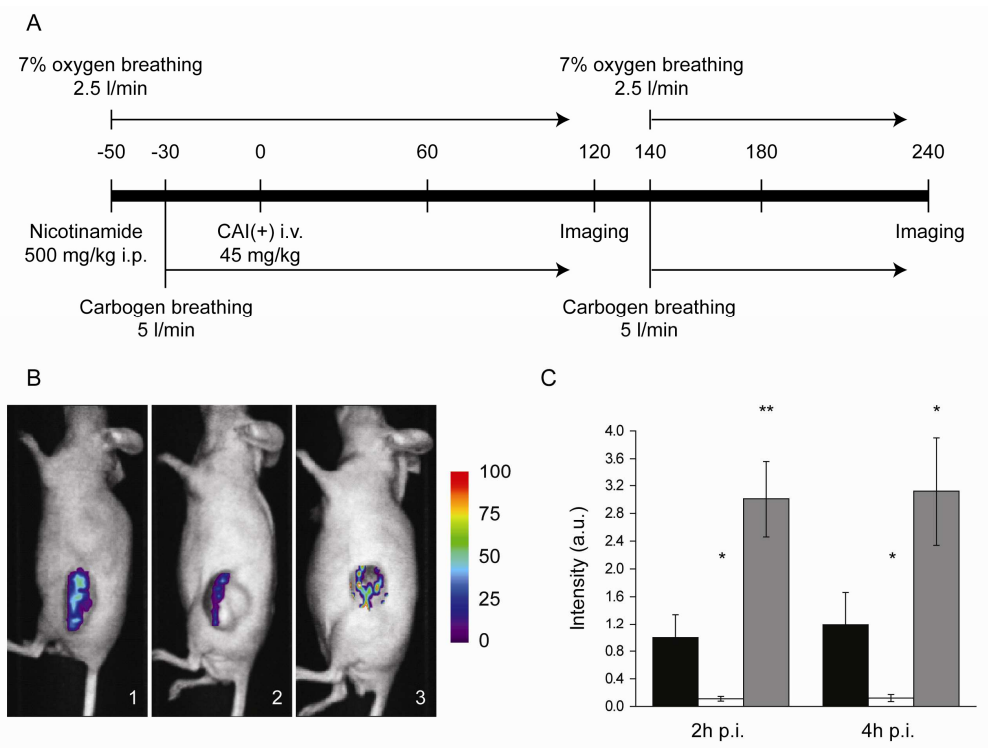

Figure 3. (A) Treatment schedule and experimental design. Animals are injected with $\mathrm{CAI}(+)$ at time $=0 \mathrm{~min}$. Numbers represent minutes before and after injection. (B) Representative images of non-treated mice (number 1 ), mice treated with nicotinamide and carbogen (number 2 ) or with $7 \%$ oxygen (number 3 ). Images are scaled to the maximum intensity value (set to $100 \%$ ) of all images. (C) Quantification of CAI(+) accumulation in animals treated with nicotinamide and carbogen (white) or with $7 \%$ oxygen (gray) compared to no treatment (black) at several time points. Data represent the mean \pm SD of at least 7 independent animals. Asterisk indicates significant difference $(* P<0.05, * * P<0.01)$ compared to no treatment. 


\section{Sulfonamide accumulation in vivo is reversible}

To investigate loss of fluorescent signal in HT-29 tumors exposed to $\mathrm{CAI}(+)$ during hypoxia followed by reoxygenation, animals were treated according to the schedule shown in Fig. 4A.

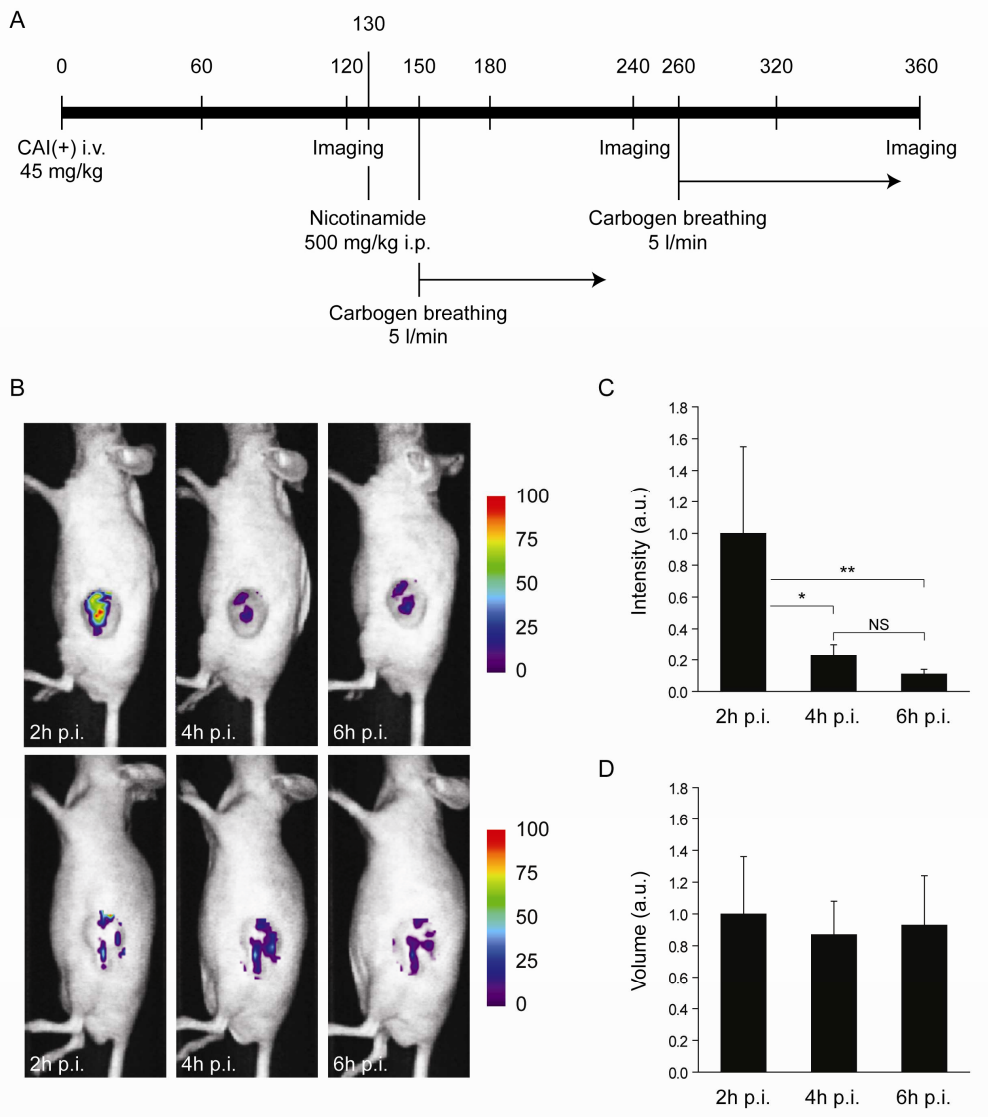

Figure 4. (A) Treatment schedule and experimental design. Animals are injected with $\mathrm{CAI}(+)$ at time $=0$. Numbers represent minutes before and after injection. Representative images (B), quantification (C) of loss of hypoxic $\mathrm{CAI}(+)$ accumulation and corresponding volumes (D) upon introduction of oxygen. Images are scaled to the maximum intensity value (set to $100 \%$ ) of the corresponding $2 \mathrm{~h} \mathrm{p.i.} \mathrm{image.} \mathrm{Data} \mathrm{represent} \mathrm{the} \mathrm{mean}$ \pm SD of 7 independent animals. Asterisks indicate significant difference ( $* P$ $<0.05 ; * * P<0.01)$. NS, not significant. 
$\mathrm{CAI}(+)$ accumulation was allowed for 2 hours, enough to acquire a significant uptake (Fig. 2B) in the tumor, followed by administration of a combination of nicotinamide and carbogen to reoxygenate the tumor. Again a clear $\mathrm{CAI}(+)$ accumulation was observed $2 \mathrm{~h}$ after fluorescent sulfonamide injection (Fig. 4B). Introduction of oxygen in the tumor by a combination of nicotinamide and carbogen, lead to a significant $(P<0.05)$ reduction in $\mathrm{CAI}(+)$ accumulation (Fig. $4 \mathrm{~B}$ and $4 \mathrm{C}$ ) $2 \mathrm{~h}$ after treatment, indicating a reversible accumulation. At later time points, accumulation was further reduced $(P<0.01$ compared with the intensity before treatment), although no statistical significance $(P=0.073)$ was reached comparing 2 and $4 \mathrm{~h}$ after treatment. We noticed a reduction in signal volume in some tumors (4/7) after treatment with nicotinamide and carbogen (Fig. 4B upper panel). In other tumors (3/7), although a clear reduction in signal intensity was observed with time, no decrease in signal volume was found (Fig. 4B lower panel). Analysis of all fluorescent volumes demonstrated a trend towards a reduction after treatment (Fig. 4D), but this was not significant ( 2 h p.i. $P=0.764$ and 4 h p.i. $P=0.892)$.

\section{Discussion}

Fluorescent labeled sulfonamides with high affinity for CA IX can be used to visualize hypoxic HT-29 cells characterized by active CA IX. CAI(+) accumulation correlated with a strong CA IX protein upregulation in HT-29 cells exposed to hypoxia. HT-29 cells also demonstrated intermediate CA IX expression under normoxic conditions, probably due to cell density-related CA IX expression ${ }^{18}$ and CA IX levels remained elevated upon reoxygenation, in 
agreement with the known CA IX half-life of $38 \mathrm{~h}^{19}$. Despite high CA IX levels in (re)-oxygenated HT-29 cells, only low CAI(+) accumulation was observed in our tumor simulation model. Previously, we obtained similar results in cervical and renal carcinoma cells ${ }^{12}$. Together, these results indicate that the binding site of CA IX is only available for sulfonamide retention during hypoxia.

We further investigated the in vivo $\mathrm{CAI}(+)$ accumulation in $\mathrm{HT}$ 29 tumor-bearing animals and demonstrated significantly higher fluorescent signals at several time points after injection compared with a fluorescent chemical analogue without sulfonamide group (20-fold increase at $4 \mathrm{~h}$ p.i.). These results are in agreement with the known inhibition constants of the used compounds. CAI $(+)$ has been shown to have a high affinity $\left(K_{\mathrm{i}}=24 \mathrm{nM}\right)$ for CA IX ${ }^{14}$, while for CAI(-) no inhibition at $100 \mu \mathrm{M}$ could be found (Supuran et al., unpublished observations). This accumulation was found to be localized in heterogeneously delineated regions in the tumor and was dependent on hypoxia as evidenced by the fact that little accumulation was observed when $\mathrm{CAI}(+)$ was administered shortly after a treatment combining nicotinamide and carbogen. Previously, it has been shown that this combination treatment is able to reduce tumor hypoxia in preclinical ${ }^{20}$ and clinical ${ }^{17}$ settings. Nicotinamide is thought to reduce perfusion-limited hypoxia by preventing intermittent vascular shutdown ${ }^{21}$, while carbogen breathing is able to reduce chronic hypoxia by increasing the oxygen diffusion distance ${ }^{22}$. Further evidence supporting the requirement of hypoxia to enable effective $\mathrm{CAI}(+)$ binding was demonstrated by a 3-fold higher accumulation following a brief period of $7 \%$ oxygen breathing, as compared with non-treated animals. Troost et al. demonstrated a similar increase in mean 
$\left[{ }^{18}\right.$ F]FMISO signal intensity in a glioblastoma model, although severe hypoxic conditions were obtained by clamping the tumor ${ }^{23}$. Previously, we found that the in vitro $\mathrm{CAI}(+)$ bound fraction under hypoxic conditions was gradually lost over time during reoxygenation, falling nearly to background levels after more than $1 \mathrm{~h}^{12}$. Our in vivo results demonstrate a similar reversible CAI(+) accumulation upon introduction of oxygen in the tumor. Although the loss of bound $\mathrm{CAI}(+)$ was slower compared to the in vitro data, the reduction is still much faster than the normal turnover of CA $\mathrm{IX}^{19}$, indicating loss of CAI retention. Analysis of the signal volume is another possible image analysis method, which has been shown to provide similar information as signal intensity about the global level of hypoxia ${ }^{23}$. In our study, a reduction in signal volume was noticed upon the combination treatment with nicotinamide and carbogen in part of the animals. A similar reduction in hypoxic volume, evaluated with pimonidazole staining or $\left[{ }^{18} \mathrm{~F}\right] \mathrm{FMISO}$ PET, was observed in experimental mice tumors with similar treatment ${ }^{20}, 24$. However, this reduction was not a general phenomenon and differences in response to nicotinamide and carbogen were observed previously in tumors of the same site and origin ${ }^{25}$. Quantification of all data did not result in a significant decrease in signal volume after treatment, although a significant reduction in signal intensity was seen. Furthermore, a correlation between expression and distribution of CA IX and pimonidazole staining is not straightforward, which is probably related to the function of CA IX in $\mathrm{pH}$-maintenance in different tissues ${ }^{26}$. Therefore, assessment of $\mathrm{CAI}(+)$ accumulation, CA IX protein levels and patterns in relation to hypoxia measured using pimonidazole, in the different described experimental conditions are currently under investigation. 
Hypoxia-directed therapy guidance in individual patients necessitates adequate measurements of tumor oxygenation. Several simple and efficient methods to image and evaluate oxygenation are under investigation $n^{4,7}$ and recently studies are focusing on molecular markers of hypoxia, such as CA IX. Selective and specific accumulation of the M75 antibody against CA IX labeled with iodine-125 was demonstrated in HT-29 xenografts in nude mice ${ }^{18}$. Also in rats bearing renal cell carcinoma tumors, specific uptake of the cG250 antibody against CA IX labeled with zirconium-89 could be visualized using a dedicated PET camera for small animals ${ }^{27}$. Although these results are promising, no discrimination can be made between hypoxic and aerobic cells expressing CA IX, since antibody binding occurs also upon reoxygenation. Our data however indicate that $\mathrm{CAI}(+)$ accumulation occurs only under hypoxia in HT-29 xenografts and this accumulation is reversible upon reoxygenation as previously shown in vitro $^{12}$. Based on these results, we are currently investigating the accumulation of a positron emitter labeled sulfonamide. 


\section{Conclusion}

Sulfonamides with high affinity for CA IX specifically accumulate in delineated regions of human xenografts. This accumulation is dependent on the presence of hypoxia and is reversible upon tumor reoxygenation, providing a tool to image hypoxia response. Furthermore, our data indicate the potential of patient selection for hypoxia-directed and/or CA IX-directed therapies.

\section{Acknowledgements}

This work has been funded with the support of the EU $6^{\text {th }}$ framework Program (Euroxy Project Ref. 2003-502932), the EU $7^{\text {th }}$ framework (Metoxia Project Ref. 2008-222741) and the Dutch Cancer Society (KWF Grant UM 2008-4068). 


\section{References}

1. Brown J.M. and Giaccia A.J. The unique physiology of solid tumors: opportunities (and problems) for cancer therapy. Cancer Res, 1998. 58(7): p. 1408-16.

2. Kaanders J.H., Wijffels K.I., Marres H.A., et al. Pimonidazole binding and tumor vascularity predict for treatment outcome in head and neck cancer. Cancer Res, 2002. 62(23): p. 7066-74

3. Nordsmark M. and Overgaard J. A confirmatory prognostic study on oxygenation status and loco-regional control in advanced head and neck squamous cell carcinoma treated by radiation therapy. Radiother Oncol, 2000. 57(1): p. 39-43.

4. Tatum J.L., Kelloff G.J., Gillies R.J., et al. Hypoxia: importance in tumor biology, noninvasive measurement by imaging, and value of its measurement in the management of cancer therapy. Int J Radiat Biol, 2006. 82(10): p. 699-757.

5. Brown J.M. and Wilson W.R. Exploiting tumour hypoxia in cancer treatment. Nat Rev Cancer, 2004. 4(6): p. 437-47.

6. Wouters B.G. and Koritzinsky M. Hypoxia signalling through mTOR and the unfolded protein response in cancer. Nat Rev Cancer, 2008. 8(11): p. 851-64.

7. Ebbesen P., Pettersen E.O., Gorr T.A., et al. Taking advantage of tumor cel adaptations to hypoxia for developing new tumor markers and treatment strategies. J Enzyme Inhib Med Chem, 2009. 24 Suppl 1: p. 1-39.

8. Semenza G.L. Targeting HIF-1 for cancer therapy. Nat Rev Cancer, 2003. 3(10): p. 721-32.

9. Wykoff C.C., Beasley N.J., Watson P.H., et al. Hypoxia-inducible expression of tumorassociated carbonic anhydrases. Cancer Res, 2000. 60(24): p. 7075-83.

10. Jonathan R.A., Wijffels K.I., Peeters W., et al. The prognostic value of endogenous hypoxia-related markers for head and neck squamous cell carcinomas treated with ARCON. Radiother Oncol, 2006. 79(3): p. 288-97.

11. Pastorekova S., Parkkila S., and Zavada J. Tumor-associated carbonic anhydrases and their clinical significance. Adv Clin Chem, 2006. 42: p. 167-216.

12. Dubois L., Douma K., Supuran C.T., et al. Imaging the hypoxia surrogate marker CA IX requires expression and catalytic activity for binding fluorescent sulfonamide inhibitors. Radiother Oncol, 2007. 83(3): p. 367-73.

13. Moellering R.E., Black K.C., Krishnamurty C., et al. Acid treatment of melanoma cells selects for invasive phenotypes. Clin Exp Metastasis, 2008. 25(4): p. 411-25.

14. Cecchi A., Hulikova A., Pastorek J., et al. Carbonic anhydrase inhibitors. Design of fluorescent sulfonamides as probes of tumor-associated carbonic anhydrase IX that inhibit isozyme IX-mediated acidification of hypoxic tumors. J Med Chem, 2005. 48(15): p. 4834-41.

15. Svastova E., Hulikova A., Rafajova M., et al. Hypoxia activates the capacity of tumorassociated carbonic anhydrase IX to acidify extracellular pH. FEBS Lett, 2004. 577(3): p. 439-45.

16. Pastorekova S., Zavadova Z., Kostal M., et al. A novel quasi-viral agent, MaTu, is a two-component system. Virology, 1992. 187(2): p. 620-6.

17. Kaanders J.H., Pop L.A., Marres H.A., et al. Accelerated radiotherapy with carbogen and nicotinamide (ARCON) for laryngeal cancer. Radiother Oncol, 1998. 48(2): p. 115-22.

18. Chrastina A., Zavada J., Parkkila S., et al. Biodistribution and pharmacokinetics of 125I-labeled monoclonal antibody M75 specific for carbonic anhydrase IX, an intrinsic marker of hypoxia, in nude mice xenografted with human colorectal carcinoma. Int J Cancer, 2003. 105(6): p. 873-81.

19. Rafajova M., Zatovicova M., Kettmann R., et al. Induction by hypoxia combined with low glucose or low bicarbonate and high posttranslational stability upon reoxygenation contribute to carbonic anhydrase IX expression in cancer cells. Int ] Oncol, 2004. 24(4): p. 995-1004.

20. van Laarhoven H.W., Bussink J., Lok J., et al. Effects of nicotinamide and carbogen in different murine colon carcinomas: immunohistochemical analysis of vascular architecture and microenvironmental parameters. Int J Radiat Oncol Biol Phys, 2004. 60(1): p. 310-21.

21. Chaplin D.J., Horsman M.R., and Trotter M.J. Effect of nicotinamide on the microregional heterogeneity of oxygen delivery within a murine tumor. J Natl Cancer Inst, 1990. 82(8): p. 672-6.

22. Powell M.E., Hill S.A., Saunders M.I., et al. Effect of carbogen breathing on tumour microregional blood flow in humans. Radiother Oncol, 1996. 41(3): p. 225-31. 
23. Troost E.G., Laverman P., Kaanders J.H., et al. Imaging hypoxia after oxygenationmodification: comparing [18F]FMISO autoradiography with pimonidazole immunohistochemistry in human xenograft tumors. Radiother Oncol, 2006. 80(2): p. 157-64.

24. Bentzen L., Keiding S., Horsman M.R., et al. Assessment of hypoxia in experimental mice tumours by [18F]fluoromisonidazole PET and pO2 electrode measurements. Influence of tumour volume and carbogen breathing. Acta Oncol, 2002. 41(3): p. $304-12$.

25. Bussink J., Kaanders J.H., Rijken P.F., et al. Vascular architecture and microenvironmental parameters in human squamous cell carcinoma xenografts: effects of carbogen and nicotinamide. Radiother Oncol, 1999. 50(2): p. 173-84.

26. Troost E.G., Bussink J., Kaanders J.H., et al. Comparison of different methods of CAIX quantification in relation to hypoxia in three human head and neck tumor lines. Radiother Oncol, 2005. 76(2): p. 194-9.

27. Brouwers A., Verel I., Van Eerd J., et al. PET radioimmunoscintigraphy of renal cell cancer using $89 \mathrm{Zr}$-labeled cG250 monoclonal antibody in nude rats. Cancer Biother Radiopharm, 2004. 19(2): p. 155-63. 


\section{Chapter 7}

Development and evaluation of a cetuximabbased imaging probe to target EGFR and EGFRvIII

Aerts HJWL" , Dubois L" Lieuwes NG, Jutten B, Weppler SA, Lammering G, Wouters BG, Lambin $P$

Radiother Oncol. 2007 Jun;83(3):326-332

\# these authors contributed equally

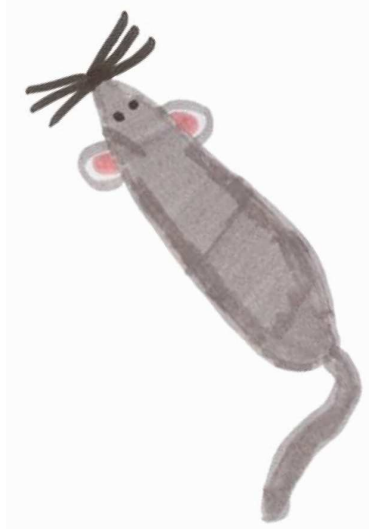




\begin{abstract}
Background and purpose: The epidermal growth factor receptor (EGFR) is overexpressed in a significant percentage of human malignancies and its expression is associated with tumor aggressiveness and treatment resistance. The monoclonal antibody cetuximab (IMC-C225) blocks the ligand-binding domain of EGFR with high affinity, preventing downstream signaling resulting in tumor growth inhibition. We developed and characterized a novel imaging probe using Oregon Green 488 labeled cetuximab to evaluate its usage as an imaging agent to target EGFR.

Materials and Methods: Cells with varying expression levels of EGFR or a mutant form of EGFR, called EGFRvIII, were used for in vitro validation. The in vivo binding of labeled cetuximab to EGFR was also assessed ex vivo on tumor material.

Results: The development of Oregon Green 488 labeled cetuximab was successful, demonstrating binding to both EGFR and EGFRvIII in vitro. Accumulation was also found in vivo, which was confirmed by histopathology using anti-EGFR antibodies. However, significant mismatch highlights differences between drug delivery in vivo, and cell expression levels of EGFR.

Conclusions: The monoclonal antibody cetuximab represents a promising probe to evaluate the biologic and pharmacokinetic effects of in vivo cetuximab binding to EGFR. It not only visualizes the presence of the wild type EGFR, but also the presence of the mutant EGFRvIII.
\end{abstract}




\section{Introduction}

The epidermal growth factor receptor (EGFR) plays an important role in tumor cell proliferation, differentiation and survival ${ }^{1,2}$. EGFR is highly expressed in a significant percentage of human malignancies and its expression is associated with tumor aggressiveness and treatment resistance ${ }^{3-6}$. Increasing evidence suggests that alterations within the EGFR gene may be as important as EGFR-overexpression to induce oncogenic effects. The most common variation is an in-frame deletion of exons 2-7 of the coding sequence resulting in a truncated mutant (EGFRvIII) which lacks a portion of the extracellular ligand-binding domain. Even though no ligand binding occurs, the tyrosine kinase in the intracellular portion is constitutively activated, leading to a receptor tyrosine autophosphorylation. EGFRvIII is expressed in certain tumors and its expression promotes tumor growth and therapy resistance ${ }^{7-9}$.

Blockade of EGFR function provides a promising approach for cancer treatment ${ }^{10-12}$. It has been shown that the human chimeric monoclonal antibody cetuximab (IMC-C225) blocks the ligandbinding domain of EGFR by binding to EGFR with high affinity, preventing downstream signaling which results in tumor growth inhibition $^{13-16}$. Consequently, cetuximab has evolved as a promising new targeting agent in oncology and is increasingly used in combination with chemo-/radiotherapy as standard treatment of solid tumors and/or metastases ${ }^{14,17-19}$. Due to the heterogeneity of EGFR expression and its modulation during treatment, an imaging tool to monitor and visualize the binding of cetuximab noninvasively in cancer patients would be of great advantage, resulting in better patient selection for anti-EGFR targeted therapy. In addition, it could dramatically increase our knowledge of the 
clinical use of cetuximab and would help to optimize and individualize treatment.

A few studies have already reported on attempts to monitor cetuximab binding by using radioisotopes, where EGFR-positive tumors have been visualized both in animal models and in patients using ${ }^{99 \mathrm{~m}} \mathrm{Tc}^{20,}{ }^{21}$ or ${ }^{64} \mathrm{Cu}^{22}$ labeled cetuximab. However, limitations exist in using radioisotopes in the laboratory in a daily practice. Therefore, we developed an Oregon Green 488 labeled cetuximab imaging probe (cetuximab-OG) to assess the biological properties of cetuximab as an imaging and targeting agent. Here, we report the development and an in vitro and in vivo evaluation of a cetuximab based imaging probe to target EGFR and/or EGFRVIII.

\section{Materials and Methods}

Oregon Green 488 labeling of cetuximab

Cetuximab (2 mg/ml; Merck, Germany) was dialyzed against Hepes-buffered saline (HBS: $25 \mathrm{mM}$ Hepes pH 7.4, $175 \mathrm{mM} \mathrm{NaCl}$ ) after which the protein concentration was determined by $A 280$ measurement $\left(\varepsilon^{1 \%}{ }_{280 \mathrm{~nm}}=14.2\right)$. Cetuximab $(12.1 \mu \mathrm{M} ; 155 \mathrm{kDa} ; 25$ $\mathrm{ml}$ ) was incubated with succinimidyl-acetylthioacetate (SATA) at $25 \mu \mathrm{M}$ (final concentration). Cetuximab-(Lys)-ATA was deacetylated by treatment with $50 \mathrm{mM}$ hydroxylamine, $2.5 \mathrm{mM}$ EDTA at $\mathrm{pH} 7.4$ for $1 \mathrm{~h}$ yielding cetuximab-(Lys)-SH. Incubation with 1 eq $(\mathrm{mol} / \mathrm{mol})$ of Oregon Green 488 (OG488)-maleimide resulted on average in a $1: 1$ labeling of cetuximab with OG488. Every reaction step was followed by analysis of 6 pmoles samples of the intermediate and final reaction product by MALDI-TOF mass spectrometry (Applied Biosystems MALDI TOF/TOF 4800) in linear high mass mode using sinapinic acid as a matrix. 


\section{In vitro cell model}

Human epidermoid carcinoma (A-431), breast carcinoma (T-47D), glioblastoma (U-373 MG, U-87 MG), cervix adenocarcinoma (HeLa), colorectal carcinoma (HT-29, LS174T, HCT116) and prostate cancer (DU145) cells were obtained from the American Type Culture Collection (ATCC) and maintained under standard conditions in the appropriate medium supplemented with $10 \%$ Fetal Bovine Serum (Hyclone, Logan, UT). U-373 MG cells were transfected with phßAcEGFRvIII using Lipofectamine Plus (Invitrogen) according the manufacturer's procedures. Forty-eight hours post transfection, geneticin selection was performed to obtain cells stably expressing EGFRvIII. The clone with the highest EGFRvIII expression, denoted U-373-vIII(+), as assessed by immunoblotting, was selected for further experiments. A clone with no EGFRvIII expression was selected as control, denoted U-373vIII(-). For all experiments, cells were plated at a density of $0.5 \times$ $10^{6}$ per $6 \mathrm{~cm}$ dish the day before.

\section{Immunoblotting}

Cells were extracted in RIPA lysis buffer for $30 \mathrm{~min}$ on ice and protein concentrations were determined by a Bradford assay (BioRad). Proteins were separated on a $10 \%$ SDS-polyacrylamide gel and transferred $\left(100 \mathrm{~V}, 1 \mathrm{~h}, 4^{\circ} \mathrm{C}\right)$ to nitrocellulose membranes (Amersham Corp.). Membranes were blocked (ON, $4^{\circ} \mathrm{C}$ ) with $5 \%$ Blotting Grade Blocker non-fat dry milk (BioRad) and subsequently incubated ( $2 \mathrm{~h}, \mathrm{RT})$, with a 1:1000 dilution of the anti-EGFR rabbit polyclonal antibody (sc-03, Santa Cruz Biotechnology, Santa Cruz, CA). Proteins were visualized by a horseradish peroxidase method using Enhanced Chemiluminescence (Amersham Corp.). Mouse monoclonal $\beta$-Actin (Sigma) was used as loading control. 


\section{Immunofluorescence}

Immunocytochemistry was performed on cells grown on plastic $10 \mathrm{~cm}$ dishes until $80 \%$ confluency and incubated with cetuximabOG $\left(60 \mathrm{nM}, 24 \mathrm{~h}, 37^{\circ} \mathrm{C}\right)$. Cells were washed 3 times using phosphate-buffered saline (PBS), fixed in $3 \mathrm{~mL}$ methanol on ice (10 min). Propidium iodide containing $1 \mu \mathrm{l} / \mathrm{ml}$ RNase (15min, RT) was used as nuclear marker. Immunohistochemistry was done on 7- $\mu \mathrm{m}$ frozen sections cut using a cryotome (Leica CM3050S). After thawing, the sections were fixed in cold $\left(10 \mathrm{~min}, 4^{\circ} \mathrm{C}\right)$ acetone and rehydrated in PBS. In between the consecutive steps of the staining procedure, sections were rinsed with PBS. Sections were incubated overnight $\left(4^{\circ} \mathrm{C}\right)$ with the primary EGFR antibody (sc-03, Santa Cruz), followed by incubation (30 min, RT) with goat antirabbit Alexa fluor 594 conjugated IgG antibody (Molecular Probes). Cells and sections were mounted with Fluorescent Mounting Medium (DAKO) and analyzed using a Leica DM5000B fluorescence microscope (Leica Microsystems). The EGFR epitope binding sites of cetuximab (310-514) and sc-03 (1005-1016) are different ${ }^{23}$. Quantitative analysis of the overlap between the cetuximab-OG and the EGFR antibody was assessed using the difference in fluorescence intensity. The images were normalized using a multiplication of the median intensity. The overlap area of cetuximab-OG uptake and EGFR expression was calculated using a difference less then $20 \%$ of the maximum.

\section{Flow cytometric analysis}

After three hours of incubation with cetuximab-OG at $37^{\circ} \mathrm{C}$ (concentration ranging from $5.2 \mathrm{fM}-5.2 \mu \mathrm{M}$ ), cells were put on ice, washed with PBS and harvested. After resuspension in PBS, the cetuximab-OG labeled cells were fixed with fresh $2 \%$ 
paraformaldehyde (30 min, RT). Single cell suspensions were obtained by passing cells through $70 \mu \mathrm{m}$ nylon cell strainers (BD Biosciences). Mean fluorescence intensity was obtained using a FACSaria ${ }^{\circledR}$ flow cytometer (BD Biosciences) using FIT-C filter settings.

Animal and tumor model

Colorectal HT-29 carcinoma cells were subcutaneously injected in NMRI-nu (nu/nu) female mice (28-32 gram) under anesthesia. When tumors reached a volume of $500 \mathrm{~mm}^{3}$, animals were injected with $100 \mathrm{\mu g}$ cetuximab-OG via a lateral tail vein. After 5 days, to ensure good uptake of cetuximab-OG into the tumor tissue, the animals were sacrificed and the tumors were excised. All animal experiments were in agreement with national guidelines, approved by the Animal Ethics Committee of the University 'KU Leuven', Belgium. Isoflurane inhalation anesthesia (induction $4 \%$ and maintenance 1-2\%) was used during all animal experiments.

\section{Results}

Oregon Green 488 labeling of cetuximab

Cetuximab was successfully labeled with OG488 at an average 1:1 stoichiometry (Fig. 1A). After incubation of cetuximab with succinimidyl-acetylthioacetate (SATA), MALDI-TOF mass spectrometry showed an approximate $100 \mathrm{Da}$ increase of molecular weight (theoretical: $116 \mathrm{Da}$ ), showing that on average a 1:1 SATA-cetuximab reaction had occurred (data not shown). Deacetylation by hydroxylamine resulted in a mass decrease of approximately $50 \mathrm{Da}$ (theoretical: $42 \mathrm{Da}$ ) corresponding to the loss of one acetyl group and generation of a free sulfhydryl moiety on a 
lysine side-chain (data not shown). Incubation with 1 eq. OG488maleimide for $2 \mathrm{~h}$ yielded cetuximab-OG in an average 1:1 stoichiometry according to MALDI-TOF mass spectral analysis (Fig. 1B). A total mass increase of $500 \mathrm{Da}$ was observed, in good agreement with the mass increase of one OG488 (theoretical mass: $436 \mathrm{Da}$ ) coupled through one thioacetate linker (theoretical mass: $74 \mathrm{Da})$.

A
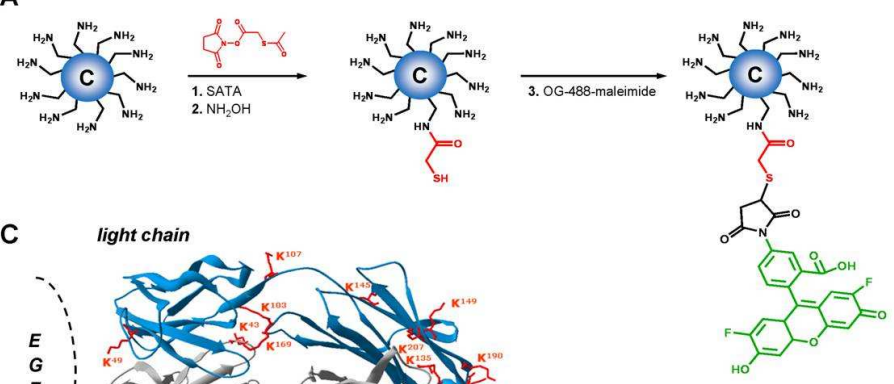

C light chain
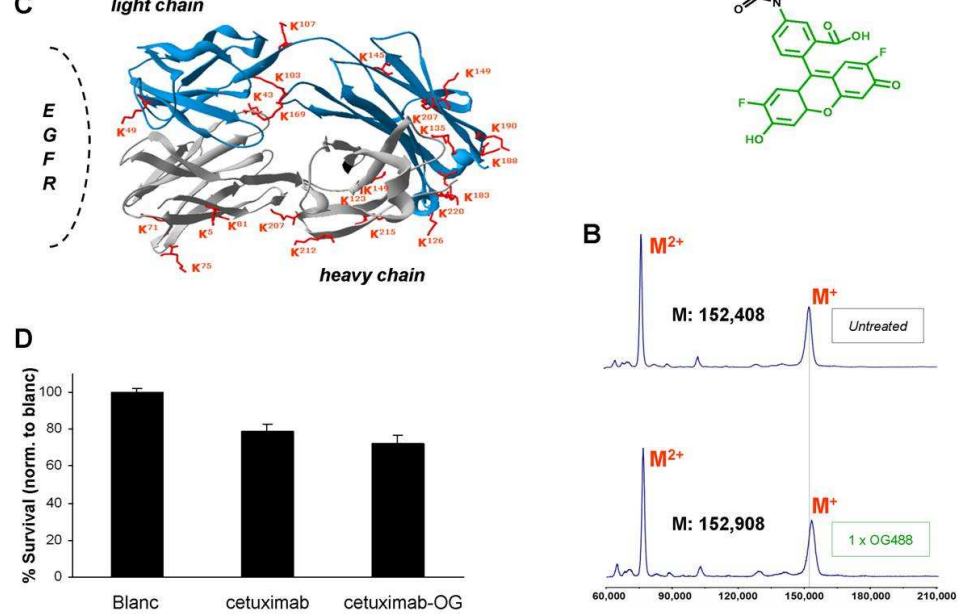

Figure 1. Labeling of cetuximab with Oregon Green 488. (A) Synthetic scheme of cetuximab (sphere $C$ ) labeling through its lysine side-chains ($\mathrm{NH}_{2}$ ) by coupling succinimidyl-acetylthioacetate (SATA) followed by deacetylation by hydroxylamine $\left(\mathrm{NH}_{2} \mathrm{OH}\right)$, and subsequent reaction with Oregon Green 488 (OG488)-maleimide. (B) Linear MALDI-TOF mass spectrum of unlabeled and OG488-labeled cetuximab showing the single and double charged state of the protein. (C) Crystal structure of the Fab fragment of cetuximab, adapted from ${ }^{23}$, showing the 23 lysine residues in the light (blue) and heavy (grey) chain that can be potentially modified. The binding site for EGFR is indicated. (D) Clonogenic survival of HT-29 cells treated with non-labeled or OG-labeled cetuximab (60 nM), normalized to non-treatment (Blanc). 
By using the described random labeling procedure it is possible that lysine side-chain modification might affect protein function. When analyzing the crystal structure of the Fab fragment of cetuximab, 23 lysine residues are visible in the light (blue) and heavy (grey) chain that can be modified ${ }^{23}$. However, only 1 lysine residue becomes apparent in the receptor-binding area of cetuximab (Fig. 1C) thereby minimizing chances on functional impairment of cetuximab by the labeling procedure. In addition, no significant differences $(P=0.408)$ between non-labeled and labeled cetuximab (79 $\pm 3.7 \%$ and $72 \pm 5 \%$ ) were seen in a clonogenic survival assay using a therapeutic dose of $60 \mathrm{nM}$ on HT29 cells (Fig. 1D).

\section{In vitro analysis}

The cetuximab-OG binding to EGFR was first investigated in A-431 cells using immunofluorescence (Fig. 2A). A clear membranous binding localization of cetuximab-OG was observed.

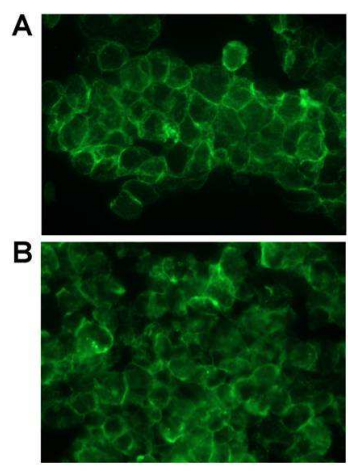

cetuximab-OG
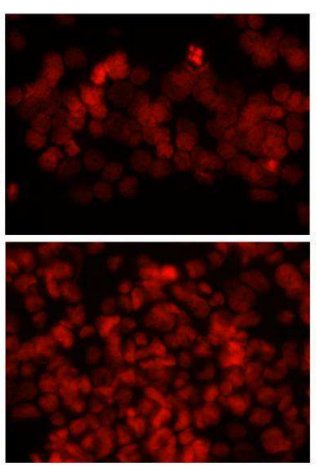

nuclear staining

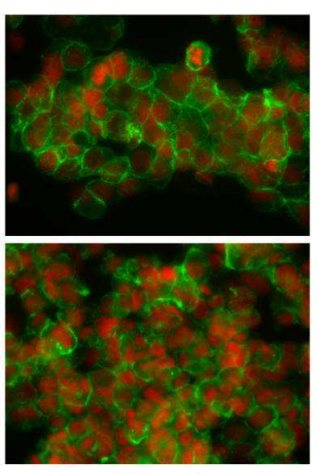

Merged

Figure 2. Immunofluorescence analysis of (A) A-431 and (B) U-373VIII(+) cells incubated for $24 \mathrm{~h}$ with cetuximab-OG. Propidium iodide was used for nuclear staining. 
In addition, we investigated if cetuximab-OG binds to EGFRvIII, using the U-373-VIII(+) transfected cells. Also in these cells, membranous staining after incubation with cetuximab-OG was seen (Fig. 2B), indicating that cetuximab-OG binds not only EGFR, but also EGFRvIII. The EGFR fraction of the U-373-vIII(+) transfected cells was limited, as assessed with immunofluorescence on the U-373-vIII(-) cell line (data not shown).

Quantitative binding of cetuximab to EGFR was determined using a flow cytometry saturation experiment. Expression of EGFR and EGFRVIII was assessed with a panel of cell lines using Western blotting (Fig. 3A). As expected, A-431 cells demonstrated high expression of EGFR, while T-47D cells showed limited expression. The U-373-vIII(+) cells showed high expression of the EGFRvIII, while the U-373-VIII(-) cells only demonstrated EGFR expression in comparable levels as the U373 cells. The other investigated cell lines showed different levels of intermediate EGFR expression. In order to find the optimal experimental binding conditions a saturation experiment with the high (A-431) and low (T-47D) EGFR expressing cells was performed (Fig. 3B). Both cell lines were incubated for $3 \mathrm{~h}$ with cetuximab-OG, using a range of concentrations $(5.2 \mathrm{fM}-5.2 \mu \mathrm{M})$. Clear cetuximab-OG binding was observed in A-431 cells, while the binding to T-47D cells was comparable to background levels. The cetuximab-OG saturation point for A-431 cells was $5.2 \mathrm{nM}$. All other cell lines were analyzed at this concentration to assure sufficient cetuximab-OG presence (Fig. 3C). T-47D signals were used as negative control in all experi-ments. As shown previously, the cetuximab-OG binding to A-431 cells was high and on average 50-fold higher compared with the negative control. Also binding to U-373-VIII(+) was high (on average 40fold), showing primarily binding of cetuximab-OG to EGFRvIII. 
A

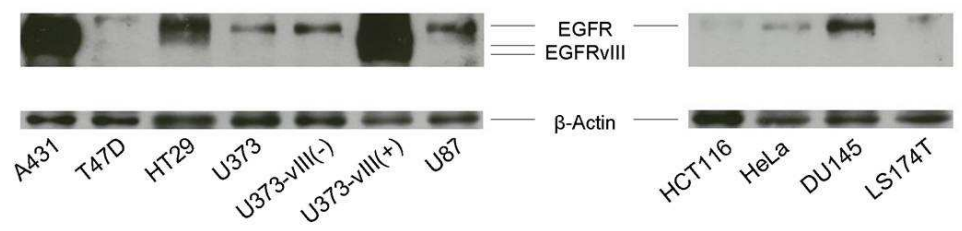

B

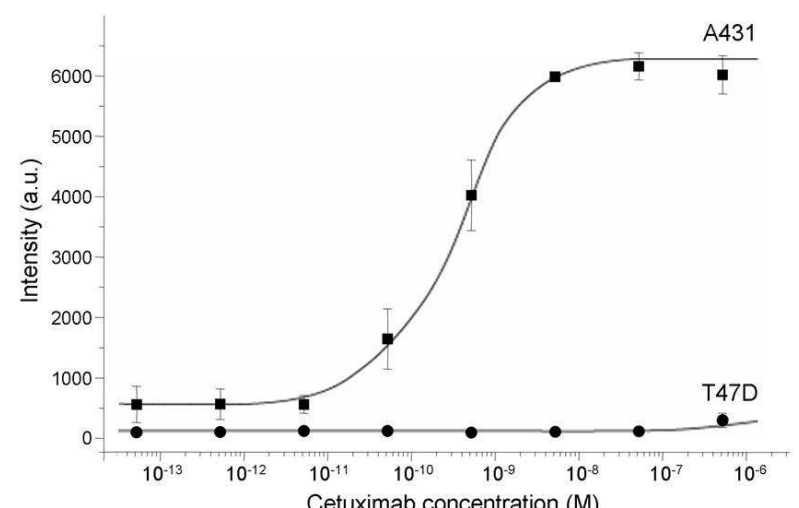

C

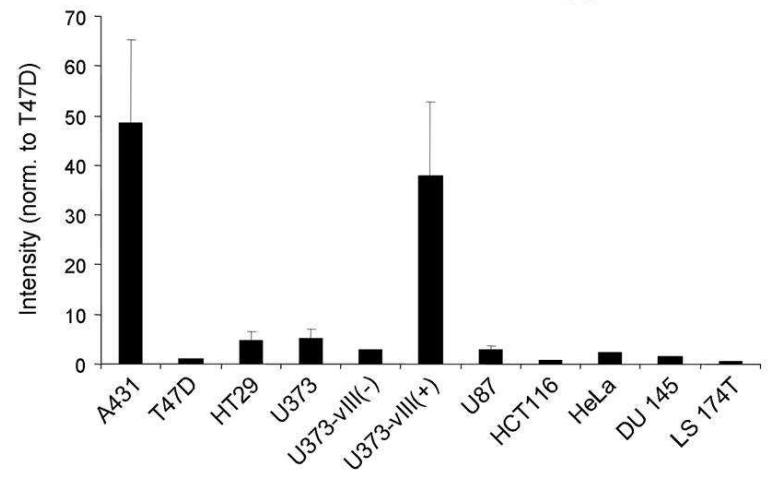

Figure 3. (A) Western blot analysis of EGFR and EGFRvIII expression in cells with varying EGFR expression levels. Forty microgram of protein was loaded on the gel. $\beta$-Actin was used as loading control. (B) FACS saturation experiment of cetuximab-OG binding to EGFR using A-431 and T-47D, showing a saturation concentration at $5.2 \mathrm{nM}$. Data points are shown as mean \pm SEM. (C) FACS analysis of cetuximab-OG binding at saturation concentration to cell lines showing varying EGFR expression levels. Intensity levels of all cell lines were normalized to the intensity of the T47D cell line. With multiple measurements, the data points are shown as mean \pm SEM. 
The other clinically relevant cells investigated showed intermediate binding of cetuximab-OG. Comparison between the binding profile of cetuximab-OG and the respective EGFR expression levels as determined by a densitometric analysis, demonstrated a significant relationship ( $r^{2}=0.842, P=0.001$; data not shown).

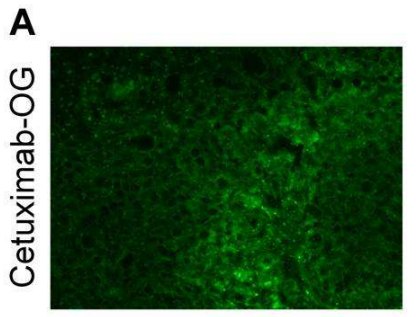

B
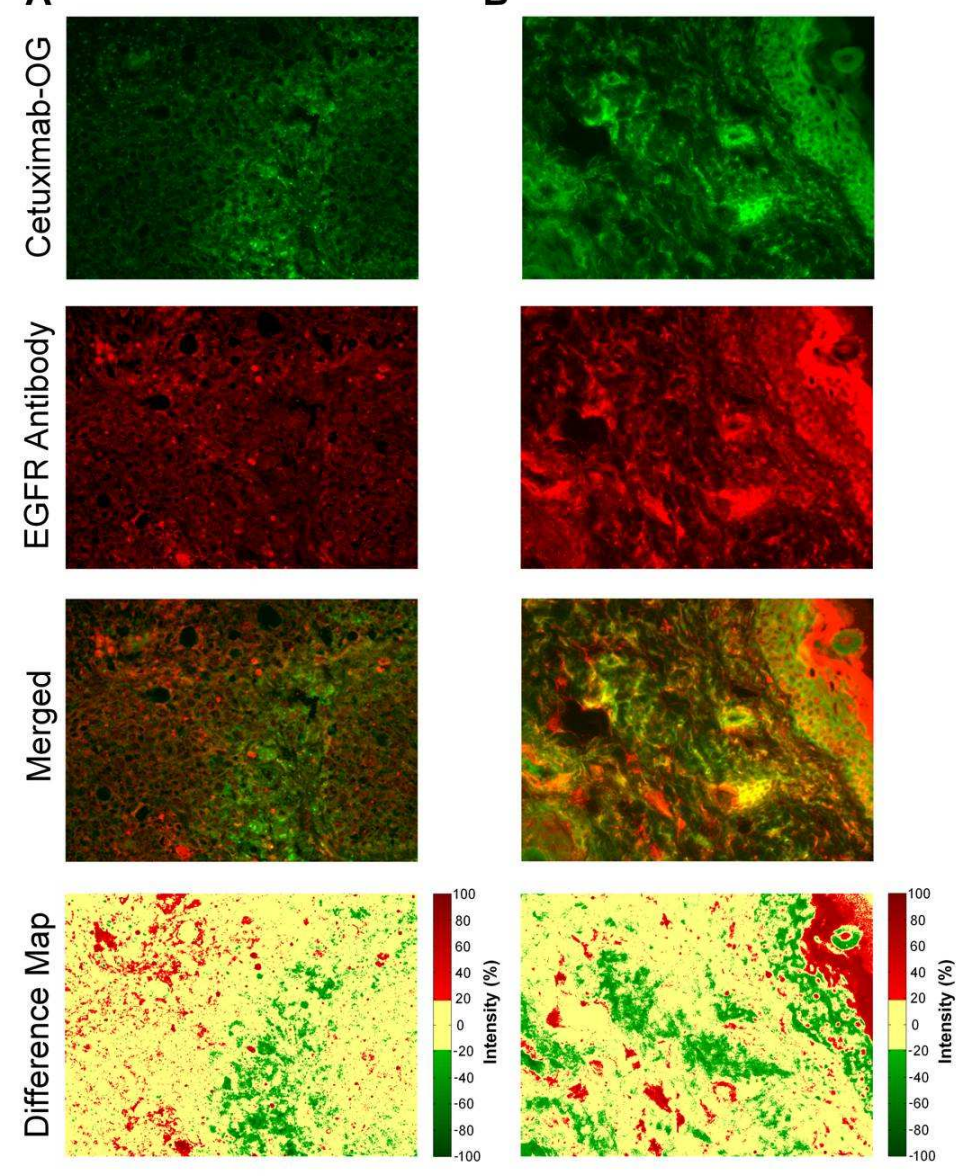

Figure 4. In vivo cetuximab-OG binding and ex vivo EGFR expression in HT-29 tumors is shown in two representative tumor sections ( $A$ and $B$ ). A merged image shows the mismatch between cetuximab-OG and EGFR expression. Quantitative mismatch was assessed using an intensity difference map, showing overlap in yellow, mismatch of cetuximab-OG positive/EGFR negative in green, and mismatch of cetuximab-OG negative/EGFR positive in red. 


\section{Ex vivo analysis}

To validate the use of the imaging agent in vivo, cetuximab-OG was injected in intermediate EGFR-expressing colorectal HT-29 tumor bearing mice. One hundred and twenty hours later, the animals were sacrificed, tumors were excised and prepared for immunohistochemistry. Heterogeneous cetuximab-OG localization is shown in two representative tumor sections (Fig. 4). EGFR expression was assessed using the polyclonal EGFR antibody, which also showed a heterogeneous staining pattern. Merging both images demonstrated a partial mismatch between EGFR expression and cetuximab-OG tracer accumulation. The degree of match (and mismatch) was calculated by a difference map of representative sections of six tumors, where the intensity within $20 \%$ of the maximum was classified as overlap (a match), and larger as a mismatch. This resulted in an overlapping area of 83.4 $\pm 5.9 \%$, a mismatch of cetuximab-OG positive/EGFR negative of $7.9 \pm 5.3 \%$, and a mismatch of cetuximab-OG negative/EGFR positive of $8.7 \pm 2.1 \%$.

\section{Discussion}

We report the successful development of an Oregon Green 488 labeled cetuximab fluorescent imaging probe. Anticipating on future conjugation strategies of DTPA-maleimide synthons to couple cetuximab or more general to antibodies ${ }^{24}$ for use in MRI, PET, and SPECT imaging, we chose a coupling strategy, in which lysine side-chains were first converted to sulfhydryl moieties followed by reaction with sulfhydryl-reactive maleimide-labels. No significant differences were found between labeled and non-labeled cetuximab preparations, indicating that cetuximab binding to EGFR 
is unaffected by the labeling procedure. To evaluate the properties of cetuximab as an imaging probe, we assessed the in vitro binding of cetuximab-OG to EGFR. Cell lines expressing varying levels of EGFR showed a corresponding accumulation of cetuximab-OG. We also demonstrated binding of cetuximab-OG to U-373 MG cells transfected for EGFRvIII. Mamot et al. showed binding of cetuximab fragments to EGFRvIII expressing tumor cells in vitro ${ }^{25}$. However, there is no conclusive evidence that the whole cetuximab complex binds to EGFRvIII.

Upon injection of cetuximab-OG in tumor bearing mice, we showed successful fluorescent imaging of EGFR in the tumor specimen. However, the distribution of the cetuximab-OG binding was found to be very heterogeneous throughout the tumor. Ex vivo immunohistochemistry also showed heterogeneous staining patterns for EGFR. Using difference mapping, quantitative analysis of the overlap between EGFR expression and cetuximab-OG uptake level was performed, showing a mismatch of both high cetuximabOG uptake with low EGFR expression, as vica versa. Possible explanations for this in vivo mismatch are multifactorial: poor drug delivery due to insufficient vasculature and perfusion of the tumor, dynamic tumor growth, and necrosis may limit the uptake of cetuximab. Also differences in internalization rates of the cetuximab-EGFR complex may be cell type specific. However, the majority of cetuximab binding was found at the cell membrane even at this time point. Importantly, these data indicate that cetuximab uptake is dependent upon tumor factors in addition to EGFR expression levels. This may help to explain the poor correlation often reported between cetuximab efficacy and EGFR expression $^{26}$. 
An increasing number of studies report on the use of cetuximab for imaging purposes, most often using SPECT and PET radioisotopes in experimental tumor models ${ }^{21}, 22$. These studies however are limited by the short half life of the used isotopes $\left({ }^{99 \mathrm{~m} T c:} 6 \mathrm{~h}\right.$ and ${ }^{64} \mathrm{Cu}: 12 \mathrm{~h}$ ). This short half life might be sufficient to perform imaging studies in mice, but for imaging studies in humans, longer durations are required to reach optimal tumor to blood ratios in humans as the biologic half life of cetuximab is longer in humans compared to mice ${ }^{27}$. Based on the findings of Verel et al. ${ }^{28}$, the positron emitter Zirconium-89 $\left({ }^{89} \mathrm{Zr}\right)$ exhibits several advantages for the use with cetuximab. One advantage is the long physical half life of ${ }^{89} \mathrm{Zr}(78 \mathrm{~h}$ ), sufficient for the long biologic half life of cetuximab in the blood pool. Another advantage is the labeling efficiency of cetuximab with ${ }^{89} \mathrm{Zr}$, because the immunoreactive fraction of the labeled complex stays above $95 \%{ }^{29}$, compared with $63 \%$ for ${ }^{64} \mathrm{Cu}^{22}$. Although the use of radioisotopes shows advantages when performing in vivo imaging, there is an urgent need for non-radioactive labeled probes for in vitro studies, to better understand the biological consequences of EGFR directed therapies. 


\section{Conclusion}

We successfully developed an Oregon Green 488 labeled cetuximab imaging probe, which is able to bind EGFR and EGFRVIII in vitro, where quantitative binding of the cetuximab is correlated with EGFR expression levels. Furthermore, we demonstrated in vivo EGFR labeling after injection of cetuximab-OG. Thus, cetuximab-OG represents a promising imaging probe to further evaluate the binding properties of cetuximab and it can be used to visualize the presence of both EGFR and EGFRvIII. However, significant mismatch differences between cell EGFR expression levels and cetuximab uptake can be expected in vivo.

\section{Acknowledgements}

This work was supported by the Euroxy $6^{\text {th }}$ framework grant LSCHCT-2003-502932 (LD, PL). 


\section{References}

1. Herbst R.S. Review of epidermal growth factor receptor biology. Int J Radiat Oncol Biol Phys, 2004. 59(2 Suppl): p. 21-6.

2. Mendelsohn J. Targeting the epidermal growth factor receptor for cancer therapy. J Clin Oncol, 2002. 20(18 Suppl): p. 1S-13S.

3. Akimoto T., Hunter N.R., Buchmiller L., et al. Inverse relationship between epidermal growth factor receptor expression and radiocurability of murine carcinomas. Clin Cancer Res, 1999. 5(10): p. 2884-90.

4. Lammering G. Molecular predictor and promising target: will EGFR now become a star in radiotherapy? Radiother Oncol, 2005. 74(2): p. 89-91.

5. Eicheler W., Krause M., Hessel F., et al. Kinetics of EGFR expression during fractionated irradiation varies between different human squamous cell carcinoma lines in nude mice. Radiother Oncol, 2005. 76(2): p. 151-6.

6. Eriksen J.G., Steiniche T., and Overgaard J. The influence of epidermal growth factor receptor and tumor differentiation on the response to accelerated radiotherapy of squamous cell carcinomas of the head and neck in the randomized DAHANCA 6 and 7 study. Radiother Oncol, 2005. 74(2): p. 93-100.

7. Pedersen M.W., Meltorn M., Damstrup L., et al. The type III epidermal growth factor receptor mutation. Biological significance and potential target for anti-cancer therapy. Ann Oncol, 2001. 12(6): p. 745-60.

8. Moscatello D.K., Holgado-Madruga M., Godwin A.K., et al., Frequent Expression of a Mutant Epidermal Growth Factor Receptor in Multiple Human Tumors. 1995. p. 55365539.

9. Sok J.C., Coppelli F.M., Thomas S.M., et al. Mutant epidermal growth factor receptor (EGFRvIII) contributes to head and neck cancer growth and resistance to EGFR targeting. Clin Cancer Res, 2006. 12(17): p. 5064-73.

10. Baselga J. and Arteaga C.L. Critical update and emerging trends in epidermal growth factor receptor targeting in cancer. J Clin Oncol, 2005. 23(11): p. 2445-59.

11. Herbst R.S. and Shin D.M. Monoclonal antibodies to target epidermal growth factor receptor-positive tumors: a new paradigm for cancer therapy. Cancer, 2002. 94(5): p. $1593-611$.

12. Imai K. and Takaoka A. Comparing antibody and small-molecule therapies for cancer. Nat Rev Cancer, 2006. 6(9): p. 714-27.

13. Huang S.M., Bock J.M., and Harari P.M. Epidermal growth factor receptor blockade with C225 modulates proliferation, apoptosis, and radiosensitivity in squamous cell carcinomas of the head and neck. Cancer Res, 1999. 59(8): p. 1935-40.

14. Xiong H.Q., Rosenberg A., LoBuglio A., et al. Cetuximab, a monoclonal antibody targeting the epidermal growth factor receptor, in combination with gemcitabine for advanced pancreatic cancer: a multicenter phase II Trial. J Clin Oncol, 2004. 22(13): p. 2610-6.

15. Dittmann K., Mayer C., and Rodemann H.P. Inhibition of radiation-induced EGFR nuclear import by C225 (Cetuximab) suppresses DNA-PK activity. Radiother Oncol, 2005. 76(2): p. 157-61.

16. Krause M., Ostermann G., Petersen C., et al. Decreased repopulation as well as increased reoxygenation contribute to the improvement in local control after targeting of the EGFR by C225 during fractionated irradiation. Radiother Oncol, 2005. 76(2): p. 162-7.

17. Bonner J.A., Harari P.M., Giralt J., et al. Radiotherapy plus Cetuximab for SquamousCell Carcinoma of the Head and Neck. N Engl J Med, 2006. 354(6): p. 567-578.

18. Huang S.M. and Harari P.M. Modulation of radiation response after epidermal growth factor receptor blockade in squamous cell carcinomas: inhibition of damage repair cell cycle kinetics, and tumor angiogenesis. Clin Cancer Res, 2000. 6(6): p. 2166-74.

19. Milas L., Fan Z., Andratschke N.H., et al. Epidermal growth factor receptor and tumor response to radiation: in vivo preclinical studies. Int J Radiat Oncol Biol Phys, 2004. 58(3): p. 966-71.

20. Schechter N.R., Wendt R.E., 3rd, Yang D.J., et al. Radiation dosimetry of 99mTclabeled C225 in patients with squamous cell carcinoma of the head and neck. J Nucl Med, 2004. 45(10): p. 1683-7.

21. Schechter N.R., Yang D.J., Azhdarinia A., et al. Assessment of epidermal growth factor receptor with $99 \mathrm{mTc}$-ethylenedicysteine-C225 monoclonal antibody. Anticancer Drugs, 2003. 14(1): p. 49-56. 
22. Cai W., Chen K., He L., et al. Quantitative PET of EGFR expression in xenograftbearing mice using (64)Cu-labeled cetuximab, a chimeric anti-EGFR monoclonal antibody. Eur J Nucl Med Mol Imaging, 2007.

23. Li S., Schmitz K.R., Jeffrey P.D., et al. Structural basis for inhibition of the epidermal growth factor receptor by cetuximab. Cancer Cell, 2005. 7(4): p. 301-11.

24. Dirksen A., Meijer E.W., Adriaens W., et al. Strategy for the synthesis of multivalent peptide-based nonsymmetric dendrimers by native chemical ligation. Chem Commun (Camb), 2006(15): p. 1667-9.

25. Mamot C., Drummond D.C., Greiser U., et al. Epidermal growth factor receptor (EGFR)-targeted immunoliposomes mediate specific and efficient drug delivery to EGFR- and EGFRvIII-overexpressing tumor cells. Cancer Res, 2003. 63(12): p. 315461.

26. Hebbar M., Wacrenier A., Desauw C., et al. Lack of usefulness of epidermal growth factor receptor expression determination for cetuximab therapy in patients with colorectal cancer. Anticancer Drugs, 2006. 17(7): p. 855-7.

27. Frieze D.A. and McCune J.S. Current status of cetuximab for the treatment of patients with solid tumors. Ann Pharmacother, 2006. 40(2): p. 241-50.

28. Verel I., Visser G.W., Boellaard R., et al. 89Zr immuno-PET: comprehensive procedures for the production of $89 \mathrm{Zr}$-labeled monoclonal antibodies. J Nucl Med, 2003. 44(8): p. 1271-81.

29. Perk L.R., Visser G.W., Vosjan M.J., et al. (89)Zr as a PET surrogate radioisotope for scouting biodistribution of the therapeutic radiometals (90)Y and (177)Lu in tumorbearing nude mice after coupling to the internalizing antibody cetuximab. J Nucl Med, 2005. 46(11): p. 1898-906. 


\section{Chapter 8}

Disparity between in vivo EGFR expression and Zirconium-89-labeled cetuximab uptake assessed with PET

Aerts HJWL ${ }^{\#}$, Dubois $L^{\#}$, Perk $L$, Vermaelen $P$, van Dongen GAMS, Wouters BG, Lambin P

J Nucl Med. 2009 Jan;50(1):123-131

\# these authors contributed equally

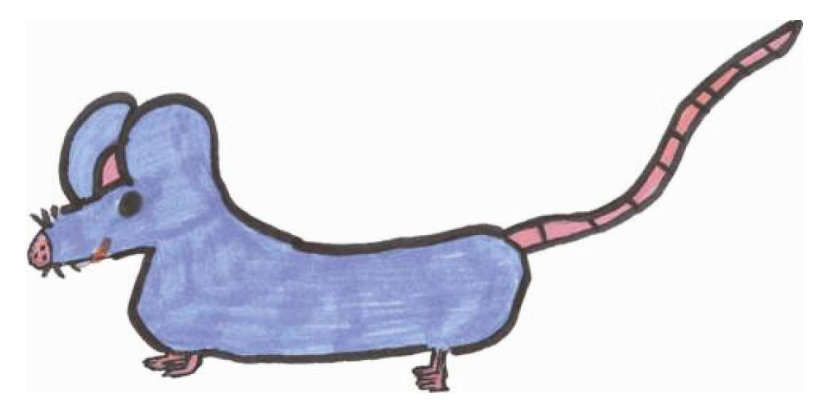




\section{Abstract}

The epidermal growth factor receptor (EGFR) is highly expressed in a significant number of human malignancies, and its expression is associated with tumor aggressiveness and overall treatment resistance. The monoclonal antibody cetuximab is increasingly used in clinical settings as a treatment modality in combination with more conventional therapies, such as radio- and chemotherapy. Currently, little is known about tumor-specific uptake and overall pharmacokinetics. Noninvasive quantification of cetuximab uptake could provide important diagnostic information for patient selection and therapy evaluation. To this end, we have developed and validated a novel probe using cetuximab labeled with the longlived positron emitter ${ }^{89} \mathrm{Zr}$ for PET imaging.

Methods: Tumor cell lines with varying EGFR expression levels were used for in vivo tumor imaging experiments. PET with ${ }^{89} \mathrm{Zr}$ labeled cetuximab (3.75 $\pm 0.14 \mathrm{MBq})$ was performed on tumorbearing NMRI-nu mice at multiple time points after injection (ranging from 1 to $120 \mathrm{~h}$ ) and quantified by drawing regions of interest on selected tissues. Uptake was compared by biodistribution $y$-counting, and ex vivo EGFR expression levels were quantified using Western blot analysis.

Results: Uptake of ${ }^{89} \mathrm{Zr}$-labeled cetuximab was demonstrated in the EGFR-positive tumors. However, the EGFR levels measured in vivo did not correlate with the relative signal obtained by PET. Tumor-to-blood ratios were significantly higher in the cell lines with intermediate (compared with the high) EGFR expression starting from $24 \mathrm{~h}$ after injection. Normal tissue uptake was unaffected by the different tumor types. Ex vivo $Y$-counting experiments confirmed the observed in vivo PET results. A similar disparity was found between ${ }^{89} \mathrm{Zr}$-labeled cetuximab tumor uptake 
and in vivo EGFR expression levels as demonstrated by Western blotting.

Conclusions: The ${ }^{89} \mathrm{Zr}$-labeled cetuximab imaging probe is a promising tool for noninvasive evaluation of cetuximab uptake. Our results demonstrate a disparity between in vivo EGFR expression levels and cetuximab uptake. In a general sense, the results indicate a disparity between antibody uptake and expression levels of a biologic target in a tumor, suggesting that additional pharmacokinetic or pharmacodynamic mechanisms influence tumor delivery of this therapy. These additional mechanisms may explain why receptor expression levels alone are not sufficient to predict patient response. 


\section{Introduction}

Over the past few decades, monoclonal antibodies (mAbs) have increasingly been used as targeting agents in oncology and are currently the subject of many important clinical trials ${ }^{1,2}$. One key biologic target for these mAbs is the epidermal growth factor receptor (EGFR), a member of the ErbB family. EGFR has been shown to play an essential role in the upregulation of tumor cell proliferation, differentiation and survival ${ }^{3,4}$. Activation of EGFR occurs when a ligand (e.g., epidermal growth factor or transforming growth factor alpha) binds to the extracellular ligandbinding domain, resulting in EGFR dimerization, internalization of the ligand-receptor complex, and activation of the downstream signaling pathway. High EGFR expression is associated with tumor aggressiveness and overall treatment resistance and is common in a significant number of human malignancies ${ }^{5,6}$. As a result, EGFR targeting has been explored as a possible antitumor strategy, where the extracellular ligand-binding domain or the intracellular domain of the receptor is targeted with mAbs or small-molecule EGFR tyrosine kinase inhibitors, respectively ${ }^{7}{ }^{8}$. Both these therapies disrupt the EGFR signaling pathway, resulting in inhibited cell cycle progression, decreased angiogenesis, and reduced metastatic invasion ${ }^{9}$.

Cetuximab (Erbitux; ImClone Systems Inc.) is an example of a $\mathrm{mAb}$ that blocks the ligand-binding domain of EGFR with high affinity, thereby preventing downstream signaling ${ }^{9,} 10$. Consequently, cetuximab has evolved as a promising new therapy agent in oncology and is increasingly used in clinical trials, mainly in combination with chemo- or radiotherapy ${ }^{11,}{ }^{12}$. The overall pharmacokinetics of cetuximab are slow (elimination rate ranging from 66 to $97 \mathrm{~h})$, partly due to the large size ( $\pm 152 \mathrm{kDa})$ of the 
antibody ${ }^{13}$. Despite the extensive use of cetuximab in clinical settings, much is still unknown about the patient-specific pharmacokinetics and pharmacodynamics of its tumor uptake, resulting in a lack of knowledge about the relationship between dosage and therapeutic effect. Also, a disparity between EGFR expression levels and treatment outcome has been reported ${ }^{14-16}$, where even tumors negative for EGFR on biopsy responded to cetuximab treatment ${ }^{17}$. Furthermore, in patients it has been shown that mAbs that inhibit EGFR are associated in a dose-dependent manner with several dermatologic side effects. In general, cutaneous side effects were most common, and patients experienced a mild to moderate eruption that did not require withdrawal of treatment ${ }^{18}$. On the other hand, an adequate cetuximab dose must be used to obtain sustained tumor uptake, since the liver has the capacity to absorb infused antibody up to 40 mg. Higher doses result in liver saturation and consequently in sufficient tumor uptake ${ }^{19}$. Therefore, noninvasive monitoring of in vivo cetuximab uptake could significantly increase knowledge of its clinical use as a targeting agent and eventually lead to the selective enrollment of patients and monitoring of cetuximab uptake before and during treatment.

Using cetuximab itself as an imaging agent has several advantages for visualizing its distribution in normal and tumor tissues. Several groups have therefore investigated cetuximabbased noninvasive imaging probes, the majority with SPECT and PET isotopes ${ }^{19-25}$. Some studies were limited by the use of isotopes with relatively short half-lives $\left({ }^{99 \mathrm{~m}} \mathrm{Tc}[6 \mathrm{~h}]\right.$ and $\left.{ }^{64} \mathrm{Cu}[12 \mathrm{~h}]\right)$, which are incompatible with the long biologic half-life of cetuximab in the blood pool and the relatively low immunoreactive fraction of the cetuximab radioimmunoconjugate ${ }^{22}$. Another PET isotope often 
suggested for antibody imaging is ${ }^{124} \mathrm{I}$, because its long half-life $(100.3 \mathrm{~h})$ allows imaging at later time points to acquire optimal information. However, an important disadvantage of ${ }^{124} \mathrm{I}$ is the rapid degradation of the radioiodinated $m A b$ upon internalization, resulting in the rapid clearance of iodine from the target cells and PET images with tumor contrast that is too low and does not reflect the actual tumor uptake of the antibody ${ }^{20}$. Based on the findings of Verel et al. ${ }^{26,27}$, the positron emitter ${ }^{89} \mathrm{Zr}$ has ideal characteristics for use with antibodies ${ }^{28} .{ }^{89} \mathrm{Zr}$ demonstrates a long physical half-life (78 h) and, upon internalization of the antibody, ${ }^{89} \mathrm{Zr}$ is trapped intracellularly in lysosomes (phenomenon of residualization $)^{29,} 30$. Moreover, radiolabeling of cetuximab with ${ }^{89} \mathrm{Zr}$ does not influence its binding potential to EGFR, resulting in an immunoreactive fraction of about $95 \%{ }^{28}$. For these reasons, ${ }^{89} \mathrm{Zr}$ is an ideal radionuclide for the labeling of slow-kinetic intact antibodies with high-quality standards and is successfully used in pre-clinical $^{31}$ and clinical settings ${ }^{20,32,33}$.

Here, we report on the development and testing of the imaging probe ${ }^{89} \mathrm{Zr}$-labeled cetuximab, which was validated preclinically in mice bearing tumors with varying EGFR expression. Using PET we assessed in vivo cetuximab uptake levels and correlated them with in vivo EGFR expression levels as determined by Western blotting.

\section{Materials and Methods}

Synthesis of ${ }^{89} \mathrm{Zr}$-labeled Cetuximab

${ }^{89} \mathrm{Zr}$ was produced by a $(p, n)$ reaction on natural ${ }^{89} \mathrm{Y}$ as described by Verel et al. ${ }^{27} .{ }^{89} \mathrm{Zr}$ labeling of the mAb cetuximab was achieved as previously reported ${ }^{28}$. Briefly, desferrioxamine $B$ was succinylated ( $N$-sucDf), temporarily filled with iron $\left(\mathrm{Fe}^{3+}\right)$, and 
coupled to cetuximab using a tetrafluorophenol- $N$-sucDf ester. The premodified mAb was purified on a PD10 column after removal of $\mathrm{Fe}^{3+}$ by transchelation to ethylenediaminetetraacetic acid. Approximately $1 \mathrm{~N}$-sucDf moiety was coupled per cetuximab, assessed by using ${ }^{59} \mathrm{Fe}$. Next, $N$-sucDf-cetuximab was labeled with ${ }^{89} \mathrm{Zr}$ in $N$-(2-hydroxyethyl)piperazine- $N$ '-(2-ethanesulfonic acid) buffer at $\mathrm{pH} 7.0$ and again purified on a PD10 column to remove unbound ${ }^{89} \mathrm{Zr}$. The high-performance liquid chromatographyisolated fractions demonstrated a radiochemical purity on the order of $98 \%$. Specific activity was typically in the range of 78 $\mathrm{MBq} / \mathrm{mg}$.

\section{Animal and Tumor Model}

Exponentially growing human epidermoid (A-431 [CRL-1555; ATCC]), breast (T-47D [HTB-133; ATCC]), glioblastoma (U-373 MG [HTB-17; ATCC]) and colorectal (HT-29 [HTB-38; ATCC]) carcinoma cells were cultivated in the appropriate medium supplemented with $10 \%$ fetal bovine serum and incubated in a humidified $5 \% \quad \mathrm{CO}_{2}$ chamber at $37^{\circ} \mathrm{C}$. Adult NMRI-nu (nu/nu) female mice $(28-32 \mathrm{~g})$ were inoculated subcutaneously in the lateral flanks with $3 \times 10^{6}$ cells resuspended in $100 \mu$ of growth medium. Tumors were measured using a Vernier Caliper in 3 orthogonal tumor diameters ( $A, B$ and $C$ ), each corrected for the thickness of the skin, and tumor volumes were calculated on the basis of the formula $A \times B \times C \times n / 6$. Once tumor volumes reached an average of $400 \mathrm{~mm}^{3}$, animals were injected with ${ }^{89} \mathrm{Zr}$ cetuximab $(3.75 \pm 0.14 \mathrm{MBq})$ via the lateral tail vein. All procedures were performed according to the guidelines of the National Institute of Health ${ }^{34}$. All animal experiments were in agreement with national guidelines, approved by the Animal Ethics 
Committee of the KU Leuven University, Belgium. Animals were given food and water ad libitum for the duration of the experiments. Isoflurane inhalation anesthesia ( $2 \%$ isoflurane in $100 \% \mathrm{O}_{2}$ at a flow rate of $1.5 \mathrm{~L} / \mathrm{min}$ ) was used during all animal experiments.

\section{PET Imaging and Analysis}

PET was performed on a Focus 220 MicroPET scanner (Concorde Microsystems Inc.) with an axial field of view of $7.6 \mathrm{~cm}$ and a resolution of approximately $1.4 \mathrm{~mm}$. For each animal, a custombuilt alginate mold was made to obtain reproducible positioning in the opening of the camera between the imaging time points. Whole-body scanning was performed with 95 axial slices each of $0.796 \mathrm{~mm}$ in a single field of view, yielding radioactivity concentration measurements in voxels of 0.633 by 0.633 by 0.796 $\mathrm{mm}$. After injection of $3.75 \pm 0.14 \mathrm{MBq}{ }^{89} \mathrm{Zr}$-cetuximab (average dose of $100 \mu \mathrm{g}$ ) into the lateral tail vein, a 25-min emission scan was obtained ( 5 frames each of $5 \mathrm{~min}$ ) for each animal at 1, 4, 24, 48, 72 and $96 \mathrm{~h}$ after injection, with correction for random counts, dead time and decay. For the HT-29 and U-373 MG tumor-bearing animals, an additional scan at $120 \mathrm{~h}$ after injection was also available. Each emission scan was preceded by a 10-min transmission scan using external rods of ${ }^{57} \mathrm{Co}$ for subsequent attenuation correction. Three-dimensional list-mode data were acquired using an energy window of 350-750 keV and a coincidence timing window of $6 \mathrm{~ns}$. The data were then stored in sonogram format and reconstructed iteratively in a $128 \times 128 \times 95$ matrix using attenuation-weighted 2-dimensional ordered-subsets expectation maximization (Fourier rebinning, 16 subsets, 10 iterations, and 5 expectation maximization iterations). The images 
were visualized with ASIPro VM software (version 6.3.3.0; Concorde Microsystems Inc.) and analyzed using MATLAB (Version 7.3, The MathWorks, Inc.). For each dataset, 3-dimensional regions of interest (ROIs) were manually drawn over the blood (heart outflow area), lungs, liver, kidneys, muscle, and tumors. Mean and maximum activity data (in $\mathrm{Bq} / \mathrm{ml}$ ) of the voxels within the ROIs were obtained. All data were corrected for ${ }^{89} \mathrm{Zr}$ decay towards injection and the percentage injected dose (\%ID) and are therefore expressed as \%ID/ml. Tumor-to-blood uptake ratios were calculated by dividing the activity data within the tumor ROI by the activity value within the blood ROI drawn on the outflow area of the heart.

\section{Immunoblotting}

Minced tumor pieces and cell pellets obtained from a $6-\mathrm{cm}$ culture dish were extracted in radioimmunoprecipitation assay lysis buffer (150 mM NaCl, $1 \%$ NP-40, $0.5 \%$ sodium deoxycholate, $0.1 \%$ sodium dodecylsulfate, $50 \mathrm{mM}$ Tris- $\mathrm{HCl}[\mathrm{pH} 7.5], 1 X$ protease inhibitor cocktail) for $30 \mathrm{~min}$ on ice, and protein concentrations were determined by a Bradford assay (Bio-Rad). Proteins were separated on a $10 \%$ sodium dodecylsulfate-polyacrylamide gel and blotted onto a nitrocellulose membrane (Amersham Corp.) by electrotransfer. The membrane was blocked with $5 \%$ blottinggrade nonfat dry milk (Bio-Rad). Blots were probed with antibodies directed against EGFR (Santa Cruz Biotechnology) or $\beta$-Actin (Sigma). Bound antibodies were visualized using horseradish peroxidase-linked secondary antibodies (antirabbit [Cell Signaling Technologies] or antimouse [Sigma]) and enhanced chemiluminescence (Amersham Corp.). 


\section{Biodistribution}

After the last PET acquisitions, the animals were sacrificed under anesthesia and dissected. Blood, tumors, skin, sternum, heart, thymus, salivary glands, thyroid, trachea, lung, esophagus, liver, gallbladder, stomach, pancreas, spleen, ileum, colon, bladder, kidney, muscle, thigh bone, brown fat, eyes, ears, cerebrum, cerebellum, medulla oblongata, fat, and tail were washed, flushed with saline, and weighed, and the amount of radioactivity in each tissue was assessed in a $\mathrm{Y}$-well counter (1480 Wallac Wizard 3" Automatic $\gamma$-counter; PerkinElmer, Inc.). The tumors were halved, with one half used for quantification of ${ }^{89} \mathrm{Zr}$-cetuximab uptake and the other rapidly frozen for protein isolation. Disintegrations for each sample were collected over 1 min using an energy window between 48 and 1,354 keV. To correct for decay, injection standards were counted simultaneously. Radioactivity uptake was calculated as the \%ID per gram of tissue.

\section{Statistics}

All statistical analyses were performed with SPSS 12.0.1 for Windows (SPSS Inc.). Graphs were drawn using Origin 6.0 (Microcal Software Inc.). Correlations among the groups were assessed using a nonparametric independent-samples test (Kruskal-Wallis test). Further, to determine the statistical significance of differences between 2 independent groups of variables, a nonparametric Mann-Whitney $U$ test for small groups was used. For all tests, a probability value of less than 0.05 was considered significant. 


\section{Results}

In Vivo Uptake of ${ }^{89} \mathrm{Zr}$-Cetuximab

To evaluate the potential of ${ }^{89} \mathrm{Zr}$-cetuximab as an imaging agent, we injected 4 cell lines with variable levels of EGFR expression into NMRI-nu mice to form xenografts. A-431 was selected for high EGFR expression, U-373 MG and HT-29 for intermediate, and T47D for low EGFR expression, as previously described ${ }^{16}$. The in vivo binding of ${ }^{89} \mathrm{Zr}$-cetuximab was assessed by performing PET imaging at $72 \mathrm{~h}$ after injection of $100 \mu \mathrm{g}{ }^{89} \mathrm{Zr}$-cetuximab in tumorbearing mice (Fig. 1). A clear accumulation of ${ }^{89} \mathrm{Zr}$-cetuximab was found in the EGFR-positive tumors (U-373 MG, HT-29, and A-431), compared with the low-expression tumors (T-47D).

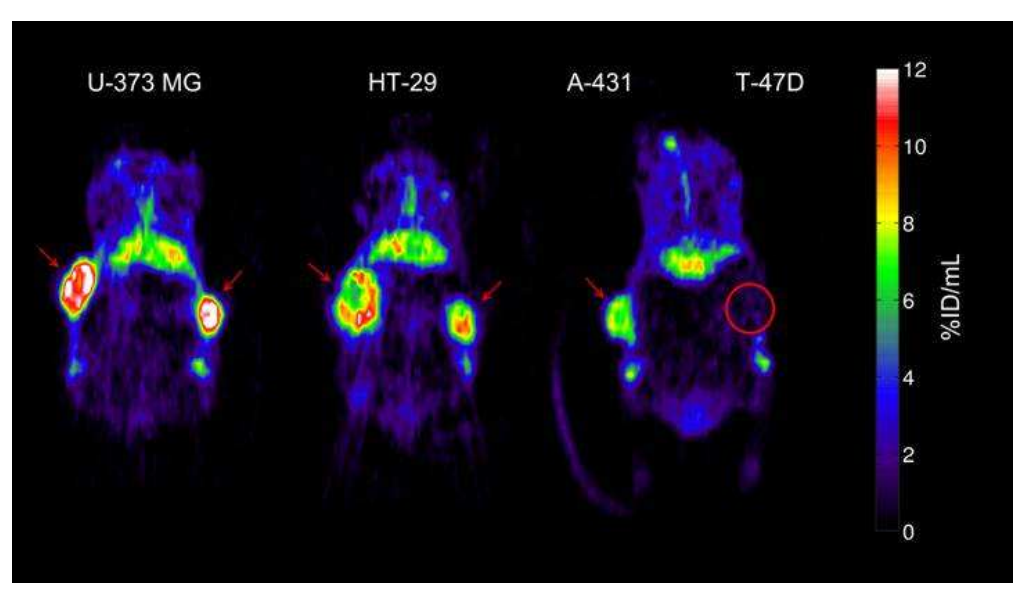

Figure 1. Representative small animal PET images $72 \mathrm{~h}$ after injection of ${ }^{89} \mathrm{Zr}$ cetuximab. Mouse bearing U-373 MG (left) or HT-29 (center) tumors in both flanks. Mouse (right) bearing an A-431 and a T-47D (circled) tumor in right and left flank, respectively. Red arrows indicate the tumors. Images at mid-plane cross-section through tumor are shown. Images are corrected for injected dose and decay, represented as \%ID/ml. High uptake is found in EGFR-expression tumors (HT-29, U-373 MG, A-431), whereas uptake of low EGFR-expression tumor (T-47D) is comparable with the overall uptake in surrounding normal tissue. ${ }^{89} \mathrm{Zr}$-cetuximab uptake was also found in catabolic organs: in the liver and kidneys (below tumors). 
Remarkably, a higher ${ }^{89} \mathrm{Zr}$-cetuximab uptake was demonstrated in the intermediate-expression U-373 MG and HT-29 tumors than in the high-expression A-431 tumor. The uptake in the lowexpression tumor T-47D was comparable with that in the surrounding tissues. A clear accumulation was seen in normal tissues such as the liver, because of the hepatobiliary clearance of the antibody. Notable uptake was also found in the kidney.

Imaging was performed at several time points after injection to assess the time-activity relationship of ${ }^{89} \mathrm{Zr}$-cetuximab uptake in the tumor. Figure 2 shows a representative time series of PET images of a HT-29 tumor-bearing mouse. From $24 \mathrm{~h}$ after injection, a clear localization of the tumors was seen above background uptake. The ${ }^{89} \mathrm{Zr}$-cetuximab uptake accumulated with time and the highest tumor uptake was reached around 72-96 h after injection. Furthermore, uptake of ${ }^{89} \mathrm{Zr}$-cetuximab was heterogeneously distributed within the tumor. Uptake in the outflow area of the heart decreased with time. Uptake in the liver also decreased, but more gradually than in the heart.

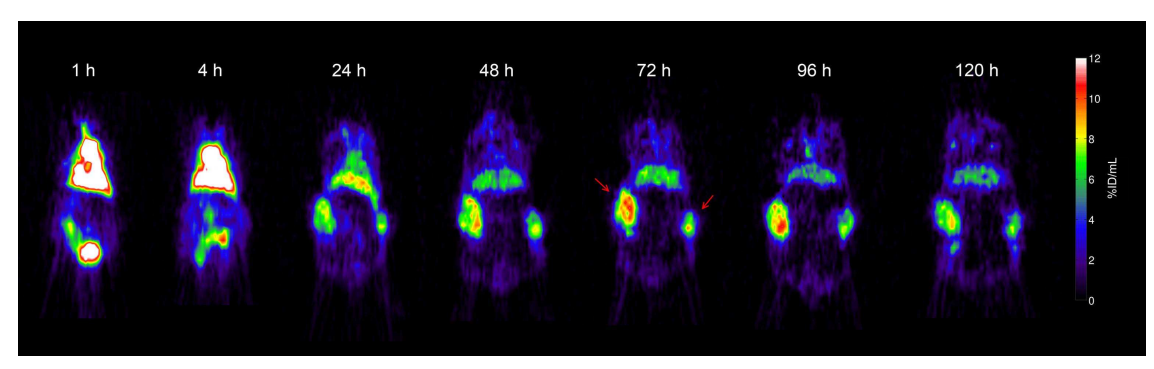

Figure 2. Time series of representative small-animal PET images at indicated time points after injection of ${ }^{89} \mathrm{Zr}$-cetuximab into HT-29 tumorbearing mouse. Red arrows indicate the tumors. Uptake levels plateaued from $72 \mathrm{~h}$ after injection onward. To allow comparison between the different time points, images are shown at mid-plane cross-section through tumor. Images are corrected for injected dose and decay and represented as $\% \mathrm{ID} / \mathrm{ml}$. 


\section{Quantification of ${ }^{89} \mathrm{Zr}$-Cetuximab Uptake}

To quantify the uptake of ${ }^{89} \mathrm{Zr}$-cetuximab in the different tumor types, we manually drew 3-dimensional ROIs were over the heart (outflow area), lungs, liver, kidneys, muscle, and tumors.

A

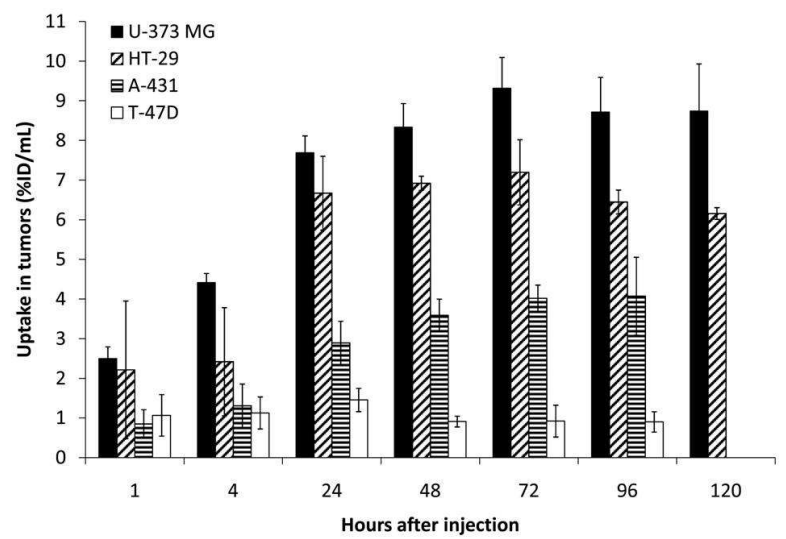

B

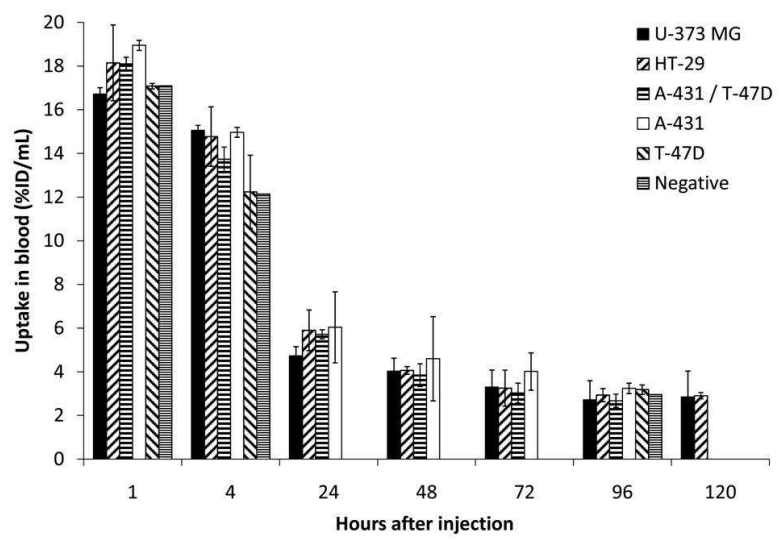

Figure 3. Quantification of ${ }^{89} \mathrm{Zr}$-cetuximab uptake from 1 to $120 \mathrm{~h}$ after injection. (A) Mean tumor uptake data for U-373 MG $(n=4)$, HT-29 $(n=$ $4)$, A-431 $(n=6)$, and T-47D $(n=5)$ tumor-bearing mice are shown and data are expressed as mean \pm SD. For U-373 MG and HT-29 tumors, images were also available at $120 \mathrm{~h}$ after injection. All data were corrected for decay and injected dose of ${ }^{89} \mathrm{Zr}$ and are expressed as \%ID/ml. (B) Mean blood uptake as measured in outflow area of the heart. Data are represented as mean \pm SD for at least 2 independent mice. For comparison reasons, non-tumor-bearing mouse was included in the analysis. 
Figure $3 \mathrm{~A}$ shows the ${ }^{89} \mathrm{Zr}$-cetuximab uptake in the different tumors at all investigated time points. The accumulation in the intermediate-expression tumors (U-373 MG and HT-29) was significantly higher at all time points than in the tumors with high (A-431) or low (T-47D) EGFR expression. Starting from $48 \mathrm{~h}$ after injection, the uptake levels differed significantly between all tumor types (i.e., uptake U-373 MG > HT-29 > A-431 > T-47D). Uptake in U-373 MG and HT-29 rose significantly until 48 and $24 \mathrm{~h}$ after injection, respectively. and plateaued at about $9 \% \mathrm{ID} / \mathrm{ml}$ and 7 $\% \mathrm{ID} / \mathrm{ml}$, respectively. For both tumor types, a $120 \mathrm{~h}$ post injection time point was available, but tracer accumulation did not differ significantly from the $96 \mathrm{~h}$ post injection time point. A similar uptake pattern was found for the A-431 tumors, although stable accumulation around $4 \% \mathrm{ID} / \mathrm{ml}$ was seen from $24 \mathrm{~h}$ after injection onward. The low-expression T-47D tumors showed no significant increase of ${ }^{89} \mathrm{Zr}$-cetuximab uptake with time ( $\left.1 \% \mathrm{ID} / \mathrm{ml}\right)$.

Blood activity was measured using an ROI drawn on the outflow area of the heart. ${ }^{89} \mathrm{Zr}$-cetuximab uptake in the blood showed a clearance pattern as depicted in Figure 3B, starting from about $18 \% \mathrm{ID} / \mathrm{ml}$ (at $1 \mathrm{~h}$ after injection) to $3 \% \mathrm{ID} / \mathrm{ml}(72-120 \mathrm{~h}$ after injection). This uptake was not influenced by the different tumor types expressing varying EGFR expression levels. We also investigated whether ${ }^{89} \mathrm{Zr}$-cetuximab uptake in normal tissues was dependent on tumor type; to this end, we quantified the uptake of ${ }^{89} \mathrm{Zr}$-cetuximab in several normal tissue regions using the $96 \mathrm{~h}$ post injection PET images (Fig. 4), since stable tumor uptake was found at that time point. Uptake in normal tissues was relatively low, compared with uptake in tumor. Of the investigated tissues, liver and kidney uptake was highest, since those are the antibody clearance organs (especially the liver). 


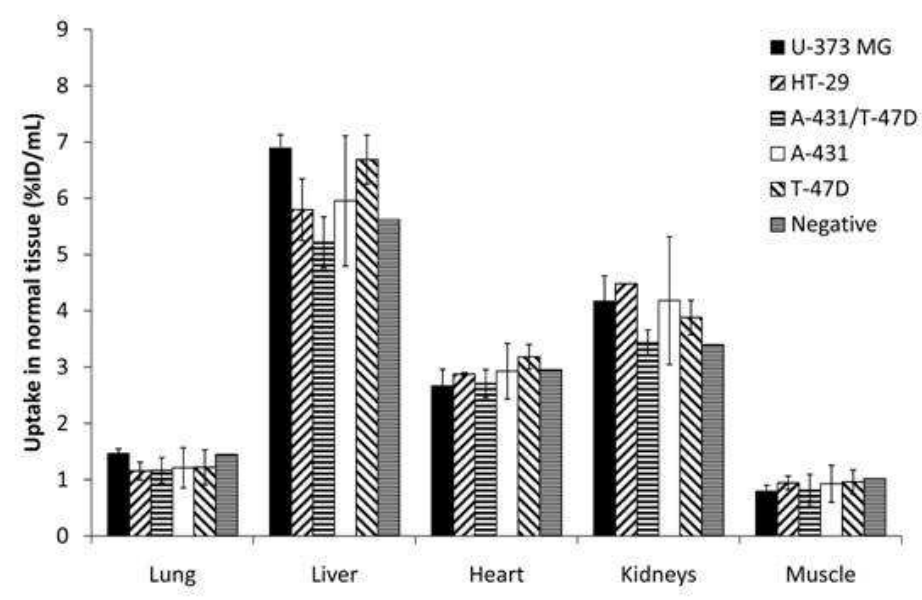

Figure 4. Normal tissue quantification of ${ }^{89} \mathrm{Zr}$-cetuximab uptake at $96 \mathrm{~h}$ after injection from animals bearing U-373 MG $(n=2), \mathrm{HT}-29(n=2), \mathrm{A}-$ 431/T-47D $(n=3), \mathrm{A}-431(n=3)$, T-47D $(n=2)$, and negative $(n=1)$ tumor types. Data for tumor-bearing mice are represented as mean uptake \pm SD. All data were corrected for decay and injected dose of ${ }^{89} \mathrm{Zr}$ and are expressed as \%ID/ml.

Small, but not significant, pharmacokinetic differences in normal tissue uptake between animals bearing different tumor types were found, indicating that the normal tissue uptake was not affected by differences in tumor uptake, and vice versa.

\section{Tumor-to-Blood Ratios}

To assess the imaging potential of ${ }^{89} \mathrm{Zr}$-cetuximab, we evaluated the tumor-to-blood activity ratios of the tracer. As shown in Figure 3 , an increasing tumor uptake and a decreasing heart uptake were found, resulting in growing tumor-to-blood ratios with time for the EGFR-positive tumors (Fig. 5). The mean tumor-to-mean blood (mean T/B) ratios are shown in Figure 5A. At more than $24 \mathrm{~h}$ after injection, all mean $T / B$ ratios were significantly different between all the investigated tumor types (i.e., U-373 MG > HT-29 > A-431 
> T-47D). The intermediate-expression tumors (U-373 MG and HT-29) showed a significantly higher mean T/B ratio than did the other tumors, reaching a plateau at 2 (HT-29) to 3 (U-373 MG) from $72 \mathrm{~h}$ after injection on.

A

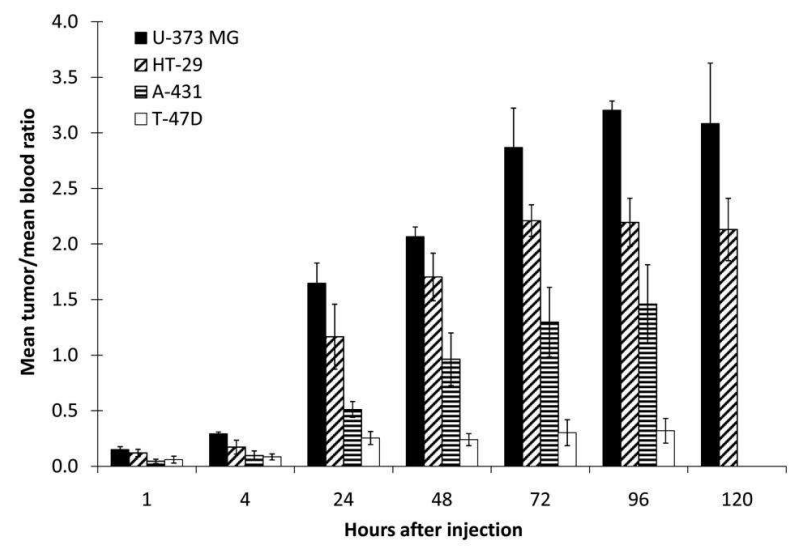

B

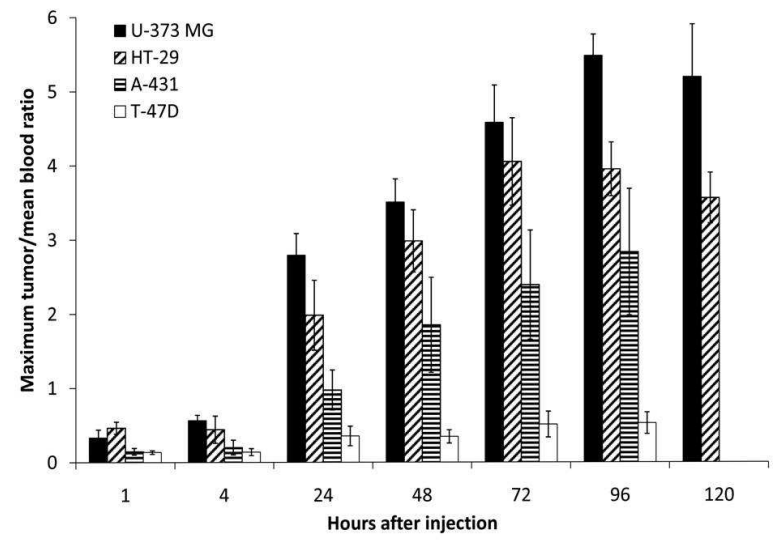

Figure 5. Tumor-to-blood ratios of ${ }^{89} \mathrm{Zr}$-cetuximab uptake from 1 to $120 \mathrm{~h}$ after injection. Ratios represent the mean (A) or maximum (B) tumor uptake divided by the mean heart uptake. Data for U-373 MG $(n=4)$, HT$29(n=4), \mathrm{A}-431(n=6)$, and T-47D $(n=5)$ tumor-bearing mice are expressed as mean \pm SD. 
In addition, the $120 \mathrm{~h}$ post injection time point showed no increase in mean $T / B$ ratio for those tumor types. The mean $T / B$ ratios for the $A-431$ tumors increased until $48 \mathrm{~h}$ after injection and plateaued at 1.5. At no point did the mean T/B ratio of the T-47D tumors exceed unity. Because tumors are known to be heterogeneous and the levels of heterogeneity between tumor types can differ, the mean and maximum uptake (i.e., the image voxel with the highest uptake) can vary considerably between different tumor types. Therefore, the ratio of maximum tumor uptake to mean blood uptake ( $\max T / B$ ) was also quantified (Fig. 5B). However, the pattern of ${ }^{89} \mathrm{Zr}$-cetuximab uptake was similar to the mean $\mathrm{T} / \mathrm{B}$ ratios, although the max T/B ratios were higher for the EGFRpositive tumors. The max T/B ratio of the T-47D tumors also never exceeded unity. Differences in tumor growth during the experiment between the tumors with varying EGFR expression could influence the mean $T / B$ and max $T / B$ ratios. However, the growth rate of the different tumor types during the experiment was comparable, indicating that the T/B ratios were largely independent of the tumor growth. The volume at the end of the experiment relative to day 0 were $127 \pm 33 \%$ for U-373 MG, 141 $\pm 22 \%$ for A-431, $142 \pm 17 \%$ for HT-29, and $132 \pm 24 \%$ for T47D.

\section{$\gamma$-Counting Validation}

To validate the PET images and pharmacokinetics of ${ }^{89} \mathrm{Zr}$ cetuximab uptake, we performed $y$-counting on ex vivo normal and tumor tissue. U-373 MG tumors had the highest average uptake, followed by the HT-29 and A-431. The lowest uptake was found in the T-47D tumors (Fig. 6A). Uptake in several selected normal tissues was found for A-431, T-47D, A-431/T-47D mixed 
and non-tumor-bearing mice (Fig. 6B). No significant differences were found in normal tissue uptake between the mice bearing different tumor types. The uptake patterns, assessed using $\mathrm{Y}^{-}$ counting, were similar to the uptake seen on the PET images. A full biodistribution was performed on the HT-29 tumor-bearing mice (Fig. 6C). Uptake of all selected normal tissues was clearly lower than in HT-29 tumor.

A

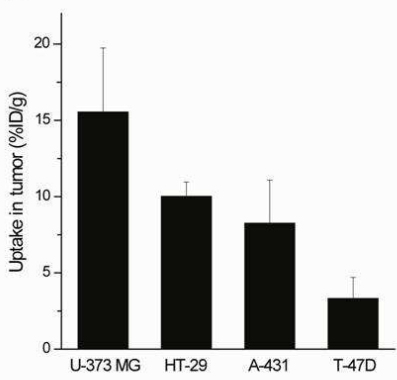

C

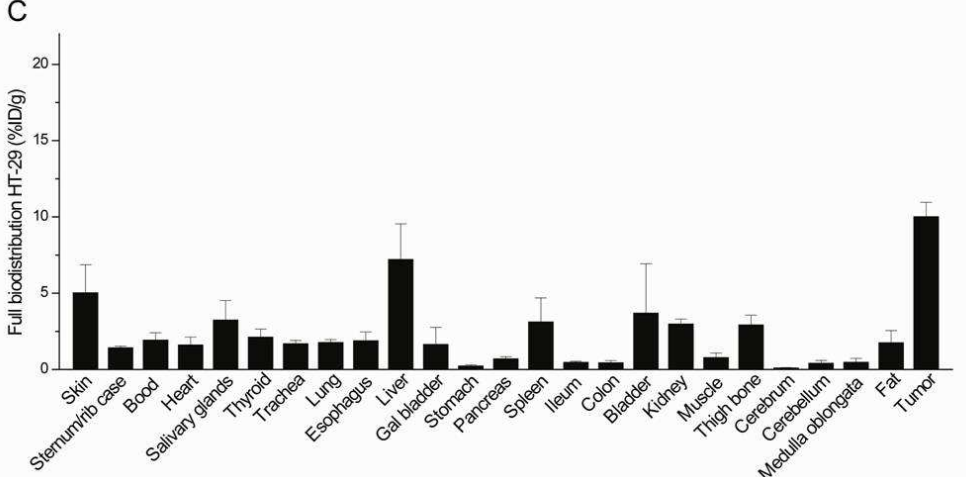

Figure 6. $y$-Counting experiment and biodistribution of ex vivo selected tissues. (A) Uptake of ${ }^{89} \mathrm{Zr}$-cetuximab of U-373 MG $(n=7)$ and HT-29 $(n=$ 9) tumors at $120 \mathrm{~h}$ after injection and by A-431 $(n=7)$ and T-47D $(n=6)$ tumors at $96 \mathrm{~h}$ after injection is shown. (B) Selected normal tissue analysis of A-431/T-47D $(n=3), \mathrm{A}-431(n=3), \mathrm{T}-47 \mathrm{D}(n=2)$ and non-tumorbearing $(n=1)$ mice. (C) Full biodistribution of HT-29 tumor-bearing mice $(n=6)$. All data represented the mean \pm SD, are decay-corrected to $96 \mathrm{~h}$ after injection, and are expressed as \%ID/g. 
The highest uptake (i.e., $>3 \% \mathrm{ID} / \mathrm{g}$ ) was found in the skin, salivary glands, liver, spleen, and bladder; other normal tissues, including stomach, pancreas, ileum, colon, muscles, cerebrum, cerebellum, and medulla oblongata, showed low uptake $(<1 \%$ $\mathrm{ID} / \mathrm{g})$.

\section{Quantification of In vivo EGFR Expression}

Several microenvironmental parameters can influence in vivo EGFR expression, resulting in a difference between the in vivo and the in vitro tissue culture EGFR expression. We therefore assessed both the in vivo and the in vitro EGFR expression using Western blotting.

A

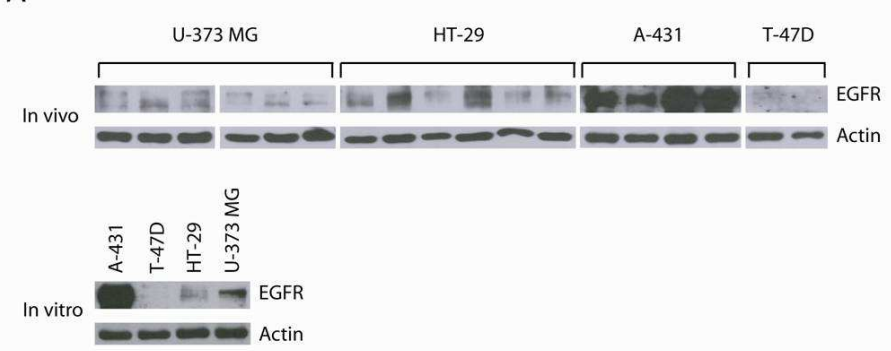

B

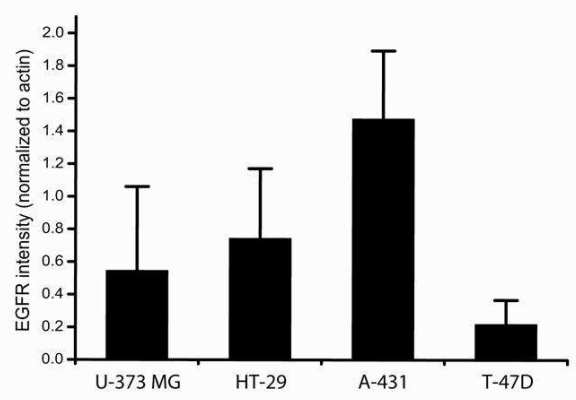

Figure 7. (A) Representative Western blots for in vivo and in vitro EGFR expression with actin as control (B) Densitometric quantificiation of in vivo EGFR expression of U-373 MG $(n=16)$, HT-29 $(n=12), \mathrm{A}-431(n=9)$, and T-47D $(n=7)$. Data are expressed as mean \pm SD. 
Figure 7A depicts representative Western blots of the different tumors in the upper panel, and in vitro samples are shown in the lower panel. Densitometric quantification of the in vivo Western blots is shown in Figure 7B. The in vivo and in vitro EGFR expressions were comparable, showing the A-431 tumors as high, U-373 MG and HT-29 as intermediate, and T-47D as low. A-431 has significantly higher in vivo EGFR expression than do the other tumor types (U-373 MG, $P=0.0002 ;$ HT-29, $P=0.0040 ;$ T-47D,$P$ $=0.0002)$. No significant differences were found between the $U$ 373 MG and HT-29 tumor types $(P=0.0902)$, whereas the T-47D was significantly lower than the other tumor types (U-373 MG, $P=$ 0.0024; HT-29, $P=0.0015 ;$ A-431, $P=0.002$ ).

\section{Discussion}

Little is known about patient-specific tumor uptake and the relationship between dosage and efficacy of the mAb cetuximab, for which a disparity between EGFR expression levels and cetuximab treatment efficiency has often been reported ${ }^{14,15,17}$. To increase knowledge of the clinical use of cetuximab as a targeting agent, it is necessary to be able to monitor in vivo cetuximab uptake noninvasively. To address this need, we developed a cetuximab-based probe for PET. Here, we report the in vivo validation of the ${ }^{89} \mathrm{Zr}$-labeled cetuximab imaging probe. The positron emitter ${ }^{89} \mathrm{Zr}$ was chosen given its ideal characteristics for use with antibodies ${ }^{27,}{ }^{28}$. Like ${ }^{68} \mathrm{Ga}$ and ${ }^{64} \mathrm{Cu},{ }^{89} \mathrm{Zr}$ demonstrates residualization, meaning that these radionuclides become trapped in lysosomes when the antibody internalizes and degrades ${ }^{27-29}$. Furthermore, ${ }^{89} \mathrm{Zr}$ has a much longer physical half-life $(78 \mathrm{~h})$ than other residualizing radionuclides. Antibodies show generally slow 
pharmacokinetics and need several days to plateau in the target organ. Therefore, ${ }^{89} \mathrm{Zr}$ is the better-suited radionuclide for combination with intact antibodies (such as cetuximab). To assess the pharmacokinetics of cetuximab noninvasively and increase current knowledge in clinical practice, using cetuximab itself as an imaging probe is the obvious solution.

To assess the pharmacokinetics of ${ }^{89} \mathrm{Zr}$-cetuximab, we performed PET at several time points after injection and found a gradual increase in uptake in the high- and intermediateexpression tumors (Figs. 2 and $3 \mathrm{~A}$ ). The corresponding blood uptake decreased with time (Figs. 2 and 3B), resulting in high tumor-to-blood ratios (Fig. 5) at the plateau phase of cetuximab uptake (72-96 $\mathrm{h}$ after injection). On the other hand, normal tissue uptake at similar time points was significantly lower (Fig. 4). Therefore, the tumor-to-blood ratios ( $\max T / B$ of $3-5$ ) are sufficient for imaging purposes. Our PET results were confirmed by ex vivo biodistribution studies assessed with $y$-counting. Again, uptake in the intermediate- and high-expression tumors was significantly higher than in the surrounding normal tissues (Fig. 6). Although the $\gamma$-counting data (in $\% \mathrm{ID} / \mathrm{g}$ ) demonstrated a trend similar to the quantified small-animal PET data (in \%ID/ml), the absolute values of the $\mathrm{y}$-counting were higher. This can be explained by the partial-volume effects of the small-animal PET scanner.

To be able to predict which patients might benefit from cetuximab treatment, one must assess in vivo EGFR expression levels. Therefore, we investigated whether in vivo cetuximab uptake is associated with EGFR expression levels. Other investigators reported the use of ${ }^{64} \mathrm{CU}$-DOTA-cetuximab for PET, showing prominent uptake in EGFR-expressing tumors but low 
accumulation in EGFR-negative tumors ${ }^{22,24}$. A linear correlation between the \%ID/g values (measured by ${ }^{64} \mathrm{Cu}$-labeled cetuximab PET) and EGFR expression levels (assessed with Western blotting) was found. However, because of the limiting half-life of the isotope ${ }^{64} \mathrm{Cu}$, imaging was possible only until $48 \mathrm{~h}$ after injection. Also, the immunoreactive fraction of ${ }^{64} \mathrm{Cu}$-labeled cetuximab was significantly lower $\left(\sim 63 \%{ }^{22}\right)$ than that of ${ }^{89} \mathrm{Zr}$-labeled cetuximab ( $95 \%{ }^{28}$ ). Another study, with the murine counterpart of cetuximab $(\mathrm{mC} 225)$ labeled with ${ }^{111} \mathrm{In}$, reported a correlation between mAb uptake and EGFR expression ${ }^{25}$. However, the aim of that study was not to evaluate this correlation, and the authors themselves stated that the observed results should be compared cautiously because of large differences in injected mAb concentration and image time points. Another explanation for these contradictory results can be the differences in tumor volume. Previous studies of De Bree et al. ${ }^{35}$ and others showed that tumor volume largely determines antibody uptake, most likely related to blood supply, interstitial pressure, and transport distance from the interstitium. To mimic a clinical situation more closely we used larger tumors $\left(\approx 400 \mathrm{~mm}^{3}\right)$ that displayed a relatively lower uptake of ${ }^{89} \mathrm{Zr}$-cetuximab, compared with other studies with smaller tumors 22,25 . However, as shown in Figure 5B, the maximum uptake voxel in the tumors is much higher $(\approx 20 \% \mathrm{ID} / \mathrm{g})$ and comparable with the uptake in the other studies.

Our results demonstrated a large disparity between uptake of the antibody and in vivo EGFR expression. Quantification of the PET images indicated that uptake in the intermediate-expression cell lines (U-373 MG and HT-29) was approximately 2 times higher than uptake in the high-expression cells (A-431) (Fig. 3). However, Western blot quantification on ex vivo tumor material 
using anti-EGFR mAbs confirmed that EGFR expression was higher in the A-431 tumors than in the U-373 MG and HT-29 tumors (Fig. 7). We confirmed tumor EGFR expression by comparison with in vitro EGFR expression in cells and found similar results, indicating that the EGFR expression levels did not change in the tumor. We considered the possibility that differences in in vivo tumor growth could have affected the tumor uptake of the various xenograft lines; however, the growth was comparable between the various xenograft lines.

Tumors originating from different cell lines have (besides EGFR expression) other physiologic effects, like inadequate vasculature, differences in capillary permeability perfusion, and differences in necrosis. All these factors can play an important role in in vivo drug delivery ${ }^{36,37}$. Also, cancer cells can bypass the dependency of EGFR for cell growth and survival by altering EGFR levels through promoting EGFR ubiquitination and degradation, resulting in overall cetuximab resistance ${ }^{37}$. Therefore, it should be noted that if cetuximab is not able to reach the complete tumor, no therapeutic effect can be expected in these regions. However, if cetuximab is able to reach the complete tumor, a therapeutic effect may not necessarily occur given the redundancy in the EGFR pathway.

Taken together, the relationship between EGFR expression levels, cetuximab binding and, ultimately, clinical outcome is complex. In vitro there is a strong relationship between cetuximab binding and EGFR expression levels ${ }^{16}$. Also, high levels of EGFR expression correlate with poor clinical outcomes ${ }^{5}$. However, the treatment efficacy of cetuximab does not correlate with EGFR expression ${ }^{14,15,17}$. Our results, revealing additional mechanisms influencing tumor delivery of cetuximab, show that cetuximab uptake is not only dependent on EGFR expression levels. These 
mechanisms may partially reveal why expression alone may not be sufficient to explain therapy effects. Possible explanations for the mismatch may include inadequate vasculature and perfusion, resulting in a heterogeneous and limited cetuximab uptake, even upon treatment at a high mAb dose. A future quantification of the results, assessing differences in vasculature, perfusion, hypoxia, and proliferation, could explain why the "reachability" in the xenografts is disparate.

The chelate labeling of ${ }^{89} \mathrm{Zr}$ with cetuximab is very stable: indeed, it can be produced under good-manufacturing-practice settings, making it an ideal candidate for a fast translation to the clinic $^{27}$. In future clinical trials, ${ }^{89} \mathrm{Zr}$-labeled cetuximab may be used to noninvasively examine the uptake of cetuximab into the tumor, thus allowing selection of patients who can potentially benefit from cetuximab treatment. Sequential imaging during treatment can also reveal microenvironmental changes influencing cetuximab perfusion and uptake. On the basis of these images, treatment can be monitored and dosage adjusted, making individualized treatment of cetuximab a possibility. 


\section{Conclusion}

This study has demonstrated that cetuximab uptake in tumors can be assessed by PET using ${ }^{89} \mathrm{Zr}$-labeled cetuximab. This probe can thus potentially be used to evaluate the biologic and pharmacokinetic clinical effects of EGFR inhibitors, both cetuximab and others. A disparity was found between cetuximab uptake and in vivo EGFR expression; the imaging therefore represents cetuximab uptake instead of a quantification of EGFR expression levels. More generally, the results reveal additional mechanisms that influence antibody uptake in tumors besides the expression levels of a biologic target in a tumor alone.

\section{Acknowledgements}

We thank Nicole Bitsch for technical assistance with the animal experiments. We acknowledge financial support from the Dutch Cancer Society (KWF Kankerbestrijding grant UM2008-4210). 


\section{References}

1. Imai K. and Takaoka A. Comparing antibody and small-molecule therapies for cancer. Nat Rev Cancer, 2006. 6(9): p. 714-27.

2. Sebolt-Leopold J.S. and English J.M. Mechanisms of drug inhibition of signalling molecules. Nature, 2006. 441(7092): p. 457-62.

3. Herbst R.S. Review of epidermal growth factor receptor biology. Int J Radiat Oncol Biol Phys, 2004. 59(2 Suppl): p. 21-6.

4. Mendelsohn J. Targeting the epidermal growth factor receptor for cancer therapy. ] Clin Oncol, 2002. 20(18 Suppl): p. 1S-13S.

5. Akimoto T., Hunter N.R., Buchmiller L., et al. Inverse relationship between epidermal growth factor receptor expression and radiocurability of murine carcinomas. Clin Cancer Res, 1999. 5(10): p. 2884-90.

6. Eriksen J.G., Steiniche T., and Overgaard J. The influence of epidermal growth factor receptor and tumor differentiation on the response to accelerated radiotherapy of squamous cell carcinomas of the head and neck in the randomized DAHANCA 6 and 7 study. Radiother Oncol, 2005. 74(2): p. 93-100.

7. Herbst R.S. and Shin D.M. Monoclonal antibodies to target epidermal growth factor receptor-positive tumors: a new paradigm for cancer therapy. Cancer, 2002. 94(5): p. $1593-611$.

8. Baselga J. and Arteaga C.L. Critical update and emerging trends in epidermal growth factor receptor targeting in cancer. J Clin Oncol, 2005. 23(11): p. 2445-59.

9. Huang S.M., Bock J.M., and Harari P.M. Epidermal growth factor receptor blockade with C225 modulates proliferation, apoptosis, and radiosensitivity in squamous cell carcinomas of the head and neck. Cancer Res, 1999. 59(8): p. 1935-40.

10. Huang S.M. and Harari P.M. Modulation of radiation response after epidermal growth factor receptor blockade in squamous cell carcinomas: inhibition of damage repair, cell cycle kinetics, and tumor angiogenesis. Clin Cancer Res, 2000. 6(6): p. 2166-74.

11. Bonner J.A., Harari P.M., Giralt J., et al. Radiotherapy plus Cetuximab for SquamousCell Carcinoma of the Head and Neck. N Engl J Med, 2006. 354(6): p. 567-578.

12. Lammering G. Molecular predictor and promising target: will EGFR now become a star in radiotherapy? Radiother Oncol, 2005. 74(2): p. 89-91.

13. Erbitux (Cetuximab) in the treatment of metastatic colorectal cancer. Company Report Merck KGaA, Merck KGaA. p. 44.

14. Hebbar M., Wacrenier A., Desauw C., et al. Lack of usefulness of epidermal growth factor receptor expression determination for cetuximab therapy in patients with colorectal cancer. Anticancer Drugs, 2006. 17(7): p. 855-7.

15. Lenz H.J., Van Cutsem E., Khambata-Ford S., et al. Multicenter phase II and translational study of cetuximab in metastatic colorectal carcinoma refractory to irinotecan, oxaliplatin, and fluoropyrimidines. J Clin Oncol, 2006. 24(30): p. 4914-21.

16. Aerts H.J., Dubois L., Hackeng T.M., et al. Development and evaluation of a cetuximab-based imaging probe to target EGFR and EGFRvIII. Radiother Oncol, 2007. 83(3): p. 326-32.

17. Chung K.Y. Shia J., Kemeny N.E., et al. Cetuximab shows activity in colorectal cancer patients with tumors that do not express the epidermal growth factor receptor by immunohistochemistry. J Clin Oncol, 2005. 23(9): p. 1803-10.

18. Heidary N., Naik H., and Burgin S. Chemotherapeutic agents and the skin: An update. J Am Acad Dermatol, 2008. 58(4): p. 545-70.

19. Divgi C.R., Welt S., Kris M., et al. Phase I and imaging trial of indium 111-labeled anti-epidermal growth factor receptor monoclonal antibody 225 in patients with squamous cell lung carcinoma. J Natl Cancer Inst, 1991. 83(2): p. 97-104.

20. van Dongen G.A., Visser G.W., Lub-de Hooge M.N., et al. Immuno-PET: a navigator in monoclonal antibody development and applications. Oncologist, 2007. 12(12): p. 1379-89.

21. Schechter N.R., Yang D.J., Azhdarinia A., et al. Assessment of epidermal growth factor receptor with 99mTc-ethylenedicysteine-C225 monoclonal antibody. Anticancer Drugs, 2003. 14(1): p. 49-56.

22. Cai W., Chen K., He L., et al. Quantitative PET of EGFR expression in xenograftbearing mice using (64)Cu-labeled cetuximab, a chimeric anti-EGFR monoclonal antibody. Eur J Nucl Med Mol Imaging, 2007.

23. Schechter N.R., Wendt R.E., 3rd, Yang D.J., et al. Radiation dosimetry of 99mTclabeled C225 in patients with squamous cell carcinoma of the head and neck. J Nucl Med, 2004. 45(10): p. 1683-7. 
24. Ping Li W., Meyer L.A., Capretto D.A., et al. Receptor-Binding, Biodistribution, and Metabolism Studies of (64)Cu-DOTA-Cetuximab, a PET-Imaging Agent for Epidermal Growth-Factor Receptor-Positive Tumors. Cancer Biother Radiopharm, 2008. 23(2): p. $158-71$.

25. Goldenberg A., Masui H., Divgi C., et al. Imaging of human tumor xenografts with an indium-111-labeled anti-epidermal growth factor receptor monoclonal antibody. J Natl Cancer Inst, 1989. 81(21): p. 1616-25.

26. Verel I., Visser G.W., Boellaard R., et al. Quantitative $89 \mathrm{Zr}$ immuno-PET for in vivo scouting of $90 \mathrm{Y}$-labeled monoclonal antibodies in xenograft-bearing nude mice. J Nucl Med, 2003. 44(10): p. 1663-70.

27. Verel I., Visser G.W., Boellaard R., et al. 89Zr immuno-PET: comprehensive procedures for the production of $89 \mathrm{Zr}$-labeled monoclonal antibodies. J Nucl Med, 2003. 44(8): p. 1271-81.

28. Perk L.R., Visser G.W., Vosjan M.J., et al. (89)Zr as a PET surrogate radioisotope for scouting biodistribution of the therapeutic radiometals (90)Y and (177)Lu in tumorbearing nude mice after coupling to the internalizing antibody cetuximab. J Nucl Med, 2005. 46(11): p. 1898-906.

29. Verel I., Visser G.W., Boerman O.C., et al. Long-lived positron emitters zirconium-89 and iodine-124 for scouting of therapeutic radioimmunoconjugates with PET. Cancer Biother Radiopharm, 2003. 18(4): p. 655-61.

30. Verel I., Visser G.W., Vosjan M.J., et al. High-quality 124I-labelled monoclonal antibodies for use as PET scouting agents prior to 131I-radioimmunotherapy. Eur J Nucl Med Mol Imaging, 2004. 31(12): p. 1645-52.

31. Nagengast W.B., de Vries E.G., Hospers G.A., et al. In vivo VEGF imaging with radiolabeled bevacizumab in a human ovarian tumor xenograft. J Nucl Med, 2007. 48(8): p. 1313-9.

32. Borjesson P.K., Jauw Y.W., Boellaard R., et al. Performance of immuno-positron emission tomography with zirconium-89-labeled chimeric monoclonal antibody U36 in the detection of lymph node metastases in head and neck cancer patients. Clin Cancer Res, 2006. 12(7 Pt 1): p. 2133-40.

33. Perk L.R., Visser O.J., Stigter-van Walsum M., et al. Preparation and evaluation of (89)Zr-Zevalin for monitoring of (90)Y-Zevalin biodistribution with positron emission tomography. Eur J Nucl Med Mol Imaging, 2006. 33(11): p. 1337-45.

34. Guide for the Care and Use of Laboratory Animals. Washington, DC: Government Printing Office, 1985: p. NIH publication 86-23.

35. de Bree R., Kuik D.J., Quak J.J., et al. The impact of tumour volume and other characteristics on uptake of radiolabelled monoclonal antibodies in tumour tissue of head and neck cancer patients. Eur J Nucl Med, 1998. 25(11): p. 1562-5.

36. Viloria-Petit A., Crombet T., Jothy S., et al. Acquired resistance to the antitumor effect of epidermal growth factor receptor-blocking antibodies in vivo: a role for altered tumor angiogenesis. Cancer Res, 2001. 61(13): p. 5090-101.

37. Lu Y., Li X., Liang K., et al. Epidermal growth factor receptor (EGFR) ubiquitination as a mechanism of acquired resistance escaping treatment by the anti-EGFR monoclonal antibody cetuximab. Cancer Res, 2007. 67(17): p. 8240-7. 
Chapter 9

General discussion and summary

Concluding remarks and future perspectives 


\section{General discussion and summary}

Tumor hypoxia is associated with increased malignant progression and metastatic potential of primary carcinomas. Furthermore, hypoxia is a major cause of resistance to cancer treatment, independent of the treatment modality (radiotherapy, chemotherapy or radical surgery $)^{1}$. The importance of hypoxia in cancer coupled with the fact that it is not usually present in normal tissues, except for avascular tissues such as cartilage and cornea ${ }^{2}$ 3 , makes it an attractive target for development of new drugs to increase the therapeutic effect of conventional cancer treatment modalities ${ }^{4}$. Although treatment approaches to counteract the negative effect of hypoxia have, and continue to be investigated, only modest improvements in outcome have been achieved so far $^{5}$. Since levels of hypoxia vary substantially amongst patients, the use of hypoxia-directed treatments may be superior if given to those tumors with the greatest amount of hypoxia. To do this effectively requires the ability to assess tumor hypoxia in a non invasive manner. The use of PET employing one of several hypoxia-specific tracers enables quantification of hypoxia, which provides a basis for this type of rational patient selection ${ }^{6}$.

$\left[{ }^{18} \mathrm{~F}\right]$ Fluoromisonidazole ( $\left.\left[{ }^{18} \mathrm{~F}\right] \mathrm{FMISO}\right)$ is the most widely used PET tracer for hypoxia imaging ${ }^{7}$. Based on its high cellular uptake and trapping in hypoxic cells, $\left[{ }^{18} \mathrm{~F}\right] \mathrm{FMISO}$ has been tested for in vivo visualization of reduced oxygen levels in tumors both preclinically, using different animal models ${ }^{8,9}$, and clinically, for different cancer types $^{10-12}$. Few comparative studies assessing new imaging methodologies in concert with established 'standard' techniques are available. Evaluation of $\left[{ }^{18} \mathrm{~F}\right] \mathrm{FMISO}$ PET uptake and comparison with $\mathrm{pO}_{2}$ electrode measurements in tumors resulted in a lack of 
correlation in $\mathrm{C} 3 \mathrm{H}$ mammary carcinomas ${ }^{13}$, while a correlation was found in a study of hypoxia in pig liver tissue ${ }^{14}$. In chapter 2 , we demonstrate the first validation of $\left[{ }^{18} \mathrm{~F}\right]$ FMISO PET using a nitroimidazole related histopathology assay. Using an experimental rat tumor model, we found a strong and significant relationship between $\left[{ }^{18} \mathrm{~F}\right] \mathrm{FMISO}$ accumulation assessed with PET and pimonidazole-stained sections. This was confirmed in human head and neck xenografts, where both $\left[{ }^{18} \mathrm{~F}\right] \mathrm{FMISO}$ autoradiography and pimonidazole immunohistochemistry might be used for visualizing changes in tumor hypoxia, as witnessed from a moderate pixel-topixel correlation between the two techniques ${ }^{15,16}$. Furthermore, we found that $\left[{ }^{18} \mathrm{~F}\right]$ FMISO PET imaging was also able to visualize hypoxia response, since a strong correlation was found with the hypoxia responsive CA IX expression. Recently, He and colleagues supported this finding in a HT-29 colorectal xenograft model by demonstrating a colocalization between the exogenous (pimonidazole and $\left[{ }^{18} \mathrm{~F}\right] \mathrm{FMISO}$ ), the endogenous (CA IX) hypoxia markers and the hypoxia-induced expression of eGFP ${ }^{17}$.

In terms of impact of hypoxia on outcome, pre-therapy determination of hypoxia is important, because most biological changes occur early, persist through therapy and are used to predict survival ${ }^{18}$. To assess the clinical efficacy of bioreductive drugs which are activated upon hypoxia such as tirapazamine ${ }^{19}$, pre-therapy evaluation of oxygenation is therefore essential. Furthermore, tumor control probability models based on repeated noninvasive PET acquisition using hypoxia markers during radiotherapy are the key for future hypoxia image-guided dose escalation in radiotherapy ${ }^{20}$ and in planning boost radiotherapy to persistent hypoxic subvolumes ${ }^{4}$. $\left[{ }^{18} \mathrm{~F}\right] \mathrm{FMISO}$ is currently the most 
widely investigated PET hypoxia marker in the clinic and has been demonstrated in some studies to be a valuable tool for therapy response evaluation ${ }^{10,11}$. However, there are concerns about the stability of the fluorine-18 linkage and the formation of metabolites in blood and urine ${ }^{21}$. Furthermore, diffusion of this compound into tissues and, in particular, into tumor tissues may not be optimal due to the lipophilicity of the compound. Second generation nitroimidazole hypoxia markers (e.g., FETNIM, FETA, EF3, EF5, FAZA, etc.) that are more water soluble have been developed and lower degradation has been demonstrated, resulting in higher tumor to background contrast ${ }^{22-24}$. Based on ex vivo pharmacokinetics and biodistribution data, Mahy and colleagues demonstrated that $\left[{ }^{18} \mathrm{~F}\right] \mathrm{EF} 3$ could be a good alternative for $\left[{ }^{18} \mathrm{~F}\right] \mathrm{FMISO}$, since only few circulating metabolites and a better diffusion into tissues was observed ${ }^{25}$. In chapter 3, we demonstrated, using noninvasive PET imaging, that $\left[{ }^{18} \mathrm{~F}\right] \mathrm{EF} 3$ uptake was indeed slightly faster cleared and lower background levels were obtained compared with $\left[{ }^{18} \mathrm{~F}\right] \mathrm{FMISO}$. However, the $\left[{ }^{18} \mathrm{~F}\right] \mathrm{EF} 3$ tumor uptake was significantly lower, consequently this compound is not superior over $\left[{ }^{18} \mathrm{~F}\right] \mathrm{FMISO}$.

Alternatively, the 2-nitroimidazole nucleoside analogue $\left[{ }^{18} \mathrm{~F}\right] \mathrm{HX} 4$ was developed to have a higher water solubility and faster clearance compared with established hypoxia PET markers (Kolb et al, personal communication $)^{26}$. In chapter 4 , we investigated the potential of $\left[{ }^{18} \mathrm{~F}\right] \mathrm{HX} 4$ as a noninvasive marker for hypoxic tumor cells. We observed a clear $\left[{ }^{18} \mathrm{~F}\right] \mathrm{HX} 4$ accumulation in several tumor models compared with surrounding muscle tissue and this uptake was influenced by tumor oxygenation, since exposing animals to the combination treatment of nicotinamide and carbogen reduced 
$\left[{ }^{18} \mathrm{~F}\right] \mathrm{HX} 4$ accumulation. This combination has previously been shown to efficiently reduce tumor hypoxia in preclinical $^{27}$ and clinical $^{28}$ settings. Further evidence for the requirement of hypoxia to enable effective $\left[{ }^{18} \mathrm{~F}\right] \mathrm{HX} 4$ uptake was demonstrated by a significant higher accumulation following 7\% oxygen breathing.

We further evaluated $\left[{ }^{18} \mathrm{~F}\right] \mathrm{HX} 4$ tumor to blood (T/B) ratios and clearance compared with the previously validated noninvasive hypoxia markers $\left[{ }^{18} \mathrm{~F}\right] \mathrm{FMISO}$ and $\left[{ }^{18} \mathrm{~F}\right] \mathrm{EF} 3$ in the same experimental rat tumor model. The optimal time point for imaging $\left[{ }^{18} \mathrm{~F}\right] \mathrm{HX} 4$ was found to be $4 \mathrm{~h}$ after injection, where comparable mean T/B ratios were observed as for $\left[{ }^{18} \mathrm{~F}\right] \mathrm{EF} 3$ (chapter 3 ). Unfortunately, we only have $\left[{ }^{18} \mathrm{~F}\right] \mathrm{FMISO}$ uptake data up to $2 \mathrm{~h}$ after injection within the same model (chapter 2), but other studies indicate that the optimal time point for $\left[{ }^{18} \mathrm{~F}\right] \mathrm{FMISO}$ imaging is probably not yet reached at $3 \mathrm{~h}$ post injection ${ }^{10}$. Furthermore, significantly higher maximum $\left[{ }^{18} \mathrm{~F}\right] \mathrm{HX} 4 \mathrm{~T} / \mathrm{B}$ ratios compared with $\left[{ }^{18} \mathrm{~F}\right] \mathrm{EF} 3$ ratios were observed, suggesting that $\left[{ }^{18} \mathrm{~F}\right] \mathrm{HX} 4$ in this rat tumor model may better distinguish between hypoxic and nonhypoxic areas within the tumor ${ }^{29}$. A progressive clearance from normal tissues was observed with time for all hypoxia markers, and the uptake in muscle was always lower than in blood, resulting in muscle to blood (M/B) ratios below unity, which is favorable for imaging purposes ${ }^{30}$. However, whereas $\left[{ }^{18} \mathrm{~F}\right] \mathrm{EF} 3 \mathrm{M} / \mathrm{B}$ ratios remained constant over time (chapter 3 ), $\left[{ }^{18} \mathrm{~F}\right] \mathrm{HX} 4 \mathrm{M} / \mathrm{B}$ ratios decreased over time suggesting a more rapid clearance from normal tissues.

Although $\left[{ }^{18} \mathrm{~F}\right] \mathrm{HX} 4$ seemed to be superior to $\left[{ }^{18} \mathrm{~F}\right] \mathrm{FMISO}$ and $\left[{ }^{18} \mathrm{~F}\right] \mathrm{EF} 3$ in the experimental rat tumor model, comparison of 
$\left[{ }^{18} \mathrm{~F}\right] \mathrm{HX} 4,\left[{ }^{18} \mathrm{~F}\right] \mathrm{FMISO}$ and $\left[{ }^{18} \mathrm{~F}\right] \mathrm{FAZA}$ in several xenograft models did not result in significant differences in uptake. $\left[{ }^{18} \mathrm{~F}\right] \mathrm{FMISO}$ tumor to muscle $(\mathrm{T} / \mathrm{M})$ ratios followed a similar pattern, but were in general higher than $\left[{ }^{18} \mathrm{~F}\right] \mathrm{HX} 4 \mathrm{~T} / \mathrm{M}$ ratios, although these differences are not significant, while $\left[{ }^{18} \mathrm{~F}\right] \mathrm{FAZA} \mathrm{T} / \mathrm{M}$ ratios were less consistent over the different tumor types (chapter 4), explained by the highly tumor dependent $\left[{ }^{18} \mathrm{~F}\right] \mathrm{FAZA}$ uptake. In advanced Walker 256 rat tumors, $\left[{ }^{18} \mathrm{~F}\right] \mathrm{FAZA}$ uptake was slightly but significantly lower compared with $\left[{ }^{18} \mathrm{~F}\right] \mathrm{FMISO}$ uptake ${ }^{31}$. On the other hand, in mice bearing different murine and human tumor models, $\left[{ }^{18} \mathrm{~F}\right] \mathrm{FAZA}$ T/B ratios were almost 3-fold higher ${ }^{30,32}$. Our results support that tracer distribution and accumulation is dependent on the tumor type, which has also been observed for several patient tumors ${ }^{33}$. Based on the obtained results across different tumor models comparing the uptake of different hypoxia markers, we believe that $\left[{ }^{18} \mathrm{~F}\right] \mathrm{HX} 4$ is the most promising noninvasive hypoxia marker based on its faster clearance from normal tissues and better reflection of tumor heterogeneity.

It has also been suggested that the degree of $\left[{ }^{18} \mathrm{~F}\right] \mathrm{FDG}$ uptake by tumors might reflect the level of hypoxia, obviating the need for more specific PET markers for hypoxia imaging. This is based on the widely availability of $\left[{ }^{18} \mathrm{~F}\right] \mathrm{FDG}$ and on the Warburg effect or tumor hyperglycolysis, which can be driven by the activation of HIF-1 and tumor hypoxia ${ }^{34}$. However, many discrepancies have been observed between $\left[{ }^{18} \mathrm{~F}\right] \mathrm{FDG}$ and hypoxia tracer uptake, indicating that regional hypoxia and glycolysis do not always correlate ${ }^{12,24}$. Therefore, it is suggested that identification of hypoxia in solid tumors of patients is best pursued through noninvasive imaging using validated hypoxia markers. 
Substantial evidence associates hypoxia with tumor development, growth, metastasis and poor response to therapy ${ }^{1,35-37}$. This tumor phenotype is due to hypoxia-influenced signaling pathways that regulate the expression of many genes important for the development and growth of solid tumors ${ }^{38}$. It is important to understand the hypoxia response pathways in order to increase the success of recent molecular cancer therapeutics specifically designed to target hypoxic responses. Noninvasive evaluation of these pathways is therefore a potentially important tool for treatment guidance and patient selection. Tumor-associated carbonic anhydrase (CA) IX, upregulated by a strong transcriptional activation of the CA9 gene by HIF-1a, is a good candidate since its expression is associated with poor prognosis, tumor progression and aggressiveness, suggesting that CA IX may also be a good therapeutic target.

Several simple and efficient methods to evaluate molecular markers of hypoxia, such as CA IX, are under investigation. Indeed, accumulation of ${ }^{125} \mathrm{I}$ or ${ }^{89} \mathrm{Zr}$ labeled CA IX antibody was demonstrated in xenografts in animals ${ }^{39,} 40$. However, no discrimination can be made between hypoxic and aerobic cells expressing CA IX, since antibody binding occurs also upon reoxygenation due to the slow normal turnover of CA IX (half life of CA IX upon reoxygenation is $\sim 38$ hours) ${ }^{41}$. Therefore, imaging of CA IX using antibodies will be unable to reveal periodic or cyclic areas of tumor oxygenation. Various sulfonamide derived inhibitors of CA IX have been developed over the past years ${ }^{42}$. Recently, a fluorescent sulfonamide with high affinity for CA IX was developed and in chapter 5 we investigated its cellular binding properties. Our 
results indicate that sulfonamide binding to CA IX was exclusively observed during hypoxia in several cell lines, irrespective of the levels of CA IX or HIF-1a activity. We hypothesize that CA IX protein has to be in an open conformation during hypoxia to allow interaction between the sulfonamide and the CA IX active site, but further confirmation needs to be obtained. No significant sulfonamide binding was observed during aerobic exposure in cells which express CA IX and other HIF-1a dependent genes during normoxia, indicating availability for binding of the CA IX active site only during hypoxia. Furthermore, bound sulfonamide to CA IX under hypoxic conditions remained associated with cells during reoxygenation. This bound fraction was gradually lost with time during reoxygenation, but was much faster than the normal turnover of CA IX, due to either loss of binding or induced internalization and degradation.

The fact that sulfonamide binding and colocalization with the antibody is only observed upon hypoxia exposure (Chapter 5), suggests that sulfonamides may be an attractive tool for evaluation of tumor areas exposed to chronic, but also fluctuating hypoxia. Based on these results, we further investigated in chapter 6 the in vivo sulfonamide accumulation as evaluated by noninvasive fluorescence imaging. We observed a clear accumulation in delineated hotspots in the tumor after injection of the sulfonamide compared to a fluorescent analogue lacking the critical CA IX interaction sulfonamide group. The sulfonamide accumulation was dependent not only on the presence of CA IX protein, but also on available oxygen, since accumulation was significantly reduced upon treatment with carbogen and nicotinamide. On the other hand, $7 \%$ oxygen breathing resulted in 
an increased accumulation. Also, in vivo sulfonamide accumulation proved to be reversible upon tumor reoxygenation. These data suggest that it will be interesting to pursue further clinical development of sulfonamides for imaging and potential patient selection for hypoxia-directed and/or CA IX-directed therapies.

Interactions between hypoxia and the epidermal growth factor receptor (EGFR) have been demonstrated in non-small-cell lung cancer, which suggest that hypoxia induces expression of EGFR or its ligands, while EGFR might enhance the cellular response to hypoxia by increasing HIF-1a expression ${ }^{43-45}$. Although targeting EGFR with receptor-blocking monoclonal antibodies seems promising ${ }^{46}$, many patients do not show favorable responses to EGFR-targeted therapy ${ }^{44}$. A possible explanation is the hampered drug delivery due to heterogeneity in EGFR expression, vasculature, capillary permeability perfusion and necrosis. In chapter 7 and 8, we developed and validated a cetuximab based imaging probe to evaluate its uptake and usage as an imaging marker for EGFR. We successfully developed an Oregon Green 488 labeled cetuximab imaging probe and observed a clear membranous localization in EGFR overexpressing cells (Chapter 7). Comparison between the binding profile of the fluorescent cetuximab and the EGFR expression levels demonstrated a significant relationship for tumor cell lines with varying EGFR expression.

To increase knowledge of the clinical use of cetuximab as a targeting agent in patients, it is necessary to be able to monitor its in vivo uptake noninvasively. To address this need, we developed in chapter 8 a cetuximab-based probe for PET, by labeling with 
${ }^{89} \mathrm{Zr}$. It has been shown that ${ }^{89} \mathrm{Zr}$ is the best-suited radionuclide for combination with intact antibodies, based on its residualizing properties and long physical half life, better matching the slow pharmacokinetics of antibodies ${ }^{47}$. In chapter 8 , performing PET imaging, we observed a gradual increase in uptake in tumors with varying EGFR expression levels, corresponding with decreasing activities in normal tissues, which was confirmed by ex vivo $\mathrm{Y}^{-}$ counting biodistribution studies. Although other groups reported a correlation between cetuximab uptake and EGFR expression levels ${ }^{48,49}$, surprisingly our results demonstrate a large disparity between both, revealing additional mechanisms influencing tumor delivery of cetuximab. The absence of an association could not be explained by changed in vivo EGFR expression levels or differences in tumor growth. Taken together, the relationship between EGFR expression levels, cetuximab uptake and clinical outcome is complex. Even if cetuximab is able to reach the complete tumor, a therapeutic effect may not necessarily occur, indicating the value of noninvasive imaging of drug delivery in order to make individualized patient treatment possible. 


\section{Concluding remarks and future perspectives}

The overwhelming evidence showing that hypoxia is important in tumor progression and prognosis has directed research into developing strategies to target hypoxic cells, including modification of the hypoxic environment or targeting components of the HIF-1 signaling pathway. To identify hypoxic tumors and those patients that will benefit from hypoxia-targeted therapy, reliable methods to evaluate tumor oxygenation are necessary. Noninvasive imaging allows an accurate estimation of the hypoxic fraction and offers the possibility of in vivo mapping of regional tumor hypoxia as well as monitoring of therapy through follow-up mapping of hypoxia. However, the success of incorporating new hypoxia imaging markers into treatment planning depends on the accuracy of quantifying it.

Ideally, a hypoxia marker should demonstrate high diffusion in tumor tissues, water solubility and low degradation, which combined result in higher tumor to background contrast. Based on our results, $\left[{ }^{18} \mathrm{~F}\right] \mathrm{HX} 4$ uptake is similar to other noninvasive hypoxia markers, but clearance from normal tissues is faster and $\left[{ }^{18} \mathrm{~F}\right] \mathrm{HX} 4$ better represents tumor heterogeneity, making it a more promising agent for further testing for of clinical applicability. A phase 1 study done in our institute indicates that $\left[{ }^{18} \mathrm{~F}\right] \mathrm{HX} 4$ causes no obvious toxicity and could be used as noninvasive hypoxia marker in patients. $\left[{ }^{18} \mathrm{~F}\right] \mathrm{HX} 4$ can therefore be used to assess the effect on hypoxia of hypoxia-targeted therapies, such as increasing perfusion and corresponding oxygen levels using nitroglycerin. A tumor is a heterogeneous entity, characterized by regions of low oxygen, high proliferation and high perfusion. Therefore, tumor control probability models based on repeated $\left[{ }^{18} \mathrm{~F}\right] \mathrm{HX} 4$ PET 
acquisitions during radiotherapy, combining the perfusion efficiency and the degree of hypoxia, could be the key for hypoxia image-guided dose escalation and in planning boost radiation to persistent hypoxic sub-volumes.

On the other hand, besides being able to evaluate tumor oxygenation as such, it is also important to understand the cellular responses to hypoxia in order to increase the success of recent molecular cancer therapeutics specifically designed to target hypoxic responses, such as the HIF-1 pathway. Recently, molecular markers of hypoxia such as CA IX have been under investigation, but a major problem is that no discrimination can be made between hypoxic and aerobic/reoxygenated cells based on antibody imaging. However, we were able to demonstrate that fluorescent sulfonamides directed against CA IX are able to discriminate between such areas and are therefore a promising complement to image active hypoxia responses. Using antibody imaging to identify cells that have been exposed to hypoxia, complemented with sulfonamide imaging that binds only to cells that are hypoxic while exposed to the drug, would be useful to estimate the acute hypoxic fraction. To make this more clinical applicable, labeling of sulfonamides with radionuclides is ongoing and promising preliminary results are already obtained. Furthermore, specific targeting of active CA IX increasing the efficacy of conventional therapies seems also feasible, since radio - or chemosensitizing sulfonamides are able to enhance the effect of radiotherapy and chemotherapy respectively. Additionally, it has been shown that an acidic extracellular $\mathrm{pH}$ promotes metastasis formation. These acidity-induced metastases were inhibited by treatment with matrix metalloproteinase inhibitors, cysteine 
proteinase inhbitors or blocking antibody against VEGF or IL-8 ${ }^{50}$. Also neutralizing the extracellular acidosis of tumors by administration of $\mathrm{NaHCO}_{3}$ has been shown to inhibit invasion and to reduce the number of spontaneous metastases ${ }^{51}$. We demonstrated that sulfonamides directed against CA IX are able to reduce the hypoxia induced acidification and therefore hypothesize that CA IX plays a role in acidity-induced metastases.

In addition to assessment of tumor microenvironmental features such as oxygen levels, imaging may also be a useful way to monitor drug delivery to tumors. For example, imaging drug delivery could be used to individualize drug exposures, or to omit patients where targeted agents show no selective uptake. Our results show that cetuximab uptake is variable in tumors, and cannot be explained solely by EGFR expression levels. Possible explanations for this mismatch may include inadequate vasculature and perfusion, resulting in a heterogeneous and limited cetuximab uptake. To test this hypothesis, cetuximab uptake could be assessed after increasing the vascular perfusion using nitroglycerin ${ }^{52}$. Furthermore, the mismatch could also explain why patient treatment efficacy of cetuximab does not correlate with EGFR expression ${ }^{53,54}$. Therefore, we believe that development of novel therapeutic agents by the pharmaceutical industry should also include, where possible, visualization of the drug delivery in comparison with imaging of tumor related characteristics. This will at the end allow better selection of patients who can benefit from hypoxia-targeted therapies and therapeutic drugs in combination with conventional treatment modalities and result in individualized patient treatment. A phase 1 study in our institute is started to 
assess if ${ }^{89} \mathrm{Zr}$-cetuximab causes no toxicity and whether it could be used as noninvasive marker in patients.

1. Vaupel P. and Mayer A. Hypoxia in cancer: significance and impact on clinical outcome. Cancer Metastasis Rev, 2007. 26(2): p. 225-39.

2. Fonn D., Sweeney D., Holden B.A., et al. Corneal oxygen deficiency. Eye Contact Lens, 2005. 31(1): p. 23-7.

3. Schipani E. Hypoxia and HIF-1 alpha in chondrogenesis. Semin Cell Dev Biol, 2005. 16(4-5): p. 539-46.

4. Tatum J.L., Kelloff G.J., Gillies R.J., et al. Hypoxia: importance in tumor biology, noninvasive measurement by imaging, and value of its measurement in the management of cancer therapy. Int J Radiat Biol, 2006. 82(10): p. 699-757.

5. Brown J.M. and Wilson W.R. Exploiting tumour hypoxia in cancer treatment. Nat Rev Cancer, 2004. 4(6): p. 437-47.

6. Rajendran J.G. and Mankoff D.A. Beyond detection: novel applications for PET imaging to guide cancer therapy. J Nucl Med, 2007. 48(6): p. 855-6.

7. Dunphy M.P. and Lewis J.S. Radiopharmaceuticals in preclinical and clinical development for monitoring of therapy with PET. J Nucl Med, 2009. 50 Suppl 1: p. 106S-21S.

8. Koh W.J., Rasey J.S., Evans M.L., et al. Imaging of hypoxia in human tumors with [F18]fluoromisonidazole. Int J Radiat Oncol Biol Phys, 1992. 22(1): p. 199-212.

9. Tochon-Danguy H.J., Sachinidis J.I., Chan F., et al. Imaging and quantitation of the hypoxic cell fraction of viable tumor in an animal model of intracerebral high grade glioma using [18F]fluoromisonidazole (FMISO). Nucl Med Biol, 2002. 29(2): p. 191-7.

10. Gagel B., Reinartz P., Demirel C., et al. [18F] fluoromisonidazole and [18F] fluorodeoxyglucose positron emission tomography in response evaluation after chemo-/radiotherapy of non-small-cell lung cancer: a feasibility study. BMC Cancer, 2006. 6: p. 51.

11. Rajendran J.G., Schwartz D.L., O'Sullivan J., et al. Tumor hypoxia imaging with [F18] fluoromisonidazole positron emission tomography in head and neck cancer. Clin Cancer Res, 2006. 12(18): p. 5435-41.

12. Zimny M., Gagel B., DiMartino E., et al. FDG--a marker of tumour hypoxia? A comparison with [18F]fluoromisonidazole and pO2-polarography in metastatic head and neck cancer. Eur J Nucl Med Mol Imaging, 2006. 33(12): p. 1426-31.

13. Bentzen L., Keiding S., Horsman M.R., et al. Assessment of hypoxia in experimental mice tumours by [18F]fluoromisonidazole PET and pO2 electrode measurements. Influence of tumour volume and carbogen breathing. Acta Oncol, 2002. 41(3): p. 304-12.

14. Piert M., Machulla H.J., Becker G., et al. Dependency of the [18F]fluoromisonidazole uptake on oxygen delivery and tissue oxygenation in the porcine liver. Nucl Med Biol, 2000. 27(8): p. 693-700.

15. Troost E.G., Laverman P., Kaanders J.H., et al. Imaging hypoxia after oxygenationmodification: comparing [18F]FMISO autoradiography with pimonidazole immunohistochemistry in human xenograft tumors. Radiother Oncol, 2006. 80(2): p. 157-64.

16. Troost E.G., Laverman P., Philippens M.E., et al. Correlation of [18F]FMISO autoradiography and pimonidazole [corrected] immunohistochemistry in human head and neck carcinoma xenografts. Eur J Nucl Med Mol Imaging, 2008. 35(10): p. 180311.

17. He F., Deng X., Wen B., et al. Noninvasive molecular imaging of hypoxia in human xenografts: comparing hypoxia-induced gene expression with endogenous and exogenous hypoxia markers. Cancer Res, 2008. 68(20): p. 8597-606.

18. Rajendran J.G., Mankoff D.A., O'Sullivan F., et al. Hypoxia and glucose metabolism in malignant tumors: evaluation by [18F]fluoromisonidazole and [18F]fluorodeoxyglucose positron emission tomography imaging. Clin Cancer Res, 2004. 10(7): p. 2245-52.

19. McKeown S.R., Cowen R.L., and Williams K.J. Bioreductive drugs: from concept to clinic. Clin Oncol (R Coll Radiol), 2007. 19(6): p. 427-42. 
20. Thorwarth D., Eschmann S.M., Paulsen F., et al. A model of reoxygenation dynamics of head-and-neck tumors based on serial 18F-fluoromisonidazole positron emission tomography investigations. Int J Radiat Oncol Biol Phys, 2007. 68(2): p. 515-21.

21. Krohn K.A., Link J.M., and Mason R.P. Molecular imaging of hypoxia. J Nucl Med, 2008. 49 Suppl 2: p. 129S-48S.

22. Davda S. and Bezabeh T. Advances in methods for assessing tumor hypoxia in vivo: implications for treatment planning. Cancer Metastasis Rev, 2006. 25(3): p. 469-80.

23. Lucignani G. PET imaging with hypoxia tracers: a must in radiation therapy. Eur J Nucl Med Mol Imaging, 2008. 35(4): p. 838-42.

24. Serganova I., Humm J., Ling C., et al. Tumor hypoxia imaging. Clin Cancer Res, 2006. 12(18): p. 5260-4.

25. Mahy P., De Bast M., Leveque P.H., et al. Preclinical validation of the hypoxia tracer 2-(2-nitroimidazol-1-yl)- N-(3,3,3-[(18)F]trifluoropropyl)acetamide, [(18)F]EF3. Eur ] Nucl Med Mol Imaging, 2004. 31(9): p. 1263-72.

26. van Loon J., Janssen M.H.M., Oellers M., et al. PET imaging of hypoxia using [18F]HX4: A phase 1 trial. J Nucl Med, 2009. submitted.

27. van Laarhoven H.W., Bussink J., Lok J., et al. Effects of nicotinamide and carbogen in different murine colon carcinomas: immunohistochemical analysis of vascular architecture and microenvironmental parameters. Int J Radiat Oncol Biol Phys, 2004. 60(1): p. 310-21.

28. Kaanders J.H., Pop L.A., Marres H.A., et al. Accelerated radiotherapy with carbogen and nicotinamide (ARCON) for laryngeal cancer. Radiother Oncol, 1998. 48(2): p. 115-22.

29. Stadler P., Becker A., Feldmann H.J., et al. Influence of the hypoxic subvolume on the survival of patients with head and neck cancer. Int J Radiat Oncol Biol Phys, 1999. 44(4): p. 749-54.

30. Piert M., Machulla H.J., Picchio M., et al. Hypoxia-specific tumor imaging with $18 \mathrm{~F}-$ fluoroazomycin arabinoside. J Nucl Med, 2005. 46(1): p. 106-13.

31. Sorger D., Patt M., Kumar P., et al. [18F]Fluoroazomycinarabinofuranoside (18FAZA) and [18F]Fluoromisonidazole (18FMISO): a comparative study of their selective uptake in hypoxic cells and PET imaging in experimental rat tumors. Nucl Med Biol, 2003. 30(3): p. 317-26.

32. Reischl G., Dorow D.S., Cullinane C., et al. Imaging of tumor hypoxia with [124I]IAZA in comparison with [18F]FMISO and [18F]FAZA--first small animal PET results. J Pharm Pharm Sci, 2007. 10(2): p. 203-11.

33. Rasey J.S., Koh W.J., Evans M.L., et al. Quantifying regional hypoxia in human tumors with positron emission tomography of [18F]fluoromisonidazole: a pretherapy study of 37 patients. Int J Radiat Oncol Biol Phys, 1996. 36(2): p. 417-28.

34. Dierckx R.A. and Van de Wiele C. FDG uptake, a surrogate of tumour hypoxia? Eur J Nucl Med Mol Imaging, 2008. 35(8): p. 1544-9.

35. Brizel D.M., Sibley G.S., Prosnitz L.R., et al. Tumor hypoxia adversely affects the prognosis of carcinoma of the head and neck. Int J Radiat Oncol Biol Phys, 1997. 38(2): p. 285-9.

36. Hockel M., Schlenger K., Aral B., et al. Association between tumor hypoxia and malignant progression in advanced cancer of the uterine cervix. Cancer Res, 1996. 56(19): p. 4509-15.

37. Nordsmark M., Alsner J., Keller J., et al. Hypoxia in human soft tissue sarcomas: adverse impact on survival and no association with p53 mutations. Br J Cancer, 2001. 84(8): p. 1070-5.

38. Dewhirst M.W., Cao Y., and Moeller B. Cycling hypoxia and free radicals regulate angiogenesis and radiotherapy response. Nat Rev Cancer, 2008. 8(6): p. 425-37.

39. Brouwers A., Verel I., Van Eerd J., et al. PET radioimmunoscintigraphy of renal cell cancer using 89Zr-labeled cG250 monoclonal antibody in nude rats. Cancer Biother Radiopharm, 2004. 19(2): p. 155-63.

40. Chrastina A., Zavada J., Parkkila S., et al. Biodistribution and pharmacokinetics of 125I-labeled monoclonal antibody M75 specific for carbonic anhydrase IX, an intrinsic marker of hypoxia, in nude mice xenografted with human colorectal carcinoma. Int J Cancer, 2003. 105(6): p. 873-81.

41. Rafajova M., Zatovicova M., Kettmann R., et al. Induction by hypoxia combined with low glucose or low bicarbonate and high posttranslational stability upon reoxygenation contribute to carbonic anhydrase IX expression in cancer cells. Int J Oncol, 2004. 24(4): p. 995-1004.

42. Supuran C.T. Carbonic anhydrases: novel therapeutic applications for inhibitors and activators. Nat Rev Drug Discov, 2008. 7(2): p. 168-81. 
43. Franovic A., Gunaratnam L., Smith K., et al. Translational up-regulation of the EGFR by tumor hypoxia provides a nonmutational explanation for its overexpression in human cancer. Proc Natl Acad Sci U S A, 2007. 104(32): p. 13092-7.

44. Lu Y., Liang K., Li X., et al. Responses of cancer cells with wild-type or tyrosine kinase domain-mutated epidermal growth factor receptor (EGFR) to EGFR-targeted therapy are linked to downregulation of hypoxia-inducible factor-1alpha. Mol Cancer, 2007. 6: p. 63.

45. Swinson D.E. and O'Byrne K.J. Interactions between hypoxia and epidermal growth factor receptor in non-small-cell lung cancer. Clin Lung Cancer, 2006. 7(4): p. 250-6.

46. Baselga J. and Arteaga C.L. Critical update and emerging trends in epidermal growth factor receptor targeting in cancer. J Clin Oncol, 2005. 23(11): p. 2445-59.

47. Verel I., Visser G.W., Boellaard R., et al. 89Zr immuno-PET: comprehensive procedures for the production of $89 \mathrm{Zr}$-labeled monoclonal antibodies. J Nucl Med, 2003. 44(8): p. 1271-81.

48. Cai W. Chen K., He L., et al. Quantitative PET of EGFR expression in xenograftbearing mice using 64Cu-labeled cetuximab, a chimeric anti-EGFR monoclonal antibody. Eur J Nucl Med Mol Imaging, 2007. 34(6): p. 850-8.

49. Goldenberg A., Masui H., Divgi C., et al. Imaging of human tumor xenografts with an indium-111-labeled anti-epidermal growth factor receptor monoclonal antibody. ] Natl Cancer Inst, 1989. 81(21): p. 1616-25.

50. Rofstad E.K., Mathiesen B., Kindem K., et al. Acidic extracellular pH promotes experimental metastasis of human melanoma cells in athymic nude mice. Cancer Res, 2006. 66(13): p. 6699-707.

51. Robey I.F., Baggett B.K., Kirkpatrick N.D., et al. Bicarbonate increases tumor pH and inhibits spontaneous metastases. Cancer Res, 2009. 69(6): p. 2260-8.

52. Yasuda H., Nakayama K., Watanabe M., et al. Nitroglycerin treatment may enhance chemosensitivity to docetaxel and carboplatin in patients with lung adenocarcinoma. Clin Cancer Res, 2006. 12(22): p. 6748-57.

53. Chung K.Y., Shia J., Kemeny N.E., et al. Cetuximab shows activity in colorectal cancer patients with tumors that do not express the epidermal growth factor receptor by immunohistochemistry. J Clin Oncol, 2005. 23(9): p. 1803-10.

54. Hebbar M., Wacrenier A., Desauw C., et al. Lack of usefulness of epidermal growth factor receptor expression determination for cetuximab therapy in patients with colorectal cancer. Anticancer Drugs, 2006. 17(7): p. 855-7. 


\section{Algemene discussie en samenvatting}

Tumor hypoxie wordt geassocieerd met verhoogde maligniteit en potentieel tot uitzaaien van primaire kankers. Verder is hypoxie een belangrijke oorzaak van resistentie aan kanker behandelingen en dit ongeacht het type therapie (bestraling, chemotherapie of chirurgie $)^{1}$. Het belang van hypoxie in kanker, samen met het feit dat hypoxie normaal niet voorkomt in normale weefsels, met uitzondering van kraakbeen en hoornvlies ${ }^{2,3}$, maakt hypoxie een interessant doelwit voor de ontwikkeling van nieuwe geneesmiddelen om het therapeutisch effect van de klassieke kankerbehandelingen te verhogen ${ }^{4}$. Ondanks dat verschillende manieren om de negatieve effecten van hypoxie tegen te werken onderzocht zijn en nog steeds onderzocht worden, werd er tot op heden slechts een kleine verbetering in prognose bereikt ${ }^{5}$. Aangezien de hoeveelheid hypoxie nogal wat varieert tussen verschillende patiënten, kan men ervan uitgaan dat behandelingen gericht tegen hypoxie efficiënter zijn wanneer een tumor meer hypoxisch is. Om dit praktisch mogelijk te maken, is het noodzakelijk om tumor hypoxie op een niet invasieve manier in beeld te kunnen brengen. Het gebruik van PET met een van de verschillende hypoxie-specifieke merkers laat nauwkeurige bepaling van hypoxie toe, waardoor PET beeldvorming een basis vormt voor deze vorm van rationeel selecteren van patiënten ${ }^{6}$.

$\left[{ }^{18} \mathrm{~F}\right]$ Fluoromisonidazole ([$\left.\left.{ }^{18} \mathrm{~F}\right] \mathrm{FMISO}\right)$ is wereldwijd de meest gebruikte PET merker voor hypoxie beeldvorming ${ }^{7}$. Op basis van zijn hoge opname in hypoxische cellen, werd $\left[{ }^{18} \mathrm{~F}\right] \mathrm{FMISO}$ uitvoerig getest om lage zuurstofspanning in tumoren te visualiseren in proefdier modellen ${ }^{8,9}$ en ook klinisch voor verschillende vormen van kanker ${ }^{10-12}$. Er zijn echter weinig studies beschikbaar waarbij 
nieuwe beeldvormingmethoden vergeleken worden met de huidige standaard technieken. Evalueren van $\left[{ }^{18} \mathrm{~F}\right] \mathrm{FMISO}$ PET opname en vergelijking met zuurstof elektrode metingen in muis $\mathrm{C} 3 \mathrm{H}$ borstkanker toonde geen relatie tussen beide ${ }^{13}$, terwijl er wel een correlatie gevonden werd in hypoxische varkenslevers ${ }^{14}$. In hoofdstuk 2 hebben we $\left[{ }^{18} \mathrm{~F}\right] \mathrm{FMISO}$ PET opname in een experimenteel rat tumor model gevalideerd met een nitroimidazole gerelateerde kleuringtechniek en stelden we een sterke en significante relatie tussen beiden vast. Deze resultaten werden bevestigd in muizen met humaan hoofd hals tumoren, waar een matige pixel tot pixel relatie werd gevonden tussen beide technieken ${ }^{15,}{ }^{16}$. Dus zowel $\left[{ }^{18} \mathrm{~F}\right] \mathrm{FMISO}$ autoradiografie of PET als pimonidazole immunohistochemie kan gebruikt worden om veranderingen in tumor hypoxie te visualiseren. Verder hebben we ook aangetoond dat $\left[{ }^{18} \mathrm{~F}\right] \mathrm{FMISO}$ PET beeldvorming in staat is om hypoxie response te evalueren, sinds een sterke relatie werd gevonden met de hypoxie geïnduceerde CA IX expressie. He en collega's hebben dit recent ondersteunt in muizen met humane HT-29 colorectale tumoren, waar een colokalisatie werd aangetoond tussen exogene (pimonidazole en $\left[{ }^{18} \mathrm{~F}\right] \mathrm{FMISO}$ ) en endogene (CA IX) hypoxie merkers en de hypoxie geïnduceerde expressie van eGFP ${ }^{17}$.

Op het vlak van prognose is de bepaling van hypoxie voor behandeling essentieel, aangezien de meeste biologische veranderingen vroeg gebeuren, standhouden tijdens de behandeling en gebruikt worden om overleving te voorspellen ${ }^{18}$. Om de klinische efficiëntie van hypoxie-geactiveerde bioreductieve geneesmiddelen zoals tirapazamine ${ }^{19}$ te bepalen, is het uitermate belangrijk om de zuurstofspanning in de tumor voor behandeling 
te kunnen evalueren. Bovendien zijn modellen om de kans op tumor controle te bepalen, gebaseerd op niet invasieve PET beeldvorming met hypoxie merkers, de sleutel voor verdere hypoxie beeldvorming gebaseerde dosis escalatie tijdens bestraling $^{20}$ en voor het plannen van boost bestraling op hardnekkige hypoxische subvolumes ${ }^{4}$. $\left[{ }^{18} \mathrm{~F}\right] \mathrm{FMISO}$ is momenteel de meest onderzochte PET hypoxie merker in klinische praktijk en sommige studies hebben aangetoond dat het een waardevolle techniek is voor het evalueren van behandeling response ${ }^{10,11}$. Toch zijn er redenen tot bezorgdheid in verband met de stabiliteit van de fluor-18 verbinding en de vorming van metabolieten in bloed en urine $^{21}$. Ook is de diffusie van deze stof in weefsels, en meer specifiek in tumor weefsels, niet optimaal omwille van de lipofiliciteit van de stof. Tweede generatie nitroimidazole hypoxie merkers (FETNIM, FETA, EF3, EF5, FAZA, etc.) werden daarom ontwikkeld die beter water oplosbaar en stabieler zijn, wat resulteert in een hoger contrast tussen tumor en achtergrond opname $^{22-24}$. Mahy en collega's hebben aan de hand van ex vivo farmacokinetische en biodistributie data aangetoond dat $\left[{ }^{18} \mathrm{~F}\right] \mathrm{EF} 3$ een goed alternatief kan zijn voor $\left[{ }^{18} \mathrm{~F}\right] \mathrm{FMISO}$. Zo werden er slechts weinig circulerende metabolieten en een betere weefsel diffusie opgemerkt ${ }^{25}$. In hoofdstuk 3 , hebben we aangetoond met niet invasieve PET beeldvorming dat de opname van $\left[{ }^{18} \mathrm{~F}\right] \mathrm{EF} 3$ sneller geklaard was uit de bloedbaan en zo tot lagere achtergrond niveaus leidde in vergelijking met $\left[{ }^{18} \mathrm{~F}\right] \mathrm{FMISO}$. Toch was de tumor opname van $\left[{ }^{18} \mathrm{~F}\right] \mathrm{EF} 3$ significant lager, met andere woorden, deze stof is niet superieur ten opzichte van $\left[{ }^{18} \mathrm{~F}\right] \mathrm{FMISO}$.

Als alternatief werd de 2-nitroimidazole nucleoside analoog $\left[{ }^{18} \mathrm{~F}\right] \mathrm{HX} 4$ ontwikkeld, gekenmerkt door een betere water 
oplosbaarheid en snellere klaring in vergelijking met bestaande hypoxie PET merkers (Kolb et al, persoonlijke communicatie) ${ }^{26}$. In hoofdstuk 4 hebben we het potentieel van $\left[{ }^{18} \mathrm{~F}\right] \mathrm{HX} 4$ als niet invasieve merker van hypoxische tumor cellen onderzocht. Er werd een duidelijke $\left[{ }^{18} \mathrm{~F}\right] \mathrm{HX} 4$ opname waargenomen in verschillende tumor modellen in vergelijking met het omgevende spierweefsel en de zuurstofspanning in de tumor beïnvloedde deze accumulatie, aangezien dieren blootgesteld aan een combinatie van nicotinamide en carbogen een verlaagde $\left[{ }^{18} \mathrm{~F}\right] \mathrm{HX} 4$ opname vertoonden. Zowel in preklinische ${ }^{27}$ als in klinische ${ }^{28}$ studies werd al aangetoond dat deze combinatie in staat is om efficiënt hypoxie in de tumor te verlagen. Extra bewijs voor het vereiste van hypoxie om efficiënte $\left[{ }^{18} \mathrm{~F}\right] \mathrm{HX} 4$ opname mogelijk te maken werd geleverd door de significant hogere accumulatie na beademen van de proefdieren met $7 \%$ zuursof.

Verder werden de $\left[{ }^{18} \mathrm{~F}\right] \mathrm{HX} 4$ tumor tot bloed $(\mathrm{T} / \mathrm{B})$ ratio's en klaring vergeleken met deze van de vroeger gevalideerde niet invasieve hypoxie merkers $\left[{ }^{18} \mathrm{~F}\right] \mathrm{FMISO}$ en $\left[{ }^{18} \mathrm{~F}\right] \mathrm{EF} 3$ in hetzelfde experimentele rat tumor model. Het optimale tijdstip voor $\left[{ }^{18} \mathrm{~F}\right] \mathrm{HX} 4$ beeldvorming bleek $4 \mathrm{~h}$ na injectie te zijn. Bij dit tijdstip waren de gemiddelde T/B ratio's vergelijkbaar met deze van $\left[{ }^{18} \mathrm{~F}\right] \mathrm{EF} 3$ (hoofdstuk 3). Jammer genoeg waren er slechts $\left[{ }^{18} \mathrm{~F}\right] \mathrm{FMISO}$ opname data beschikbaar tot $2 \mathrm{~h}$ na injectie voor dit rat tumor model (hoofdstuk 2). Andere studies hebben echter gesuggereerd dat het optimale tijdspunt voor $\left[{ }^{18} \mathrm{~F}\right] \mathrm{FMISO}$ beeldvorming waarschijnlijk nog niet bereikt is $3 \mathrm{~h}$ na injectie ${ }^{10}$. Anderzijds waren de maximum $\left[{ }^{18} \mathrm{~F}\right] \mathrm{HX} 4 \mathrm{~T} / \mathrm{B}$ ratio's significant hoger in vergelijking met de $\left[{ }^{18} \mathrm{~F}\right] \mathrm{EF} 3$ ratio's, wat suggereert dat $\left[{ }^{18} \mathrm{~F}\right] \mathrm{HX} 4$ in dit rat tumor model beter in staat is om een onderscheid te maken tussen 
hypoxische en niet-hypoxische gebieden in de tumor ${ }^{29}$. Voorts hebben we een toenemende klaring uit normale weefsels vastgesteld voor alle onderzochte hypoxie merkers. De spier opname was altijd lager dan deze in het bloed, wat resulteert in spier tot bloed (M/B) ratio's lager dan één, gunstig voor beeldvorming ${ }^{30}$. $\left[{ }^{18} \mathrm{~F}\right] \mathrm{EF} 3 \mathrm{M} / \mathrm{B}$ ratio's veranderen niet met tijd (hoofdstuk 3), terwijl $\left[{ }^{18} \mathrm{~F}\right] \mathrm{HX} 4 \mathrm{M} / \mathrm{B}$ ratio's een dalende trend vertoonden, suggestief voor een snellere klaring uit normale weefsels.

Hoewel $\left[{ }^{18} \mathrm{~F}\right] \mathrm{HX} 4$ superieur lijkt te zijn over $\left[{ }^{18} \mathrm{~F}\right] \mathrm{FMISO}$ en $\left[{ }^{18} \mathrm{~F}\right] \mathrm{EF} 3$ in een experimenteel rat tumor model, vergelijking van $\left[{ }^{18} \mathrm{~F}\right] \mathrm{HX} 4$, $\left[{ }^{18} \mathrm{~F}\right] \mathrm{FMISO}$ en $\left[{ }^{18} \mathrm{~F}\right] \mathrm{FAZA}$ in een variëteit van humane tumor modellen toonde geen significante verschillen in opname aan tussen de hypoxie merkers. $\left[{ }^{18} \mathrm{~F}\right] \mathrm{FMISO}$ tumor tot spier (T/M) ratio's vertoonden een vergelijkbaar patroon, maar was algemeen gezien hoger dan de $\left[{ }^{18} \mathrm{~F}\right] \mathrm{HX} 4 \mathrm{~T} / \mathrm{M}$ ratio's, hoewel de verschillen niet significant waren. $\left[{ }^{18} \mathrm{~F}\right] \mathrm{FAZA}$ T/M ratio's waren minder consistent over de verschillende tumor types (hoofdstuk 4), wat verklaard kan worden doordat de $\left[{ }^{18} \mathrm{~F}\right] \mathrm{FAZA}$ opname meer afhankelijk is van het tumor type. Zo was de $\left[{ }^{18} \mathrm{~F}\right] \mathrm{FAZA}$ opname beperkt, maar significant lager in gevorderde Walker 256 rat tumoren in vergelijking met de $\left[{ }^{18} \mathrm{~F}\right] \mathrm{FMISO}$ opname ${ }^{31}$. Anderzijds, in muis modellen van humane of muis tumoren waren $\left[{ }^{18} \mathrm{~F}\right] \mathrm{FAZA}$ T/B ratio's bijna 3 keer hoger ${ }^{30,32}$. Onze data ondersteunen dat de merker distributie en accumulatie afhankelijk is van het tumor type, iets wat ook al werd waargenomen in verschillende patiënten tumoren ${ }^{33}$. Gebaseerd op onze resultaten waarbij de opname van verschillende hypoxie merkers werd vergeleken in meerdere tumor modellen, zijn we van mening dat $\left[{ }^{18} \mathrm{~F}\right] \mathrm{HX} 4$, naar aanleiding van 
zijn snellere klaring uit normale weefsels en zijn beter weergeven van de tumor heterogeniteit, de meest belovende niet invasieve hypoxie merker is.

Recent werd gesuggereerd dat de graad van $\left[{ }^{18} \mathrm{~F}\right] \mathrm{FDG}$ opname in tumoren een weerspiegeling is van de hoeveelheid hypoxie, waardoor het niet meer nodig is om onderzoek te doen naar meer specifieke PET merkers voor hypoxie beeldvorming. Deze stelling is gebaseerd op de weidse beschikbaarheid van $\left[{ }^{18} \mathrm{~F}\right] \mathrm{FDG}$ en op het Warburg effect ofwel tumor hyperglycolyse, wat gedreven wordt door activering van HIF-1 en tumor hypoxie ${ }^{34}$. Toch zijn er verschillende studies die een discrepantie aantonen tussen $\left[{ }^{18} \mathrm{~F}\right] \mathrm{FDG}$ en hypoxia merker opname, wat erop wijst dat er niet altijd een relatie is tussen regionale hypoxie en glycolyse ${ }^{12,} 24$. Daarom dient de identificatie van hypoxie in solide tumoren het best te gebeuren met niet invasieve beeldvorming gebruik makende van gevalideerde hypoxie merkers.

Voldoende bewijs toont aan dat hypoxie geassocieerd is met tumor ontwikkeling, groei, uitzaaiing en slechte prognose aan behandeling ${ }^{1,35-37}$. Dit is voornamelijk gerelateerd aan hypoxie beïnvloedbare pathways die de expressie van verschillende genen belangrijk voor de ontwikkeling en groei van solide tumoren reguleren ${ }^{38}$. Daarom is het belangrijk om de hypoxie response pathways te begrijpen om zo het succes van recent ontwikkelde moleculaire kanker behandelingen gericht tegen deze pathways te verhogen. Niet invasieve evaluatie van deze pathways is daarom een potentieel belangrijk hulpmiddel voor het bepalen van de behandeling en het selecteren van patiënten. Tumor geassocieerd koolzuur anhydrase IX (CA IX), opgereguleerd door een sterke 
transcriptionele activering van het $C A 9$ gen door HIF-1a, is een goede kandidaat omdat verhoogde CA IX expressie gekoppeld is met slechte prognose, tumor progressie en agressiviteit, wat suggereert dat CA IX een goed therapeutisch doelwit kan zijn.

Er wordt tot op heden onderzoek gedaan naar verschillende eenvoudige en efficiënte technieken om moleculaire hypoxie merkers zoals CA IX te evalueren. Zo werd er een verhoogde opname van ${ }^{125} \mathrm{I}$ of ${ }^{89} \mathrm{Zr}$ gemerkt CA IX antilichaam vastgesteld in humane tumor modellen ${ }^{39,40}$. Er kan echter geen onderscheid gemaakt worden tussen hypoxische en aerobe cellen die CA IX tot expressie brengen, aangezien het antibody ook CA IX bind onder reoxygenatie condities. Dit is te wijten aan de trage afbraak van het CA IX proteïne dat een half leven van 38 uur vertoont tijdens reoxygenatie ${ }^{41}$. Daarom is CA IX beeldvorming gebruik makende van antilichamen niet geschikt om periodieke of cyclische gebieden van tumor hypoxie in beeld te brengen. In de voorbije jaren werden er verschillende sulfonamide gebaseerde remmers van CA IX ontwikkeld ${ }^{42}$. Recent werd er een fluorescent sulfonamide ontwikkeld die een hoge affiniteit voor CA IX vertoont en in hoofdstuk 5 zijn we zijn cellulaire binding eigenschappen nagegaan. Onze resultaten tonen in verschillende cellijnen aan dat sulfonamide binding aan CA IX exclusief gebeurt tijdens hypoxie, onafhankelijk van de CA IX expressie niveaus en de HIF-1a activiteit. Daarom suggereren we dat het CA IX proteïne tijdens hypoxie in een open structuur dient te zijn om zo een interactie tussen sulfonamide en de CA IX actieve site mogelijk te maken. Dit dient echter nog verder bevestigd te worden. Er werd geen sulfonamide binding vastgesteld tijdens aerobe condities in cellen die CA IX en andere HIF-1a afhankelijke genen tot expressie 
brengen. Dit impliceert dat de CA IX actieve site enkel beschikbaar is voor sulfonamide binding tijdens hypoxische condities. Gebonden sulfonamide aan CA IX onder hypoxie, bleef geassocieerd tijdens reoxygenatie. Deze gebonden fractie ging echter verloren met tijd onder reoxygenatie en dit gebeurde veel sneller dan de normale afbraak van het CA IX proteïne te wijten aan ofwel verlies van sulfonamide binding ofwel aan geïnduceerde internalisatie en degradatie.

Dat sulfonamide binding en colokalisatie met het antilichaam enkel gezien wordt tijdens hypoxie (hoofdstuk 5) suggereert dat sulfonamides interessant kunnen zijn voor de evaluatie van tumor gebieden blootgesteld aan chronische, maar ook fluctuerende hypoxie. Op basis van deze resultaten, hebben we in hoofdstuk 6 met behulp van niet invasieve fluorescentie beeldvorming de in vivo sulfonamide accumulatie onderzocht. Duidelijke accumulatie in afgebakende regio's van de tumor werd vastgesteld na injectie van het sulfonamide in vergelijking met een fluorescent analoog waarbij de kritische CA IX interactie sulfonamide groep werd verwijderd. Sulfonamide accumulatie was niet enkel afhankelijk van de aanwezigheid van het CA IX proteïne, maar ook van de beschikbare zuurstof. Behandeling met carbogen en nicotinamide leidde tot een significant lagere sulfonamide accumulatie, terwijl beademing met $7 \%$ zuurstof resulteerde in een verhoogde opname. Bovendien was de in vivo sulfonamide accumulatie ook omkeerbaar bij tumor reoxygenatie. Onze data suggereren dat het veelbelovend kan zijn om verder onderzoek te doen naar de klinische ontwikkeling van sulfonamides voor beeldvorming doeleinden om uiteindelijk in staat te zijn om patiënten te 
selecteren voor hypoxie-gerichte en/of CA IX-gerichte behandelingen.

Een relatie tussen hypoxie en de epidermale groeifactor receptor (EGFR) is aangetoond in niet-kleincellig long kanker, wat suggereert dat hypoxie de expressie van EGFR of van zijn liganden induceert, terwijl EGFR de cellulaire response aan hypoxie versterkt door de HIF-1a expressie te verhogen ${ }^{43-45}$. Hoewel EGFR gerichte therapieën met behulp van receptor blokkerende monoklonale antilichamen veelbelovend lijken ${ }^{46}$, hebben veel patiënten nog steeds geen gunstigere prognose ${ }^{44}$. Een mogelijke verklaring is de verstoorde drug aanlevering ten gevolge van de heterogene EGFR expressie, vaatstructuur, capillaire permeabiliteit en necrose. In hoofdstuk 7 en 8 hebben we de opname van cetuximab geëvalueerd als een maat voor de EGFR expressie in tumoren. We hebben met succes een Oregon Green 488 fluorescent gemerkte cetuximab probe voor beeldvorming ontwikkeld en een duidelijk membranaire lokalisatie in cellen die EGFR tot overexpressie brengen aangetoond (Hoofdstuk 7). Vergelijking tussen het bindingsprofiel van het fluorescente cetuximab en de hoeveelheid EGFR toonde een significante relatie tussen beide en dit voor verschillende tumor cellijnen met variërende EGFR expressie.

Om het klinisch gebruik van cetuximab als therapie beter te begrijpen, is het noodzakelijk om zijn in vivo opname op een niet invasieve manier te kunnen opvolgen. Om hieraan te voldoen, hebben we in hoofdstuk 8 een cetuximab gebaseerde probe voor PET beeldvorming ontwikkeld op basis van een koppeling met het radio-isotoop Zirconium-89. Studies hebben immers aangetoond 
dat ${ }^{89} \mathrm{Zr}$ het meest geschikte isotoop is om te combineren met volledige antilichamen op basis van zijn residualizerende eigenschappen en lang fysisch half leven wat beter overeenkomt met de trage farmacokinetiek van antilichamen ${ }^{47}$. In hoofdstuk 8 hebben we met behulp van PET beeldvorming een geleidelijke toename van cetuximab aangetoond in tumoren met variërende EGFR expressie, terwijl de activiteit in normale weefsels daalde. Deze in vivo PET data werden bevestigd met ex vivo biodistributie studies. Hoewel andere groepen een relatie hebben aangetoond tussen cetuximab opname en EGFR expressie ${ }^{48,49}$, tonen onze resultaten verrassend genoeg een groot verschil tussen beide, wat erop wijst dat er additionele mechanismen zijn die de toevoer van cetuximab naar de tumor kunnen beïnvloeden. Het afwezig zijn van een associatie kon niet verklaard worden door veranderde in vivo EGFR expressie of verschillen in tumor groei. In conclusie, de relatie tussen EGFR expressie, cetuximab opname en klinisch effect is een complex gegeven. Zelfs al is cetuximab in staat om de volledige tumor te bereiken, een therapeutisch effect is daarom niet vanzelfsprekend, wat de toegevoegde waarde van niet invasieve beeldvorming van drug toevoer aangeeft om geïndividualiseerde patiënt behandeling mogelijk te maken. 


\section{Conclusies en toekomstperspectieven}

Overtuigend bewijs toont dat hypoxie een belangrijke factor is voor tumorgroei en prognose. Hierdoor wordt er steeds meer en meer onderzoek gedaan naar het ontwikkelen van strategieën om hypoxische cellen aan te vallen, zoals het veranderen van de hypoxische omgeving of behandelingen gericht tegen componenten van de HIF-1 signaal cascade. Er zijn echter betrouwbare methoden nodig om tumor zuurstofspanning te evalueren om hypoxische tumoren en deze patiënten die baat hebben bij behandelingen gericht tegen hypoxie te identificeren. Niet invasieve beeldvorming biedt de mogelijkheid om een accurate schatting te maken van de hypoxische fractie, om regionale tumor hypoxie in vivo in beeld te brengen en om het effect van behandeling op te volgen door follow-up beeldvorming van hypoxie. Het succes van invoeren van nieuwe hypoxie merkers in het dagelijkse behandelingschema is echter afhankelijk van de accuraatheid van kwantificeren.

Een hypoxie merker zou idealiter een hoge diffusie in tumor weefsel, wateroplosbaarheid en een lage afbraak moeten vertonen, wat gecombineerd resulteert in een hoger tumor tot achtergrond contrast. Onze resultaten tonen dat $\left[{ }^{18} \mathrm{~F}\right] \mathrm{HX} 4$ opname vergelijkbaar is met andere niet invasieve hypoxie merkers, maar dat zijn klaring uit normale weefsels sneller is en dat $\left[{ }^{18} \mathrm{~F}\right] \mathrm{HX} 4$ beter in staat is om tumor heterogeniteit weer te geven. Dit maakt $\left[{ }^{18} \mathrm{~F}\right] \mathrm{HX} 4$ de meest belovende merker voor het verder uittesten van zijn klinische toepasbaarheid. Een fase 1 klinische studie uitgevoerd binnen ons instituut geeft aan dat $\left[{ }^{18} \mathrm{~F}\right] \mathrm{HX} 4$ geen verhoogde toxiciteit veroorzaakt en gebruikt kan worden als niet invasieve hypoxie merker in patiënten ${ }^{26}$. In de toekomst zou 
$\left[{ }^{18} \mathrm{~F}\right] \mathrm{HX} 4$ daarom gebruikt kunnen worden om het effect op hypoxie van hypoxie-gerichte behandelingen, zoals verhoogde perfusie en de daarbij horende zuurstof concentraties door het gebruik van nitroglycerine, na te gaan. Een tumor is een heterogene entiteit, gekenmerkt door regio's met lage zuurstofspanning, hoge proliferatie en doorbloeding. Modellen om de kans op tumor controle te bepalen op basis van herhaalde $\left[{ }^{18} \mathrm{~F}\right] \mathrm{HX} 4$ PET scans tijdens bestraling, die de doorbloeding efficiëntie en de graad van hypoxie combineren, zijn daarom hoogstwaarschijnlijk de sleutel voor hypoxie beeldvorminggerichte dosis escalatie en het plannen van boost bestraling op hardnekkige hypoxische subvolumes.

Anderzijds, naast de mogelijkheid om tumor zuurstofspanning op zich te evalueren, is het ook belangrijk om de cellulaire reactie op hypoxie te begrijpen om zo de kans op succes van recent ontwikkelde moleculaire kanker therapieën specifiek gericht tegen hypoxie response, zoals de HIF-1 pathway, te verhogen. Recent is er heel wat onderzoek gedaan naar moleculaire hypoxie merkers zoals CA IX. Het grootste probleem bij deze merkers is dat er geen onderscheid gemaakt kan worden tussen hypoxische en aerobe/gereoxygeneerde cellen op basis van antilichaam beeldvorming. Wij hebben echter kunnen aantonen dat fluorescent gemerkte sulfonamides gericht tegen CA IX wel in staat zijn om dit onderscheid te kunnen maken. Daarom suggereren we dat deze sulfonamides een waardevolle toevoeging zijn om actieve hypoxie response te evalueren. Antilichaam beeldvorming, om cellen te identificeren die blootgesteld geworden zijn aan hypoxie, gecombineerd met sulfonamide beeldvorming, die enkel bindt aan cellen die hypoxisch waren op het moment van blootstelling, zou 
heel nuttig kunnen zijn om de acuut hypoxische fractie te schatten. Om sulfonamide beeldvorming toepasbaar te maken in klinische praktijk, is onderzoek aan de gang om sulfonamides te merken met radioactieve isotopen waarbij beloftevolle resultaten al behaald werden. Specifieke behandelingen gericht tegen actief $C A$ IX waarbij de efficiëntie van klassieke therapieën verhoogd wordt lijken ook haalbaar te zijn, omdat sulfonamides die de gevoeligheid aan bestraling of chemotherapie verhogen het effect van deze therapieën ook versterkt. Verder is het ook aangetoond dat een zure extracellulaire omgeving de kans om uitzaaiingen verhoogt. Deze zuurgeïnduceerde metastases kunnen behandeld worden met matrix metalloproteïnase remmers, cysteïne proteïnase remmers of met blokkerende antilichamen gericht tegen VEGF en IL-8 ${ }^{50}$. Ook het neutraliseren van de extracellulaire verzuring van tumoren door toediening van $\mathrm{NaHCO}_{3}$ is in staat om invasie te remmen en het aantal spontane metastases te verlagen ${ }^{51}$. Wij hebben aangetoond dat sulfonamides gericht tegen CA IX in staat zijn om de hypoxie geïnduceerde verzuring te verlagen en daarom nemen we als hypothese aan dat CA IX een rol speelt in zuurgeïnduceerde metastase vorming.

Naast het behalen van informatie over de karakteristieken van de tumor omgeving, zoals de zuurstofspanning, kan beeldvorming ook nuttig zijn om toevoer van geneesmiddelen in de tumor te evalueren. Beeldvorming van drug toevoer kan gebruikt worden om de toediening van geneesmiddelen te individualiseren, zodanig dat patiënten zonder selectieve opname uit de behandelingsgroep weggelaten kunnen worden. Onze resultaten tonen aan dat de opname van cetuximab in de tumor variabel is en dat deze variabiliteit niet enkel te verklaren is door de EGFR expressie. 
Mogelijke verklaring voor deze mismatch kunnen gebrekkige vaten en doorbloeding zijn, wat leidt tot een heterogene en gelimiteerde cetuximab opname. Om deze hypothese te testen, kan de cetuximab opname geëvalueerd worden na het verhogen van de doorbloeding door behandeling met nitroglycerine ${ }^{52}$. Bovendien kan deze mismatch ook verklaren waarom de efficiëntie van patient behandeling met cetuximab niet overeenkomt met EGFR expressie ${ }^{53,54}$. Daarom geloven we dat er bij de ontwikkeling van nieuwe therapeutische stoffen in de farmaceutische industrie ook aandacht dient besteedt te worden aan de visualisatie van de toevoer van het geneesmiddel in vergelijking met beeldvorming van de tumor karakteristieken. Dit zal uiteindelijk leiden tot een betere selectie van patiënten die baat hebben aan hypoxiegerichte therapieën en therapeutische geneesmiddelen gecombineerd met de klassieke behandelingen, wat resulteert in geïndividualiseerde patiënt behandeling. Als antwoord hierop is er in ons instituut een fase 1 klinische studie gestart om na te gaan of ${ }^{89} \mathrm{Zr}$ gemerkt cetuximab toxiciteit veroorzaakt en of het gebruikt kan worden als niet invasieve merker in patiënten. 
1. Vaupel P. and Mayer A. Hypoxia in cancer: significance and impact on clinical outcome. Cancer Metastasis Rev, 2007. 26(2): p. 225-39.

2. Fonn D., Sweeney D., Holden B.A., et al. Corneal oxygen deficiency. Eye Contact Lens, 2005. 31(1): p. 23-7.

3. Schipani E. Hypoxia and HIF-1 alpha in chondrogenesis. Semin Cell Dev Biol, 2005. 16(4-5): p. 539-46.

4. Tatum J.L., Kelloff G.J., Gillies R.J., et al. Hypoxia: importance in tumor biology, noninvasive measurement by imaging, and value of its measurement in the management of cancer therapy. Int J Radiat Biol, 2006. 82(10): p. 699-757.

5. Brown J.M. and Wilson W.R. Exploiting tumour hypoxia in cancer treatment. Nat Rev Cancer, 2004. 4(6): p. 437-47.

6. Rajendran J.G. and Mankoff D.A. Beyond detection: novel applications for PET imaging to guide cancer therapy. J Nucl Med, 2007. 48(6): p. 855-6.

7. Dunphy M.P. and Lewis J.S. Radiopharmaceuticals in preclinical and clinical development for monitoring of therapy with PET. J Nucl Med, 2009. 50 Suppl 1: p. 106S-21S.

8. Koh W.J., Rasey J.S., Evans M.L., et al. Imaging of hypoxia in human tumors with [F18]fluoromisonidazole. Int J Radiat Oncol Biol Phys, 1992. 22(1): p. 199-212.

9. Tochon-Danguy H.J., Sachinidis J.I., Chan F., et al. Imaging and quantitation of the hypoxic cell fraction of viable tumor in an animal model of intracerebral high grade glioma using [18F]fluoromisonidazole (FMISO). Nucl Med Biol, 2002. 29(2): p. 191-7.

10. Gagel B., Reinartz P., Demirel C., et al. [18F] fluoromisonidazole and [18F] fluorodeoxyglucose positron emission tomography in response evaluation after chemo-/radiotherapy of non-small-cell lung cancer: a feasibility study. BMC Cancer, 2006. 6: p. 51.

11. Rajendran J.G., Schwartz D.L., O'Sullivan J., et al. Tumor hypoxia imaging with [F18] fluoromisonidazole positron emission tomography in head and neck cancer. Clin Cancer Res, 2006. 12(18): p. 5435-41.

12. Zimny M., Gagel B., DiMartino E., et al. FDG--a marker of tumour hypoxia? A comparison with [18F]fluoromisonidazole and pO2-polarography in metastatic head and neck cancer. Eur J Nucl Med Mol Imaging, 2006. 33(12): p. 1426-31.

13. Bentzen L., Keiding S, Horsman M.R. et al. Assessment of hypoxia in experimental mice tumours by [18F]fluoromisonidazole PET and $\mathrm{pO} 2$ electrode measurements. Influence of tumour volume and carbogen breathing. Acta Oncol, 2002. 41(3): p. 304-12.

14. Piert M., Machulla H.J., Becker G., et al. Dependency of the [18F]fluoromisonidazole uptake on oxygen delivery and tissue oxygenation in the porcine liver. Nucl Med Biol, 2000. 27(8): p. 693-700.

15. Troost E.G., Laverman P., Kaanders J.H., et al. Imaging hypoxia after oxygenationmodification: comparing [18F]FMISO autoradiography with pimonidazole immunohistochemistry in human xenograft tumors. Radiother Oncol, 2006. 80(2): p. 157-64.

16. Troost E.G., Laverman P., Philippens M.E., et al. Correlation of [18F]FMISO autoradiography and pimonidazole [corrected] immunohistochemistry in human head and neck carcinoma xenografts. Eur J Nucl Med Mol Imaging, 2008. 35(10): p. 180311.

17. He F., Deng X., Wen B., et al. Noninvasive molecular imaging of hypoxia in human xenografts: comparing hypoxia-induced gene expression with endogenous and exogenous hypoxia markers. Cancer Res, 2008. 68(20): p. 8597-606.

18. Rajendran J.G., Mankoff D.A., O'Sullivan F., et al. Hypoxia and glucose metabolism in malignant tumors: evaluation by [18F]fluoromisonidazole and [18F]fluorodeoxyglucose positron emission tomography imaging. Clin Cancer Res, 2004. 10(7): p. 2245-52.

19. Mckeown S.R., Cowen R.L., and Williams K.J. Bioreductive drugs: from concept to clinic. Clin Oncol (R Coll Radiol), 2007. 19(6): p. 427-42.

20. Thorwarth D., Eschmann S.M., Paulsen F., et al. A model of reoxygenation dynamics of head-and-neck tumors based on serial 18F-fluoromisonidazole positron emission tomography investigations. Int J Radiat Oncol Biol Phys, 2007. 68(2): p. 515-21.

21. Krohn K.A., Link J.M., and Mason R.P. Molecular imaging of hypoxia. J Nucl Med, 2008. 49 Suppl 2: p. 129S-48S.

22. Davda S. and Bezabeh T. Advances in methods for assessing tumor hypoxia in vivo: implications for treatment planning. Cancer Metastasis Rev, 2006. 25(3): p. 469-80.

23. Lucignani G. PET imaging with hypoxia tracers: a must in radiation therapy. Eur ] Nucl Med Mol Imaging, 2008. 35(4): p. 838-42. 
24. Serganova I., Humm J., Ling C., et al. Tumor hypoxia imaging. Clin Cancer Res, 2006. 12(18): p. 5260-4.

25. Mahy P., De Bast M., Leveque P.H., et al. Preclinical validation of the hypoxia tracer 2-(2-nitroimidazol-1-yl)- N-(3,3,3-[(18)F]trifluoropropyl)acetamide, [(18)F]EF3. Eur ] Nucl Med Mol Imaging, 2004. 31(9): p. 1263-72.

26. van Loon J., Janssen M.H.M., Oellers M., et al. PET imaging of hypoxia using [18F]HX4: A phase 1 trial. ] Nucl Med, 2009. submitted.

27. van Laarhoven H.W., Bussink J., Lok J., et al. Effects of nicotinamide and carbogen in different murine colon carcinomas: immunohistochemical analysis of vascular architecture and microenvironmental parameters. Int J Radiat Oncol Biol Phys, 2004. 60(1): p. 310-21.

28. Kaanders J.H., Pop L.A., Marres H.A., et al. Accelerated radiotherapy with carbogen and nicotinamide (ARCON) for laryngeal cancer. Radiother Oncol, 1998. 48(2): p. 115-22.

29. Stadler P., Becker A., Feldmann H.J., et al. Influence of the hypoxic subvolume on the survival of patients with head and neck cancer. Int J Radiat Oncol Biol Phys, 1999. 44(4): p. 749-54.

30. Piert M., Machulla H.J., Picchio M., et al. Hypoxia-specific tumor imaging with $18 \mathrm{~F}-$ fluoroazomycin arabinoside. J Nucl Med, 2005. 46(1): p. 106-13.

31. Sorger D., Patt M., Kumar P., et al. [18F]Fluoroazomycinarabinofuranoside (18FAZA) and [18F]Fluoromisonidazole (18FMISO): a comparative study of their selective uptake in hypoxic cells and PET imaging in experimental rat tumors. Nucl Med Biol, 2003. 30(3): p. 317-26.

32. Reischl G., Dorow D.S., Cullinane C., et al. Imaging of tumor hypoxia with [124I]IAZA in comparison with [18F]FMISO and [18F]FAZA--first small animal PET results. J Pharm Pharm Sci, 2007. 10(2): p. 203-11.

33. Rasey J.S., Koh W.J., Evans M.L., et al. Quantifying regional hypoxia in human tumors with positron emission tomography of [18F]fluoromisonidazole: a pretherapy study of 37 patients. Int J Radiat Oncol Biol Phys, 1996. 36(2): p. 417-28.

34. Dierckx R.A. and Van de Wiele C. FDG uptake, a surrogate of tumour hypoxia? Eur J Nucl Med Mol Imaging, 2008. 35(8): p. 1544-9.

35. Brizel D.M., Sibley G.S., Prosnitz L.R., et al. Tumor hypoxia adversely affects the prognosis of carcinoma of the head and neck. Int J Radiat Oncol Biol Phys, 1997. 38(2): p. 285-9.

36. Hockel M., Schlenger K., Aral B., et al. Association between tumor hypoxia and malignant progression in advanced cancer of the uterine cervix. Cancer Res, 1996. 56(19): p. 4509-15.

37. Nordsmark M., Alsner J., Keller J., et al. Hypoxia in human soft tissue sarcomas: adverse impact on survival and no association with p53 mutations. Br J Cancer, 2001. 84(8): p. 1070-5.

38. Dewhirst M.W., Cao Y., and Moeller B. Cycling hypoxia and free radicals regulate angiogenesis and radiotherapy response. Nat Rev Cancer, 2008. 8(6): p. 425-37.

39. Brouwers A., Verel I., Van Eerd J., et al. PET radioimmunoscintigraphy of renal cell cancer using $89 \mathrm{Zr}$-labeled cG250 monoclonal antibody in nude rats. Cancer Biother Radiopharm, 2004. 19(2): p. 155-63.

40. Chrastina A., Zavada J., Parkkila S., et al. Biodistribution and pharmacokinetics of 125I-labeled monoclonal antibody M75 specific for carbonic anhydrase IX, an intrinsic marker of hypoxia, in nude mice xenografted with human colorectal carcinoma. Int $\mathrm{J}$ Cancer, 2003. 105(6): p. 873-81.

41. Rafajova M., Zatovicova M., Kettmann R., et al. Induction by hypoxia combined with low glucose or low bicarbonate and high posttranslational stability upon reoxygenation contribute to carbonic anhydrase IX expression in cancer cells. Int J Oncol, 2004. 24(4): p. 995-1004.

42. Supuran C.T. Carbonic anhydrases: novel therapeutic applications for inhibitors and activators. Nat Rev Drug Discov, 2008. 7(2): p. 168-81.

43. Franovic A., Gunaratnam L., Smith K., et al. Translational up-regulation of the EGFR by tumor hypoxia provides a nonmutational explanation for its overexpression in human cancer. Proc Natl Acad Sci U S A, 2007. 104(32): p. 13092-7.

44. Lu Y., Liang K., Li X., et al. Responses of cancer cells with wild-type or tyrosine kinase domain-mutated epidermal growth factor receptor (EGFR) to EGFR-targeted therapy are linked to downregulation of hypoxia-inducible factor-1alpha. Mol Cancer, 2007. 6: p. 63.

45. Swinson D.E. and O'Byrne K.J. Interactions between hypoxia and epidermal growth factor receptor in non-small-cell lung cancer. Clin Lung Cancer, 2006. 7(4): p. 250-6. 
46. Baselga J. and Arteaga C.L. Critical update and emerging trends in epidermal growth factor receptor targeting in cancer. J Clin Oncol, 2005. 23(11): p. 2445-59.

47. Verel I., Visser G.W., Boellaard R., et al. 89Zr immuno-PET: comprehensive procedures for the production of $89 \mathrm{Zr}$-labeled monoclonal antibodies. J Nucl Med, 2003. 44(8): p. 1271-81.

48. Cai W., Chen K., He L., et al. Quantitative PET of EGFR expression in xenograftbearing mice using 64Cu-labeled cetuximab, a chimeric anti-EGFR monoclonal antibody. Eur J Nucl Med Mol Imaging, 2007. 34(6): p. 850-8.

49. Goldenberg A., Masui H., Divgi C., et al. Imaging of human tumor xenografts with an indium-111-labeled anti-epidermal growth factor receptor monoclonal antibody. J Natl Cancer Inst, 1989. 81(21): p. 1616-25.

50. Rofstad E.K., Mathiesen B., Kindem K., et al. Acidic extracellular pH promotes experimental metastasis of human melanoma cells in athymic nude mice. Cancer Res, 2006. 66(13): p. 6699-707.

51. Robey I.F., Baggett B.K., Kirkpatrick N.D., et al. Bicarbonate increases tumor pH and inhibits spontaneous metastases. Cancer Res, 2009. 69(6): p. 2260-8.

52. Yasuda H., Nakayama K., Watanabe M., et al. Nitroglycerin treatment may enhance chemosensitivity to docetaxel and carboplatin in patients with lung adenocarcinoma. Clin Cancer Res, 2006. 12(22): p. 6748-57.

53. Chung K.Y., Shia J., Kemeny N.E., et al. Cetuximab shows activity in colorectal cancer patients with tumors that do not express the epidermal growth factor receptor by immunohistochemistry. J Clin Oncol, 2005. 23(9): p. 1803-10.

54. Hebbar M., Wacrenier A., Desauw C., et al. Lack of usefulness of epidermal growth factor receptor expression determination for cetuximab therapy in patients with colorectal cancer. Anticancer Drugs, 2006. 17(7): p. 855-7. 


\section{Acknowledgements / Dankwoord}

$\mathrm{Na}$ vijf jaar onderzoek is mijn boekje eindelijk een feit. Door de jaren heen heb ik het geluk gehad om verschillende mensen te leren kennen en daarom wil ik iedereen bedanken die direct of indirect heeft bijgedragen aan de totstandkoming van dit proefschrift en een aantal mensen in het bijzonder.

In de eerste plaats wil ik mijn promotoren Philippe Lambin en Brad Wouters bedanken. Beste Philippe, ik ben je uitermate dankbaar voor de kans die je me hebt geboden om bij MaastRo mijn promotie onderzoek te starten. Jouw enthousiasme, je overvloed aan nieuwe ideeën en soms strakke deadlines hebben tot dit resultaat geleid. Jij zorgt ervoor dat resultaten vanuit het lab hun weg naar de kliniek vinden en ik ben blij dat ik hieraan in de toekomst ook kan aan deelnemen. Dear Brad, as lab supervisor you taught me science in all its aspects. Thanks for your inspiration and enthusiasm, your guidance in setting up lab experiments and the discussions which improved my work significantly.

Verder wil ik de leden van de beoordelingscommissie (Prof. dr. F. Ramaekers, Prof. dr. C. Reutelingsperger, Prof. dr. M. van Zandvoort en Prof. dr. A. van der Kogel) graag bedanken voor jullie kostbare tijd om dit boekje kritisch te beoordelen en van waardevolle opmerkingen te voorzien.

Beste Willy, jij bent de volgende persoon die ik van harte wil bedanken. Zonder jouw begeleiding tijdens mijn eerste stapjes in de wetenschappelijke wereld tijdens mijn master stage, was ik 
waarschijnlijk nooit begonnen aan een promotie traject. Mijn dank voor het richting geven aan mijn verdere wetenschappelijke carrière. Ik wens je veel succes toe in je tweede carrière als muzikant.

Natasja, ondanks dat je pas in de laatste jaren van mijn promotie onderzoek onze project groep kwam versterken, kan ik me niet meer inbeelden wat het werk zou zijn zonder jou. Bedankt voor alle hulp, in de vroege en in de late uurtjes, bij de proefdierexperimenten. Dankzij jou zijn de data voor de laatste twee publicaties er in een record tempo gekomen.

Beste Maud, ik weet dat een kantoor met mij delen niet evident is. Bedankt voor het beantwoorden van de talloze telefoontjes, het negeren van de verschillende stapeltjes papier op mijn (en deels op jouw) bureau, de leuke gesprekken en de wetenschappelijke discussies tijdens en buiten de gewone werkuren.

Hugo, samen hebben we de link tussen het lab en de fysica een beetje versterkt en dit leidde tot de publicatie van onze cetuximab imaging onderzoeksresultaten. Bedankt voor de samenwerking en succes met het afronden van jouw boekje.

Ook een woord van dank aan Carla, Rianne en Simone voor alle administratieve ondersteuning. Het is schitterend hoe jullie door de bomen het bos nog kunnen zien. Verder wil ik alle andere MaastRO-Lab collega's Jan, Kasper, Barry, Nejla, Sherry, Younan, Hilda, Kim S, Kim P en Tom bedanken voor de leuke tijd samen in het lab. Verder wil ik ook Marianne, Twan en Chantal bedanken. Het gaat jullie goed in Toronto. 
Voor de fysische begeleiding op het gebied van bestraling en het analyseren van beeldjes, wil ik mijn dank ook uitdrukken aan de mensen van MaastRO-Physics, en in het bijzonder aan Lars, Wouter, Michel en Marco. Verder wil ik ook de mensen van MaastRO-clinic bedanken voor de klinisch gerichte visie op het proefdieronderzoek. Dank aan Dirk en Guido voor hun continue stroom aan ideeën, discussies en het in praktijk brengen van onze onderzoeksresultaten.

Beeldvorming op en het bestralen van proefdieren vereist accuraat positioneren en loodafscherming van niet te bestralen lichaamsdelen. Dank aan Hans en Jan om hun technische kennis op het vlak van patiënten even te willen aanpassen tot op het niveau van proefdieren. Veelal diende de beeldvorming en bestraling te gebeuren tussen of na de patiënten. Dank aan René, Jean en Rob voor het inplannen van de verschillende proefdierexperimenten.

Dit boekje is mede tot stand gekomen door samen te werken met verschillende afdelingen binnen de Universiteit Maastricht. Nicole, ik wil je bedanken voor de leerrijke gesprekken betreffende proefdierkundige technieken. Sandra en Pascal, bedankt voor alle hulp bij het leveren van en de experimenten met radioactiviteit. Jos, Eline en Marlies, bedankt voor de begeleiding bij de micro-MRI experimenten. We gaan hier in de toekomst zeker mee door. Marc en Kim, zonder jullie expertise waren de 2-foton experimenten nooit tot een goed einde gebracht. Tilman, bedankt voor de snelle fluorescente merking van eiwitten en de daarbij nog snellere MS analyses. Willem, Hanneke, Frank, Peggy en Ramon, bedankt voor de interessante discussies en jullie bijdrage tijdens de lab meeting. 
Ook buiten de Universiteit Maastricht kon ik rekenen op de hulp van verschillende mensen om dit boekje tot een goed eind te brengen. Hierbij bedank ik Guus, Lars en Bert (VU Medisch Centrum Amsterdam) voor het radioactief merken van onze tracers en Bert, Jan en Hans (Radboud Universiteit Nijmegen Medisch Centrum) voor de verschillende kleuringen op het tumor materiaal.

Ik heb Leuven ingeruild voor Maastricht, maar dit betekende echter niet dat de samenwerking met Leuven verdween. Peter, bedankt voor de hulp tijdens de micro-PET experimenten, ook in de weekends. We moeten samen nog zeker eens een restaurantje aandoen om na te genieten. Guy en Vamsi, bedankt voor het radioactief merken van verschillende stofjes om beeldvorming mogelijk te maken. Annelies, Sofie, Hilde, Ellen, Harlinde en Laurence, bedankt voor het openstellen van jullie lab voor onze experimenten, voor het invallen en de hulp tijdens de experimenten en voor de leuke gesprekken tussendoor. Tom, bedankt voor je hulp tijdens de MRS experimenten.

Chère Anne et Bernard (Université de Namur), merci pour votre collaboration scientifique. Anne, ta vie a pris un autre tournant et je vous souhaite bonne change avec ta pharmacie.

Ondertussen is het voor iedereen duidelijk dat het grootste gedeelte van dit boekje onderzoek met proefdieren omvat. Daarom wil ik ook de mensen van de proefdiercentra in Leuven en Maastricht bedanken. Nadine, Marlies, Erna, Michel en Julien, bedankt voor het bestellen van de proefdieren en alle administratieve ondersteuning. Inez, Karin, Richard, Rik en Clarice, 
bedankt voor het verzorgen van de proefdieren tijdens de talloze experimenten.

Natuurlijk kon dit werk niet tot stand komen dankzij de financiële steun van Siemens MI, van het EU 6th framework Program (Euroxy) onder leiding van Prof. Peter Ebbesen en van het EU 7th framework Program (Metoxia) onder leiding van Prof. Erik Pettersen. Werken binnen het Euroxy en Metoxia project zorgde naast financiële steun ook voor samenwerkingen met verschillende Europese universiteiten. Claudiu and Andrea (University of Florence), thanks for providing the sulfonamides directed against CA IX for the imaging and therapy studies, most of the times on short notice. Silvia and Jaromir (Slovak Academy of Sciences, Bratislava), thanks for sharing your expertise in the CA IX field and for providing us the CA IX antibody. Adrian (University of Oxford) and Patrick (Imperial College of Science, Technology and Medicine, London), thanks for providing several cell lines essential for our research. Kaye (University of Manchester), Michael and Agnes (Technical University München), Erik (University of Oslo) and Peter (University of Aalborg), thanks for sharing data, expertise and scientific discussions during the several meetings.

Iedereen weet dat ik mijn ontspanning kon vinden in het muziek spelen. Omwille van de afstand (Kortrijk is nu ook niet echt bij de deur) heb ik helaas een stapje terug moeten zetten, maar ik heb dit kunnen doen op een van de hoogtepunten van de Brass Band, het Europees kampioenschap in Birmingham. Tot op heden vind ik ontspanning bij de blazerssectie van onze in house band: The ProTones. Bedankt Lars, Erik, Jørgen, Jean, Denis, Rob, Jan, 
Jolanda, Sherry, Robin, Haike, Rianne en Wilma voor de vele uurtjes plezier.

Verder wil ik alle kindjes van de kinderopvang Riemst bedanken voor hun bijdrage aan de cover van dit boekje.

Ook wil ik mijn toekomstige schoonouders, Angeline en Servais bedanken voor hun interesse in mijn werk. Eveneens bedankt voor het lekkere eten de vrijdag avond en de andere ontspannende momenten. Beste broers, stiefbroer, stiefzusters en schoonbroer, ook al was het niet altijd even duidelijk wat ik doe, hopelijk snappen jullie met dit boekje mijn werk een beetje beter.

Lieve mama en Djaka, bedankt voor de kansen die jullie me geboden hebben. Bedankt voor jullie steun en vertrouwen in mij. Ook al liggen Wervik en Bilzen ver uit elkaar, die afstand hebben we altijd weten te overbruggen.

Liefste schat, liefste Mieke, bedankt voor je liefde, steun en begrip. Bedankt dat je er altijd voor me bent. Laten we samen een mooie toekomst tegemoet gaan en nog vele jaren van elkaar genieten.

Bedankt! 


\section{Curriculum Vitae}

Ludwig Dubois was born on June $12^{\text {th }}, 1981$ in Ieper, Belgium and spent his childhood in Wervik. In 1999, he completed High School, with Latin-Mathematics as the main subject at the St.Aloysiuscollege in Menen. In 2001, he obtained his Bachelor Degree in Biomedical Science at the Catholic University of Leuven Campus Kortrijk (KULAK). He graduated as Master in the Biomedical Science on June $30^{\text {th }} 2003$ at the Catholic University of Leuven (KUL) with the subject: "Evaluation of hypoxia in an experimental rat tumour model by $\left[{ }^{18} \mathrm{~F}\right]$ Fluoromisonidazole PET and immunohistochemistry" under the supervision of Prof. Dr. L. Mortelmans (promoter) and Dr. W. Landuyt (co-promoter). In July 2003, he joined the Department of Nuclear Medicine (UZ Gasthuisberg Leuven) as a scientific assistant. In March 2004, he started as a PhD student at the Department of Radiation Oncology (Maastro Lab), GROW (School for Oncology and Developmental Biology) at Maastricht University, under the supervision of Prof. Dr. P. Lambin and Prof. Dr. B.G. Wouters.

Ludwig Dubois werd geboren op 12 juni 1981 in Ieper (België) en groeide op in Wervik. In 1999 behaalde hij zijn diploma voor het secundair onderwijs (Latijn-Wiskunde) aan het St.-Aloysiuscollege in Menen. In 2001 haalde hij het diploma Kandidaat in de Biomedische Wetenschappen aan de Katholieke Universiteit Leuven Campus Kortrijk (KULAK). Op 30 juni 2003 behaalde hij zijn licentiaatsdiploma Biomedische Wetenschappen aan de Katholieke Universiteit Leuven (KUL) met het onderwerp: "Vergelijkende analyse van hypoxie in een tumordiermodel d.m.v. positron emissie tomografie ([ $\left.{ }^{18} \mathrm{~F}\right]$-fluoromisonidazole) en immunohistochemie" o.I.v. In juli 2003, vervoegde hij de afdeling Nucleaire Geneeskunde (UZ Gasthuisberg Leuven) als wetenschappelijk medewerker. Vanaf Maart 2004, startte hij met zijn promotie onderzoek, zoals beschreven in dit proefschrift onder directe begeleiding van Prof. Dr. P. Lambin en Prof. Dr. B.G. Wouters. Dit onderzoek vond plaats binnen Maastro Lab (Maastricht Radiation Oncology), GROW (School for Oncology and Developmental Biology) aan de Universiteit Maastricht. 


\section{List of Publications}

\section{Papers}

\# indicates equal contribution

1. Dubois L, Lieuwes NG, Janssen MHM, Secrest J, Windhorst $A D$, van Dongen GAMS, Kolb $\mathrm{H}$, Oellers MC, Zhang J, Lambin P. Preclinical evaluation of $\left[{ }^{18} \mathrm{~F}\right]-\mathrm{HX} 4$, a novel promising hypoxia marker for PET imaging. In preparation.

2. van Loon $J$, Janssen $M$, Oellers $M$, Aerts $H$, Dubois $L$, Hochstenbag $M$, Dingemans $A C$, Lalisang $R$, Windhorst $A D$, van Dongen GAMS, Kolb $H$, Zhang J, De Ruysscher D, Lambin P. PET imaging of hypoxia using $\left[{ }^{18} \mathrm{~F}\right] \mathrm{HX} 4$ : A phase I trial. J Nucl Med. Submitted.

3. Akurathi V, Dubois L, Lieuwes NG, Chitneni SK, Cleynhens BJ, Verbruggen AM, Lambin $P$, Bormans GM. Synthesis and biological evaluation of a ${ }^{99 \mathrm{~m}} \mathrm{Tc}$-labelled sulfonamide conjugate for in vivo visualization of Carbonic Anhydrase IX (CA IX) expression in tumor hypoxia. Nucl Med Biol. Accepted (IF: 2.419)

4. Rouschop KMA, van den Beucken TM, Dubois $\mathbf{L}$, Niessen $\mathbf{H}$, Bussink J, Savelkouls K, Mujcic H, Voncken JW, Landuyt W, Lambin $P$, van der Kogel AJ, Koritzinsky M, Wouters BG. The PERK/eIF2alpha/ATF4 arm of the unfolded protein response protects cells during hypoxia through transcriptional regulation of the autophagy genes LC3b and ATG5. J Clin Invest. 2010 Jan;120 In Press (IF: 16.559)

5. Dubois L, Lieuwes NG, Maresca A, Thiry A, Supuran CT, Scozzafava A, Wouters BG, Lambin P. Imaging of CA IX with fluorescent labelled sulfonamides distinguishes hypoxic and (re)-oxygenated cells in a xenograft tumour model. Radiother Oncol. 2009 Sep;92(3): 423-428. (IF: 3.990)

6. Theys J, Jutten B, Dubois L, Rouschop K, Chiu RK, Li Y, Paesmans K, Lambin P, Lammering $\mathrm{G}^{\#}$, Wouters BG ${ }^{\#}$. The deletion mutant EGFRvIII significantly contributes to stress resistance typical for the tumour microenvironment. Radiother Oncol. 2009 Sep;92(3): 399-404. (IF: 3.990) 
7. Jutten B, Dubois L, Li Y, Aerts HJWL, Wouters BG, Lambin P, Theys $\mathrm{J}^{\#}$, Lammering $\mathrm{G}^{\#}$. Binding of cetuximab to the EGFRvIII deletion mutant and its biological consequences in malignant glioma cells. Radiother Oncol. 2009 Sep;92(3): 393-398. (IF: 3.990)

8. van den Beucken TM, Koritzinsky M, Niessen $H$, Dubois $\mathbf{L}$, Savelkouls K, Mujcic H, Jutten B, Kopacek J, Pastorekova S, van der Kogel AJ, Lambin P, Voncken JW, Rouschop KMA, Wouters BG. Hypoxia-induced expression of carbonic anhydrase 9 is dependent on the unfolded protein response. J Biol Chem. 2009 Sep;284(36): 24204-24012. (IF: 5.808)

9. Ebbesen P, Pettersen EO, Gorr T, Jobst G, Williams K, Kienninger J, Wenger R, Pastorekova S, Dubois L, Lambin $P$, Wouters BG, Van den Beucken $T$, Supuran $C T$, Poellinger $L$, Ratcliffe P, Kanopka A, Görlach A, Gasmann M, Harris A, Maxwell $P$, Scozzafava A. Taking advantage of tumor cell adaptations to hypoxia for developing new tumor markers and treatment strategies. J Enzym Inhib Med Chem. 2009 Apr;24 Suppl 1:1-39 (IF:1.421)

10. Dubois $\mathbf{L}^{\#}$, Magagnin MG\#, Cleven AHG, Weppler SA, Grenacher B, Landuyt W, Lieuwes NG, Lambin P, Gorr TA, Koritzinsky M, Wouters BG. Inhibition of 4E-BP1 sensitizes U87 glioblastoma xenograft tumors to irradiation by decreasing hypoxia tolerance. Int J Radiat Oncol Biol Physics. 2009 March;73(4): 1219-1227 (IF: 4.639)

11. Dubois L, Landuyt W, Cloetens L, Bol A, Bormans G, Haustermans K, Labar D, Nuyts J, Grégoire V, Mortelmans L. [(18)F]EF3 is not superior to [(18)F]FMISO for PET-based hypoxia evaluation as measured in a rat rhabdomyosarcoma tumour model. Eur J Nucl Med Mol Imaging. 2009 Feb;36(2): 209-218 (IF: 4.532)

12. Aerts HJWL ${ }^{\#}$, Dubois $L^{\#}$, Perk $L$, Vermaelen $P$, van Dongen GAMS, Wouters BG, Lambin P. Disparity between in vivo EGFR expression and Zirconium-89-labeled cetuximab uptake assessed with PET. J Nucl Med. 2009 Jan;50(1):123-131. (IF: 6.662) 
13. Dubois L, Douma K, Supuran CT, Chiu RK, van Zandvoort MAMJ, Pastoreková S, Scozzafava A, Wouters BG, Lambin P. Imaging the hypoxia surrogate marker $C A$ IX requires expression and catalytic activity for binding fluorescent sulfonamide inhibitors. Radiother Oncol. 2007 Jun;83(3):36773. (IF: 3.990)

14. Weppler SA ${ }^{\#}$, Li $Y^{\#}$, Dubois $\mathbf{L}$, Lieuwes $N$, Jutten B, Lambin $P$, Wouters BG, Lammering G. Expression of EGFR variant VIII promotes both radiation resistance and hypoxia tolerance. Radiother Oncol. 2007 Jun;83(3):333-9. (IF: 3.990)

15. Aerts HJWL ${ }^{\#}$, Dubois $\mathbf{L}^{\#}$, Hackeng TM, Straathof $R$, Chiu RK, Lieuwes NG, Jutten B, Weppler SA, Lammering G, Wouters BG, Lambin P. Development and evaluation of a cetuximab-based imaging probe to target EGFR and EGFRvIII. Radiother Oncol. 2007 Jun;83(3):326-32. (IF: 3.990)

16. Mengesha A, Dubois L, Paesmans K, Chiu RK, Wouters BG, Lambin P, Theys J. Potential and limitations of bacterialmediated cancer therapy. Front Biosci. 2007 May 1;12:388091. (IF: 3.308)

17. Dubois L, Dresselaers T, Landuyt W, Paesmans K, Mengesha A, Wouters BG, Van Hecke $P$, Theys $\mathrm{J}^{\#}$, Lambin $\mathrm{P}^{\#}$. Efficacy of gene therapy-delivered cytosine deaminase is determined by enzymatic activity but not expression. Br J Cancer. 2007 Mar 12;96(5):758-61. (IF: 4.846)

18. Theys J, Dubois LJ, Mengesha A, Paesmans K, Landuyt W, Wouters BG, Lambin P. Het gebruik van bacteriën als vector bij behandeling van kanker. Ned Tijdschrift voor Oncologie. 2007; 4(2):79-86.

19. Theys J", Pennington O\#, Dubois L, Landuyt W, Anné J, Burke PJ, Anlezark G, Dürre P, Wouters BG, Minton NP\#, Lambin P\#. Repeated cycles of Clostridium-directed enzyme prodrug therapy result in sustained antitumour effects in vivo. $\mathrm{Br} J$ Cancer. 2006 Nov 6;95(9):1212-9. (IF: 4.846) 
20. Mengesha A, Dubois L, Lambin P, Chiu RK, Wouters BG, Theys J. Development of a flexible and potent hypoxia-inducible promoter for tumor-targeted gene expression in attenuated Salmonella. Cancer Biol Ther. 2006 Sep;5(9):1120-8. (IF: 2.761)

21. Dubois L, Landuyt W, Haustermans K, Dupont P, Bormans G, Vermaelen $\mathrm{P}$, Flamen P, Verbeken E, Mortelmans L. Evaluation of hypoxia in an experimental rat tumour model by [(18)F]fluoromisonidazole PET and immunohistochemistry. Br ] Cancer. 2004 Nov 29;91(11):1947-54. (IF: 4.846)

\section{Book contribution}

1. Mengesha A, Dubois L, Paesmans K, Wouters BG, Lambin P, Theys J. Clostridia in anti-tumour therapy. Book Chapter in "Clostridia, Molecular Biology in the Post-genomic Era" Edited by Holger Brüggemann and Gerhard Gottschalk, Caister Academic Press 2009, Norfolk UK 